\title{
Non-fullerene acceptors with branched side chains and improved molecular packing to exceed $18 \%$ efficiency in organic solar cells
}

Chao Li, Jiadong Zhou, Jiali Song, Jinqiu Xu, Huotian Zhang, Xuning Zhang, Jing Guo, Lei Zhu, Donghui Wei, Guangchao Han, Jie Min, Yuan Zhang, Zengqi Xie, Yuanping Yi, He Yan, Feng Gao, Feng Liu and Yanming Sun

The self-archived postprint version of this journal article is available at Linköping University Institutional Repository (DiVA):

http://urn.kb.se/resolve?urn=urn:nbn:se:liu:diva-175681

N.B.: When citing this work, cite the original publication.

Li, C., Zhou, J., Song, J., Xu, J., Zhang, H., Zhang, X., Guo, J., Zhu, L., Wei, D., Han, G., Min, J., Zhang, Y., Xie, Z., Yi, Y., Yan, He, Gao, F., Liu, F., Sun, Y., (2021), Non-fullerene acceptors with branched side chains and improved molecular packing to exceed $18 \%$ efficiency in organic solar cells, Nature Energy. https://doi.org/10.1038/s41560-021-00820-x

Original publication available at:

https://doi.org/10.1038/s41560-021-00820-X

Copyright: Nature Research

http://www.nature.com/ 


\section{Non-fullerene acceptors with branched side chains and improved molecular packing to exceed $18 \%$ efficiency in organic solar cells}

Chao Li ${ }^{1, \dagger}$, Jiadong Zhou ${ }^{2, \dagger}$, Jiali Song ${ }^{1}$, Jinqiu Xu ${ }^{3}$, Huotian Zhang ${ }^{4}$, Xuning Zhang ${ }^{1}$, Jing Guo , Lei Zhu', Donghui Wei ${ }^{6}$, Guangchao Han ${ }^{7}, J_{i e} \mathrm{Min}^{5}$, Yuan Zhang ${ }^{1}$, Zengqi Xie ${ }^{2}$, Yuanping $\mathrm{Yi}^{7}, \mathrm{He}$ Yan $^{8}$, Feng Gao ${ }^{4}$ Feng Liu ${ }^{3 *} \&$ Yanming Sun ${ }^{1,9 *}$

${ }^{1}$ School of Chemistry, Beihang University, Beijing 100191, China

${ }^{2}$ Institute of Polymer Optoelectronic Materials and Devices, State Key Laboratory of Luminescent Materials and Devices, South China University of Technology, Guangzhou 510640, China

${ }^{3}$ Frontiers Science Center for Transformative Molecules, In-situ Center for Physical Science, and Center for Hydrogen Science, School of Chemistry and Chemical Engineering, Shanghai Jiao Tong University, Shanghai 200240, China

${ }^{4}$ Department of Physics, Chemistry, and Biology, Linköping University, Linköping 58183, Sweden

${ }^{5}$ The Institute for Advanced Studies, Wuhan University, Wuhan 430072, China

${ }^{6}$ The College of Chemistry and Molecular Engineering, Zhengzhou University, Zhengzhou 450001, China

${ }^{7}$ Beijing National Laboratory for Molecular Science, Key Laboratory of Organic Solids, Institute of Chemistry, Chinese Academy of Sciences, Beijing 100190, China

${ }^{8}$ Department of Chemistry, Hong Kong University of Science and Technology, Clear Water Bay, Kowloon, Hong Kong, China

${ }^{9}$ Beijing Advanced Innovation Center for Biomedical Engineering, Beijing 100191, China

${ }^{\dagger}$ These authors contributed equally

*Correspondence to: fengliu82@sjtu.edu.cn (F.L.); sunym@buaa.edu.cn (Y.S.) 
Molecular design of non-fullerene acceptors (NFAs) is of vital importance for highefficiency organic solar cells. The branched alkyl chain modification is often regarded as a counter-intuitive approach as which may introduce undesirable steric hindrance that reduces charge transport in NFAs. Here we show the design and synthesis of a highly efficient NFA family by substituting the beta position of thiophene unit on Y6-based A-DAD-A backbone with branched alkyl chains. It was found that such modification of different alkyl chain length could completely change the molecular packing behavior of NFAs, leading to improved structure order and charge transport in thin films. Unprecedented efficiency of $\mathbf{1 8 . 3 2} \%$ (certified value of $17.9 \%$ ) with a fill factor of $81.5 \%$ is achieved for single-junction organic solar cells. This work reveals the importance of branched alkyl chain topology in tuning the molecular packing and blend morphology that leads to improved organic photovoltaic performance. 
Solution-processed bulk-heterojunction (BHJ) organic solar cells (OSCs) have emerged as a promising alternative to inorganic solar cells due to the advantages of low cost, lightweight, transparency, and flexibility ${ }^{1-3}$. The recent development of nonfullerene acceptors (NFAs) that can better harness the long wavelength absorption and optimize electronic structure induces elevated photocurrent density and voltage output, which significantly boosts the power conversion efficiency (PCE) of $\mathrm{OSCs}^{4,5}$. Resultantly, the OSCs have surpassed 18\% PCE using Y6-type acceptors ${ }^{6-11}$. However, comparing to inorganic and perovskite solar cells, OSCs show inferior energy loss $\left(E_{\text {loss }}\right)$ and fill factor (FF), which retards the device performance ${ }^{12-14}$. A systematic optimization to design the right materials is key to these issues ${ }^{15-17}$.

The rapid advances of NFAs bring in new opportunities in OSCs ${ }^{18-28}$. Reduced driving force in charge generation in NFA-OSCs was effective in improving the opencircuit voltage $\left(V_{\mathrm{oc}}\right)$, and the proper morphology and charge transport enable OSCs with high FFs over $75 \%{ }^{29-32}$. Such momentum should be carried on and extended to further manipulate material properties. The complexity in device energy loss and FF lies in 
not only electronic structure but also morphology, in which the molecular ordering, phase separation, and mixing are involved ${ }^{6,33-37}$. Thus, the paradigm of material construction is shifted to intermolecular interaction manipulation, from which we try to strike an avenue to control the intermolecular coupling and carrier transport to improve FF and suppress $E_{\text {loss. }}$

In this contribution, we initiated systematic effort to search for NFA materials with superior electronic properties in solids. We utilize the electronic structure of Y6 backbone due to its high photovoltaic performance. Side-chain modification is taken as a design strategy that benefits from Y6 physical properties can be retained and intermolecular packing can be manipulated. Different aliphatic chains were introduced to varied positions on $\mathrm{Y} 6$ backbone at the max possibility, shifting from pyrrole site to thiophene beta position. A series of NFAs, L8-R (with R being the alkyl chain), are developed. They showed blue-shifted light absorption, reduced bandgap, and upshifted LUMO energy levels that hold the potential to improve device performance. Precise molecular packing is examined in single crystals, in which the backbone interaction showed systematic changes. And different crystallization behaviors in crystal and thin film are recorded. Thus the morphology can be effectively optimized through crystallization control. These progresses in together deliver improved device performance, in which L8-BO (2-butyloctyl substitution) blended with polymer donor PM6 yielded a high PCE of $18.32 \%$, with a low $E_{\text {loss }}$ of $0.55 \mathrm{eV}$, and a high FF of $81.5 \%$. The high PCE and FF indicate that connecting morphology optimization with electronic 
structure refining is a plausible avenue towards $20 \%$ efficiency for solution-processed OSCs.

\section{Optoelectronic characterization and device performance}

The synthetic routes for L8-R are presented in Supplementary Fig. 1. L8-R and Y6 share the same synthetic procedures except for the synthesis of 3-alkylthieno[3,2b]thiophene unit. For Y6, the linear 3-alkylthieno[3,2-b]thiophene is synthesized through four-step reaction from 3-bromothiophene. For L8-R, the branched 3alkylthieno[3,2-b]thiophene is prepared in a two-step reaction from 3-bromothieno[3,2b]thiophene. The design provides an effective route to synthesize 3-alkylthieno[3,2b]thiophene with different alkyl chain topology. The branched alkyl chain and extended alkyl chain length in L8-R enable better solubility than Y6 in common solvents. The decomposition temperatures (at 5\% weight loss) of L8-R were over $320{ }^{\circ} \mathrm{C}$ (Supplementary Fig. 3), indicating good thermal stability. From differential scanning calorimetry (DSC) measurements, the Y6, L8-BO, L8-HD, and L8-OD exhibited exothermal peaks at $298.8,319.6,302.4$, and $276.7^{\circ} \mathrm{C}$, respectively (Supplementary Fig. 4). The melting enthalpy $\left(\Delta \mathrm{H}_{\mathrm{m}}\right)$ of Y6, L8-BO, L8-HD, and L8-OD were calculated to be $28.4,38.5,34.2$, and $31.7 \mathrm{~J} / \mathrm{g}$, respectively. The results demonstrated that sidechain modification could control the L8-R molecular ordering, which, with moderate branched alkyl chain, can be improved comparing to Y6. This property provides an important input in thin film crystallization and morphology control, which will be elaborated in the grazing-incidence wide-angle X-ray scattering (GIWAXS) section. 
The UV-visible absorption spectra of L8-R were shown in Fig. $1 \mathrm{~b}$ and Supplementary Fig. 5. In dilute chloroform solution, the absorption spectra of Y6 and L8-R are nearly identical, with a maximum absorption peak located at $731 \mathrm{~nm}$. From solution to thin film, the absorption spectra of L8-R become broader and the maximum absorption peak red-shifts to $807 \mathrm{~nm}$, which is slightly shorter in wavelength comparing to Y6 (Supplementary Table 1). Electronic-structure calculations are performed on L8R and Y6 molecules. As shown in Supplementary Table 2, the calculated absorption maxima $\lambda_{\max , \mathrm{ab}}$ of the four NFA dimers (geometry extracted from single crystals) are obviously bigger than those of the monomers, and the Y6 dimer has the biggest $\lambda_{\text {max,ab, }}$ which is consistent with the experimental results. Higher $\pi-\pi$ stacking overlaps exist in Y6 dimers along the molecular backbone comparing to L8-R dimers. Thus Y6 dimers possess the stronger $\pi$ - $\pi$ stacking interactions as seen from the results of the noncovalent interaction $(\mathrm{NCI})$ and the transfer integral calculations using the dimer structures in crystals (Supplementary Figs. 6 and 7), which leads to a stronger electronic coupling of the monomers and a narrower energy gap between the highest occupied molecular orbital (HOMO) and the lowest unoccupied molecular orbital (LUMO) for the dimer. As shown in Supplementary Figs. 8 and 9, the HOMO and LUMO become highly symmetric and delocalized in Y6 dimer, which accounts for the redshift of absorption in thin film. The optical bandgaps of L8-BO, L8-HD, and L8-OD were determined to be $1.40,1.43$, and $1.42 \mathrm{eV}$, respectively, slightly larger than that of Y6 $(1.35 \mathrm{eV})$. The electrochemical properties of L8-R and Y6 were studied by cyclic voltammetry (Supplementary Fig. 10). The energy level diagrams of PM6, Y6 and L8- 
R series were displayed in Fig. 1c. L8-R exhibited similar HOMO energy levels that are comparable to Y6. However, they showed upshifted LUMO energy levels versus Y6, agreeing well with the simulated results (Supplementary Fig. 9). The photophysical properties of Y6 and L8-R were listed in Supplementary Table 1.
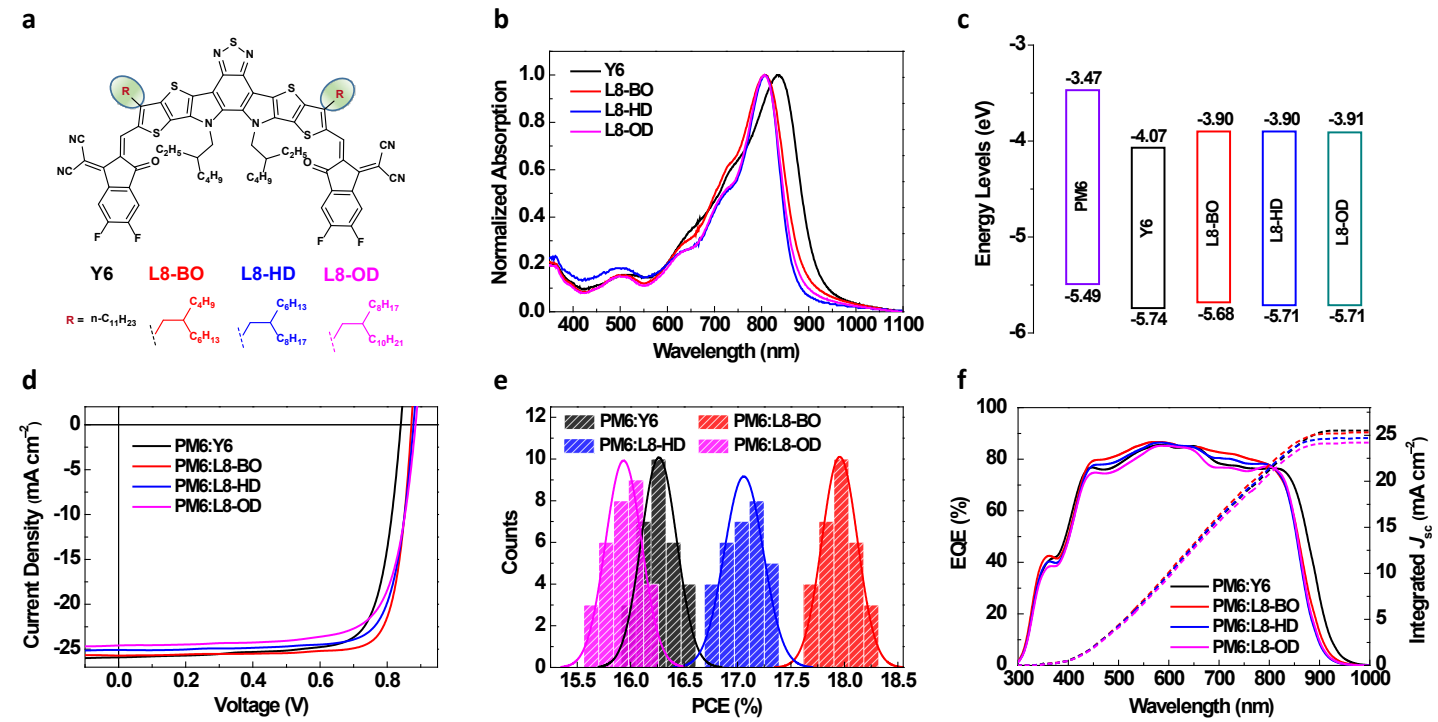

Fig. 1 Molecular structures, photophysical and photovoltaic properties. a, Molecular structures of Y6 and L8-R. b, Normalized absorption spectra of Y6 and L8$\mathrm{R}$ in thin film. c, Energy level diagrams of PM6, Y6 and L8-R. d $J-V$ characteristics for optimized OSCs. e, Histogram of the efficiency measurements of Y6- and L8-Rbased OSCs. f, EQE spectra (solid lines) and integrated current densities (dashed lines) of the optimized OSCs.

\begin{tabular}{|c|c|c|c|c|c|}
\hline Device structure & Active layer & $V_{\text {oc }}(\mathrm{V})$ & $J_{\mathrm{sc}}\left(\mathrm{mA} \mathrm{cm} \mathrm{cm}^{-2}\right)$ & FF (\%) & $\operatorname{PCE}^{\mathrm{a}}(\%)$ \\
\hline \multirow{2}{*}{ Conventional } & PM6:Y6 & $0.84(0.84 \pm 0.01)$ & $25.91(25.57 \pm 0.37)$ & $76.0(75.7 \pm 0.9)$ & $16.61(16.27 \pm 0.17)$ \\
\hline & PM6:L8-BO & $0.87(0.87 \pm 0.01)$ & $25.72(25.66 \pm 0.27)$ & $81.5(80.5 \pm 0.9)$ & $18.32(17.97 \pm 0.18)$ \\
\hline
\end{tabular}




\begin{tabular}{cccccc} 
PM6:L8-HD & $0.88(0.88 \pm 0.01)$ & $25.08(24.87 \pm 0.29)$ & $78.8(78.0 \pm 1.0)$ & $17.39(17.09 \pm 0.20)$ \\
& PM6:L8-OD & $0.89(0.89 \pm 0.01)$ & $24.57(24.61 \pm 0.23)$ & $74.6(73.9 \pm 1.1)$ & $16.26(15.93 \pm 0.17)$ \\
& PM6:L8-BO & 0.87 & 25.38 & 81.0 & $17.9^{\mathrm{b}}$ \\
\hline PM6:Y6 & $0.85(0.85 \pm 0.01)$ & $25.52(25.46 \pm 0.20)$ & $74.6(74.3 \pm 1.1)$ & $16.11(15.95 \pm 0.18)$ \\
\hline PMverted & PM6:L8-BO & $0.87(0.87 \pm 0.01)$ & $26.28(25.99 \pm 0.38)$ & $79.4(78.9 \pm 0.6)$ & $18.05(17.89 \pm 0.21)$ \\
& PM6:L8-OD & $0.88(0.89 \pm 0.01)$ & $25.28(25.12 \pm 0.10)$ & $71.1(70.1 \pm 1.2)$ & $15.80(15.62 \pm 0.17)$
\end{tabular}

The error bars correspond to the standard deviation of multiple independent solar cells.

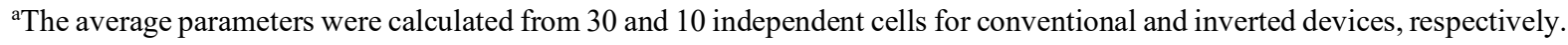

${ }^{\mathrm{b} C e r t i f i e d ~ b y ~ N a t i o n a l ~ I n s t i t u t e ~ o f ~ M e t r o l o g y ~(N I M), ~ C h i n a . ~}$

To study the influence of the alkyl chain topology on device performance, OSCs were fabricated. The optimized device conditions were described in Supplementary Information (Supplementary Figs. 11-13, Supplementary Tables 3-5, and Table 1). As shown in Fig. 1d, 1e and Table 1, the Y6-based devices showed a PCE of 16.61\%, with a $V_{\mathrm{oc}}$ of $0.84 \mathrm{~V}$, a $J_{\mathrm{sc}}$ of $25.91 \mathrm{~mA} \mathrm{~cm}^{-2}$, and a $\mathrm{FF}$ of $76.0 \%$. In L8-R-based devices, increased $V_{\text {ocs }}$ were found, which was ascribed to the upshifted LUMO energy levels in L8-R. Among them, PM6:L8-BO devices showed the best photovoltaic performance, with a high PCE of $18.32 \%$, with a $V_{\mathrm{oc}}$ of $0.874 \mathrm{~V}$, a $J_{\mathrm{sc}}$ of $25.72 \mathrm{~mA} \mathrm{~cm}{ }^{-2}$, and a FF of $81.5 \%$. To the best of our knowledge, such PCE and FF are among the highest values for solution-processed OSCs thus far (Supplementary Table 6), indicating that efficient charge transport and reduced charge recombination in L8-BO-based devices. As shown in Fig. 1f and Table 1, the calculated $J_{\mathrm{sc}}$ from external quantum efficiency (EQE) spectra are in good agreement with the $J_{\text {sc }}$ measured in $J$ - $V$ curves. To confirm the 
reliability of device performance, the best PM6:L8-BO device was sent to National Institute of Metrology (NIM), China for certification. A certified efficiency of $17.9 \%$ was achieved (Supplementary Figs. 14 and 15). Besides, a PCE of 18.22\% was independently verified by a third-party research group (Supplementary Fig. 16). It was noted that PM6:L8-BO device exhibited excellent stability under nitrogen atmosphere. After storage in a nitrogen filled glove box for 60 days, the device maintained $98 \%$ of its initial PCE value (Supplementary Fig. 17). Moreover, inverted OSCs based on Y6 and L8-R acceptors have been also fabricated (Supplementary Fig. 18 and Table 1), which exhibited comparable PCEs to the devices with conventional architecture.

To study the charge transport properties in OSCs, the hole/electron mobilities of the optimized PM6:NFA blended films were evaluated by using space charge limited current (SCLC) method. As shown in Supplementary Fig. 19 and Supplementary Table 7, the hole/electron mobilities of PM6:Y6, PM6:L8-BO, PM6:L8-HD, and PM6:L8OD blended films were $1.82 \times 10^{-4} / 3.71 \times 10^{-4}, \quad 3.58 \times 10^{-4} / 5.79 \times 10^{-4}$, $1.75 \times 10^{-4} / 4.62 \times 10^{-4}$, and $1.61 \times 10^{-4} / 2.31 \times 10^{-4} \mathrm{~cm}^{2} \mathrm{~V}^{-1} \mathrm{~s}^{-1}$, which corresponded to $\mu_{\mathrm{h}} / \mu_{\mathrm{e}}$ ratios of $2.04,1.62,2.64$, and 1.43 , respectively. The high and balanced charge transport in the L8-BO-based blended film was conducive to prohibit charge accumulation and recombination, thus endowing the corresponding device with higher FF of $81.5 \%$.

To evaluate the charge generation and exciton dissociation in these OSCs, the dependence of the photocurrent density $\left(J_{\mathrm{ph}}\right)$ on the effective voltage $\left(V_{\text {eff }}\right)$ was 
measured. The exciton dissociation probability $\left(P_{\text {diss }}\right)$, determined from $J_{\text {ph }}$ under the short-circuit condition divided by the saturated photocurrent density $\left(J_{\text {sat }}\right)$, was estimated to be $98.5 \%, 99.3 \%, 98.9 \%$, and $97.8 \%$ for the OSCs based on Y6, L8-BO, L8-HD, and L8-OD, respectively (Supplementary Fig. 20a). To probe the charge recombination behavior in devices, the dependence of $V_{\mathrm{oc}}$ on the light intensity $\left(P_{\text {light }}\right)$ was examined (Supplementary Fig. 20b). When the slope of $V_{\text {oc }}$ versus the natural logarithm of $P_{\text {light }}$ is equal to $\mathrm{kT} / \mathrm{q}$ (where k is the Boltzmann constant, T is the Kelvin temperature and q is the elementary charge), bimolecular recombination is the dominant recombination mechanism. The slope values from Y6, L8-BO, L8-HD, and L8-OD devices were determined to be $1.20,1.09,1.18$, and $1.32 \mathrm{kT} / \mathrm{q}$, respectively. It can be seen that the slope value of L8-OD-based devices increases significantly, suggesting that trap-assisted recombination plays a major role. To confirm the recombination mechanism, we further performed transient photo-voltage (TPV) measurements to examine the lifetime of photo-carriers in OSCs (Supplementary Fig. 21). The TPV decay time can be correlated to the slope values in $\ln \left(P_{\text {light }}\right)-V_{\text {oc }}$ plot. For the L8-OD based device, the shortest decay time was observed, indicating a reduction of carrier lifetime. This behavior is caused by the higher trap density that accelerates recombination. In contrast, the L8-BO device exhibits the longest carrier lifetime, indicating a suppress of recombination, which contributes to the enhanced FF and improved PCE in L8-BO-based OSCs.

\section{Molecular packing in crystal and thin film}


Single crystals of L8-BO, L8-HD, and L8-OD were cultivated to investigate the chemical modification and its impact on intermolecular packing (Supplementary Table 8). Similar molecular conformations are seen regardless of the side-chain size. In crystal, the molecules show a planar backbone due to the non-covalent S-O interaction that constrains the backbone planarity. The branched alkyl chains show disordered arrangement that protruding out from the backbone plane to interaction with adjacent ones to condense (Fig. 2a, Supplementary Fig. 22). These molecules assemble via the backbone stacking to form linear transport channels via $\pi-\pi$ stacking. Although similar in structure comparing to Y6, L8-R packs differently in solid state. As seen in Fig. 2b, L8-R forms molecular arrangement with small ellipse voids from tilled a-axis projection, which is different from the Y6 packing that forms orthorhombic vacancies in c-axis projection. Such change originates from the difference of alkyl chain spacial arrangement and packing symmetry. As seen from Supplementary Fig. 22, L8-R side chain in single crystal tilts out of the conjugated plane, and interact with adjacent ones in different height to condense. Y6 side chain is less crowded in density, which tilts out with small angle and resides largely in plane. Y6 side chain interacts more favorably with in-plane molecules and thus forms large spaced orthorhombic voids. In molecular arrangement, Y6 molecules pack in mirror symmetry, and L8-R molecules pack in rotational symmetry to suit the side-chain interaction and backbone-stacking (Supplementary Fig. 23). The combination of these factors leads to different molecular packing motif in crystal, which induces different electronic and transport properties in films. It is also observed that the difference in side-chain length gives rise to different 
void size. As seen from Fig. $2 \mathrm{a}$ and $2 \mathrm{~b}$, increasing side-chain length reduces the marked lateral distances and increases the marked vertical distances. The packing coefficients for L8-BO, L8-HD, L8-OD are 64.1\%, 64.2\%, and 63.7\% respectively, and this value is $54.5 \%$ for Y6 (Supplementary Table 9). Thus a more condensed molecular assembly exists in L8-R molecules. An important feature of side-chain substitution is that the close molecular interaction can be modified. In this case, the average $\pi$ - $\pi$ distances were seen changing form $3.19 \AA$ to $3.40 \AA$ from short to long branched side chains (Supplementary Fig. 24 and Supplementary Table 9), and such value for Y6 is $3.20 \AA$. Moreover, we find that Y6 single crystal exhibits two $\pi-\pi$ packing forms. In contrast, L8-BO single crystal exhibits three $\pi-\pi$ packing motifs, which can provide more charge hopping channels (Supplementary Fig. 7). Although L8-BO dimers have smaller $\pi-\pi$ stacking overlaps, their electronic couplings are not much smaller than Y6 dimers due to the smaller average $\pi-\pi$ stacking distances. As a result, multiple charge hopping pathways and relatively strong electronic coupling enable L8-BO with high electron mobilities in thin film (Supplementary Table 7). These results reveal the success of thiophene beta position substitution in manipulating the molecular packing in solid state. Thus though L8-R and Y6 possess identical conjugated backbone, their solid-state characteristics differ significantly in packing position and distances, leading to absorption shifts and charge transport difference in thin films. The success of the branched side-chain design strategy persuades us to explore the investigation towards other Y6-type NFAs. Several other materials and the corresponding device performance are shown in Supplementary Fig. 25, and 
Supplementary Table 10. Quite exciting results were observed from which we note that this approach can be extended to NFAs with different atom decoration and different molecular symmetry. Thus the branched side-chain design strategy is of general purpose in the design of NFAs with the Y6-type backbone.
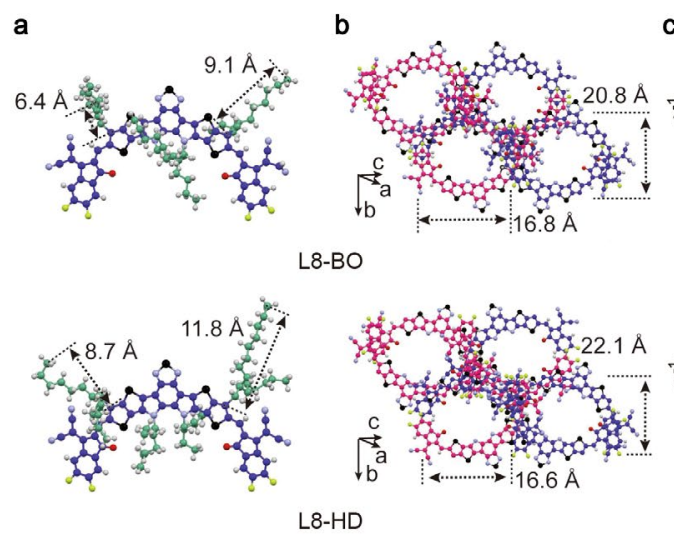

L8-HD

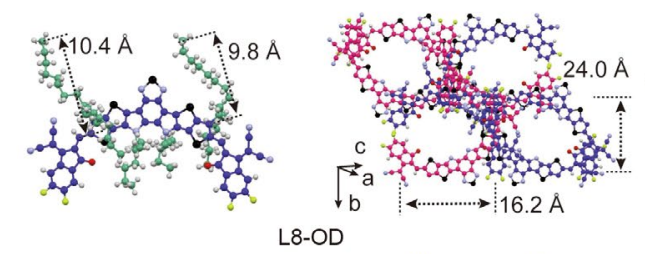

L8-OD

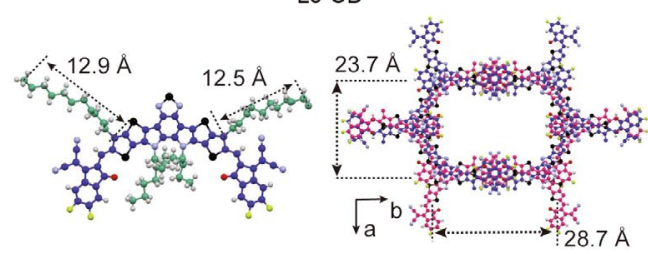

Y6
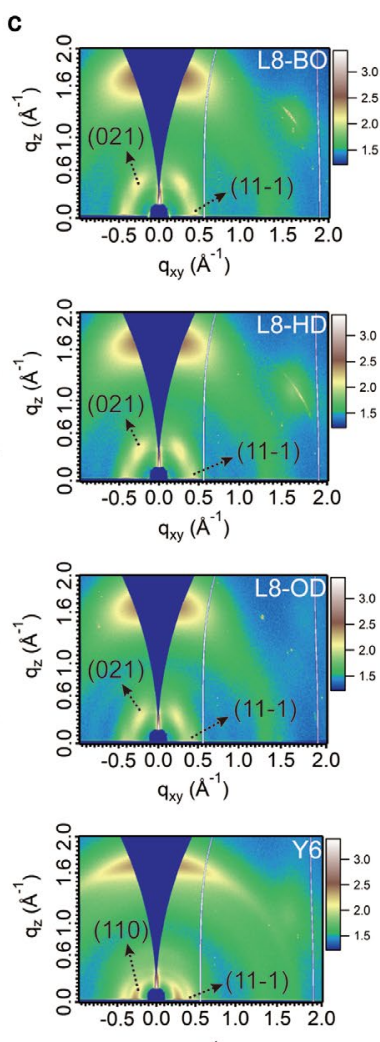

$q_{x y}\left(\AA^{-1}\right)$

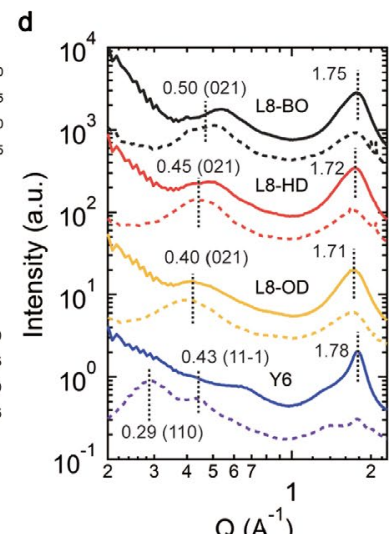

e

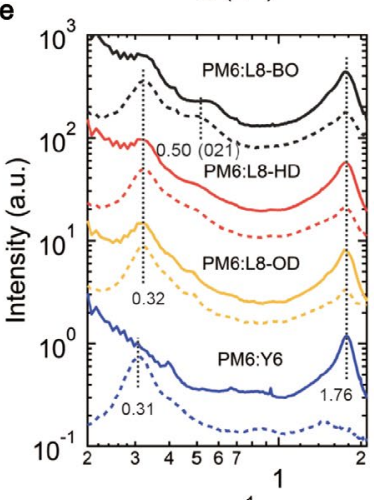

$Q\left(A^{-1}\right)$

Fig. 2 Single-crystal structures and molecular packing properties of NFAs. a, The main view of molecular conformation sketch of L8-BO, L8-HD, L8-OD and Y6 according to single crystal data. The dashed lines represent the side-chain self-assembly distance of NFAs. b, The main view of molecular packing sketch of L8-BO, L8-HD, L8-OD and Y6. For L8-R, the horizontal value represents the (101) plane distance, and the vertical value represents the $b$ axis parameter of the unit cell. For Y6, the horizontal and vertical values represent the a axis and half of the $b$ axis parameters of the unit cell, respectively. c, 2D GIWAXS diffraction patterns of L8-BO, L8-HD, L8-OD and Y6 neat films. The (021) and (11-1) diffraction peaks represent intermolecular distance in 
bc lattice plane and intermolecular distance in ab-c lattice plane in L8-R series, and the (110) and (11-1) dffraction peaks represent lammellar distance and intermolecular distance in ab-c lattice plane in Y6 film. d, e, $55^{\circ}$ titled line-cut (L8-R, dotted lines), inplane line-cut (Y6, dotted lines), and out-of-plane line-cut (solid lines) profiles of L8BO, L8-HD, L8-OD and Y6 neat films (d) and the blend films (e).

Thin film crystalline feature of L8-R neat films was studied using GIWAXS technique. In 2D GIWAXS pattern (Fig. 2c), a strong scattering intensity along the $q_{\mathrm{z}}$ direction was seen in L8-R neat films than that in Y6 neat film after signal normalization. In $55^{\circ}$ titled line-cut profiles (Fig. $2 \mathrm{~d}$ ) and the $2 \mathrm{D}$ diffraction pattern, all the L8-R neat films adopted a preferentially face-on orientation, as evidenced by the strong $\pi-\pi$ stacking diffraction peak in the out-of-plane (OOP) direction and alkyl chain lamellar diffraction peak (11-1) in the in-plane (IP) direction. The appearance of (021) diffraction peak off the major planes indicates the unit cell orientation on substrate, by taking tilted orientation with molecular end groups towards substrate. From L8-BO, to L8-HD, and to L8-OD neat films, the locations of alkyl chain lamellar and $\pi-\pi$ stacking diffraction peaks were gradually shifted to lower $q$ values, corresponding to gradually increased lamellar and $\pi-\pi d$-spacings. The crystal coherence length (CCL) estimated from $\pi-\pi$ stacking diffraction peak decreased with increasing the branched alkyl chain length (Supplementary Table 11). It should be noted that L8-R in single crystal showed closer $\pi-\pi$ stacking than in thin films, indicating the influence of processing on molecular self-assembly. Compared with Y6, L8-BO neat thin film is featured with a broad $\pi-\pi$ stacking peak, with a smaller CCL, which can be caused by paracrystalline disorder in the film ${ }^{38,39}$. Although the Y6 neat thin film displays a sharp stacking peak, 
it has an obvious diffraction signature located at $1.4 \mathrm{~A}^{-1}$, corresponding to the amorphous content in thin film. The detailed structure information is summarized in Supplementary Fig. 26 and Supplementary Table 12. Based on these observations, it is obvious that the structure order for L8-BO is better. This result is in good accordance with DSC measurement. SCLC method was used to evaluate electron transport in L8R thin films. As displayed in Supplementary Fig. 19c and Supplementary Table 7, L8BO neat film exhibited an electron mobility of $6.79 \times 10^{-4} \mathrm{~cm}^{2} \mathrm{~V}^{-1} \mathrm{~s}^{-1}$, which is slightly higher than that in Y6 neat film $\left(4.49 \times 10^{-4} \mathrm{~cm}^{2} \mathrm{~V}^{-1} \mathrm{~s}^{-1}\right)$, and the electron mobility of L8$\mathrm{R}$ was decreased in sequence with the increase of the branched alkyl chain lengths from L8-BO to L8-OD.

\section{Morphology investigation and energy loss analysis}

GIWAXS, atomic force microscopy (AFM) and transmission electron microscopy (TEM) were performed to investigate the influence of branched alkyl chain substitution on the active layer morphology. As shown in Supplementary Fig. 27, all the blend films adopt a face-on orientation with intense $\pi-\pi$ diffraction peak in the OOP direction and pronounced lamellar diffraction peak in the IP direction. The overlapping of peaks at similar position makes the quantitative analysis difficult. A strong diffraction peak located at $0.32 \AA$ is seen in all blended films in the IP direction, corresponding to a lamellar interchain $d$-spacing of $19.5 \AA$, which comes from PM6 (100) diffraction in L8-R blends and a combination of PM6 (100) and Y6 (110) diffraction in Y6 blends (Fig. 2e and Supplementary Fig. 28). Y6 blend film exhibited a sharper $\pi-\pi$ diffraction 
peak and an enlarged CCL of $24.7 \AA$, which was higher than those in L8-R blend films (range from $17.4 \AA$ to $18.4 \AA$, Supplementary Table 11 ). In the L8-R blend films, the $\pi-\pi$ stacking $d$-spacing was increased gradually when the branched alkyl chain length increased in sequence. And thus the L8-BO blended film had the tightest $\pi$ - $\pi$ stacking among L8-R blended thin films. It should be noted that L8-BO in blends showed the most distinctive (021) diffraction peak comparing to longer side-chain analogues (a CCL of $4.3 \mathrm{~nm}$ in blends compared to that of $2.8 \mathrm{~nm}$ in neat film). Thus L8-BO is most effective in preserving the packing structure as in single crystal, which can be the result from its high tendency to order due to short side chains.

AFM measurements were used to investigate the surface morphology of BHJ blends. As illustrated in Fig. 3, fibrillar network morphology was seen in all blended films, which is favorable for charge transport ${ }^{30,40}$. The root-mean-square (RMS) roughness was increased from PM6:Y6 (1.05 nm) to PM6:L8-R blends (PM6:L8-BO, $1.11 \mathrm{~nm}$; PM6:L8-HD, $1.61 \mathrm{~nm}$; and PM6:L8-OD, $6.52 \mathrm{~nm})$. The increased roughness was ascribed to L8-R crystallization that protrudes out of the surfaces. While the PM6:Y6 and PM6:L8-BO surfaces were quite homogenous, as shown in phase images of fibril networks. PM6:L8-HD started to develop large NFA crystals, which was seen as bright area in height image. The NFA crystallization was so strong in PM6:L8-OD blends that crystals of hundred nanometer size were probed. This feature is originated to the readily crystallization nature of long chain L8-R from long chain interactions. Thermal annealing treatment (Supplementary Figs. 29 and 30) was carried out to 
investigate NFA crystallization in blended thin films. No serious NFA crystallization was seen in PM6:L8-BO blends, indicating good morphology stability. And PM6:L8BO blends form small crystallites buried in-between fibril network, as evidenced by tiny bright spots seen in the height image. Such details establish a multi-length scaled morphology, constructed by the PM6 fibril, the NFA crystallites, and a mixing region background. In this sense, tuning the crystallization of acceptor materials is a useful approach in optimizing the blended thin film morphology to suit light extraction and carrier transport purposes.

The surface morphology from AFM characterization was further supported by TEM characterization. As seen in Supplementary Fig. 31, Y6 and L8-BO blend films formed nanoscale phase separation and bicontinuous networks, while the L8-HD and L8-OD blended films showed large black NFA crystals. PM6:L8-BO film showed large density of small black crystallites in size commensurate with to fiber network characteristic length, and thus it is believed to be the best morphology in L8-R material family.
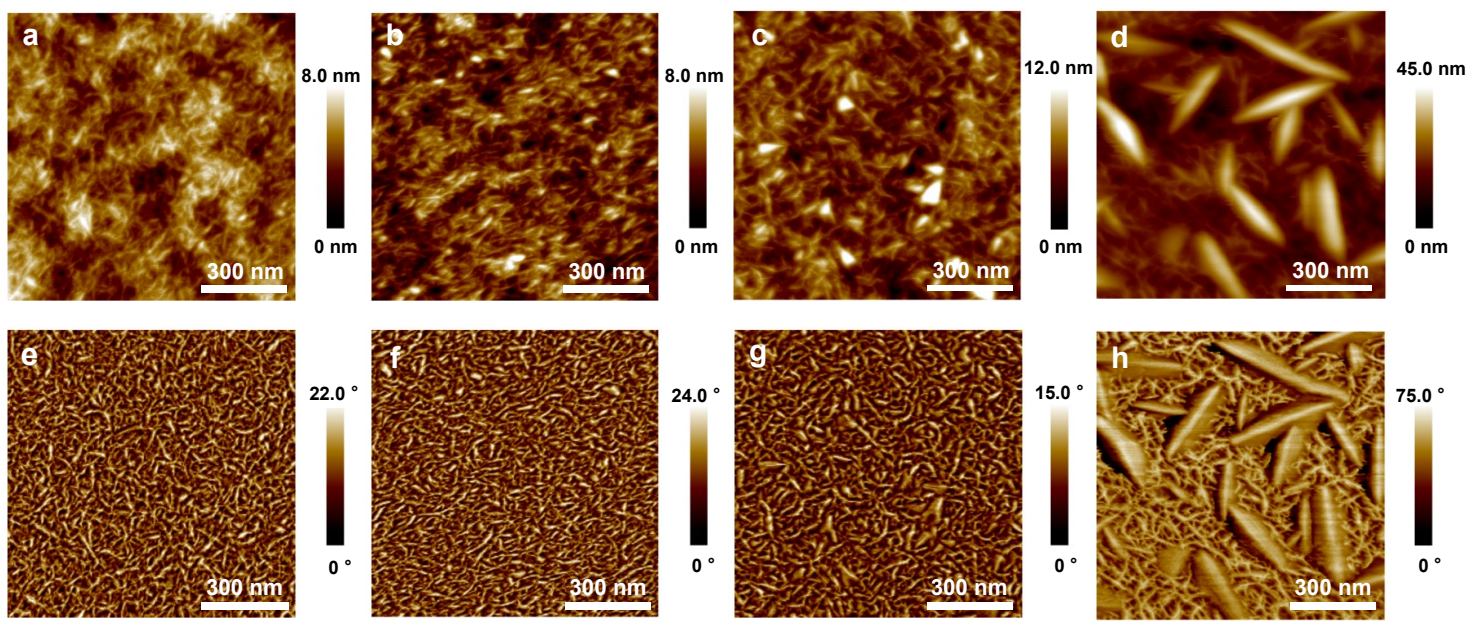
Fig. 3 Morphology characterization of blend films. a-h, AFM height and phase images of optimized PM6:Y6 (a, e), PM6:L8-BO (b, f), PM6:L8-HD (c, g), and PM6:L8-OD (d, h) films. The root mean square (RMS) roughness values are 1.05, 1.11, 1.61, and 6.52 nm for PM6:Y6, PM6:L8-BO, PM6:L8-HD, and PM6:L8-OD films, respectively.

\section{Energy loss analysis.}

To investigate the impact of alkyl chain length and topology on $E_{\text {loss, }}$ we measured the optical bandgap ( $\left.E_{\text {gap }}\right)$ of blended films from the derivatives of the EQE spectra ${ }^{41}$. As presented in Supplementary Fig. 32, the $E_{\text {gap }}$ of the blend films based on Y6, L8-BO, L8-HD, and L8-OD were 1.39, 1.42, 1.43, and $1.42 \mathrm{eV}$, respectively. We then calculated the total energy loss following $E_{\text {loss }}=E_{\text {gap }}-q V_{\text {oc }}$ equation. As summarized in Table 2, Y6-based OSCs showed a $E_{\text {loss }}$ of $0.56 \mathrm{~V}$, and L8-BO-based OSCs exhibited a $E_{\text {loss }}$ of $0.55 \mathrm{~V}$, which is among the lowest $E_{\text {loss }}$ values for highly efficient OSCs ${ }^{6,42}$.

We then quantitatively analysed the detailed $E_{\text {loss }}$ components. According to the detailed balance theory ${ }^{43}$, the $E_{\text {loss }}$ could be classified into three different constituents $\left(E_{\text {loss }}=\Delta E_{1}+\Delta E_{2}+\Delta E_{3}\right)$. The first constituent $\left(\Delta E_{1}=E_{\mathrm{g}}-q V_{\mathrm{oc}}^{\mathrm{SQ}}\right)$ is defined as the difference between $E_{\text {gap }}$ and Shockley-Queisser (SQ) limit output voltage $\left(V_{\mathrm{oc}}^{\mathrm{SQ}}\right)$, which is caused by the radiative recombination loss above the bandgap. For any types of solar cells, this $\Delta E_{1}$ is unavoidable and is typically $0.25 \mathrm{~V}$ or above. Here, the L8-R-based OSCs showed a same $\Delta E_{1}$ value $(0.27 \mathrm{~V})$ as that in Y6-based OSCs. The $V_{\mathrm{oc}}^{\mathrm{SQ}} \mathrm{S}$ were then calculated to be $1.12,1.16,1.17$, and $1.16 \mathrm{~V}$ for the OSCs based on Y6, L8-BO, 
L8-HD, and L8-OD, respectively. The second constituent $\left(\Delta E_{2}=q V_{\mathrm{oc}}^{\mathrm{SQ}}-q V_{\mathrm{oc}}^{\mathrm{rad}}=\right.$ $\left.q \Delta V_{\mathrm{oc}}^{\mathrm{rad}}\right)$ stems from radiative recombination loss below the bandgap, where the $V_{\mathrm{oc}}^{\mathrm{rad}}$ can be determined by realistic radiative recombination using reciprocity relation between Fourier transform photocurrent spectroscopy (FTPS-EQE) and electroluminescence spectroscopy (EL). As shown in Fig. 4, the $V_{\mathrm{oc}}^{\mathrm{rad}} \mathrm{S}$ of the OSCs based on Y6, L8-BO, L8-HD, and L8-OD were calculated to be 1.08, 1.11, 1.12, and $1.11 \mathrm{~V}$, respectively, which corresponded to $\Delta E_{2}$ values of $0.04,0.05,0.05$, and 0.05 $\mathrm{eV}$, respectively. The third constituent $\left(\Delta E_{3}=q V_{\mathrm{oc}}^{\mathrm{rad}}-q V_{\mathrm{oc}}=q \Delta V_{\mathrm{oc}}^{\mathrm{non}-\mathrm{rad}}=\right.$ $-\mathrm{kT} \ln \left(\mathrm{EQE}_{\mathrm{EL}}\right)$ originated from non-radiative recombination loss is the dominating and challenging factor among the three constituents ${ }^{14,44}$. It was found that the OSCs based on Y6 with linear alkyl chain exhibited a small $\Delta E_{3}$ value of $0.25 \mathrm{~V}$. In L8-R, as increasing the branched alkyl chain length, the $\Delta E_{3}$ value increased in sequence. When comparing with the Y6-based OSCs, all the L8-R-based OSCs showed reduced $\Delta E_{3}$ values except L8-HD, indicating that the thiophene beta position branched chain substitution provides a useful mechanism to suppress the non-radiative recombination loss. It has to be noted that the best-performing OSC based on L8-BO shows slightly decreased $\Delta E_{3}$ when compared with Y6-based OSCs. Specifically, the OSCs based on L8-OD with the longest branched alkyl chain length exhibited an extremely low $\Delta E_{3}$ value of $0.22 \mathrm{eV}$, close to that $(0.18 \mathrm{eV})$ of crystalline silicon solar cells ${ }^{45}$. 

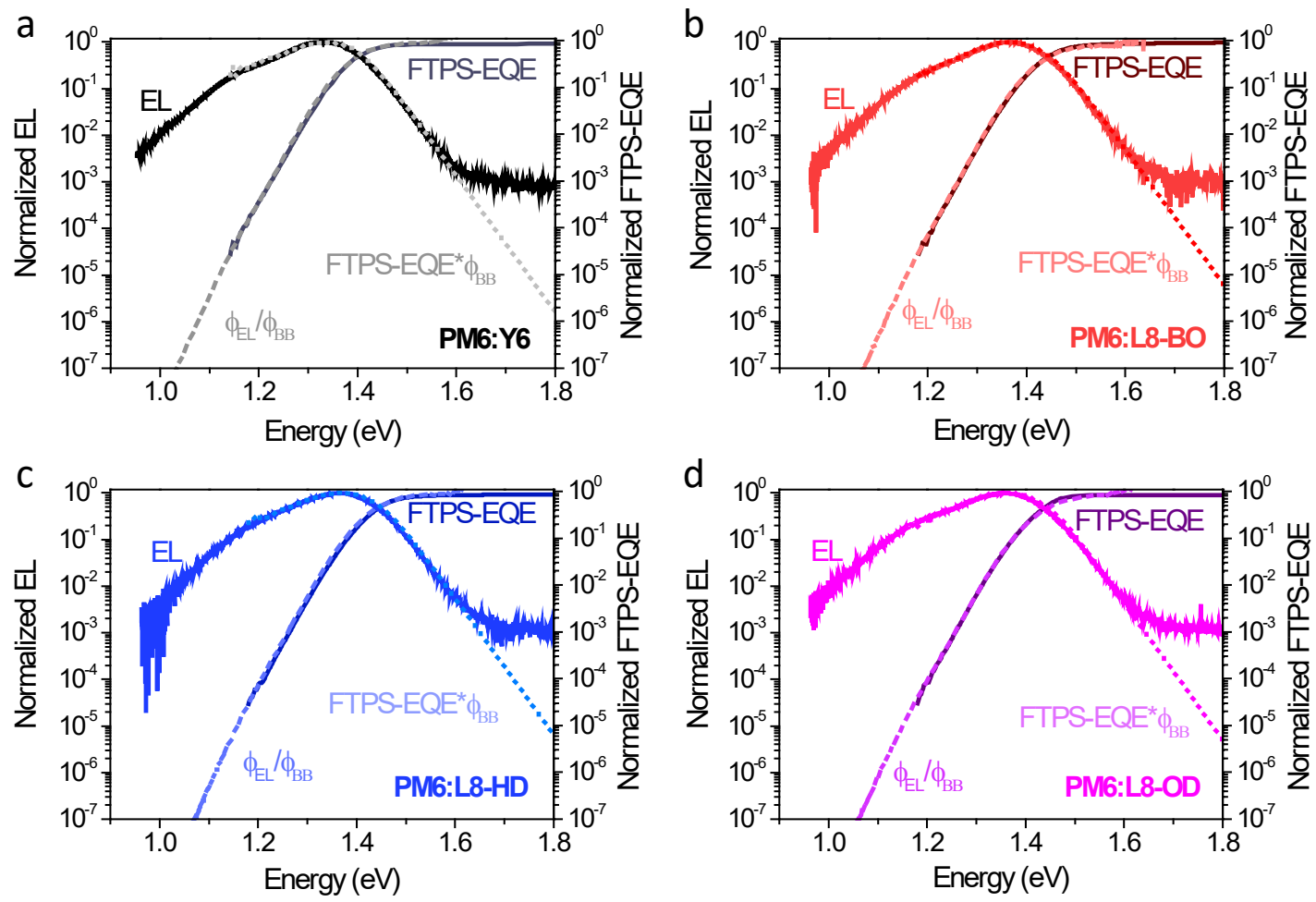

Fig. 4 Energy loss analysis in PM6:NFA solar cells. a-d Semi-logarithmic plots of normalized EL, normalized FTPS-EQE (solid lines) and reciprocally calculated EL, EQE (dashed and dotted lines) as a function of energy for OSCs based on PM6:NFA blends. The ratio of $\phi_{\mathrm{EL}}$ and $\phi_{\mathrm{bb}}$ was used to calculate the EQE while the product of FTPS-EQE and $\phi_{\mathrm{bb}}$ was used to calculate the EL, where $\phi_{\mathrm{EL}}$ and $\phi_{\mathrm{bb}}$ represent the emitted photon flux and the room-temperature black body photon flux, respectively.

Table 2 Detailed energy loss of the OSCs based on PM6:NFA

\begin{tabular}{|c|c|c|c|c|c|c|c|c|}
\hline Active layer & $\begin{array}{c}E_{\mathrm{g}}^{\mathrm{a}} \\
(\mathrm{eV})\end{array}$ & $\begin{array}{l}V_{\text {oc }} \\
(\mathrm{eV})\end{array}$ & $\begin{array}{l}E_{\text {loss }} \\
(\mathrm{eV})\end{array}$ & $\begin{array}{c}V_{\mathbf{o c}}^{S \mathbf{Q}_{\mathrm{b}}} \\
(\mathrm{V})\end{array}$ & $\begin{array}{l}\Delta E_{1} \\
(\mathrm{eV})\end{array}$ & $\begin{array}{c}V_{\mathbf{o c}}^{\mathrm{rad}_{\mathrm{c}}} \\
(\mathrm{V})\end{array}$ & $\begin{array}{l}\Delta E_{2} \\
(\mathrm{eV})\end{array}$ & $\begin{array}{c}\Delta E_{3^{\mathrm{d}}} \\
(\mathrm{eV})\end{array}$ \\
\hline PM6:Y6 & 1.39 & 0.84 & 0.56 & 1.12 & 0.27 & 1.08 & 0.04 & 0.25 \\
\hline PM6:L8-BO & 1.42 & 0.87 & 0.55 & 1.16 & 0.27 & 1.11 & 0.05 & 0.24 \\
\hline PM6:L8-HD & 1.43 & 0.88 & 0.55 & 1.17 & 0.27 & 1.12 & 0.05 & 0.25 \\
\hline PM6:L8-OD & 1.42 & 0.89 & 0.53 & 1.16 & 0.27 & 1.11 & 0.05 & 0.22 \\
\hline
\end{tabular}


${ }^{\mathrm{a}} E_{\mathrm{g}}$ is the optical bandgap of the film calculated on the basis of the intersections between the normalized absorption and electroluminescence spectra of films.

${ }^{\mathrm{b}} V_{\mathrm{oc}}^{\mathrm{SQ}}$ is the maximum $V_{\mathrm{oc}}$ by the SQ limit.

${ }^{\mathrm{c}} V_{\mathrm{oc}}^{\mathrm{rad}}$ is the $V_{\mathrm{oc}}$ when there is only radiative recombination.

d $\Delta E_{3}$ is calculated from the $\mathrm{EQE}_{\mathrm{EL}}$ measured by a silicon detector.

\section{Conclusions}

To sum up, we explored the alkyl chain chemistry in high performance non-fullerene acceptors. It was proven to be a successful endeavor that electronic structure, molecular ordering and intermolecular packing can be well tailored. The thiophene beta position is an interesting spot to be considered since the major $\pi-\pi$ stacking occurred nearby, and introducing bulky branched substituents is naturally considered. L8-BO with the 2butyloctyl side chain shows better structure order that helps to build up an optimized multi-length scaled morphology, in which high carrier generation, low charge recombination, and balanced charge transport are achieved. Such properties lead to

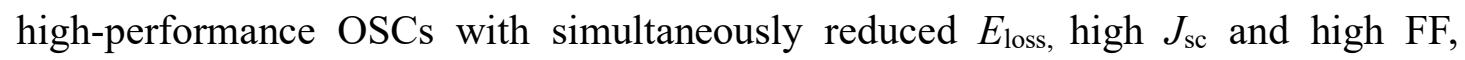
showing unprecedented efficiency. To further stress, the L8-BO gives blue-shifted thin film absorption and upshifted LUMO energy level, which better matches with PM6 donor that reduces the charge transfer driving force as well as non-radiative energy loss

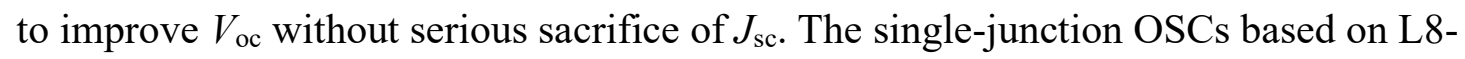
BO afforded a remarkably high PCE of $18.32 \%$, with a FF of $81.5 \%$, and a $E_{\text {loss }}$ of 0.55 
$\mathrm{V}$, which represents an important advance in high-efficiency non-fullerene acceptor development. We believe that such strategy is useful and can be extended in material design, as shown by our initiative efforts, where material chemistry needs to meet with self-assembly and morphology aspects to best explore their performance.

\section{Methods}

Materials. Polymer donor PM6 and nonfullerene acceptor Y6 were purchased from Solar Materials Inc. (Beijing, China). 3-bromothieno[3,2-b]thiophene, 4,7-dibromo-5,6dinitrobenzo[c] $][1,2,5]$ thiadiazole $\quad$ and $\quad 2$-(5,6-difluoro-3-oxo-2,3-dihydro-1H-inden-1ylidene)malononitrile were purchased from Hyper Inc. (Jiaxing, Zhejiang Province, China). Diethyl ether $\left(\mathrm{Et}_{2} \mathrm{O}\right)$ was freshly distilled before use from sodium using benzophenone as indicator. The other reagents and chemicals were purchased from commercial sources and used as received without other noted. The detailed synthetic procedures toward L8-R, LC333, LC301, and corresponding structural characterizations can be found in the Supplementary Information (Supplementary Figs. 1 and 2 and Figs. 34-81).

Single crystal growth. Single crystals of L8-BO, L8-HD, L8-OD were grown by the liquid diffusion method at room temperature. A moderate amount of ethanol was transferred into the concentrated toluene solution and the crystals were formed onto the inner glassy tube over time. The single crystal diffraction was collected at $100-150 \mathrm{~K}$ following standard procedure to reduce X-ray radiation damage. The temperature dependent XRD measurements were carried out to study the temperature effect on lattice expansions. It can be seen that the same crystal structures are preserved for Y6 and L8-BO under different temperatures (Supplementary Fig. 33), and the lattice expansions are pretty small. Only the $\pi-\pi$ stacking region in Y6 shows noticeable changes. Thus there are no major shifting in peak position or lattice structure changes with temperature ranging from $150-300 \mathrm{~K}$. The single crystal growth of Y6 was reported in the literature ${ }^{46}$. The detailed crystal 
data are summarized in Supplementary Table 8.

TGA. TGA measurements were recorded on TGA Q50 instrument with a heating rate of $10{ }^{\circ} \mathrm{C}$ $\min ^{-1}$ under nitrogen atmosphere.

DSC. DSC measurements were performed on the PerkinElmer Diamond DSC instrument with a heating rate of $10^{\circ} \mathrm{C} \mathrm{min}^{-1}$ under nitrogen atmosphere.

Ultraviolet-visible absorption. UV-visible Near Infrared absorption spectra were recorded on a Shimadzu (model UV-3700) Ultraviolet Visible Near Infrared Spectrophotometer.

Cyclic voltammetry measurement. CV measurements were carried out under nitrogen atmosphere at a scan rate of $100 \mathrm{mV} \mathrm{s}^{-1}$ using a Zahner IM6e Electrochemical workstation. A platinum plate coated with sample film, a platinum wire and a saturated $\mathrm{Ag} / \mathrm{AgCl}$ electrode were employed as a working electrode, a counter electrode and a reference electrode, respectively. The supporting electrolyte was $0.1 \mathrm{M}$ tetra-n-butylammonium hexafluorophosphate $\left(\mathrm{Bu}_{4} \mathrm{NPF}_{6}\right)$ in anhydrous acetonitrile solution and the internal standard was ferrocene/ferrocenium $\left(\mathrm{Fc} / \mathrm{Fc}^{+}\right)$. The onset oxidation potential of ferrocene external standard was measured to be $0.42 \mathrm{~V}$. Therefore, the HOMO and LUMO energy level could be obtained from the following equations: $\mathrm{HOMO}=-\left(E_{\mathrm{ox}}+4.38\right)$ $\mathrm{eV}$ and $\mathrm{LUMO}=-\left(E_{\mathrm{red}}+4.38\right) \mathrm{eV}$, where $E_{\mathrm{ox}}$ and $E_{\text {red }}$ were the onset oxidation potential and onset reduction potential relative to $\mathrm{Ag} / \mathrm{AgCl}$, respectively.

AFM. AFM measurements were performed using a Dimension Icon AFM (Bruker) in the tapping mode.

TEM. TEM measurements were carried out on a JEOL JEM-1400 transmission electron microscope.

GIWAXS. GIWAXS measurements were carried out at beamline 7.3.3 at the Advanced Light Source, Lawrence Berkeley National Laboratory.

FTPS measurements. The FTPS-EQE measurements were performed with a modified Bruker Vertex 70 FTIR spectrometer equipped with a tungsten lamp and a quartz beam-splitter, using the solar cell as the external detector, A current-voltage amplifier (SR570) was used to amplify the photocurrent produced from solar cell. The output voltage of the current amplifier was fed back to 
the external input port of the FTIR spectrometer for Fourier transform. The FTPS spectra were calibrated by a standard silicon or germanium detector.

EL measurements. The EL spectra were measured using a Shamrock SR-303i spectrometer from Andor Tech with a Newton EM-CCD Si and an iDus InGaAs array detector at $-60{ }^{\circ} \mathrm{C}$. The bias of EL measurement was applied on the devices using a Keithley 2400 SourceMeter. The emission spectrum of the OSCs was recorded at currents smaller or similar to the $\mathrm{J}_{\mathrm{SC}}$ of the device at 1 sun illumination.

EQE $_{\text {EL }}$ measurements. EQEEL values were obtained from an in-house-built system including a Hamamatsu silicon photodiode 1010B, a Keithley 2400 SourceMeter to provide voltage and injected current, and a Keithley 485 Picoammeter to measure the emitted light intensity.

Details of optical $\boldsymbol{E}_{\mathrm{g}}$ determination. As reported in the previous literature ${ }^{41}$, an $\mathrm{EQE}$ is interpreted as a superposition of a distribution of step-functions with a step at $E_{\mathrm{g}}$ having a certain probability distribution. This probability distribution can be obtained from the derivative $\mathrm{dEQE} / \mathrm{dE}$. The part where the probability is greater than half of the maximum is integrated to get an average bandgap.

Device development and testing. OSCs were fabricated with a conventional architecture of ITO/PEDOT:PSS/active layer/PNDIT-F3N-Br/Ag. The ITO-coated glass substrates were sequentially cleaned in detergent deionized water, acetone and isopropyl alcohol for 15 min each at room temperature. A $40 \mathrm{~nm}$-thick PEDOT:PSS layer was firstly spin cast on top of the ITO substrates at $4000 \mathrm{rpm}$ for $30 \mathrm{~s}$ and then annealed on a hotplate at $150{ }^{\circ} \mathrm{C}$ for 15 min under the ambient condition. The blend solutions were prepared by dissolving PM6 and NFAs in chloroform (CF) solvent with different weight ratios and 1,8-diiodooctane (DIO) contents. The total concentration of all active layer solutions is maintained at $15.4 \mathrm{mg} / \mathrm{mL}$. The active layers were generated by spin coating the blend solutions (the volume used per round is $17 \mu \mathrm{L}$ ) at a spin-coating rate of $3000 \mathrm{rpm}$ for $30 \mathrm{~s}$ on the top of PEDOT:PSS with an optimal thickness of $130 \mathrm{~nm}$ and then thermal annealed at $100{ }^{\circ} \mathrm{C}$ for $10 \mathrm{~min}$ in a $\mathrm{N}_{2}$-filled glovebox. A thin layer $(\sim 5 \mathrm{~nm})$ of PNDIT$\mathrm{F} 3 \mathrm{~N}-\mathrm{Br}$ in trifluoroethanol with a concentration of $0.5 \mathrm{mg} / \mathrm{ml}$ was spin cast on the top of the active layer at a spin-coating rate of $3000 \mathrm{rpm}$ for $30 \mathrm{~s}$. Finally, a $150 \mathrm{~nm}$-thick Ag electrode were thermally 
deposited under the vacuum condition of $2 \times 10^{-4} \mathrm{~Pa}$. The inverted OSCs were fabricated with a device structure of ITO/ZnO/active layer/ $/ \mathrm{MoO}_{3} / \mathrm{Ag}$. $\mathrm{ZnO}$ precursor was prepared by dissolving $1 \mathrm{~g}$ zinc acetate dihydrate and $280 \mu \mathrm{L}$ ethanolamine in $20 \mathrm{ml}$ 2-methoxyethanol under stirring overnight for the hydrolysis reaction. $\mathrm{ZnO}$ layer was formed by spin coating $\mathrm{ZnO}$ precursor solution onto ITO substrates and then annealed at $150{ }^{\circ} \mathrm{C}$ for 15 min under the ambient condition. The processing condition of active layers were the same as the conventional $\mathrm{OSCs} \mathrm{MoO}_{3}(5 \mathrm{~nm})$ and $\mathrm{Ag}(120 \mathrm{~nm})$ layers were prepared by vacuum evaporation deposition under the vacuum condition of $2 \times 10^{-4} \mathrm{~Pa}$. Photon mask with well-defined aperture size is used in the cell measurement to reduce the light piping and internal scattering induced edge effect to access $J_{\text {sc }}$ more accurately ${ }^{47}$. The active area of the device is $5.12 \mathrm{~mm}^{2}$, and the mask area is $3.152 \mathrm{~mm}^{2}$, thus the opening ratio is $61.6 \%$. The series resistance in L8-BO-based device is calculated to be $1.78 \Omega \mathrm{cm}^{2}$. Considering the relatively large aperture opening ratio and the low series resistance, the FF overestimation in PM6:L8-BO device is only $\sim 1 \%$, which validates the accuracy of FF and efficiency measurement ${ }^{48}$. Solar cell performance used an Air Mass 1.5 Global (AM 1.5 G) solar simulator (SS-F5-3A, Enlitech) with an irradiation intensity of $100 \mathrm{~mW} \mathrm{~cm}{ }^{-2}$, which was measured by a calibrated silicon solar cell (SRC2020, Enlitech). The $J-V$ curves are measured along the forward scan direction from -0.5 to $1 \mathrm{~V}$, with a scan step of $50 \mathrm{mV}$ and a dwell time is $10 \mathrm{~ms}$ using a Keithley 2400 Source Measure Unit. EQE spectra were measured by using a solar-cell spectral-response measurement system (QE-R3011, Enlitech).

Space-Charge Limited Current Measurement. The charge transport properties of neat film and blend film were investigated by space charge limited current (SCLC) method. The hole-only devices were fabricated with a configuration of ITO/PEDOT:PSS/PM6:NFA/Au, while the electron-only devices were fabricated with a structure of ITO/ZnO/PM6:NFA/PNDIT-F3N-Br/Ag.

The mobility was determined by fitting the dark current with Mott-Gurney law described as $J=$ $9 \varepsilon_{0} \varepsilon_{r} \mu \mathrm{V}^{2} / 8 \mathrm{~L}^{3}$, where $J$ is the current density, $\varepsilon_{0}$ is the permittivity of free space, $\varepsilon_{\mathrm{r}}$ is the permittivity of the active layer, $\mu$ is the hole mobility or electron mobility, $\mu$ is the zero-field mobility of holes $\left(\mu_{\mathrm{h}}\right)$ or electrons $\left(\mu_{\mathrm{e}}\right), V$ is the effective voltage $\left(V=V_{\mathrm{appl}}-V_{\mathrm{bi}}-V_{\mathrm{R}}\right.$, where $V_{\text {appl }}$ is the applied voltage, $V_{\mathrm{bi}}$ is the built-in potential, and $V_{\mathrm{R}}$ is the voltage loss on series resistance) and $\mathrm{L}$ is the film thickness 
of the neat film or blend film.

\section{Acknowledgements}

This work was financially supported by the National Natural Science Foundation of China (NSFC) (Grant Nos. 51825301, 21734001, 51973110, 21734009, 21674007, 21733005, and 51761135101), the 111 Project (Grant B14009), and Beijing National Laboratory for Molecular Sciences (BNLMS201902), F.G. acknowledges the Swedish Strategic Research Foundation through a Future Research Leader program (FFL 18-0322). X-ray data were acquired at beam lines 7.3 .3 at the Advanced Light Source, Lawrence Berkeley National Laboratory, which is supported by the Director, Office of Science, Office of Basic Energy Sciences, of the U.S. Department of Energy under Contract No. DE-AC02-05CH11231.

\section{Author contributions}

C.L. designed and synthesized L8-R acceptors. J.Z. and Z.X. grew the single crystals, solved and analysed the single crystal structures of L8-R acceptors. J.S. fabricated and characterized the devices. J.X., J.Z. and F.L. performed the morphology characterization and analysed the data. H.Z., F. G., J.G. and J.M. performed the electroluminescence, FTPS-EQE experiments and analysed the data. X.Z. and Y.Z. performed SCLC, TPV measurements. D.W., G.H. and Y.Y. performed the theoretical calculations of Y6 and L8-R acceptors. H.Y. helps to analyse the data and revise the manuscript. F.L. and Y.S. supervised and directed this project; C.L., F.L. and Y.S. wrote the manuscript. All authors discussed the results and commented on the manuscript.

\section{Corresponding authors}

Correspondence to Feng Liu or Yanming Sun 


\section{Reporting summary}

Further information on research design is available in the Nature Research Reporting Summary linked to this article.

\section{Data availability}

All data generated or analysed during this study are included in the published article, its Supplementary Information and Source Data. The X-ray crystallographic coordinates for structures reported in this study have been deposited at the Cambridge Crystallographic Data Centre (CCDC), under deposition numbers 2005533-2005535. These data can be obtained free of charge from The Cambridge Crystallographic Data Centre via www.ccdc.cam.ac.uk/data_request/cif.

\section{Competing interests}

The authors declare no competing interests.

\section{References}

1. Zhang, J., Tan, H.S., Guo, X., Facchetti, A. \& Yan, H. Material insights and challenges for nonfullerene organic solar cells based on small molecular acceptors. Nat. Energy 3, 720-731 (2018).

2. Zhang, G. et al. Nonfullerene Acceptor Molecules for Bulk Heterojunction Organic Solar Cells. Chem. Rev. 118, 3447-3507 (2018).

3. Yan, C. et al. Non-fullerene acceptors for organic solar cells. Nat. Rev. Mater. 3, 18003 (2018).

4. Cheng, P., Li, G., Zhan, X. \& Yang, Y. Next-generation organic photovoltaics based on nonfullerene acceptors. Nat. Photonics 12, 131-142 (2018).

5. Wadsworth, A. et al. Critical review of the molecular design progress in non-fullerene electron acceptors towards commercially viable organic solar cells. Chem. Soc. Rev. 48, 1596-1625 (2019).

6. Sun, C. et al. Achieving Fast Charge Separation and Low Nonradiative Recombination Loss by 
Rational Fluorination for High-Efficiency Polymer Solar Cells. Adv. Mater. 31, 1905480 (2019).

7. Yan, T. et al. 16.67\% Rigid and 14.06\% Flexible Organic Solar Cells Enabled by Ternary Heterojunction Strategy. Adv. Mater. 31, 1902210 (2019).

8. Sun, H. et al. A monothiophene unit incorporating both fluoro and ester substitution enabling high-performance donor polymers for non-fullerene solar cells with $16.4 \%$ efficiency. Energy Environ. Sci. 12, 3328-3337 (2019).

9. Li, S., Li, C.-Z., Shi, M. \& Chen, H. New Phase for Organic Solar Cell Research: Emergence of Y-Series Electron Acceptors and Their Perspectives. ACS Energy Lett. 5, 1554-1567 (2020).

10. Liu, L. et al. Graphdiyne Derivative as Multifunctional Solid Additive in Binary Organic Solar Cells with 17.3\% Efficiency and High Reproductivity. Adv. Mater. 32, 1907604 (2020).

11. Liu, Q. et al. 18\% Efficiency organic solar cells. Sci. Bull. 65, 272-275 (2020).

12. Qian, D. et al. Design rules for minimizing voltage losses in high-efficiency organic solar cells. Nat. Mater. 17, 703-709 (2018).

13. Menke, S.M., Ran, N.A., Bazan, G.C. \& Friend, R.H. Understanding Energy Loss in Organic Solar Cells: Toward a New Efficiency Regime. Joule 2, 25-35 (2018).

14. Hou, J., Inganäs, O., Friend, R.H. \& Gao, F. Organic solar cells based on non-fullerene acceptors. Nat. Mater. 17, 119-128 (2018).

15. Kawashima, K., Tamai, Y., Ohkita, H., Osaka, I. \& Takimiya, K. High-efficiency polymer solar cells with small photon energy loss. Nat. Commun. 6, 10085 (2015).

16. Cui, Y. et al. Over $16 \%$ efficiency organic photovoltaic cells enabled by a chlorinated acceptor with increased open-circuit voltages. Nat. Commun. 10, 2515 (2019).

17. Liu, S. et al. High-efficiency organic solar cells with low non-radiative recombination loss and low energetic disorder. Nat. Photonics 14, 300-305 (2020).

18. Lin, Y. et al. An Electron Acceptor Challenging Fullerenes for Efficient Polymer Solar Cells. Adv. Mater. 27, 1170-1174 (2015).

19. Lin, Y. et al. A Facile Planar Fused-Ring Electron Acceptor for As-Cast Polymer Solar Cells with 8.71\% Efficiency. J. Am. Chem. Soc. 138, 2973-2976 (2016).

20. Zhao, W. et al. Molecular Optimization Enables over 13\% Efficiency in Organic Solar Cells. $J$. Am. Chem. Soc. 139, 7148-7151 (2017).

21. Meng, L. et al. Organic and solution-processed tandem solar cells with $17.3 \%$ efficiency. Science 361, 1094-1098 (2018).

22. Sun, J. et al. Dithieno[3,2-b:2',3'-d]pyrrol Fused Nonfullerene Acceptors Enabling Over 13\% 
Efficiency for Organic Solar Cells. Adv. Mater. 30, 1707150 (2018).

23. Yuan, J. et al. Single-Junction Organic Solar Cell with over 15\% Efficiency Using Fused-Ring Acceptor with Electron-Deficient Core. Joule 3, 1140-1151 (2019).

24. Jiang, K. et al. Alkyl Chain Tuning of Small Molecule Acceptors for Efficient Organic Solar Cells. Joule 3 (2019).

25. Li, C., Fu, H., Xia, T. \& Sun, Y. Asymmetric Nonfullerene Small Molecule Acceptors for Organic Solar Cells. Adv. Energy Mater. 9, 1900999 (2019).

26. Yu, Z.-P. et al. Simple non-fused electron acceptors for efficient and stable organic solar cells. Nat. Commun. 10 (2019).

27. Li, X. et al. Simplified synthetic routes for low cost and high photovoltaic performance n-type organic semiconductor acceptors. Nat. Commun. 10 (2019).

28. Hong, L. et al. Eco-Compatible Solvent-Processed Organic Photovoltaic Cells with Over 16\% Efficiency. Adv. Mater. 31, 1903441 (2019).

29. Liu, J. et al. Fast charge separation in a non-fullerene organic solar cell with a small driving force. Nat. Energy 1, 16089 (2016).

30. Liu, T. et al. Optimized Fibril Network Morphology by Precise Side-Chain Engineering to Achieve High-Performance Bulk-Heterojunction Organic Solar Cells. Adv. Mater. 30, 1707353 (2018).

31. Yu, R. et al. Improved Charge Transport and Reduced Nonradiative Energy Loss Enable Over 16\% Efficiency in Ternary Polymer Solar Cells. Adv. Mater. 31, 1902302 (2019).

32. Zhou, Z. et al. Subtle Molecular Tailoring Induces Significant Morphology Optimization Enabling over 16\% Efficiency Organic Solar Cells with Efficient Charge Generation. Adv. Mater. 32, 1906324 (2020).

33. Gao, W. et al. Asymmetrical Ladder-Type Donor-Induced Polar Small Molecule Acceptor to Promote Fill Factors Approaching 77\% for High-Performance Nonfullerene Polymer Solar Cells. Adv. Mater. 30, 1800052 (2018).

34. Zhou, Z. et al. High-efficiency small-molecule ternary solar cells with a hierarchical morphology enabled by synergizing fullerene and non-fullerene acceptors. Nat. Energy 3, 952959 (2018).

35. Fei, Z. et al. An Alkylated Indacenodithieno[3,2-b]thiophene-Based Nonfullerene Acceptor with High Crystallinity Exhibiting Single Junction Solar Cell Efficiencies Greater than 13\% with Low Voltage Losses. Adv. Mater. 30, 1705209 (2018).

36. Xu, X. et al. Single-Junction Polymer Solar Cells with $16.35 \%$ Efficiency Enabled by a 
Platinum(II) Complexation Strategy. Adv. Mater. 31, 1901872 (2019).

37. Huang, H. et al. Noncovalently fused-ring electron acceptors with near-infrared absorption for high-performance organic solar cells. Nat. Commun. 10, 3038 (2019).

38. Rivnay, J. et al. Quantitative analysis of lattice disorder and crystallite size in organic semiconductor thin films. Phys. Rev. B 84, 045203 (2011).

39. Noriega R. et al. A general relationship between disorder,aggregation and charge transport in conjugated polymers. Nat. Mater. 12, 1038-1044 (2013).

40. Xia, T., Cai, Y., Fu, H. \& Sun, Y. Optimal bulk-heterojunction morphology enabled by fibril network strategy for high-performance organic solar cells, Sci. China: Chem. 62, 662-668 (2019).

41. Wang, Y. et al. Optical Gaps of Organic Solar Cells as a Reference for Comparing Voltage Losses. Adv. Energy Mater. 8, 1801352 (2018).

42. Song, J. et al. Ternary Organic Solar Cells with Efficiency $>16.5 \%$ Based on Two Compatible Nonfullerene Acceptors. Adv. Mater. 31, 1905645 (2019).

43. Shockley, W. \& Queisser, H. J. Detailed Balance Limit of Efficiency of p-n Junction Solar Cells. J. Appl. Phys. 32, 510-519 (1961).

44. Nikolis, V. C. et al. Reducing Voltage Losses in Cascade Organic Solar Cells while Maintaining High External Quantum Efficiencies. Adv. Energy Mater. 7, 1700855 (2017).

45. Yao, J. et al. Quantifying Losses in Open-Circuit Voltage in Solution-Processable Solar Cells, Phys. Rev. Appl. 4, 014020 (2015).

46. Zhu, L. et. al. Efficient Organic Solar Cell with 16.88\% Efficiency Enabled by Refined Acceptor Crystallization and Morphology with Improved Charge Transfer and Transport Properties, $A d v$. Energy Mater. 10, 1904234 (2020).

47. Emery, K. \& Moriarty, T. Accurate Measurement of Organic Solar Cell Efficiency. Proc. SPIE Optics + Photonics, session 7052-12, Aug. 10-14 (2008).

48. Kiermasch, D., Gil-Escrig, L., Bolink, H. J. \& Tvingstedt, K. Efects of masking on open-circuit voltage and fll factor in solar cells. Joule 3, 16-26 (2019). 


\section{Non-fullerene acceptors with branched side chains and improved molecular packing to exceed $18 \%$ efficiency in organic solar cells}

Chao Li $i^{1, \dagger}$, Jiadong Zhou ${ }^{2, \dagger}$, Jiali Song ${ }^{1}$, Jinqiu Xü, Huotian Zhang ${ }^{4}$, Xuning Zhang ${ }^{1}$, Jing Guo ${ }^{5}$, Lei Zhu ${ }^{3}$, Donghui Wei ${ }^{6}$, Guangchao Han ${ }^{7}$, Jie Min ${ }^{5}$, Yuan Zhang ${ }^{1}$, Zengqi Xie ${ }^{2}$, Yuanping $\mathrm{Yi}^{7}$, He Yan $^{8}$, Feng Gao ${ }^{4}$ Feng Liu $^{3 *} \&$ Yanming Sun ${ }^{1,9 *}$

${ }^{1}$ School of Chemistry, Beihang University, Beijing 100191, China

${ }^{2}$ Institute of Polymer Optoelectronic Materials and Devices, State Key Laboratory of Luminescent Materials and Devices, South China University of Technology, Guangzhou 510640, China

${ }^{3}$ Frontiers Science Center for Transformative Molecules and In-situ Center for Physical Science, and Center for Hydrogen Science, School of Chemistry and Chemical Engineering, Shanghai Jiao Tong University, Shanghai 200240, China

${ }^{4}$ Department of Physics, Chemistry, and Biology, Linköping University, Linköping 58183 , Sweden

${ }^{5}$ The Institute for Advanced Studies, Wuhan University, Wuhan 430072, China

${ }^{6}$ The College of Chemistry and Molecular Engineering, Zhengzhou University, Zhengzhou 450001, China

${ }^{7}$ Beijing National Laboratory for Molecular Science, Key Laboratory of Organic Solids, Institute of Chemistry, Chinese Academy of Sciences, Beijing 100190, China

${ }^{8}$ Department of Chemistry, Hong Kong University of Science and Technology, Clear Water Bay, Kowloon, Hong Kong, China

${ }^{9}$ Beijing Advanced Innovation Center for Biomedical Engineering, Beijing 100191, China

†These authors contributed equally

*Correspondence to: fengliu82@sjtu.edu.cn (F.L.); sunym@buaa.edu.cn (Y.S.) 


\section{Supplementary Figures}
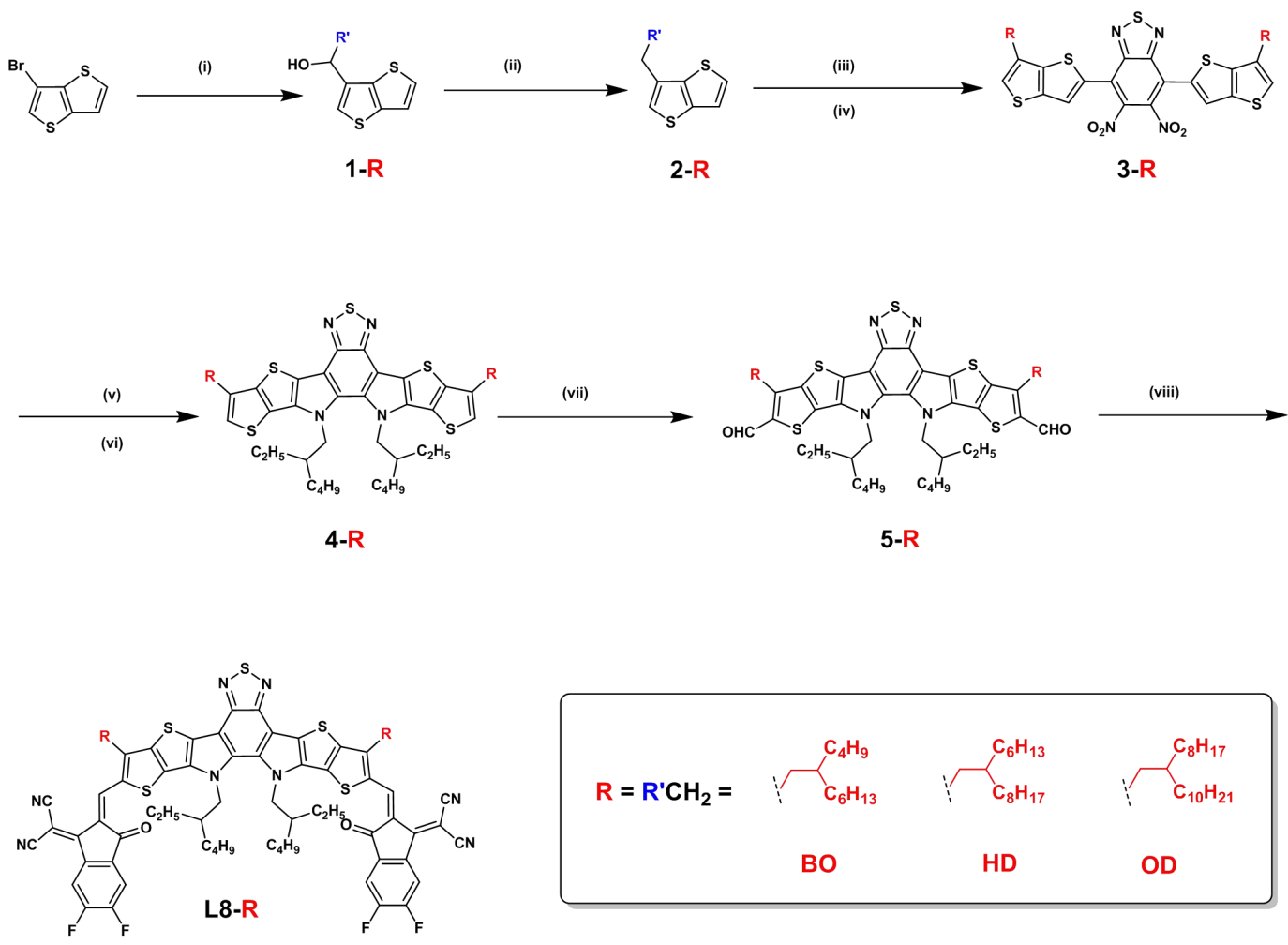

Supplementary Figure 1. Synthetic routes toward L8-R series. Reagents and conditions: (i) n-BuLi, $\mathrm{Et}_{2} \mathrm{O}, \mathrm{R}^{\prime}-\mathrm{CHO},-78{ }^{\circ} \mathrm{C}$ to room temperature; (ii) $\mathrm{LiAlH}_{4}, \mathrm{AlCl}_{3}$, $\mathrm{Et}_{2} \mathrm{O}, 0{ }^{\circ} \mathrm{C}$ to room temperature; (iii) $\mathrm{n}-\mathrm{BuLi}, \mathrm{THF}, \mathrm{SnBu} 3 \mathrm{Cl},-78{ }^{\circ} \mathrm{C}$ to room temperature; (iv) 4,7-dibromo-5,6-dinitrobenzo[c][1,2,5]thiadiazole, $\mathrm{Pd}\left(\mathrm{PPh}_{3}\right)_{2} \mathrm{Cl}_{2}$, Toluene, Reflux; (v) $\mathrm{P}(\mathrm{OEt})_{3}, \quad \mathrm{o}-\mathrm{DCB}, \quad 180{ }^{\circ} \mathrm{C}$; (vi) $\mathrm{K}_{2} \mathrm{CO}_{3}, \mathrm{KI}, \mathrm{DMF}$, 1-bromo-2-ethylhexane, $80{ }^{\circ} \mathrm{C}$; (vii) $\mathrm{POCl}_{3}, \mathrm{DMF}, \mathrm{ClCH}_{2} \mathrm{CH}_{2} \mathrm{Cl}, 80{ }^{\circ} \mathrm{C}$; (viii) 2-(5,6-difluoro-3-oxo-2,3-dihydro-1H-inden-1-ylidene)malononitrile, Pyridine, $\mathrm{CHCl}_{3}, 55^{\circ} \mathrm{C}$; 


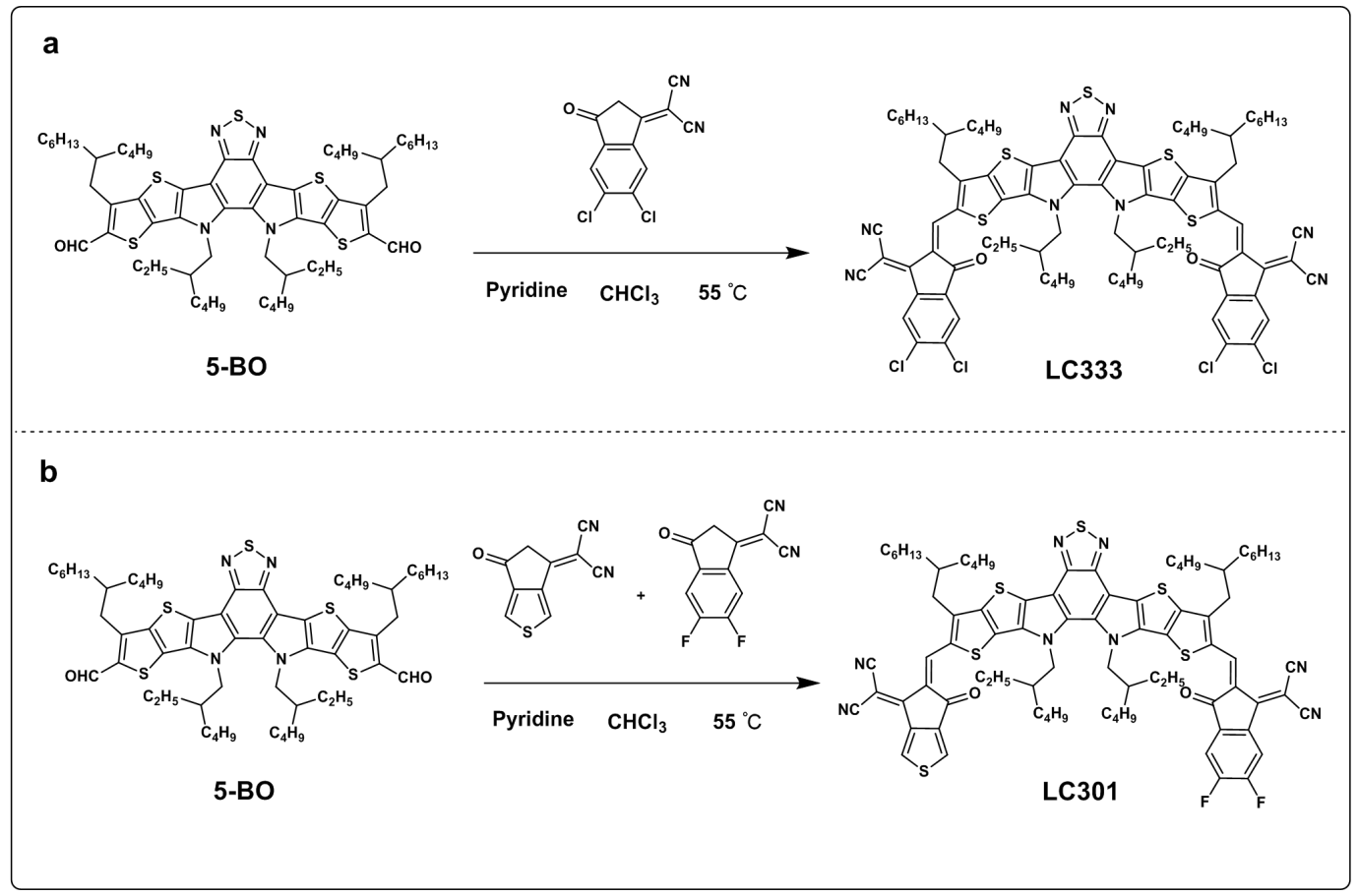

Supplementary Figure 2. Synthetic routes of NFAs. (a) Synthetic route of LC333.

(b) Synthetic route of LC333. 


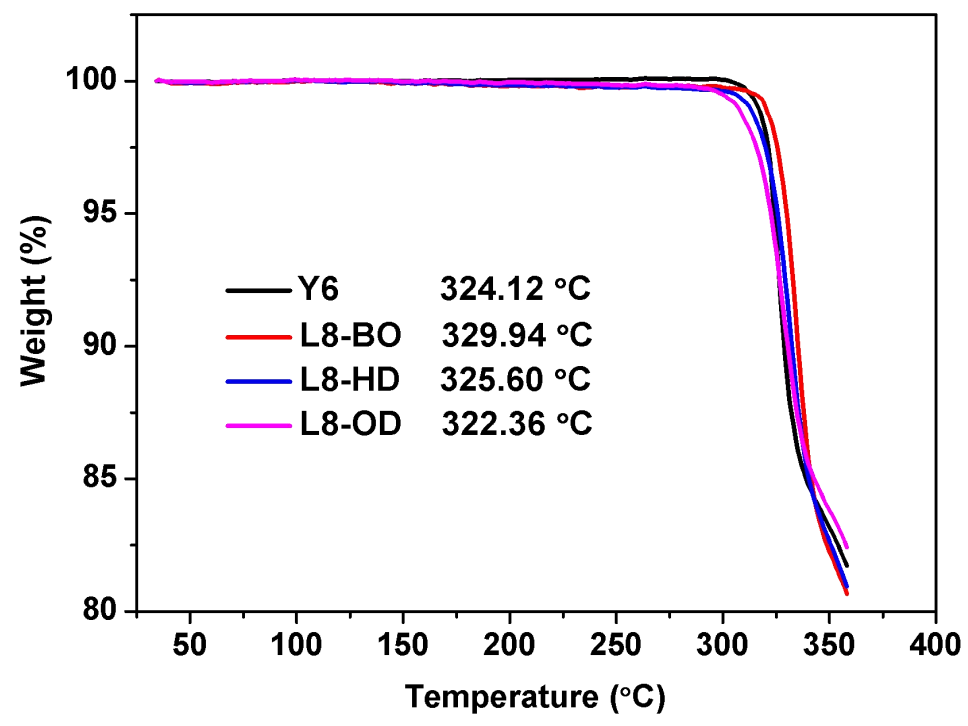

Supplementary Figure 3. TGA curves of Y6, L8-BO, L8-HD and L8-OD with a heating rate of $10^{\circ} \mathrm{C} / \mathrm{min}$ under nitrogen atmosphere. 


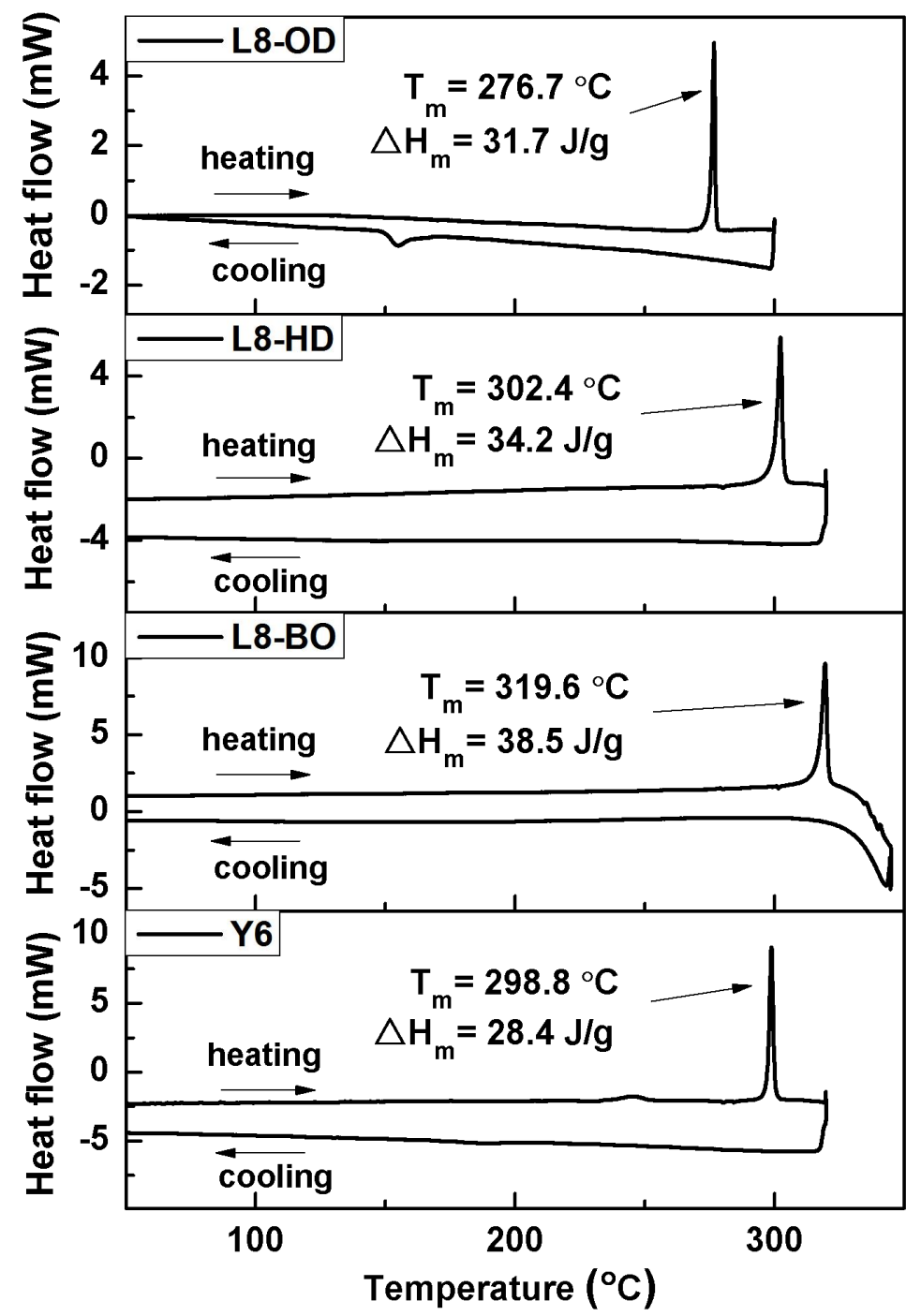

Supplementary Figure 4. DSC curves of Y6, L8-BO, L8-HD and L8-OD with a heating rate of $10{ }^{\circ} \mathrm{C} / \mathrm{min}$ under nitrogen atmosphere. The melting enthalpy is calculated according to the equation: $\Delta H_{m}=\frac{s}{m}=\frac{\int_{t 1}^{t 2} y(t)}{m}$, where $\Delta H_{m}$ is melting enthalpy, $S$ is integral area, $m$ is sample weight, $t 1$ is onset time of the melting temperature, $t 2$ is end time of the melting temperature. The integral area can be obtained by integrating over the time of onset melting temperature and end melting temperature, which can also be obtained directly from the DSC instrument. The sample weights of Y6, L8-BO, L8-HD and L8-OD used in the DSC scan ae 2.4, 1.9, 1.9 , and $1.8 \mathrm{mg}$, respectively, and the integral areas are 68.168, 73.108, 64.979, and $57.036 \mathrm{~mJ}$, respectively. The direction of heating and cooling are shown in the Figure. In testing, only one heating and cooling cycle was conducted. 


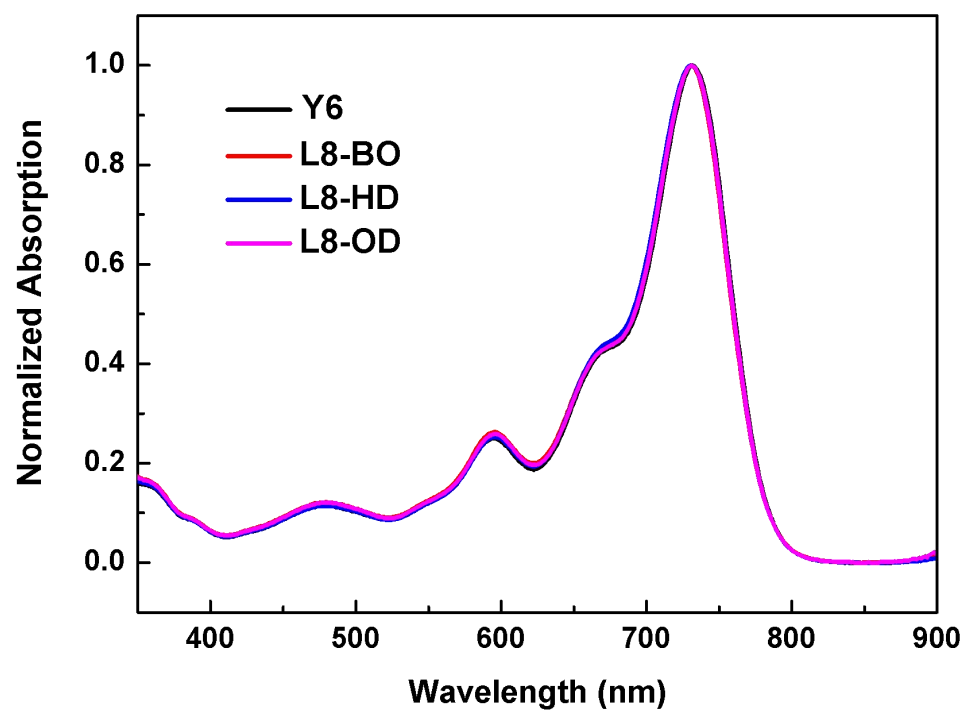

Supplementary Figure 5. Normalized absorption spectra of Y6 and L8-R in dilute chloroform solution. 


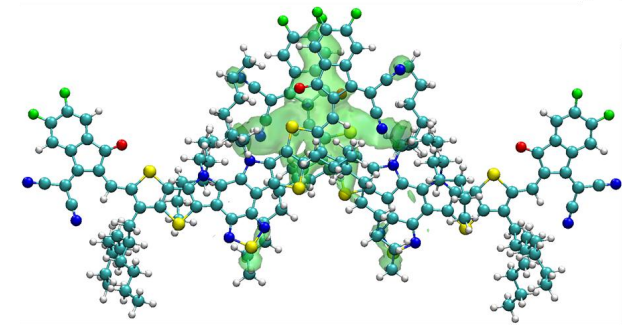

L8-BO2

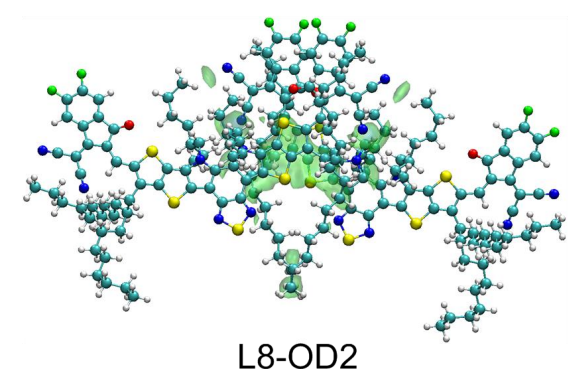

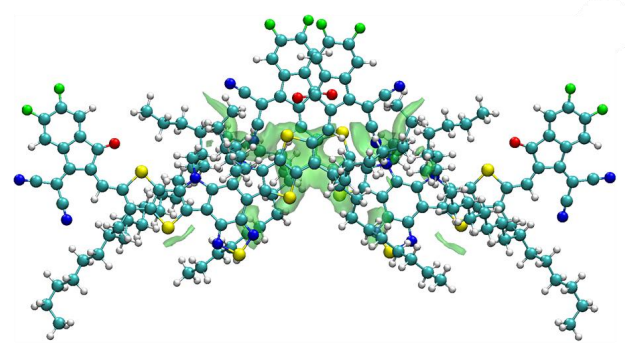

L8-HD2

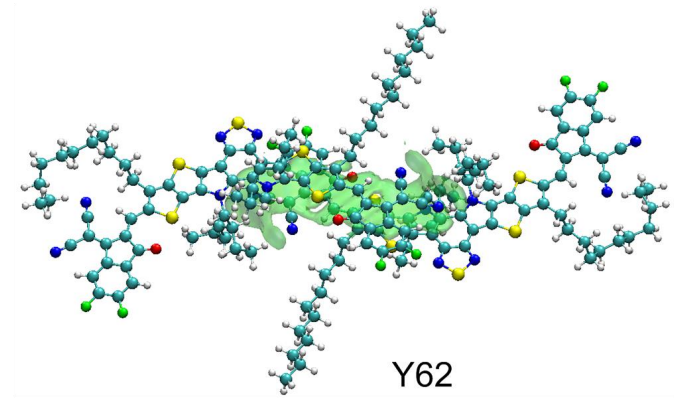

Supplementary Figure 6. The non-covalent interaction (NCI) analysis of the four dimers of NFAs. Green regions represent weak non-covalent interactions. The NCI analysis was plotted using the Multiwfn software ${ }^{1}$. 

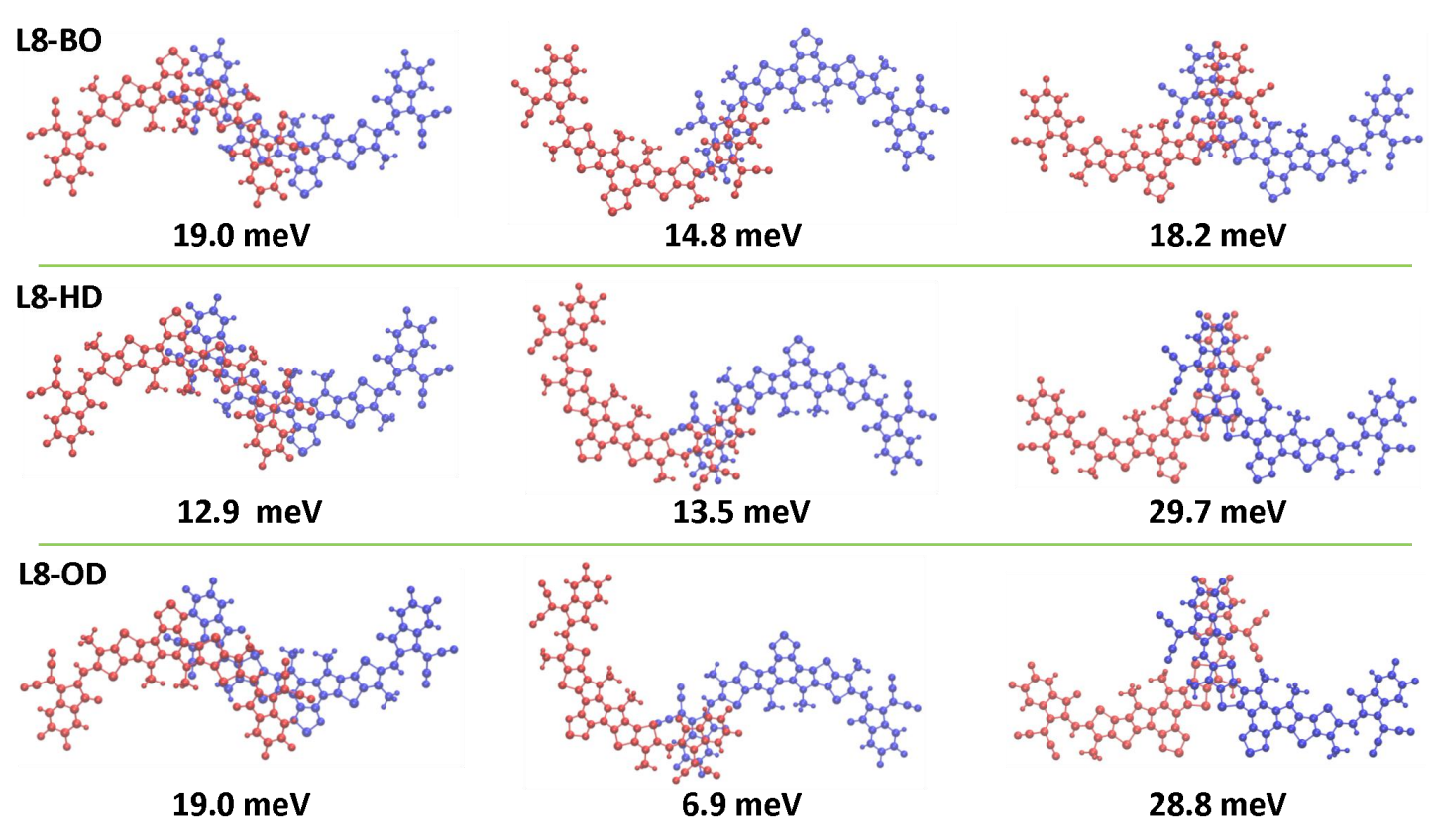

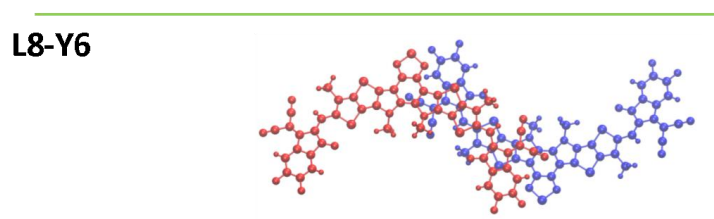

$31.2 \mathrm{meV}$

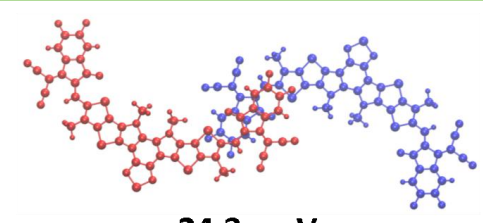

$24.3 \mathrm{meV}$

Supplementary Figure 7. Electronic coupling (meV) for L8-R and Y6 dimers with different crystal packing motif. The electronic couplings for dimers of L8-R and Y6 in crystals were computed using the Zerner's intermediate neglect of differential overlap (ZINDO) method ${ }^{2}$. 


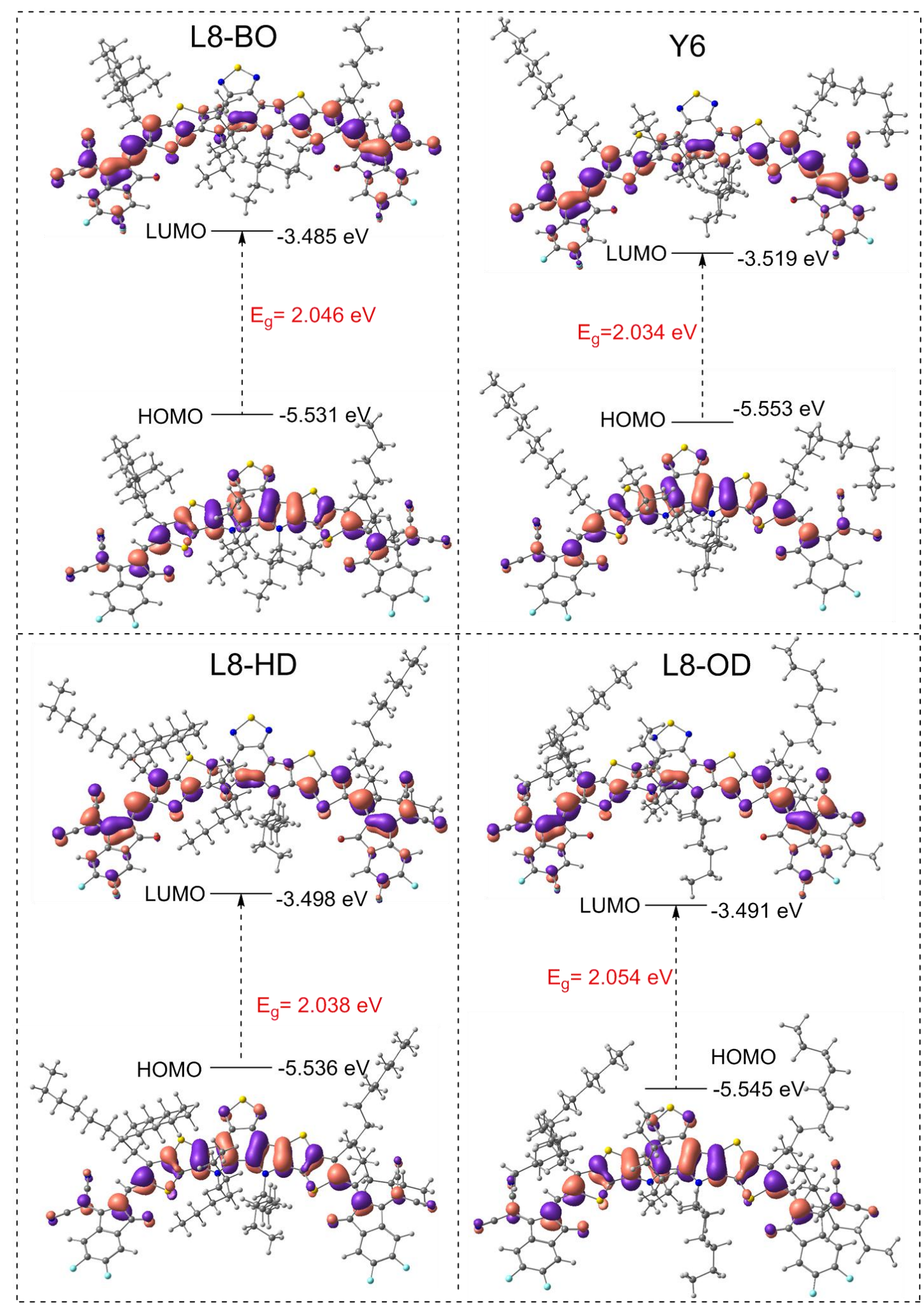

Supplementary Figure 8. The energy gaps between HOMO and LUMO of the four monomer structures. The DFT calculations were performed using the Gaussian16 program ${ }^{3}$. All structures were optimized at the B3LYP $4,5 / 6-31 G(d, p)$ level. 


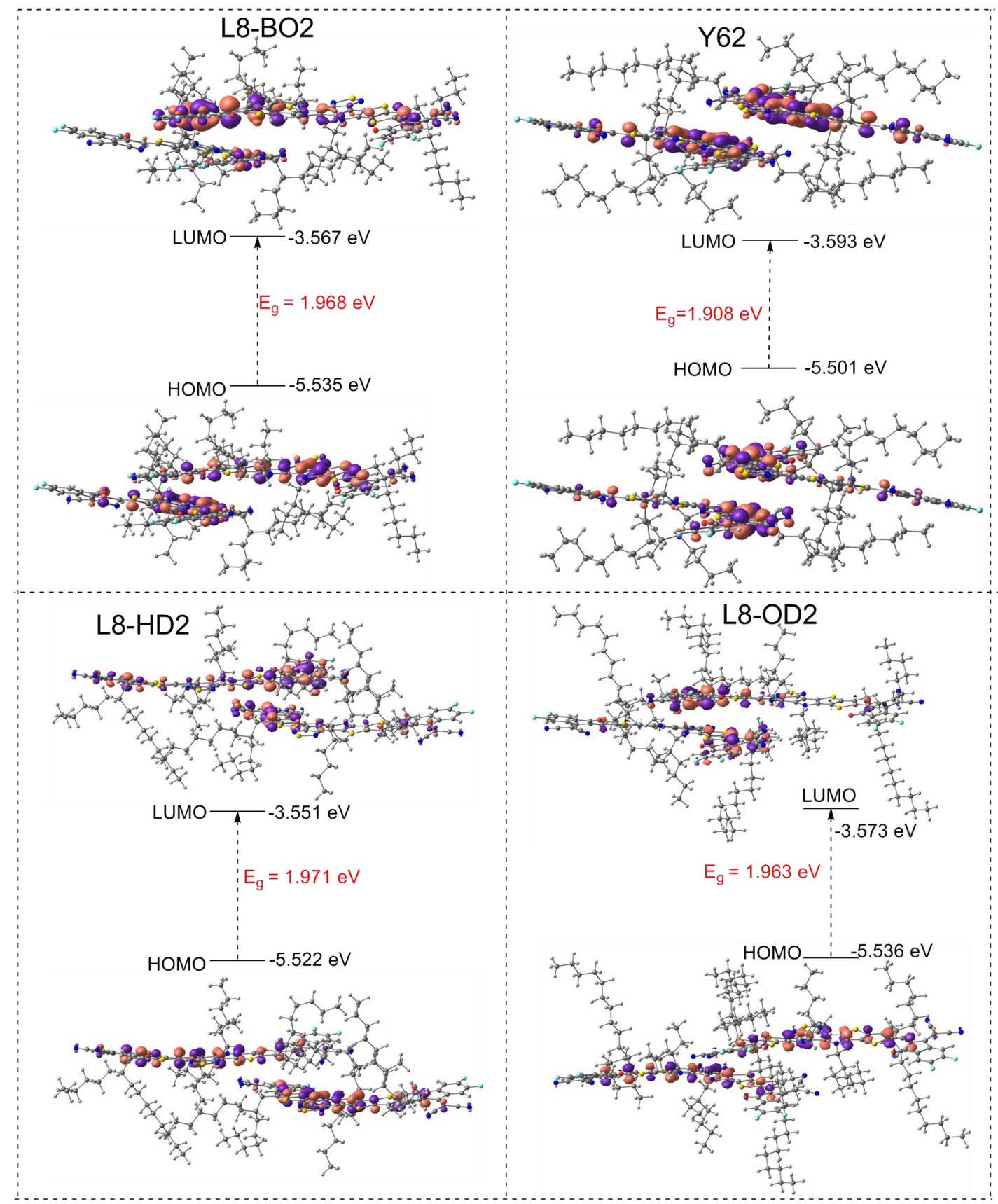

Supplementary Figure 9. The energy gaps between HOMO and LUMO of the four dimer structures. The DFT calculations were performed at the B3LYP/6-31G(d,p) level. 


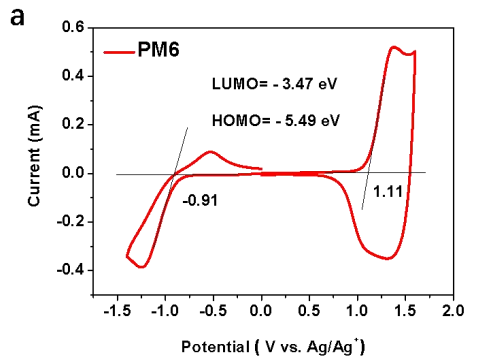

a

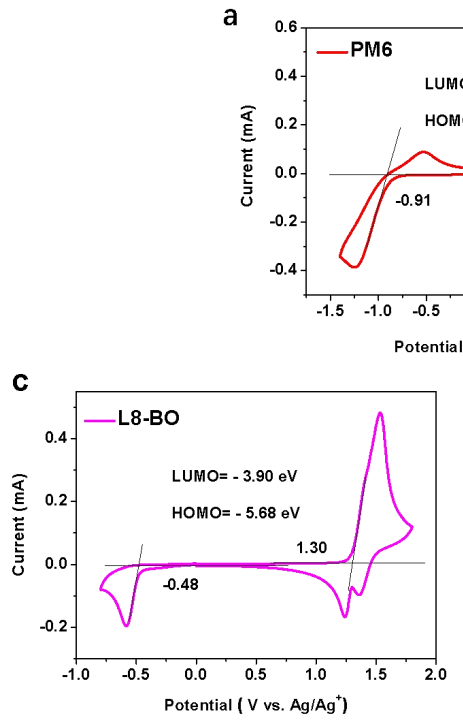

b

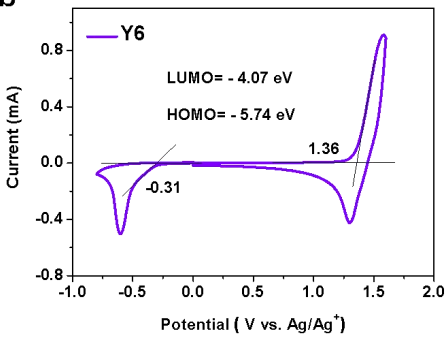

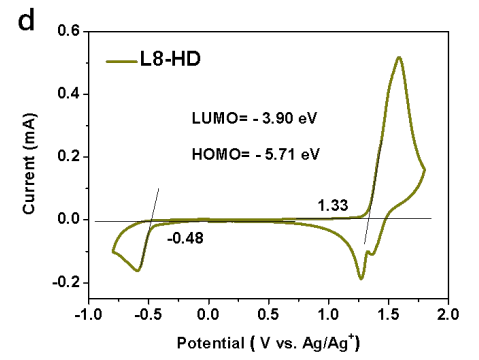

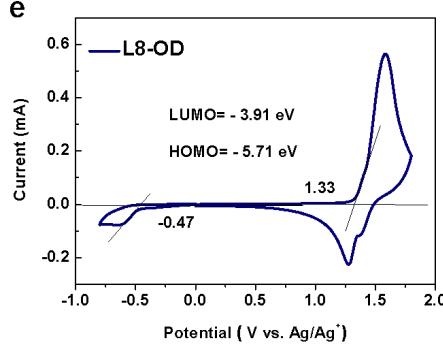

Supplementary Figure 10. Cyclic voltammetry (CV) measurements. (a-e) The CV of PM6, Y6, and L8-R films. The corresponding potential values are extracted by the crossing points of the two tangent lines. 
a

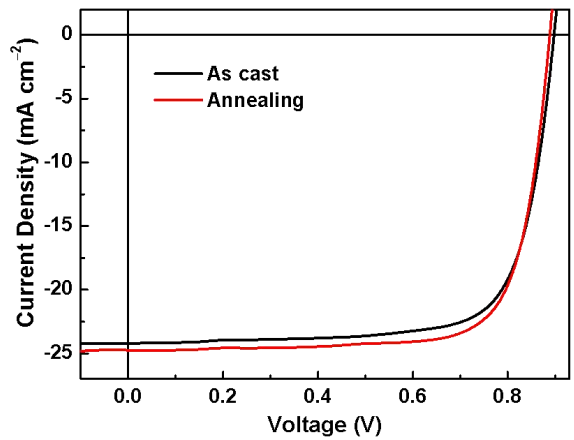

C

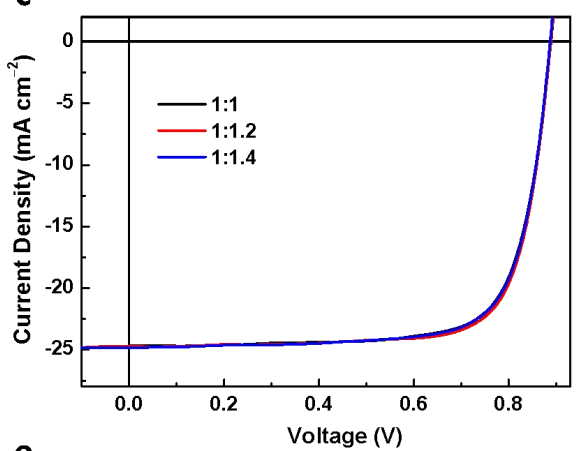

e

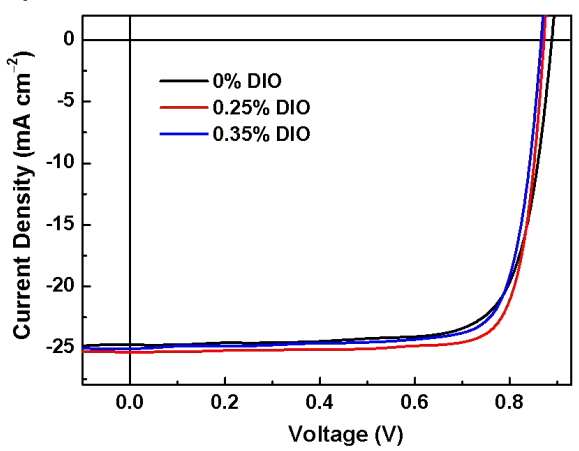

b

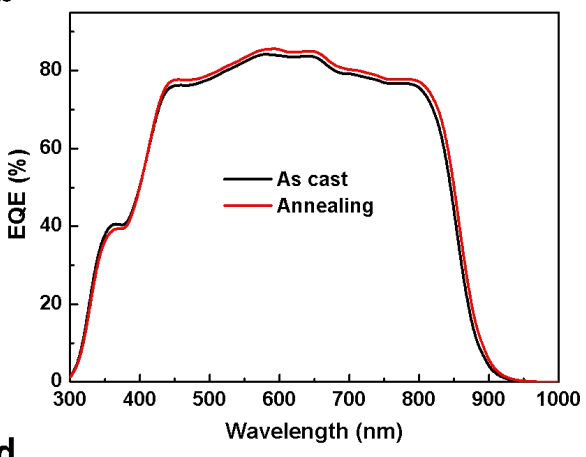

d

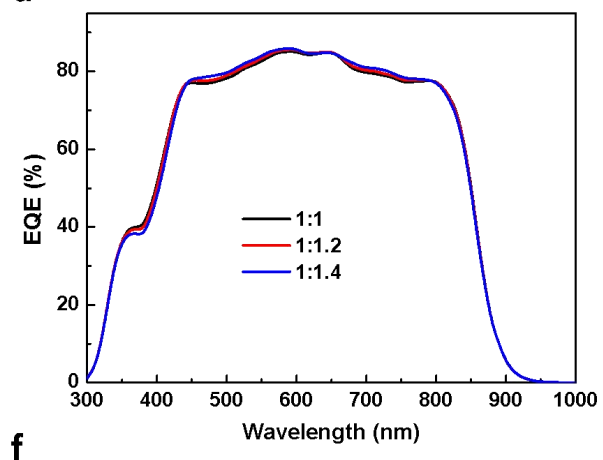

f

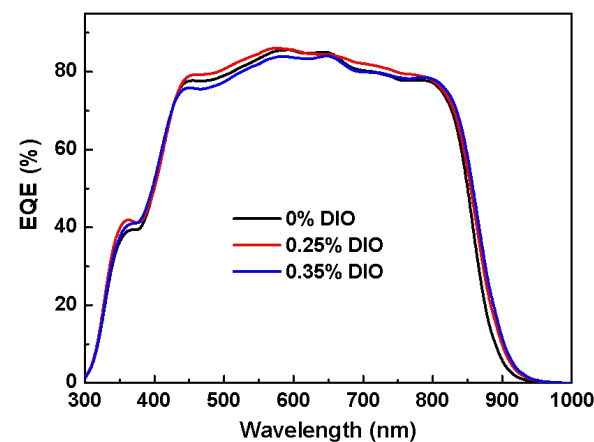

Supplementary Figure 11. Current density-voltage $(J-V)$ and EQE characteristics. The $J-V$ curves (a, c and e) and corresponding EQE spectra (b, d and f) of OSCs based on PM6:L8-BO blend under different optimization conditions. 
a

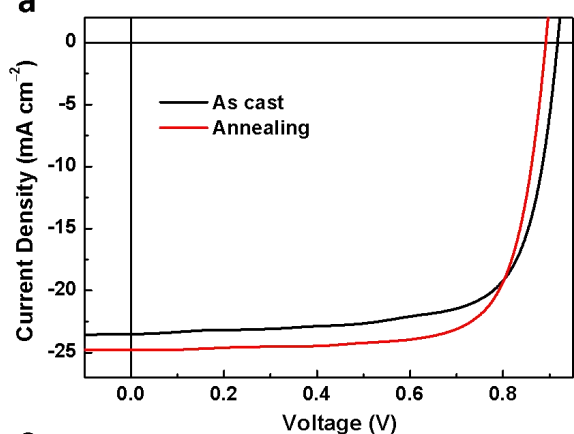

C

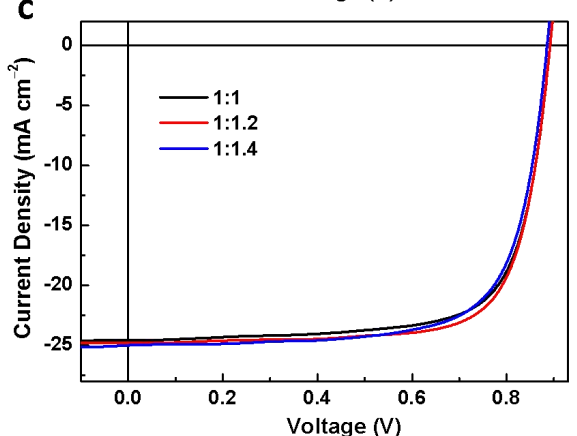

e

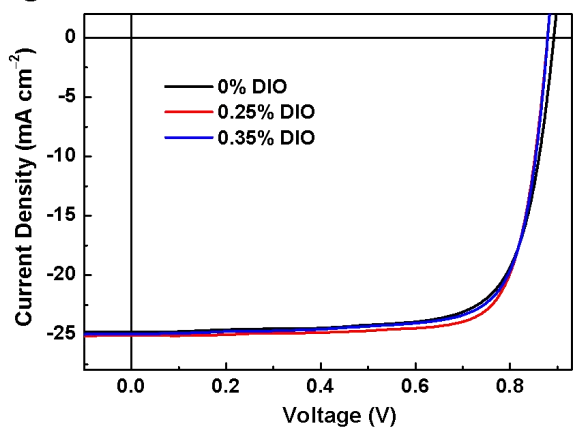

b

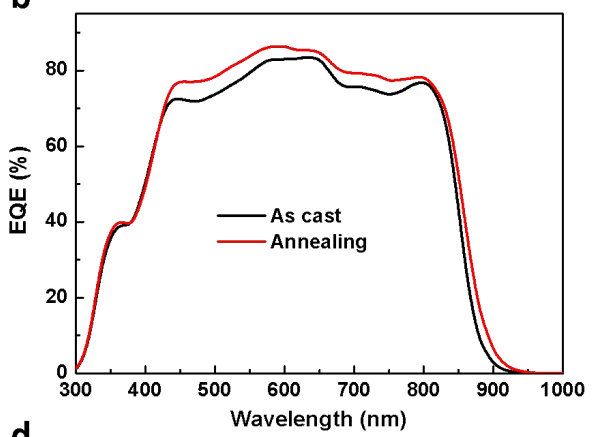

d

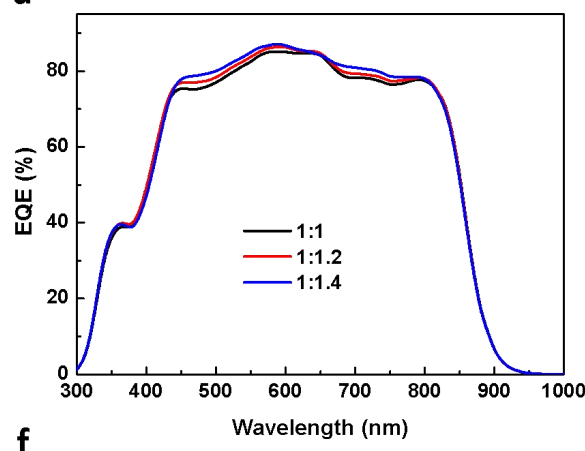

f

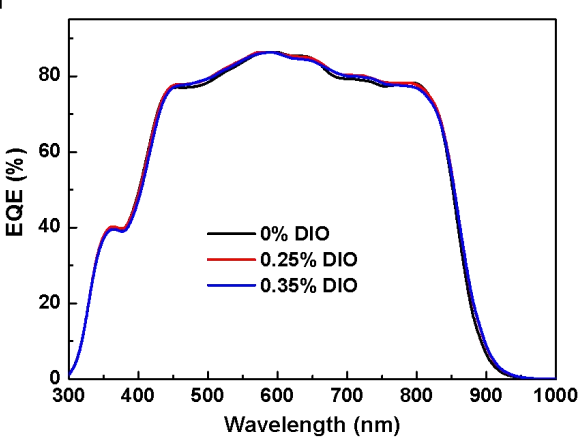

Supplementary Figure 12. Current density-voltage $(J-V)$ and EQE characteristics. The $J-V$ curves (a, $\mathbf{c}$ and $\mathbf{e})$ and corresponding EQE spectra (b, $\mathbf{d}$ and f) of OSCs based on PM6:L8-HD blend under different optimization conditions. 
a
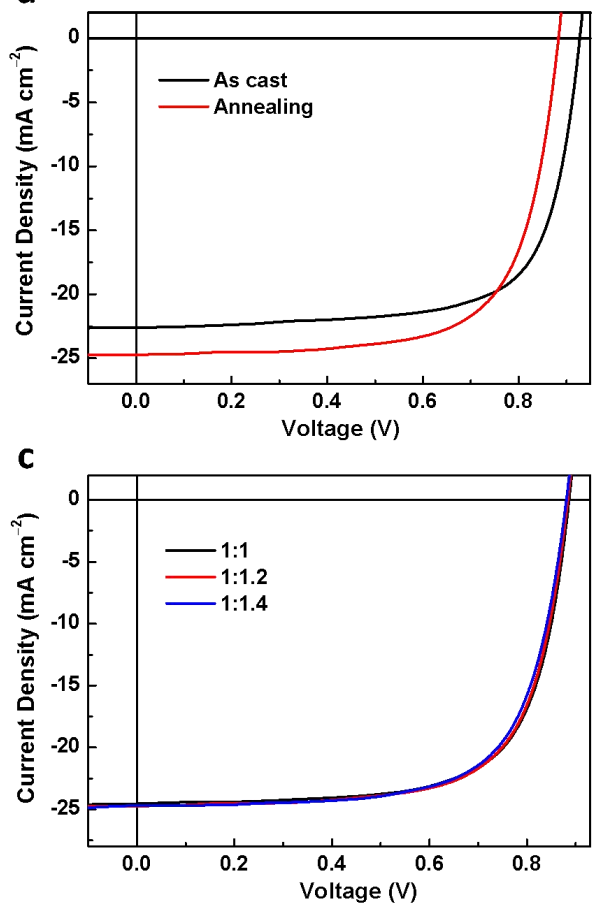

e

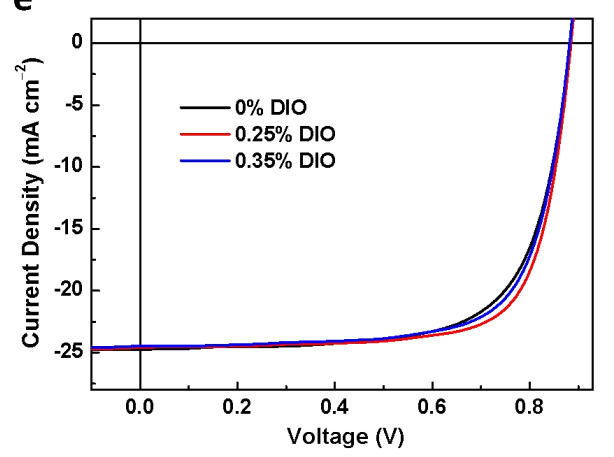

b

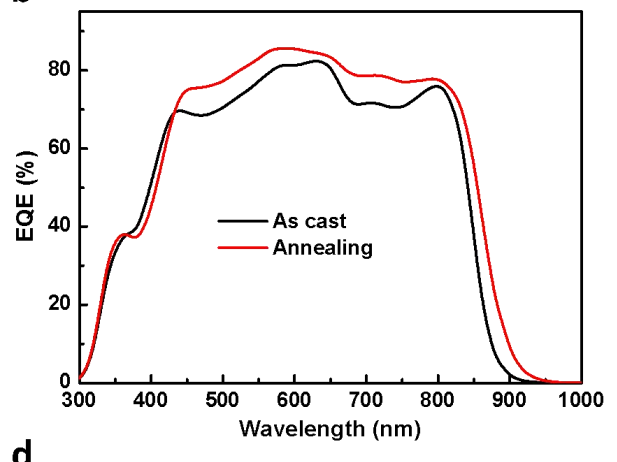

d

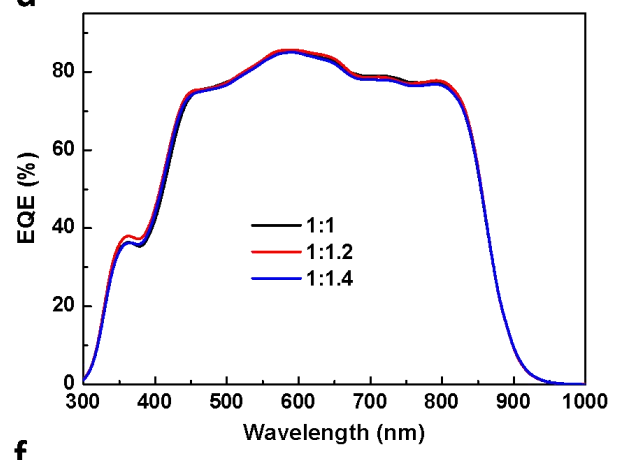

f

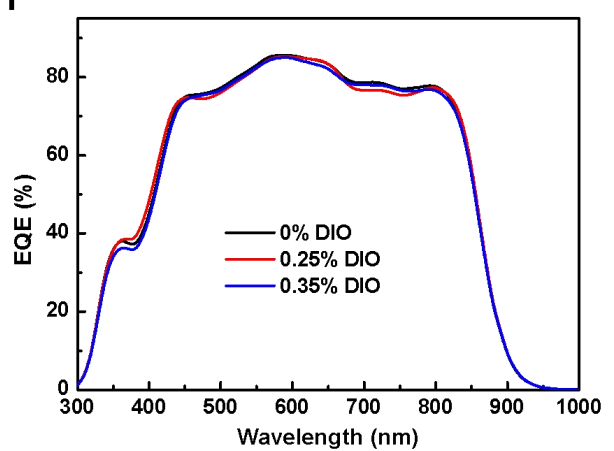

Supplementary Figure 13. Current density-voltage $(J-V)$ and EQE characteristics. The $J-V$ curves (a, c and $\mathbf{e})$ and corresponding EQE spectra (b, $\mathbf{d}$ and f) of OSCs based on PM6:L8-OD blend under different optimization conditions. 


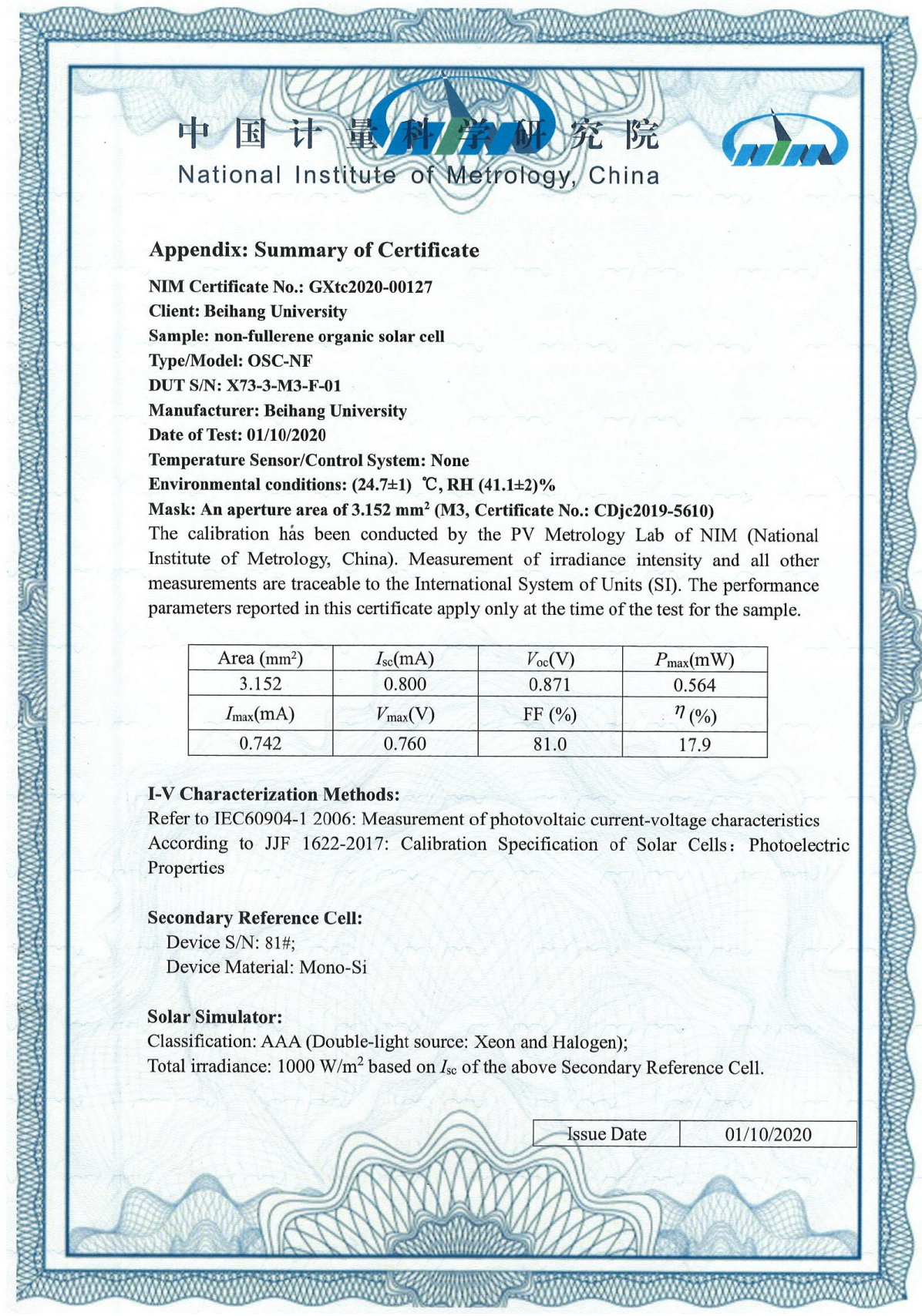

\section{Supplementary Figure 14. Certification report by National Institute of}

Metrology (NIM), China. Scanning copy of the certification report for the PM6:L8-BO-based device from NIM, China. 


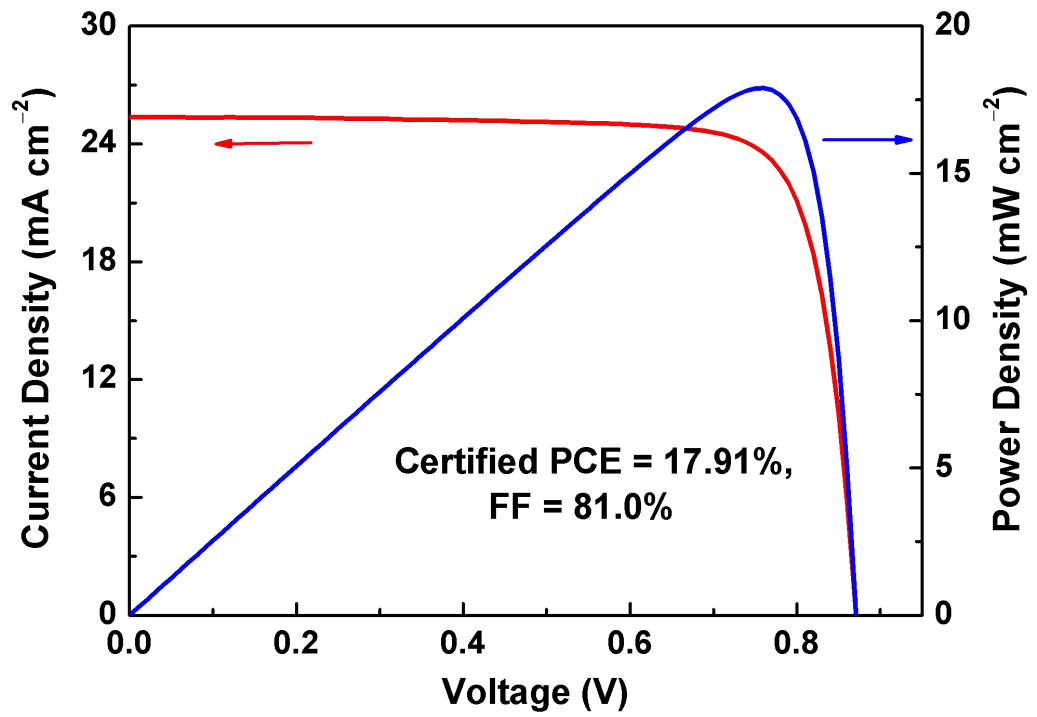

Supplementary Figure 15. Certified result of the optimum PM6:L8-BO device from NIM, China. The certified device area is $3.152 \mathrm{~mm}^{2}$. 

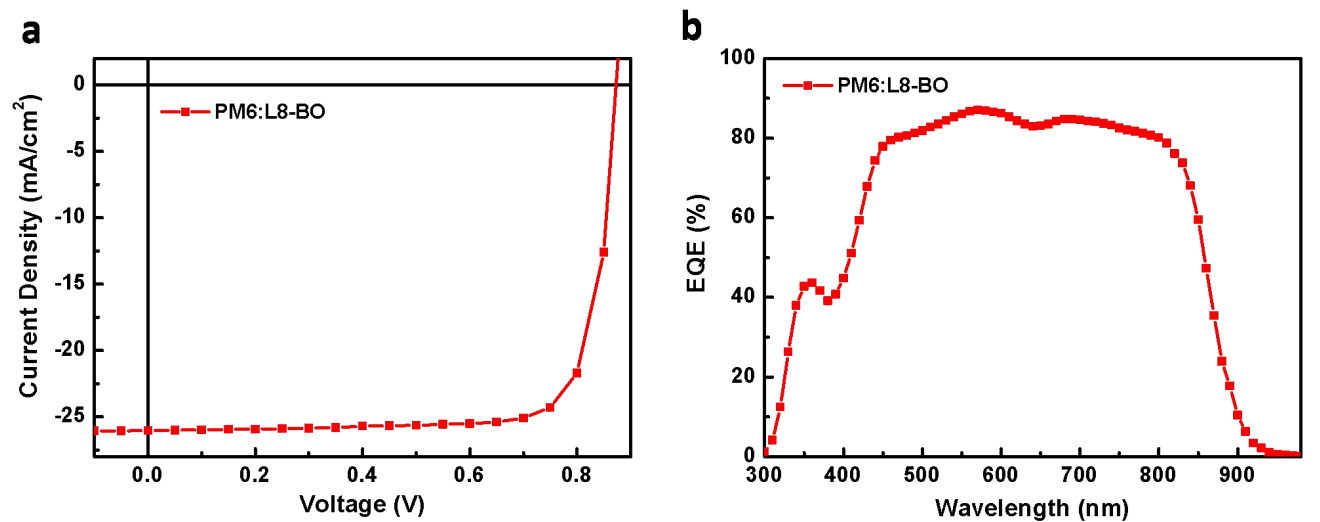

Supplementary Figure 16. Current density-voltage $(J-V)$ and EQE characteristics. $J-V$ curve (a) and the corresponding EQE spectrum (b) of the PM6:L8-BO device fabricated in Prof. Huiqiong Zhou's lab (NCNST). The device showed a PCE of $18.22 \%$, with a $V_{\text {oc }}$ of $0.873 \mathrm{~V}$, a $J_{\text {sc }}$ of $26.03 \mathrm{~mA} \mathrm{~cm}^{-2}$ and a FF of $80.2 \%$. 


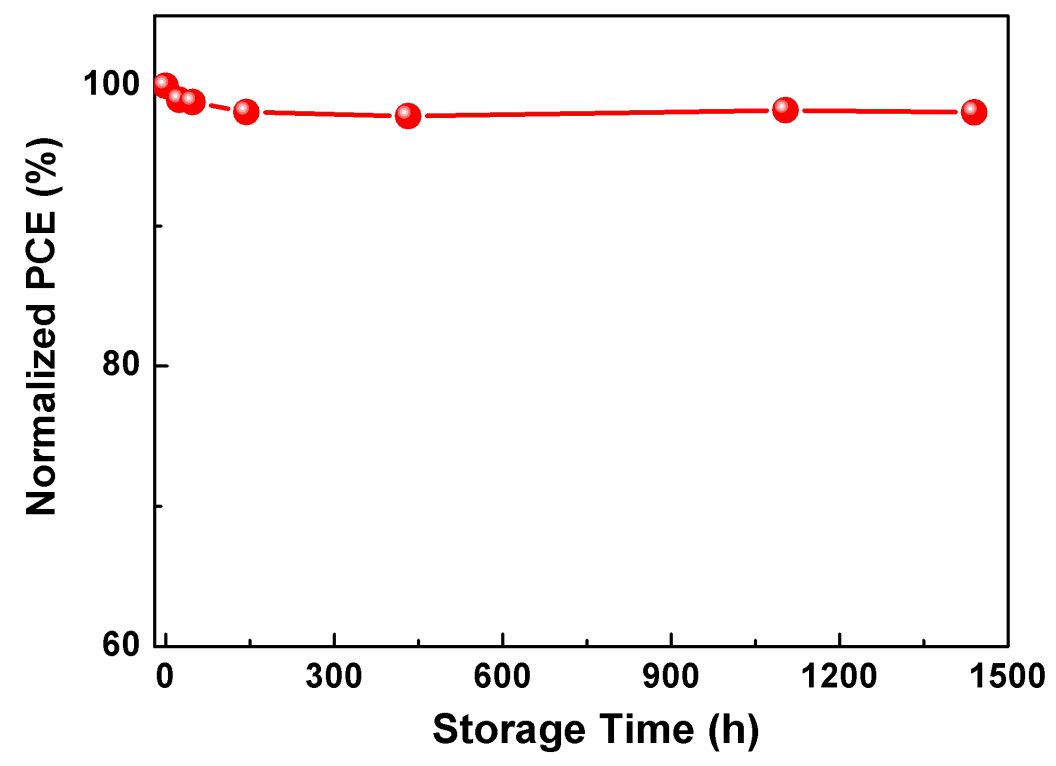

Supplementary Figure 17. Stability of optimum PM6:L8-BO device after storage in a glove box under nitrogen atmosphere. 

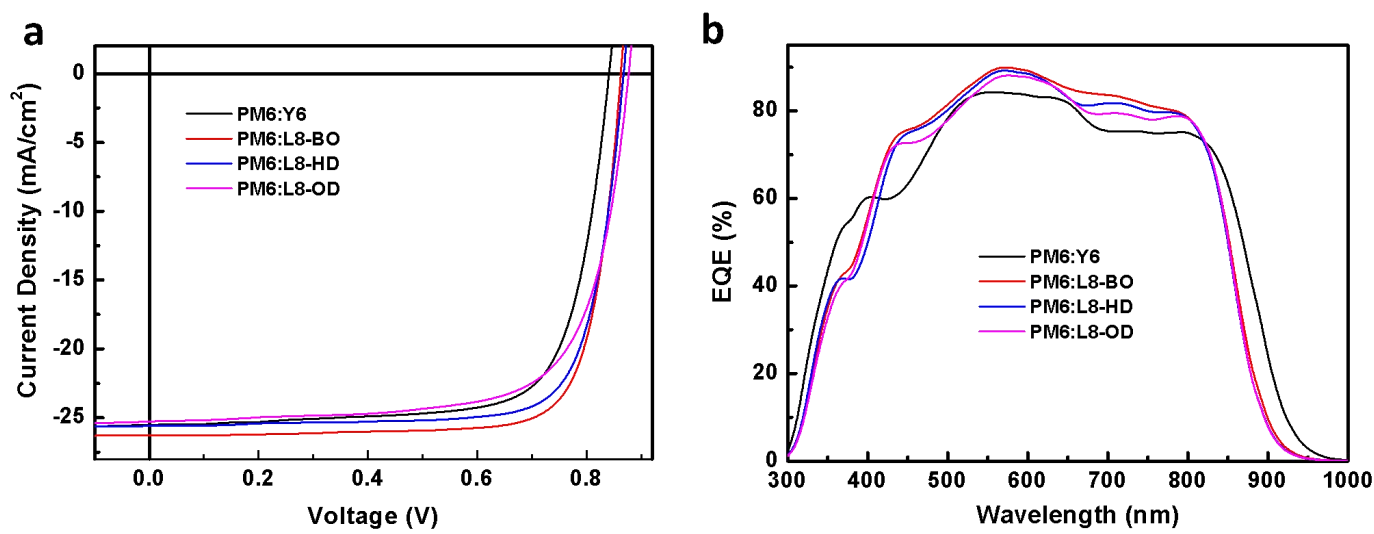

Supplementary Figure 18. Current density-voltage $(J-V)$ and EQE characteristics. $J-V$ curves (a) and the corresponding EQE spectra (b) of the inverted OSCs based on Y6 and L8-R acceptors. 

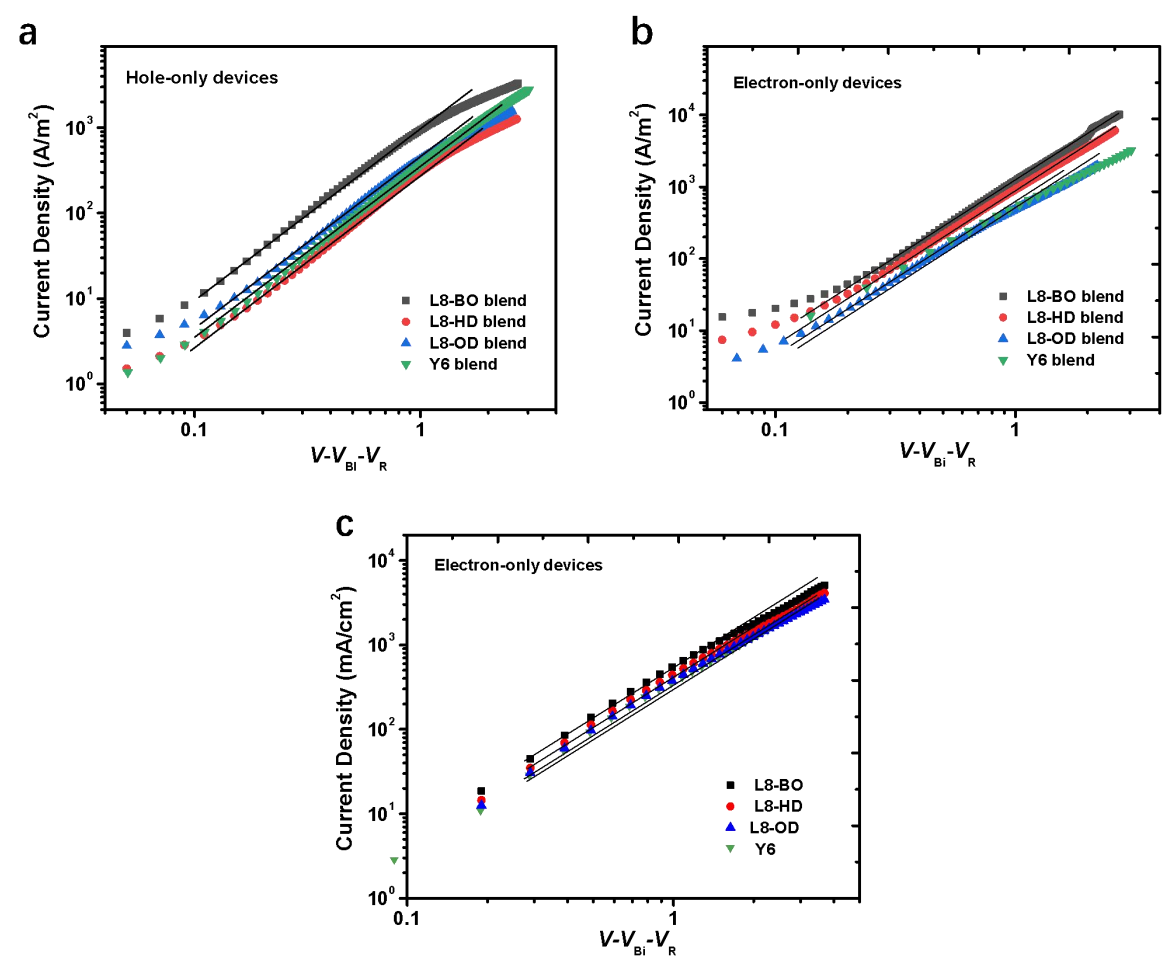

Supplementary Figure 19. Space-charge limited current (SCLC) measurements. (a) SCLC curves of hole-only devices based on Y6 and L8-R blend films. (b) SCLC curves of electron-only devices Y6 and L8-R blend films. (c) SCLC curves of electron-only devices based on Y6 and L8-R neat films. 

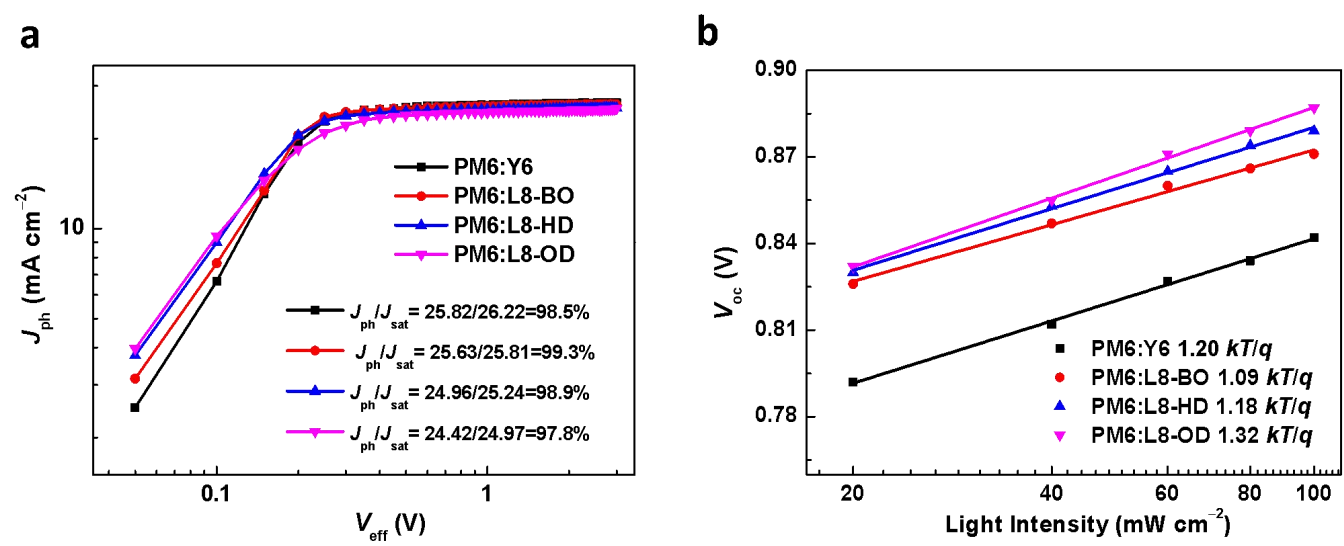

Supplementary Figure 20. Charge generation and charge recombination characterizations. (a) The photocurrent density $\left(J_{\mathrm{ph}}\right)$ versus effective voltage ( $\left.V_{\text {eff }}\right)$ curves of the optimum OSC devices. (b) The dependence of the $V_{\mathrm{oc}}$ on the light intensity for the optimum OSC devices. 


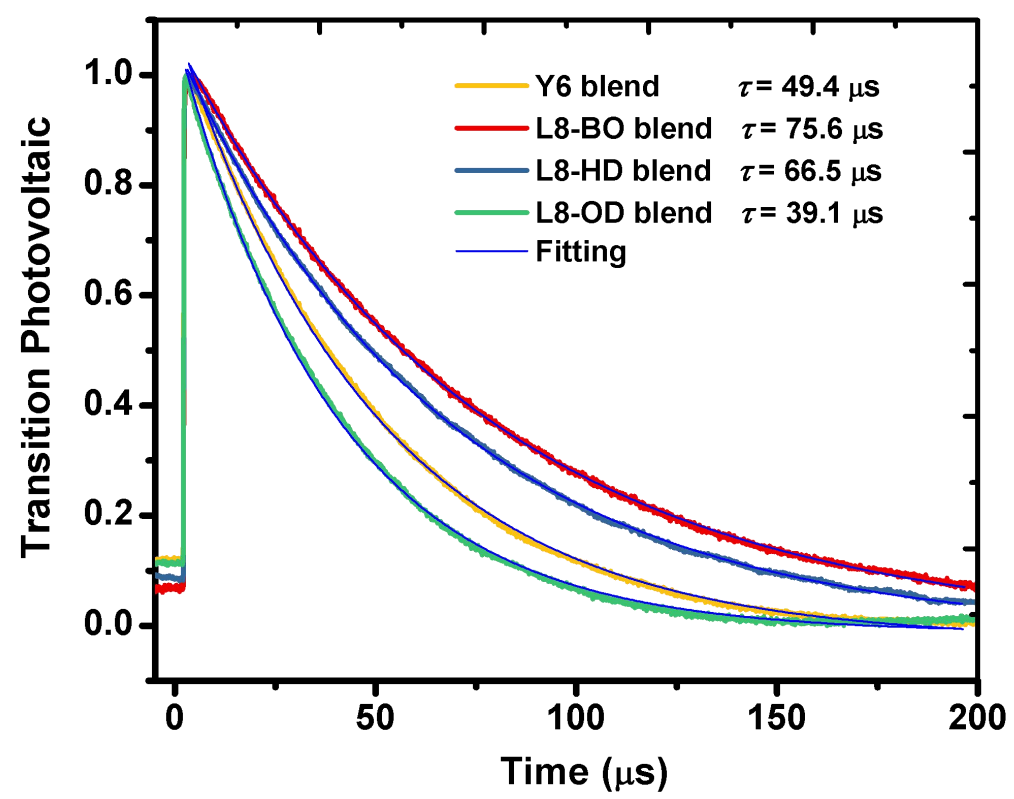

Supplementary Figure 21. Transient photovoltage (TPV) decay kinetics of OSCs based on Y6 and L8-R blends. 


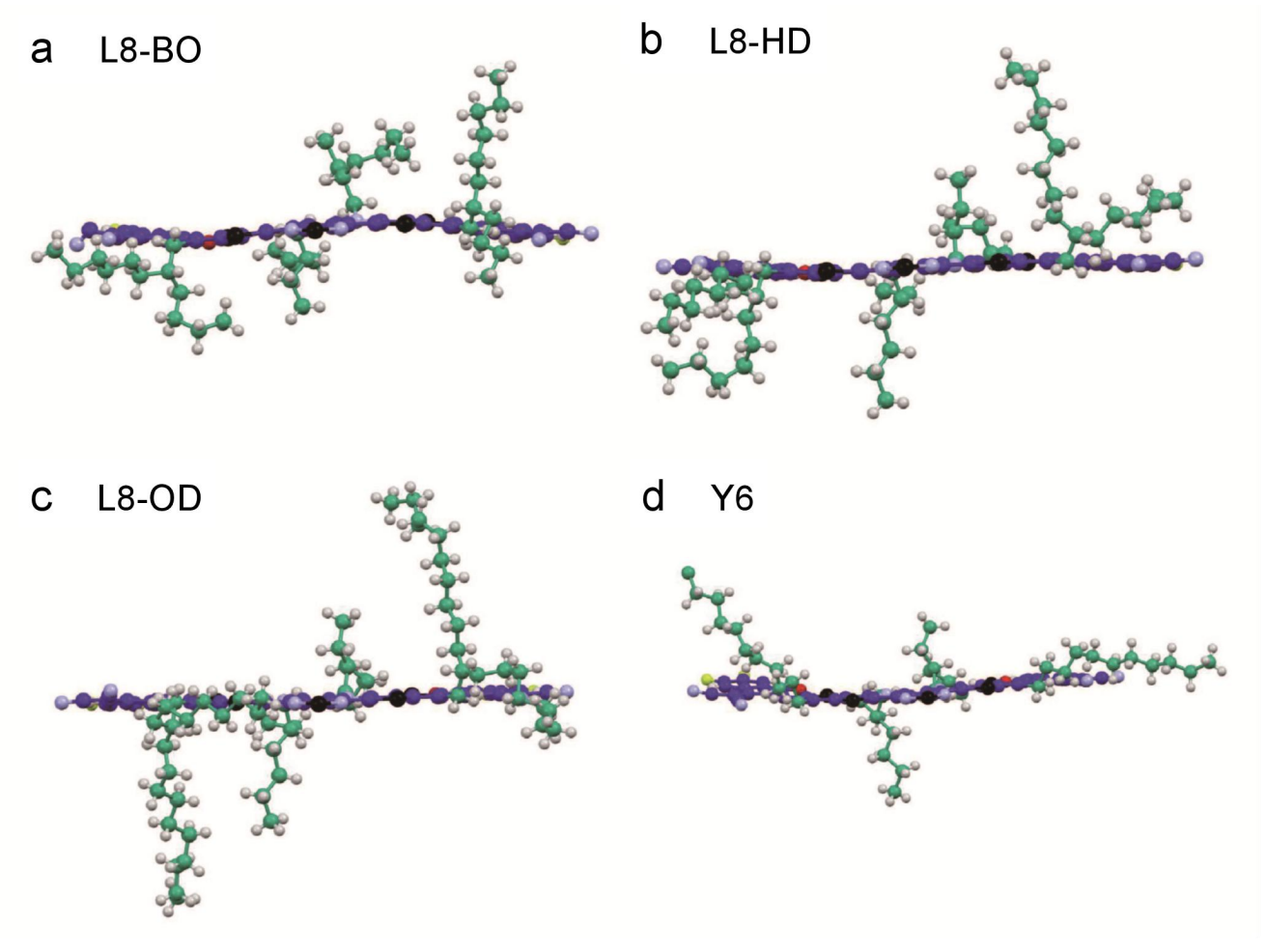

Supplementary Figure 22. The molecular conformation sketch of NFAs. (a-d) The side view of molecular conformations of L8-BO, L8-HD, L8-OD and Y6 single crystals. The backbone is marked with purple color and the side chain is marked with green color. 


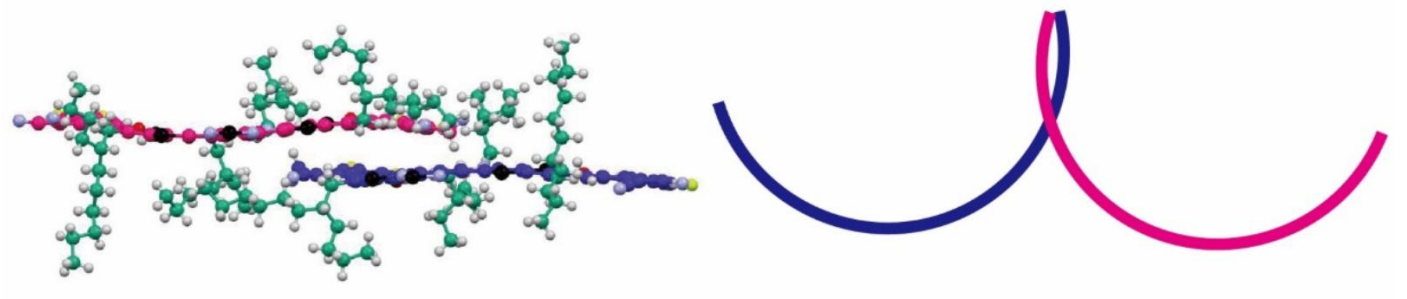

b L8-HD
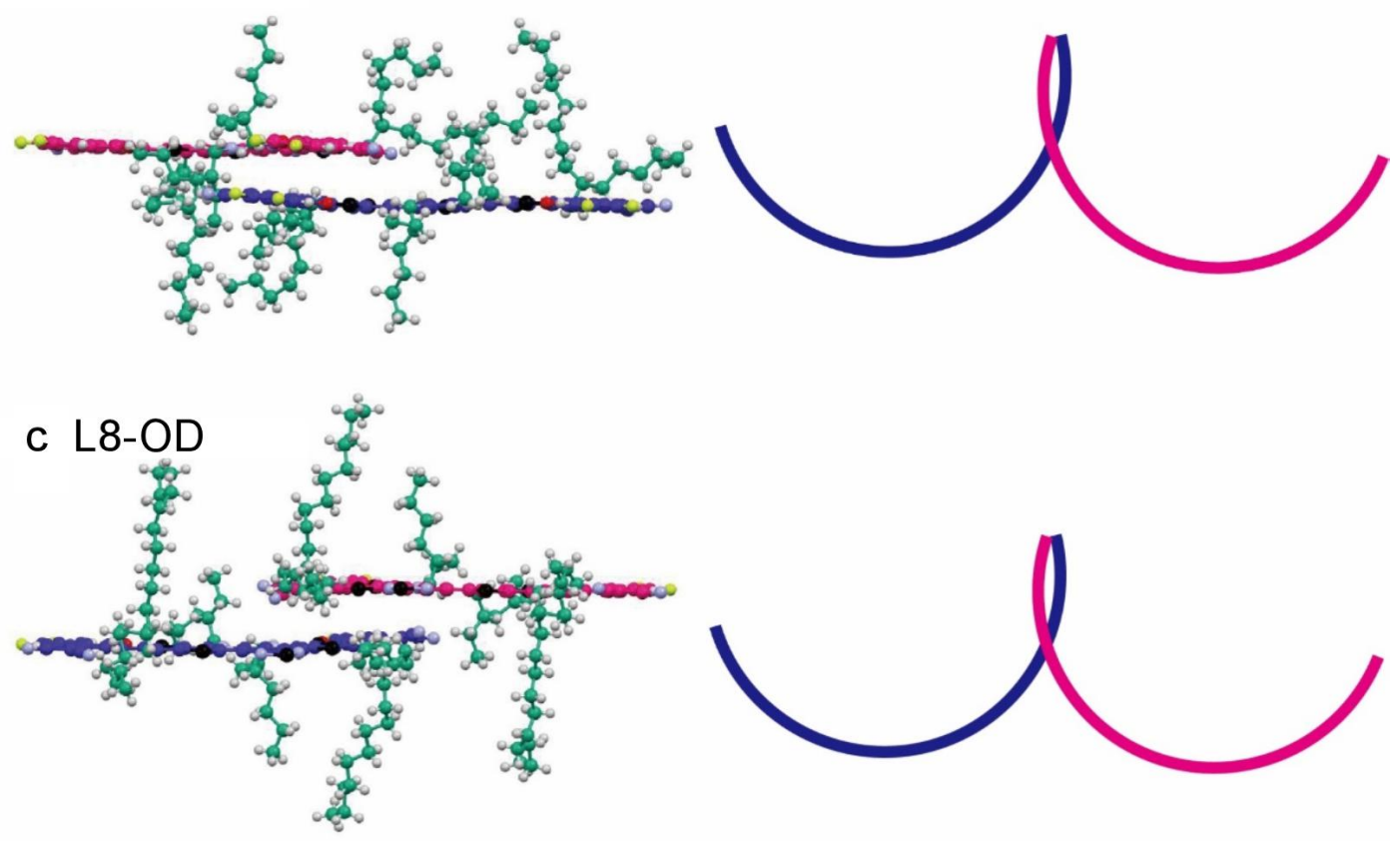

d $Y 6$
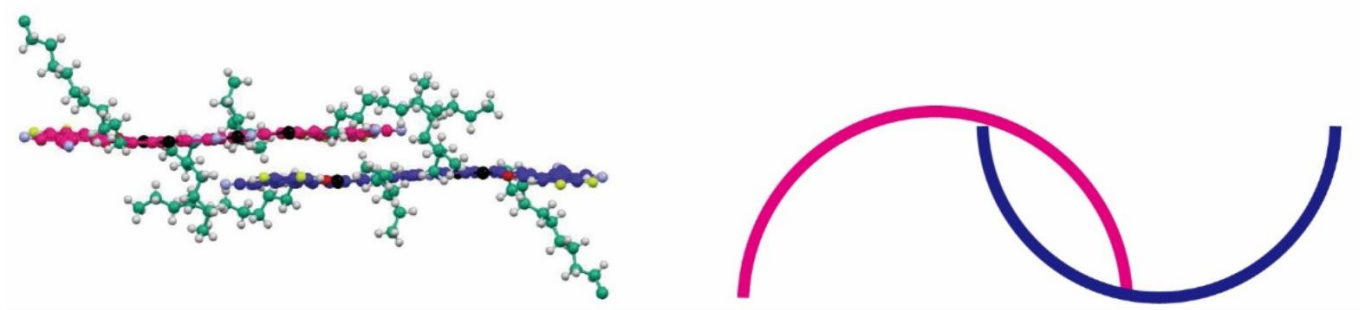

Supplementary Figure 23. The molecular packing sketch of NFAs. (a-d) The side view of the molecular dimer of L8-BO, L8-HD, L8-OD and Y6. The right side is the schematic diagram of molecular arrangement (top view) of L8-BO, L8-HD, L8-OD and Y6. 


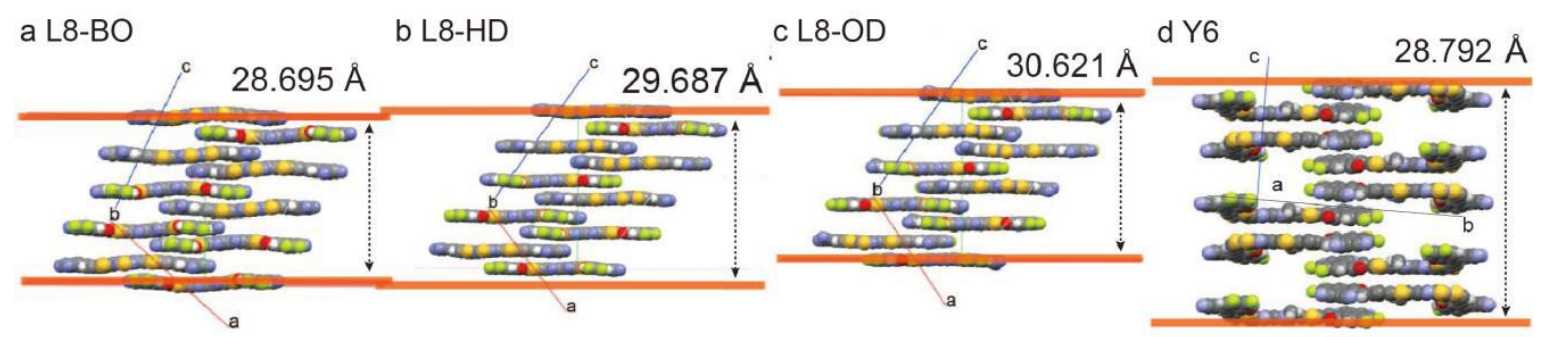

Supplementary Figure 24. $\pi-\pi$ stacking of NFAs. (a-d ) $\pi$ - $\pi$ stacking distances of L8-BO, L8-HD, L8-OD and Y6 in the crystal structures. 


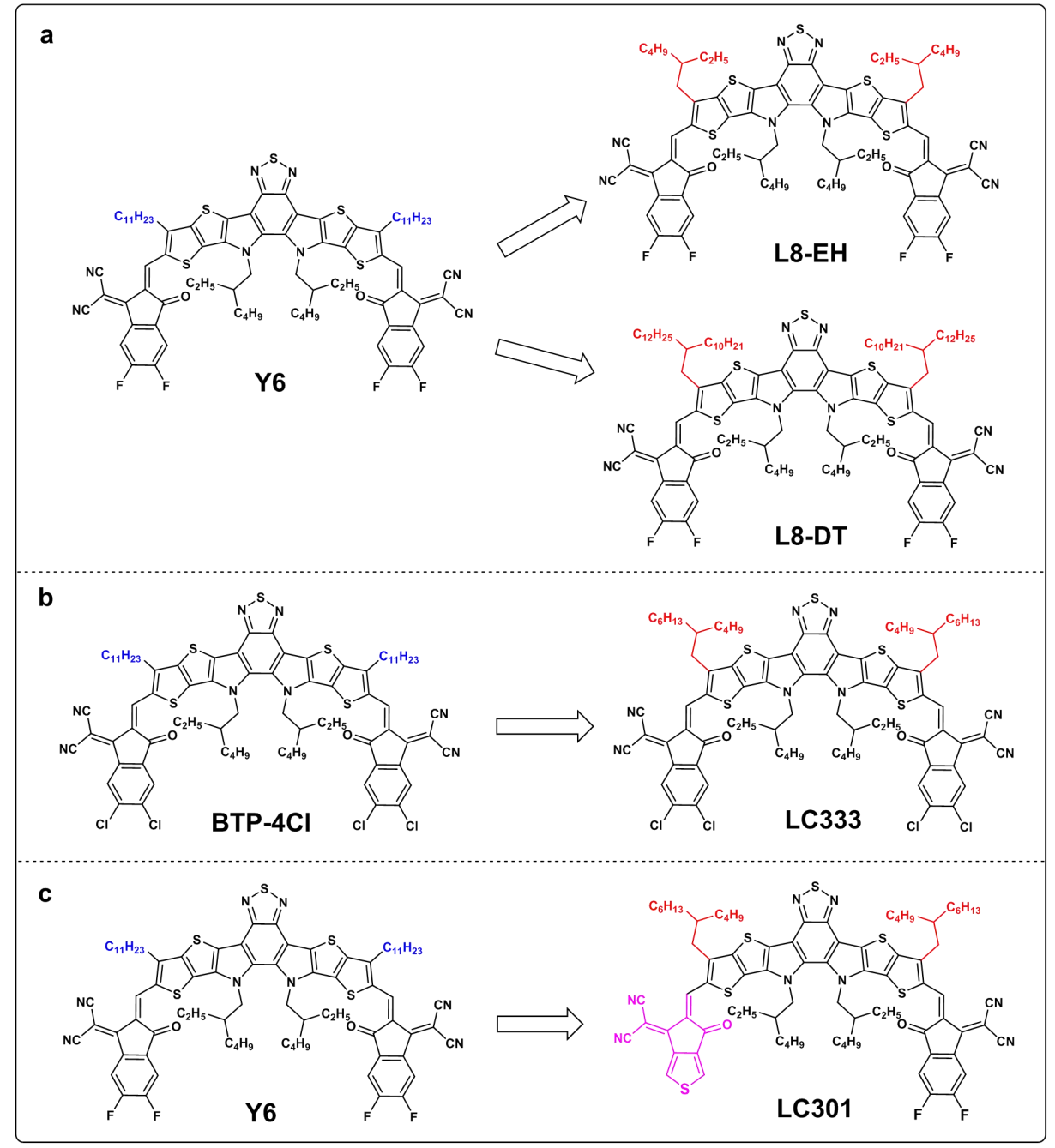

Supplementary Figure 25. Design of NFAs. (a) Design of L8-R acceptors utilizing branched 2-ethylhexyl and 2-decyltetradecyl side chains. (b) Ending group modulation of NFAs on the basis of branched alkyl chain strategy. (c) Design of asymmetric NFAs on the basis of branched alkyl chain strategy. 

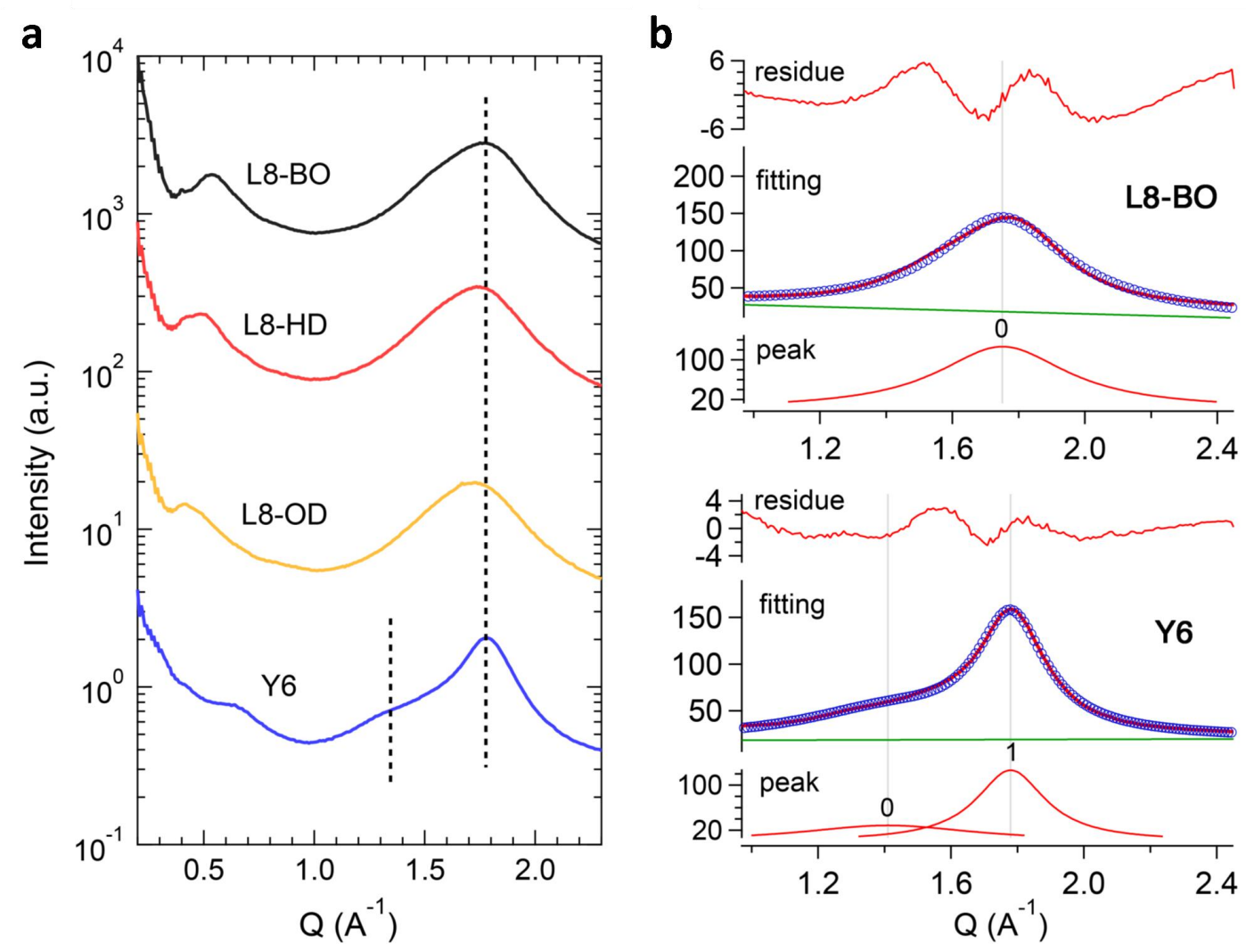

Supplementary Figure 26. GIWAXS patterns of neat NFAs film. (a) out-of-plane line-cut profiles of neat NFA thin films. (b) Peak fitting of the $\pi-\pi$ stacking region to reveal the structure order. 

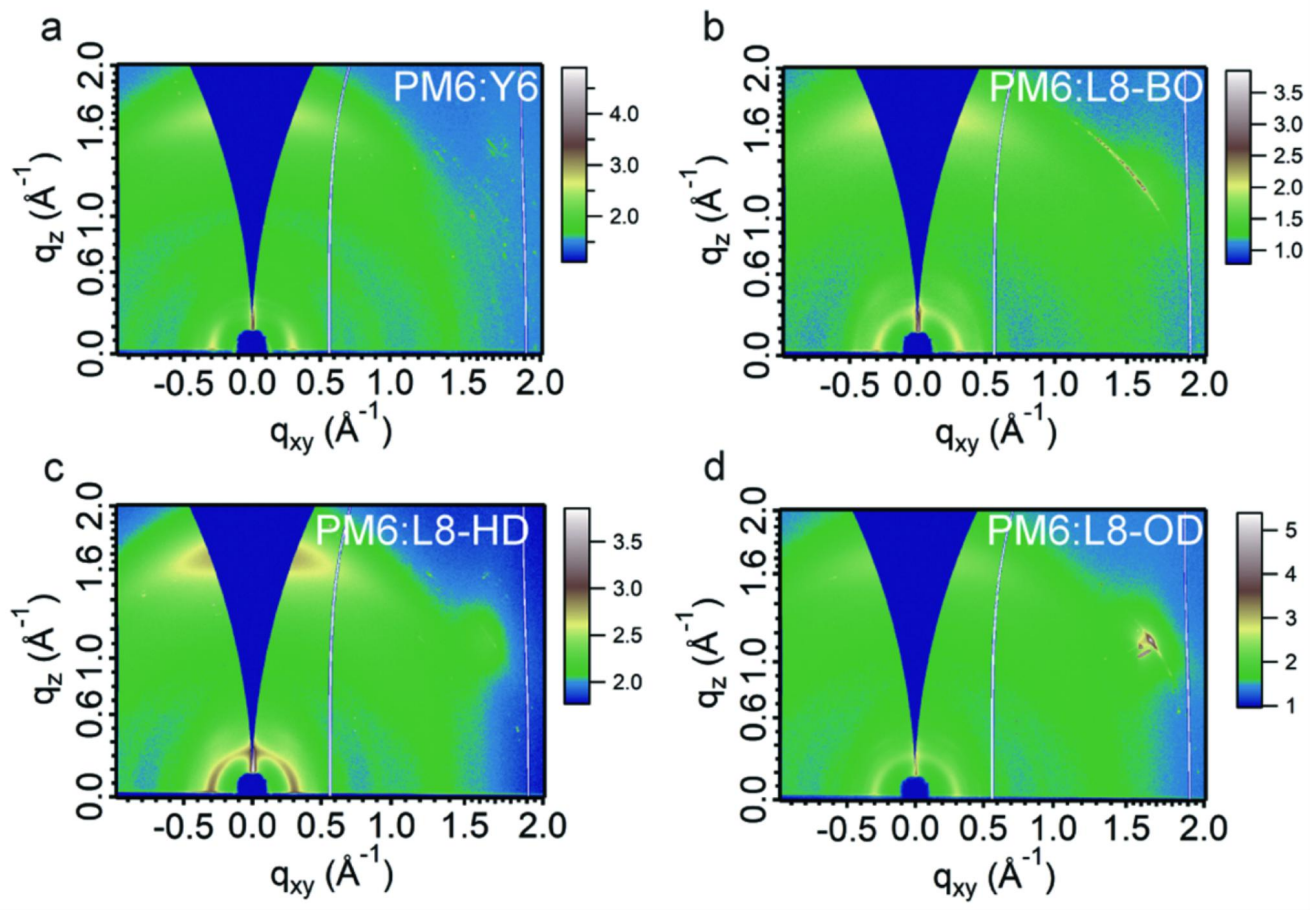

Supplementary Figure 27. Morphology characterizations of blend films. (a-d) 2D GIWAXS patterns of PM6:Y6, PM6:L8-BO, PM6:L8-HD and PM6:L8-OD blend films. 

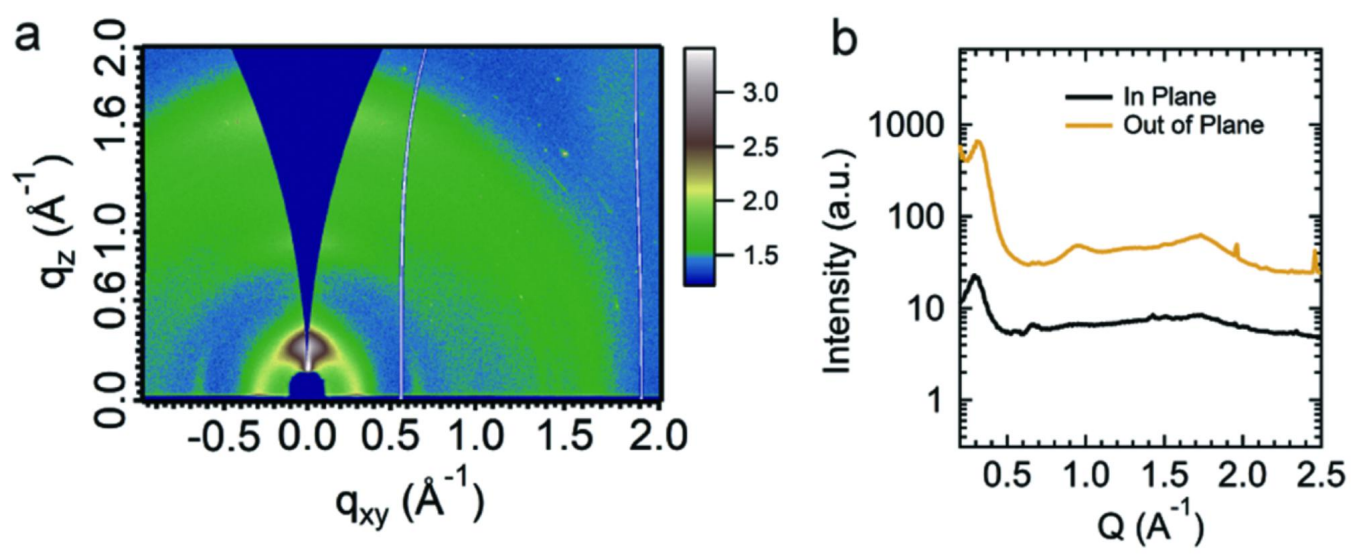

Supplementary Figure 28. Morphology characterization of PM6 film. (a) 2D GIWAXS pattern of PM6 neat film and (b) the corresponding line-cut profiles. 

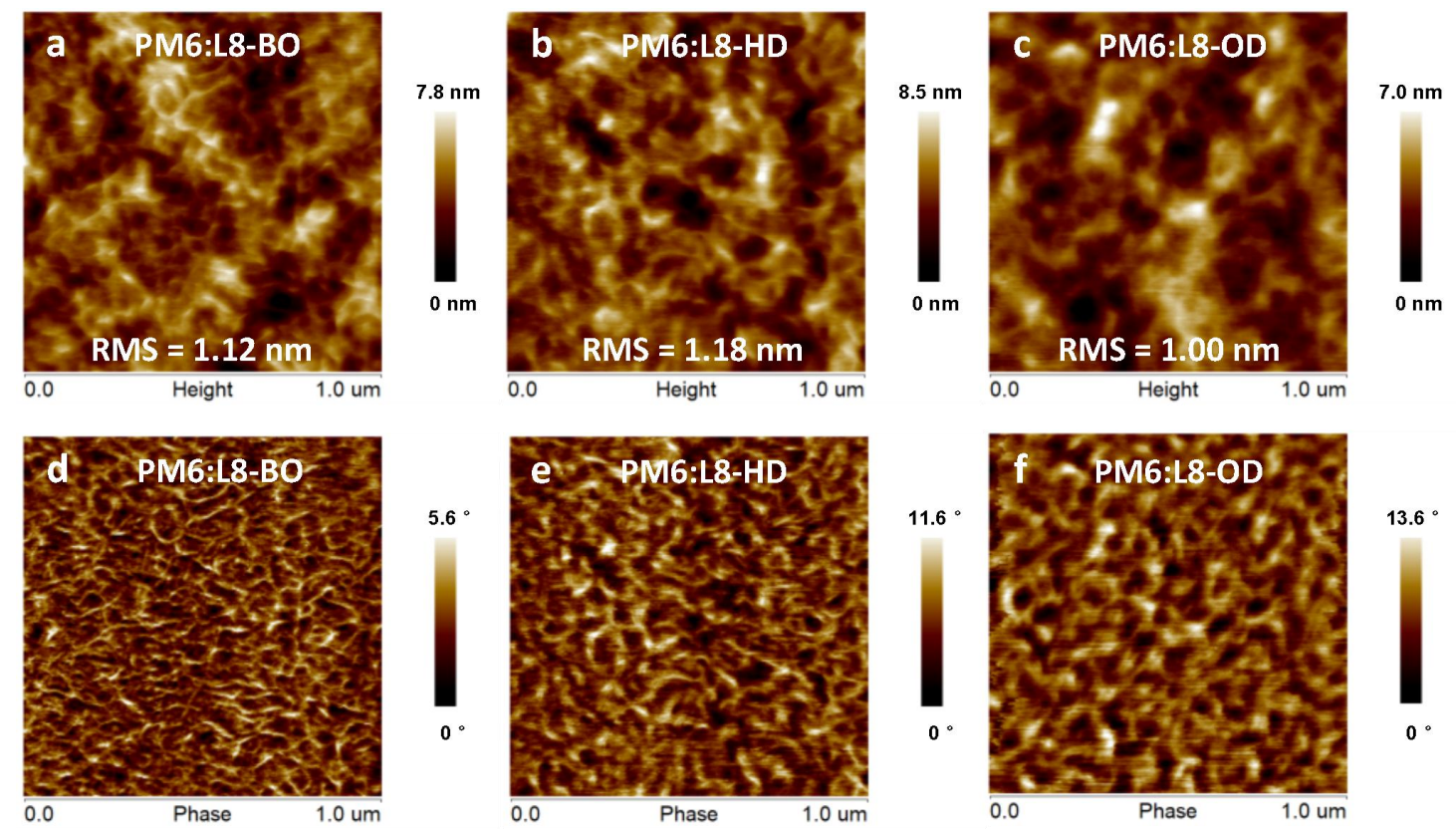

Supplementary Figure 29. Morphology characterizations of blend films. AFM height (a-c) and the corresponding phase images (d-f) of as-cast PM6:L8-R blend films. 

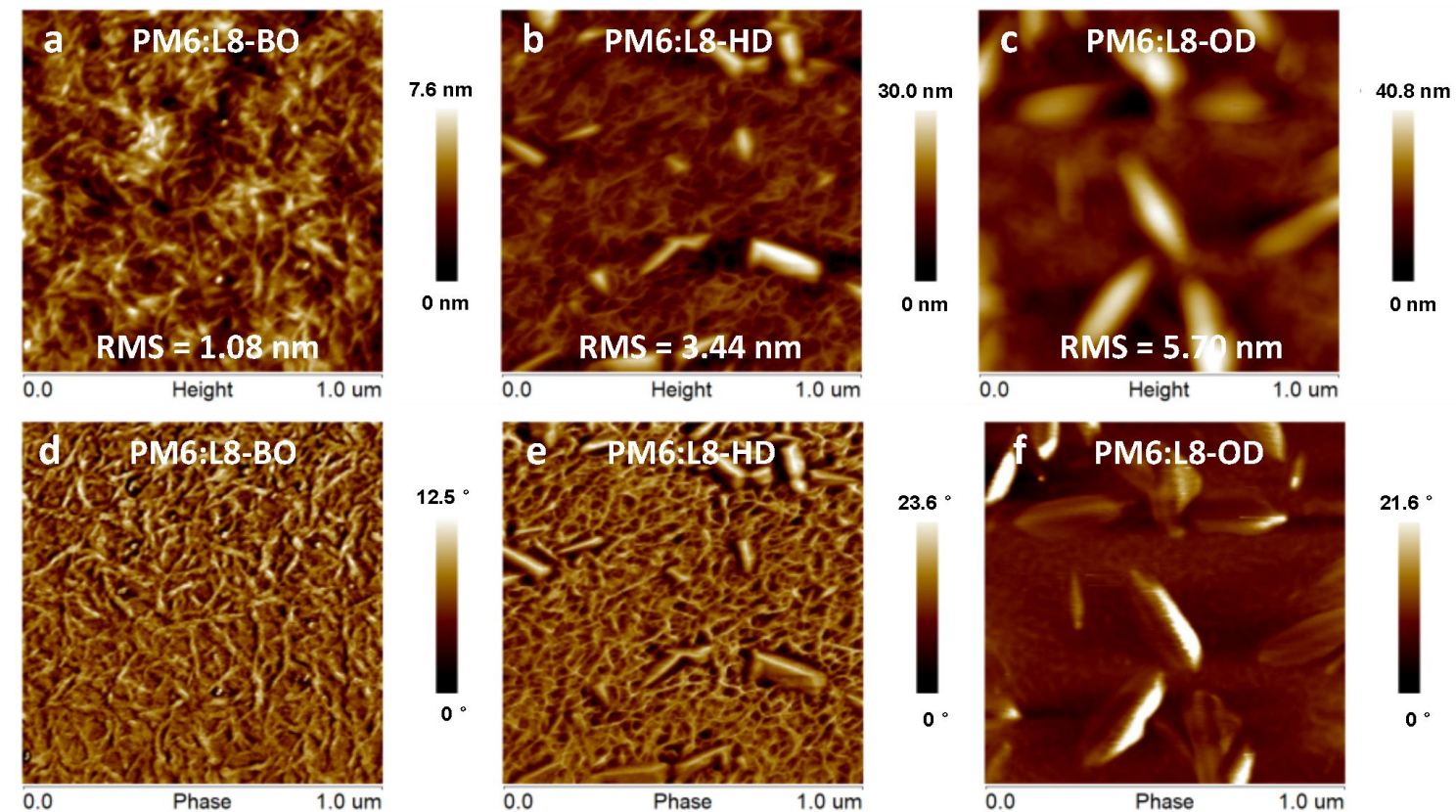

Supplementary Figure 30. Morphology characterizations of blend films. AFM height (a-c) and the corresponding phase images (d-f) of PM6:L8-R blend films with thermal annealing at $100{ }^{\circ} \mathrm{C}$ for 10 mins. 

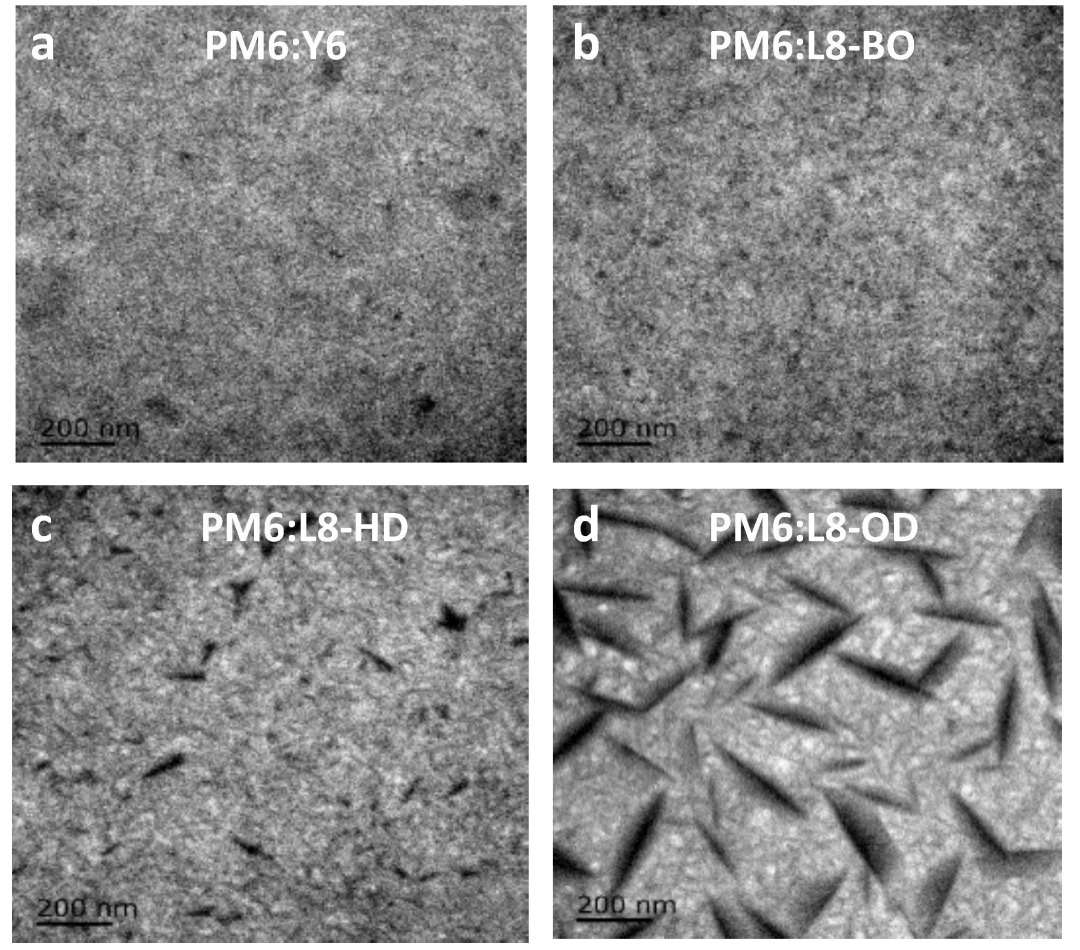

Supplementary Figure 31. Morphology characterizations of blend films. (a-d) TEM images of the optimum PM6:NFA blend films. 

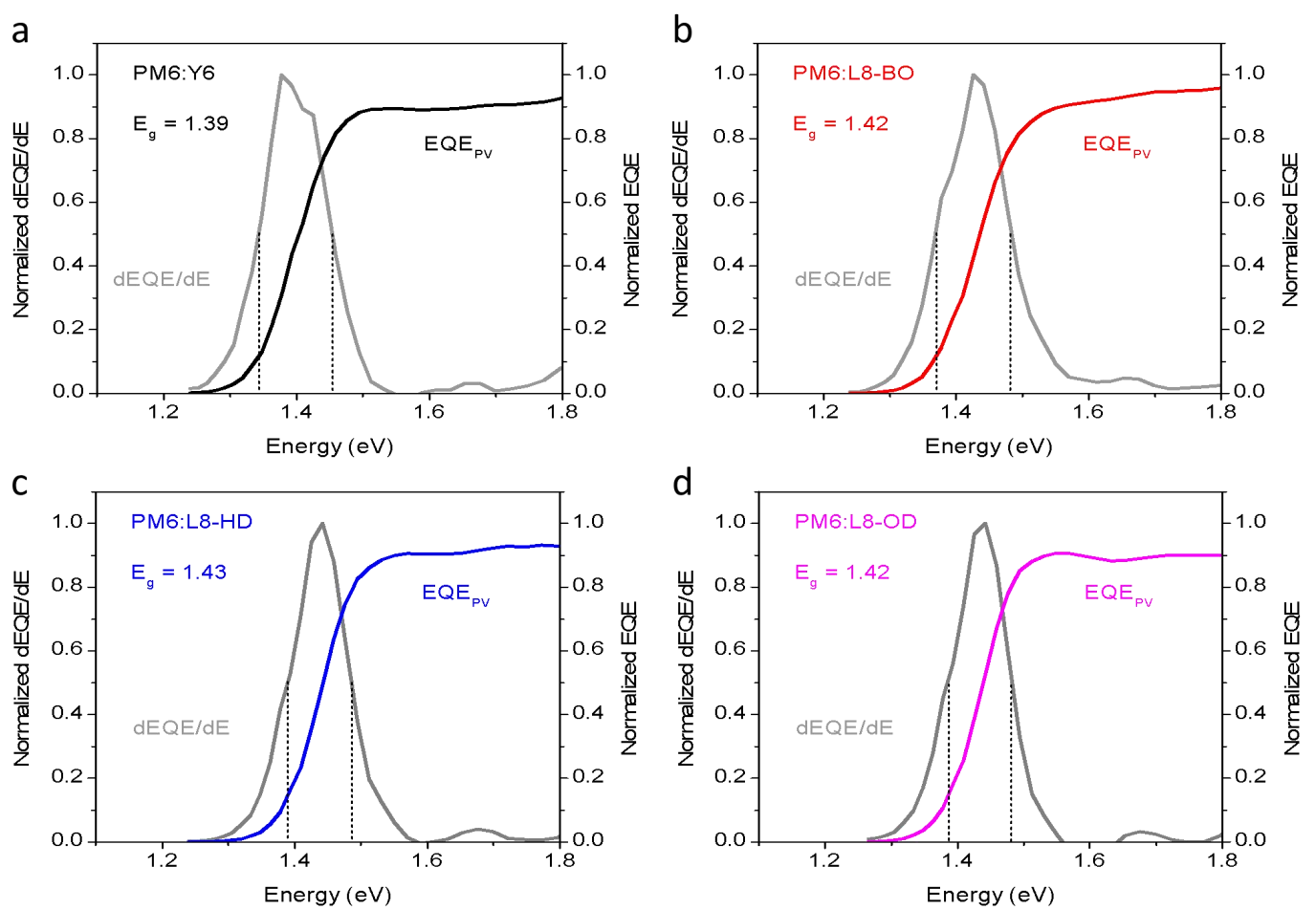

Supplementary Figure 32. Optical bandgap determination. (a-d) Optical bandgap determination of PM6:Y6, PM6:L8-BO, PM6:L8-HD and PM6:L8-OD on the basis of the derivatives of the EQE spectra (dEQE/dE, grey curves). The region between dashed lines is the part where the gap distribution probability is greater than half of the maximum, which is used for the bandgap calculation. 

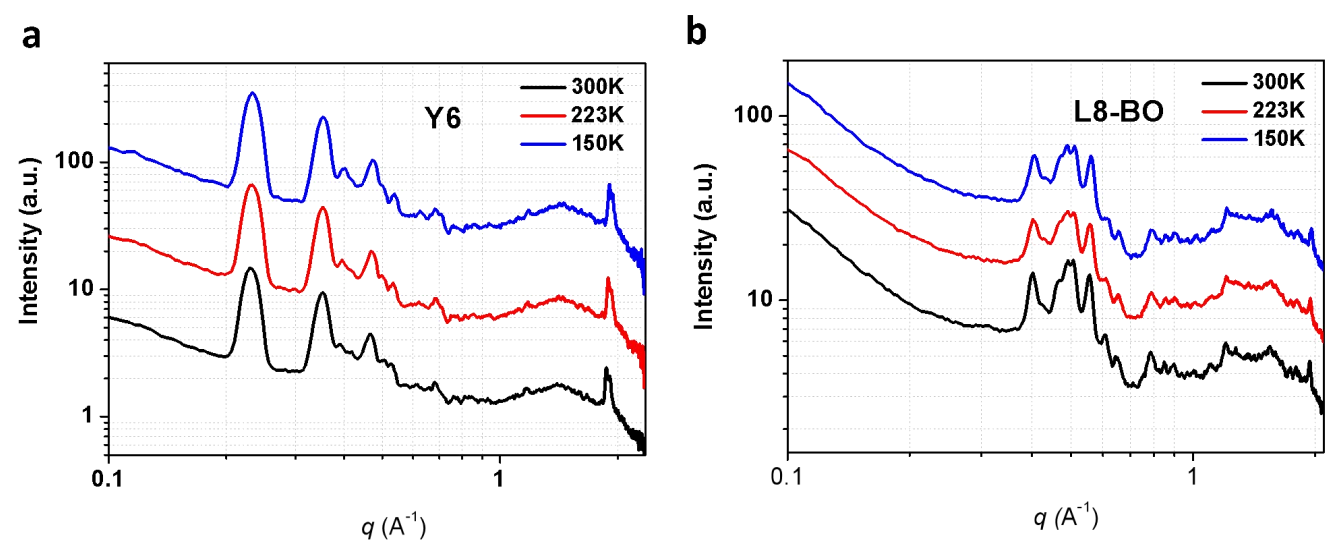

Supplementary Figure 33. The temperature effect on thermal expansion of the crystal lattice. XRD patters of Y6 (a) and L8-BO (b) powders under different temperatures. 


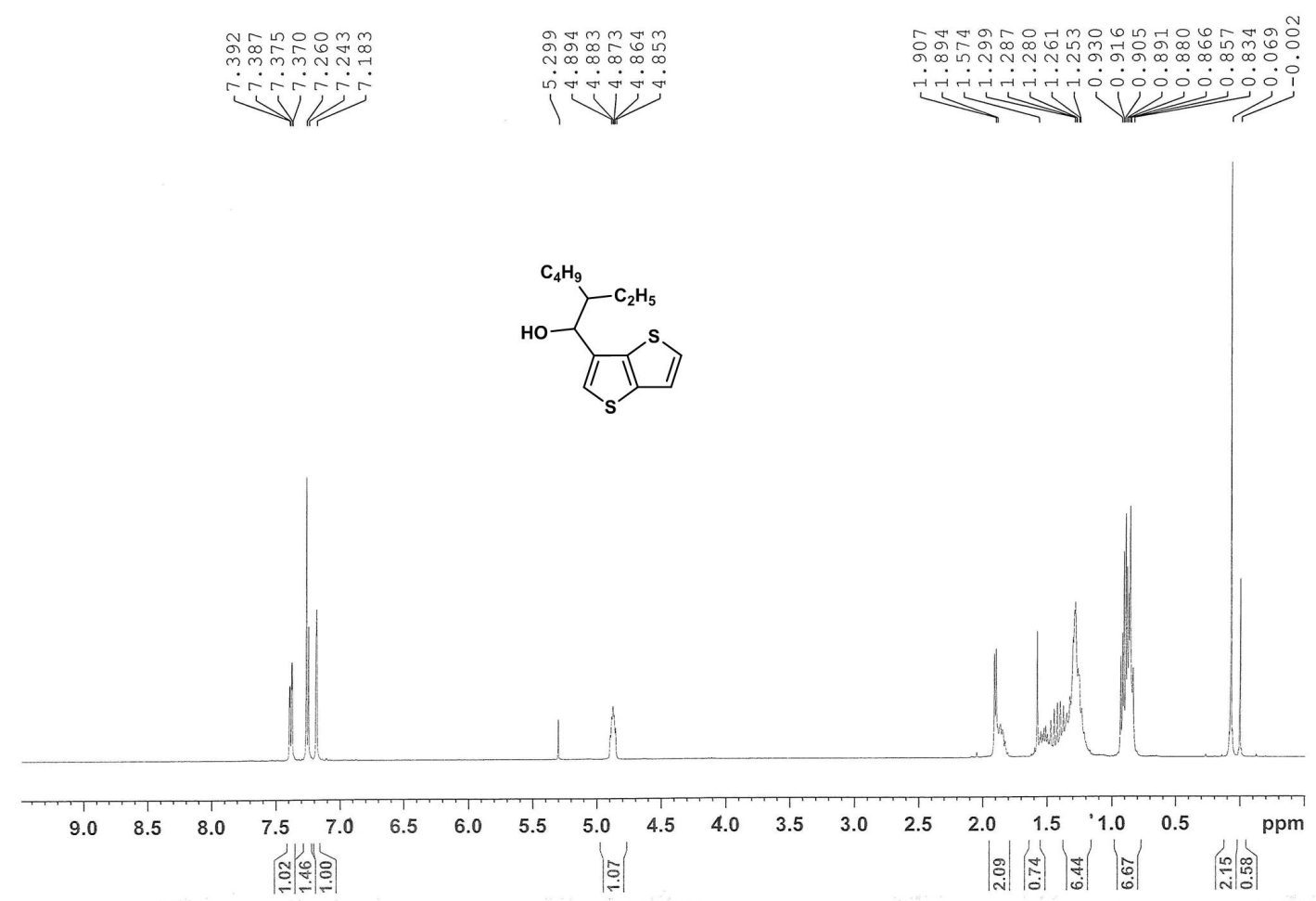

Supplementary Figure 34. ${ }^{1}$ H NMR spectrum of 1-EH. 


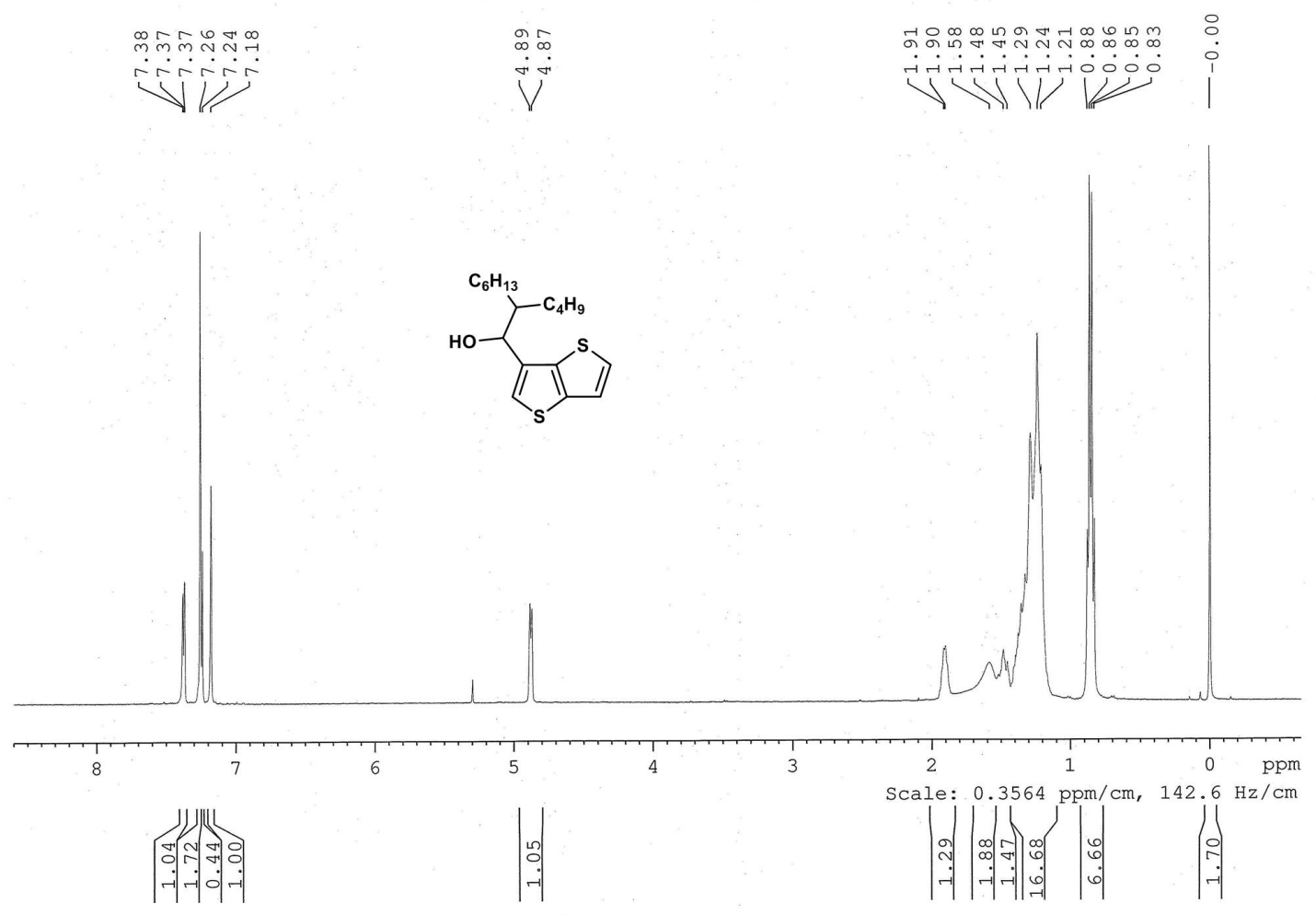

Supplementary Figure 35. ${ }^{1} \mathrm{H}$ NMR spectrum of 1-BO. 


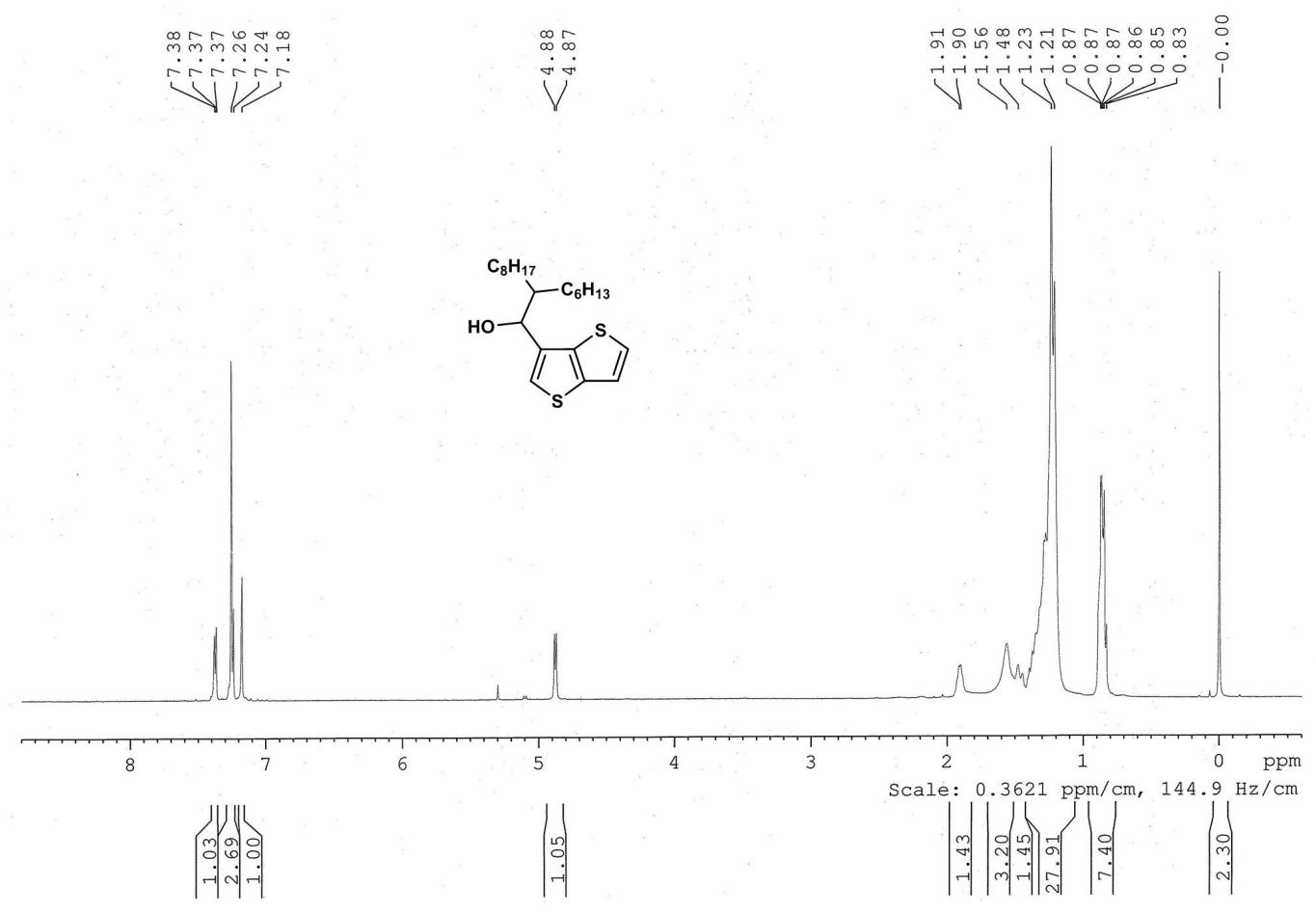

Supplementary Figure 36. ${ }^{1} \mathrm{H}$ NMR spectrum of 1-HD. 


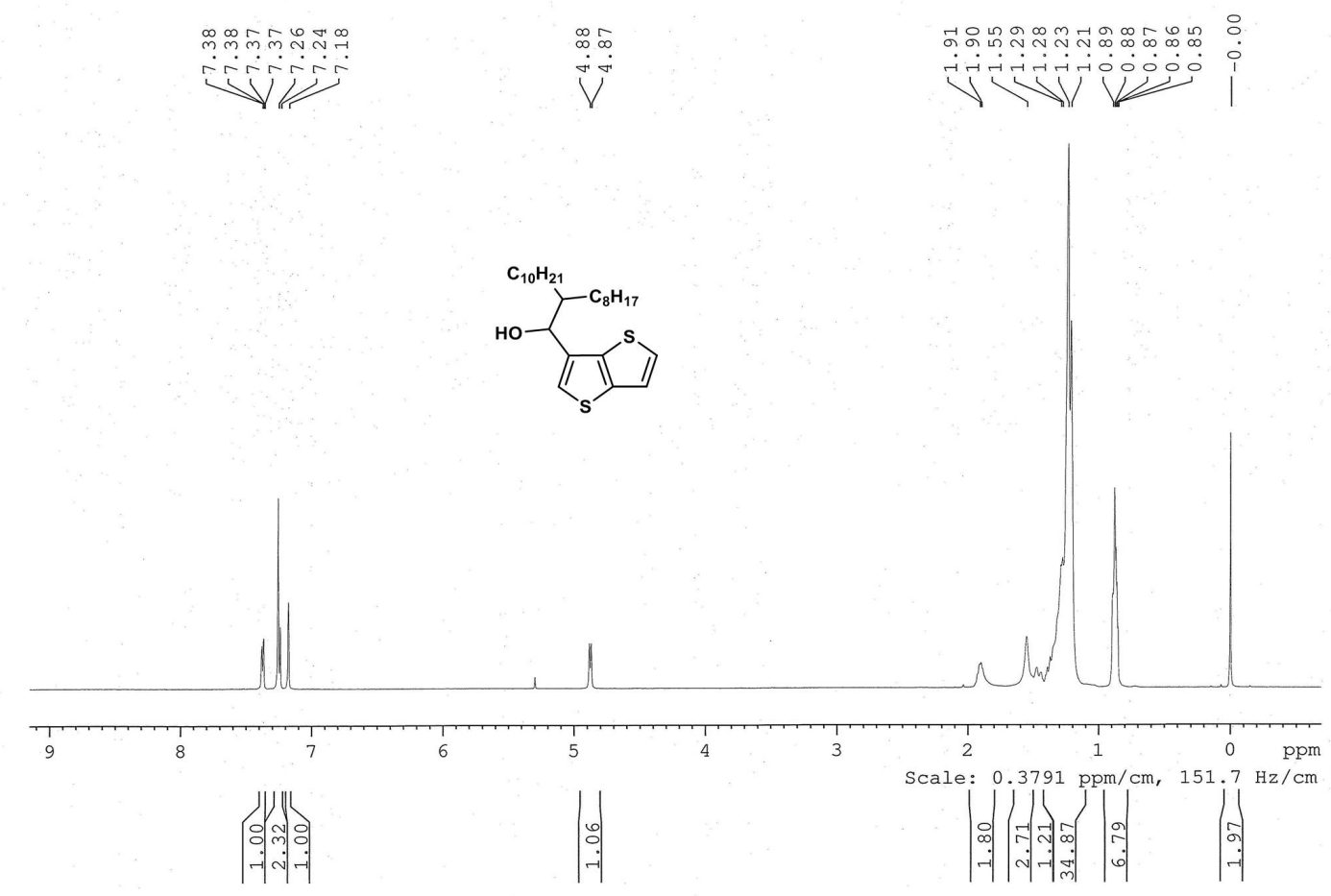

Supplementary Figure 37. ${ }^{1} \mathrm{H}$ NMR spectrum of 1-OD. 


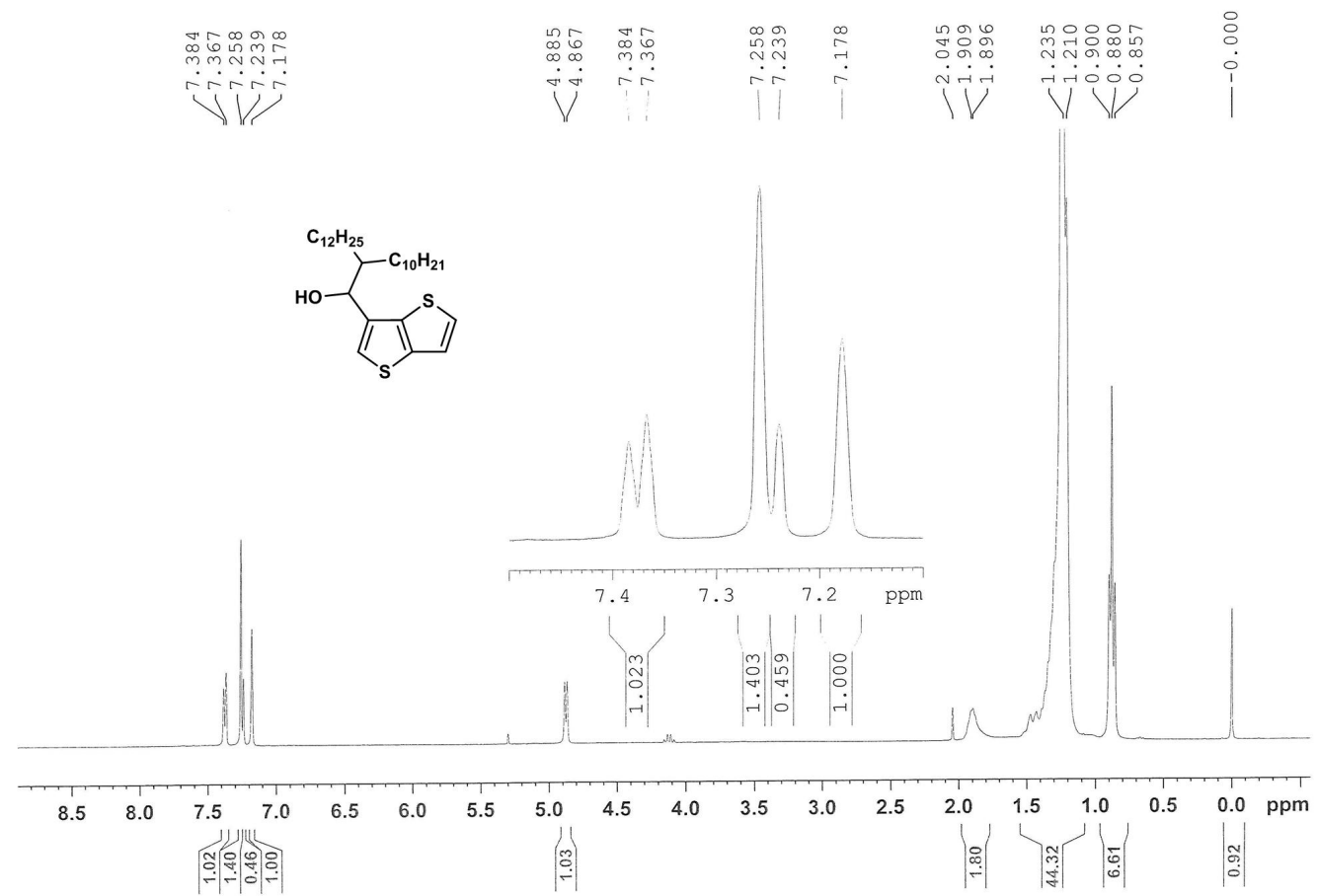

Supplementary Figure 38. ${ }^{1} \mathrm{H}$ NMR spectrum of 1-DT. 


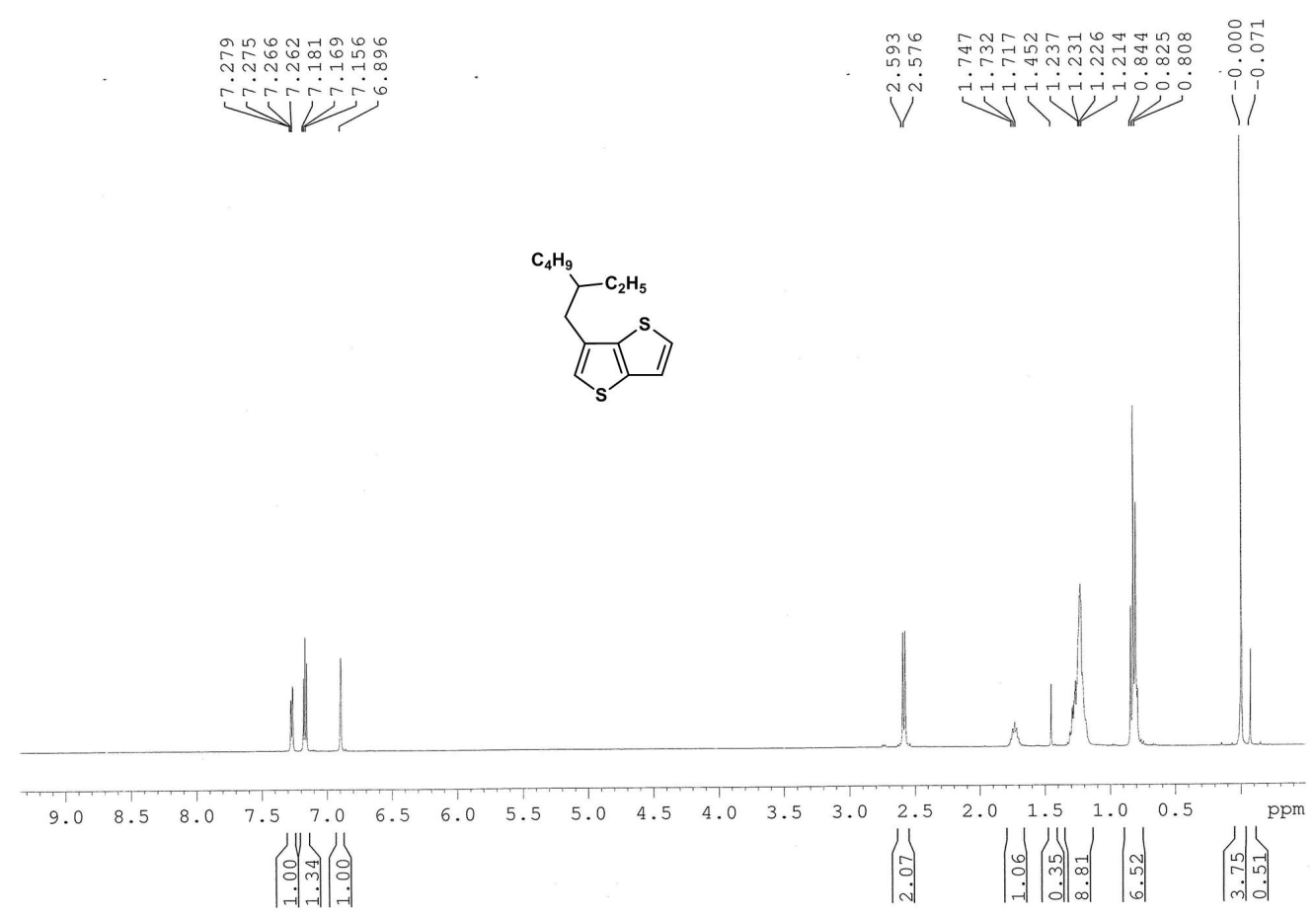

Supplementary Figure 39. ${ }^{1} \mathrm{H}$ NMR spectrum of 2-EH. 


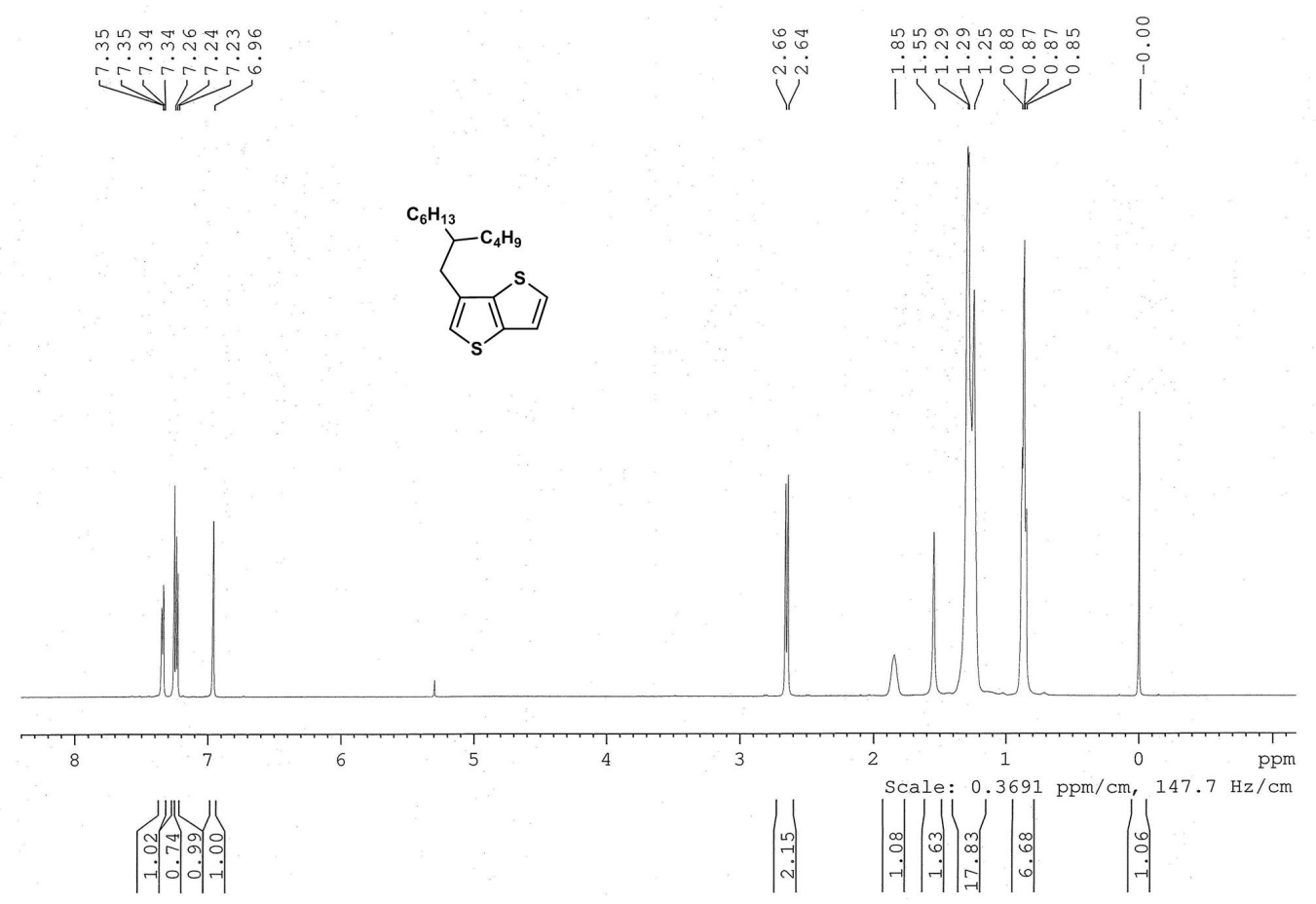

Supplementary Figure 40. ${ }^{1} \mathrm{H}$ NMR spectrum of 2-BO. 


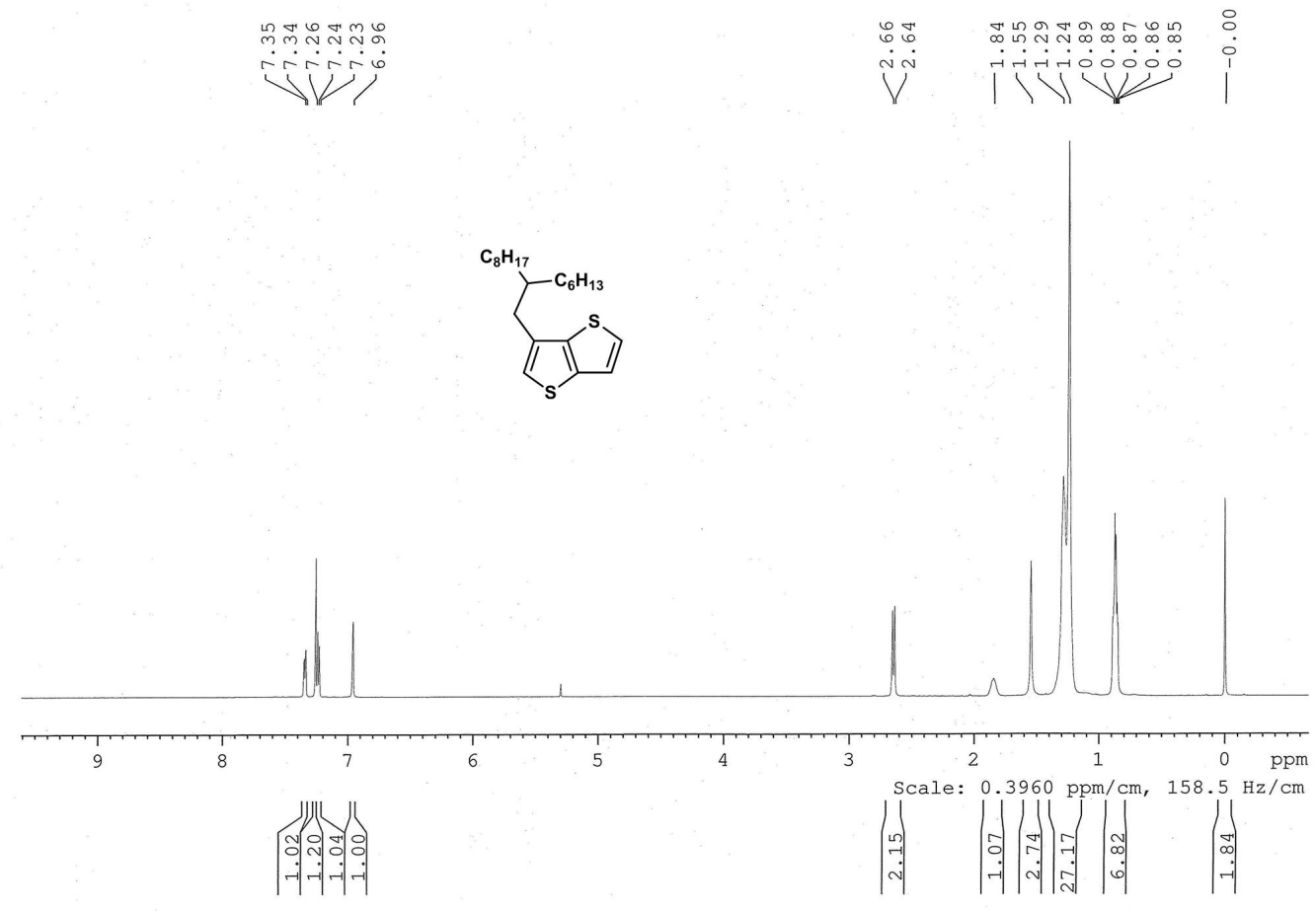

Supplementary Figure 41. ${ }^{1} \mathrm{H}$ NMR spectrum of 2-HD. 


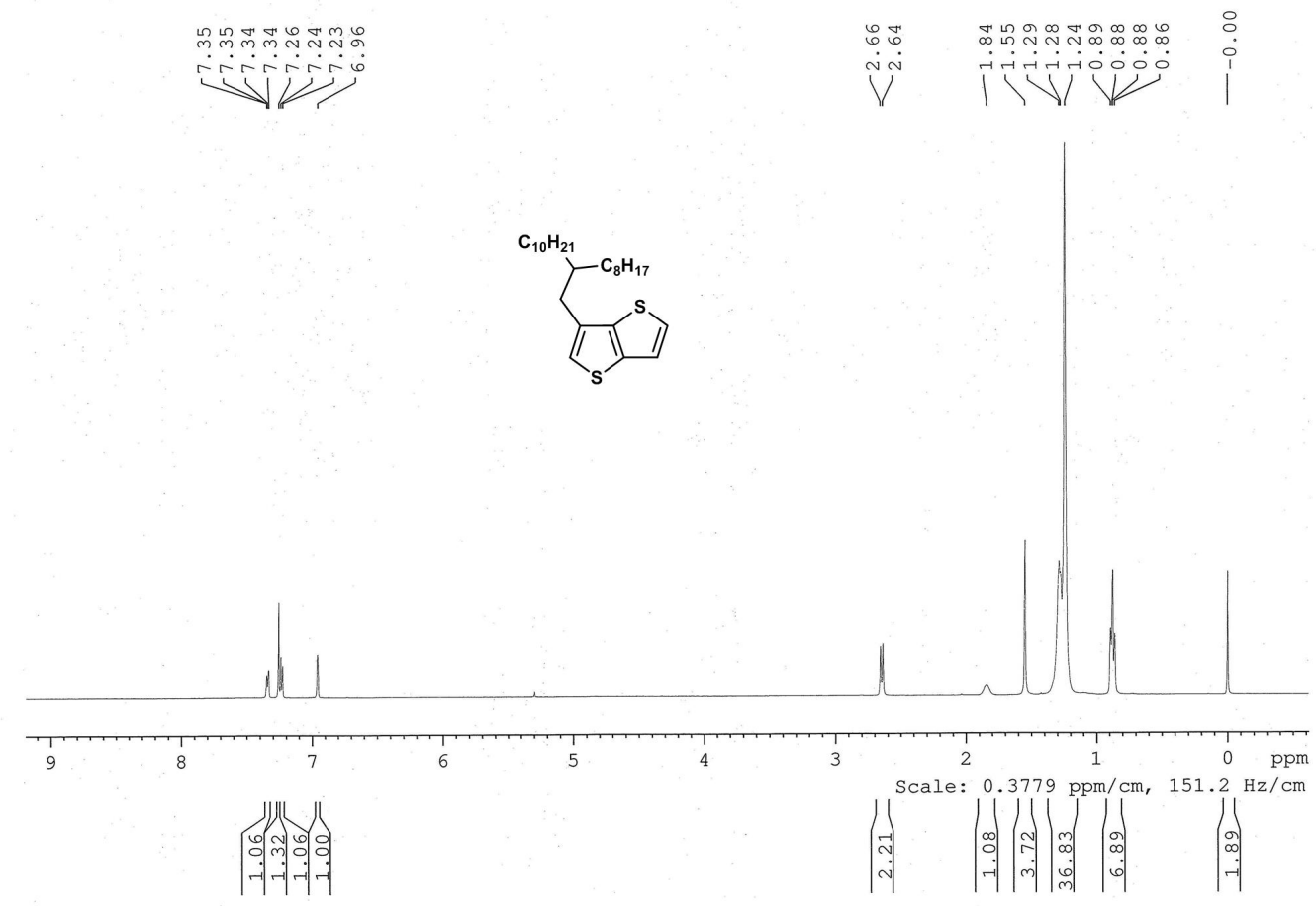

Supplementary Figure 42. ${ }^{1} \mathrm{H}$ NMR spectrum of 2-OD. 


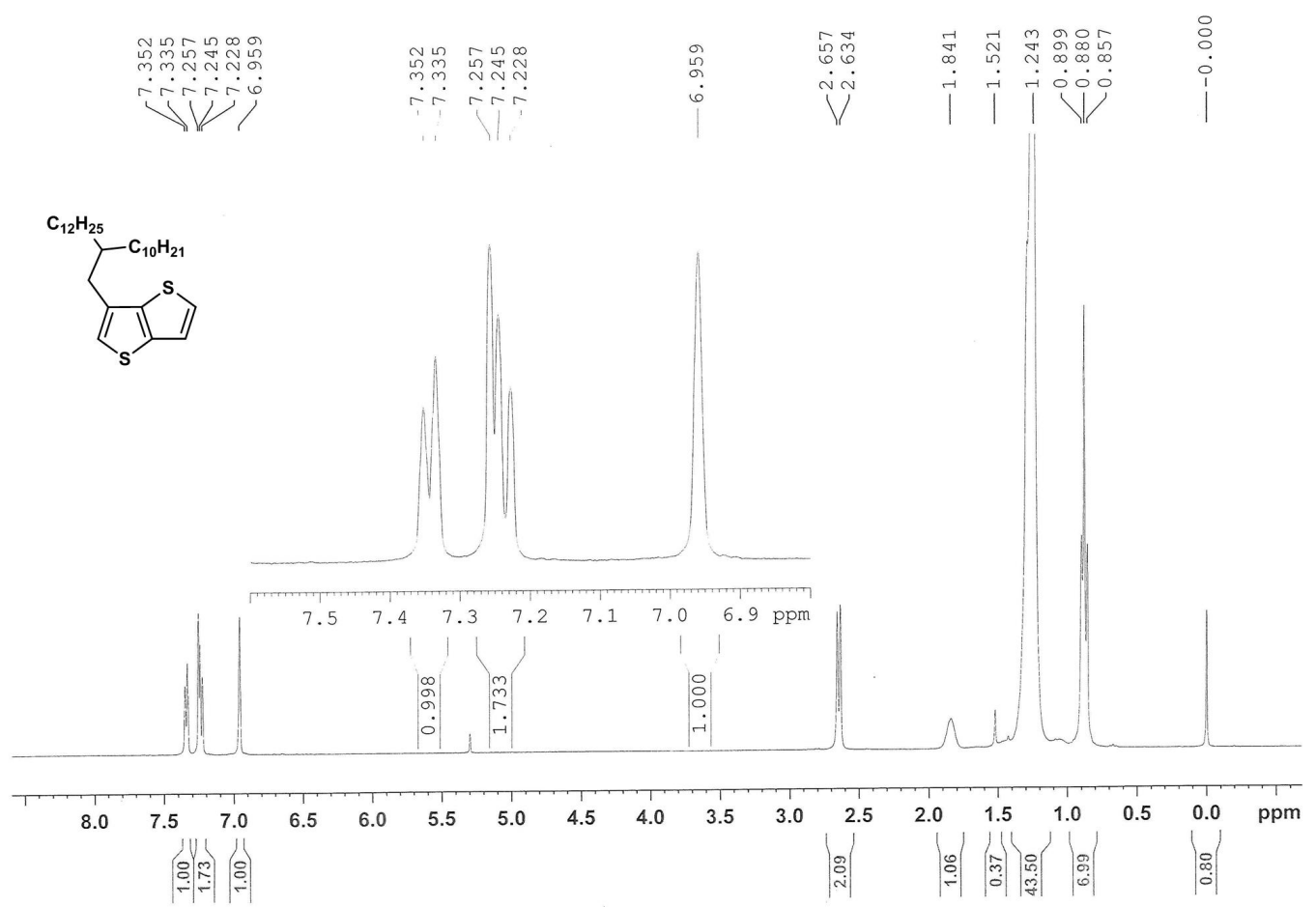

Supplementary Figure 43. ${ }^{1} \mathrm{H}$ NMR spectrum of 2-DT. 

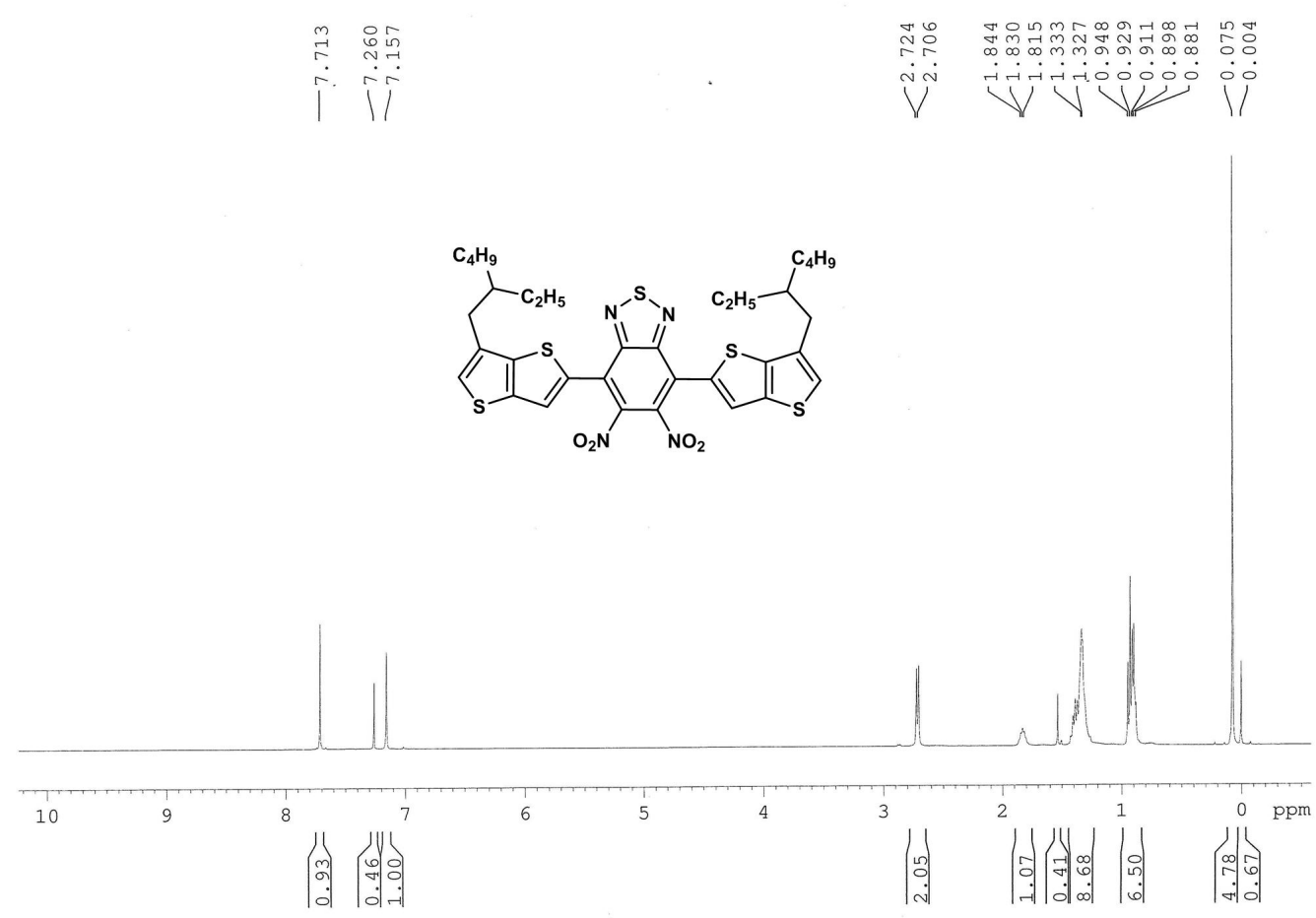

Supplementary Figure 44. ${ }^{1} \mathrm{H}$ NMR spectrum of 3-EH. 


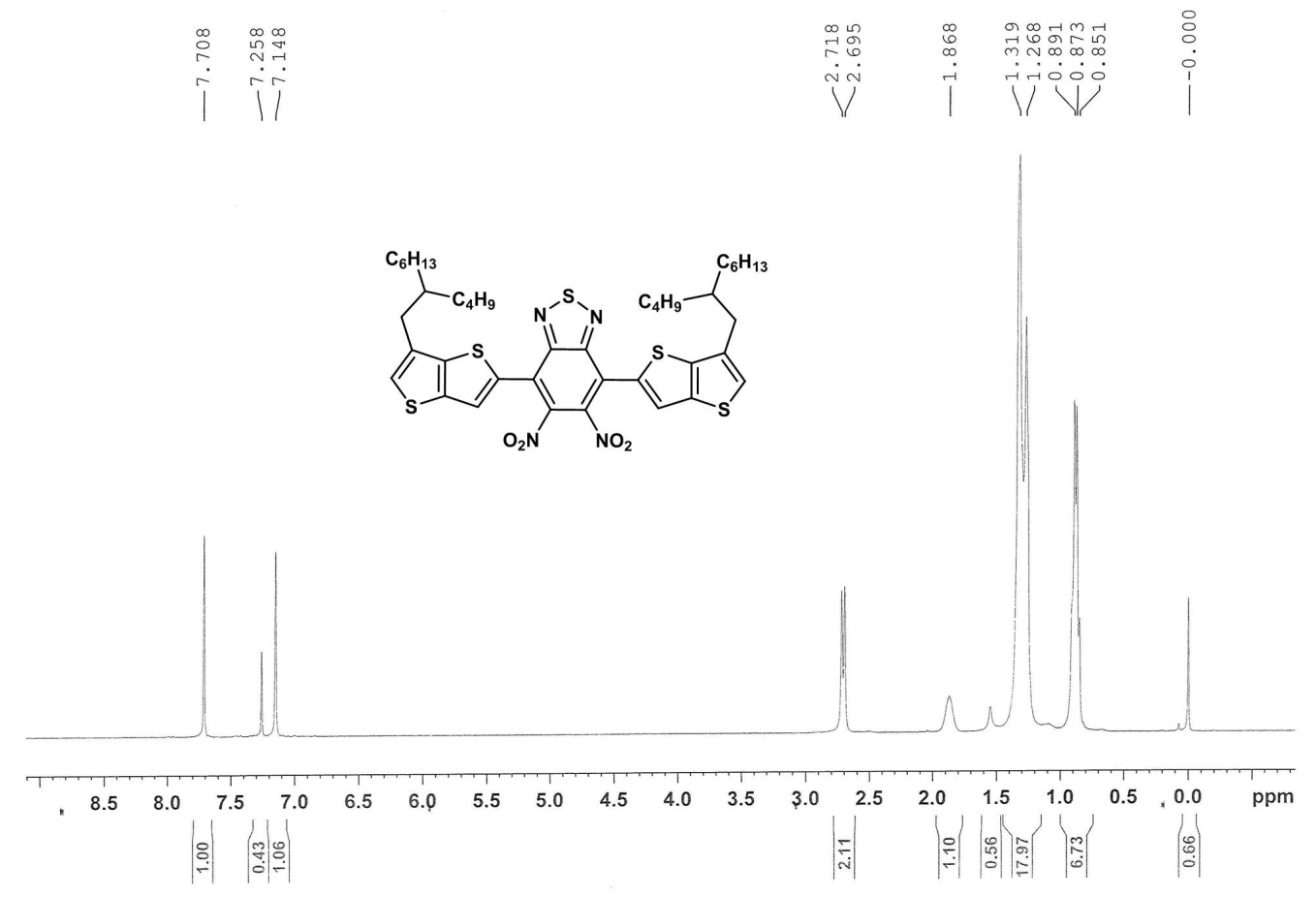

Supplementary Figure 45. ${ }^{1} \mathrm{H}$ NMR spectrum of 3-BO. 


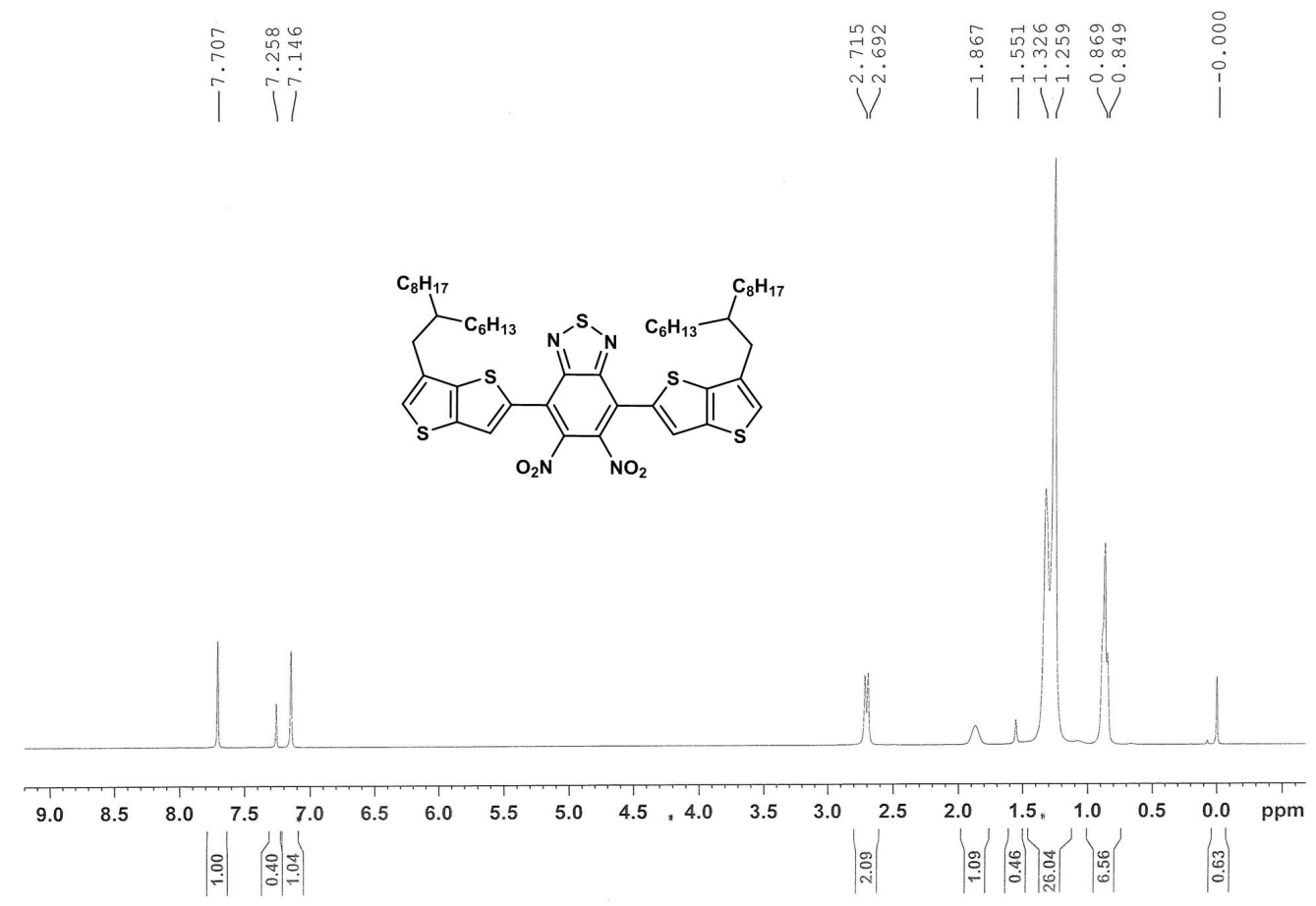

Supplementary Figure 46. ${ }^{1} \mathrm{H}$ NMR spectrum of 3-HD. 


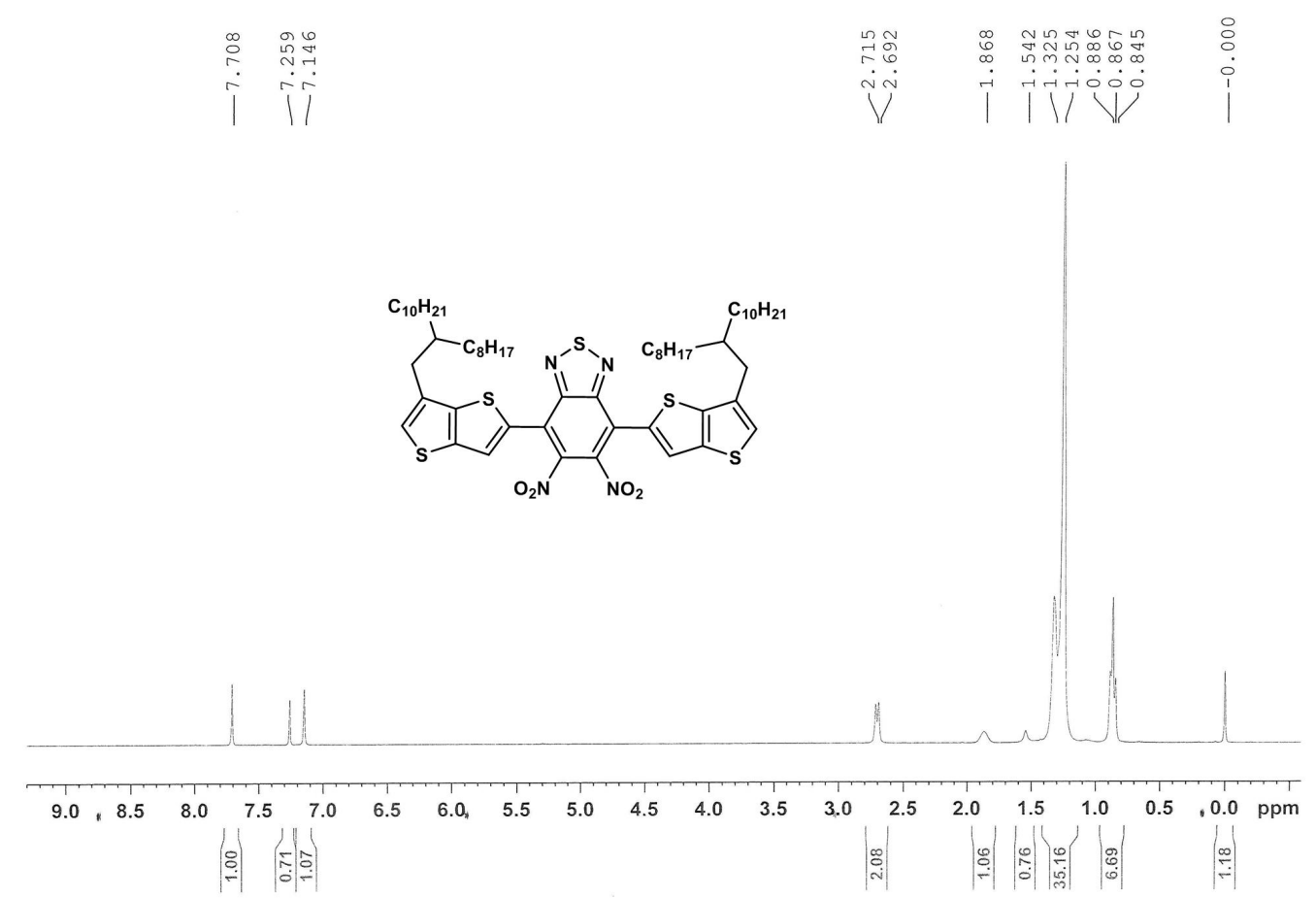

Supplementary Figure 47. ${ }^{1} \mathrm{H}$ NMR spectrum of 3-OD. 

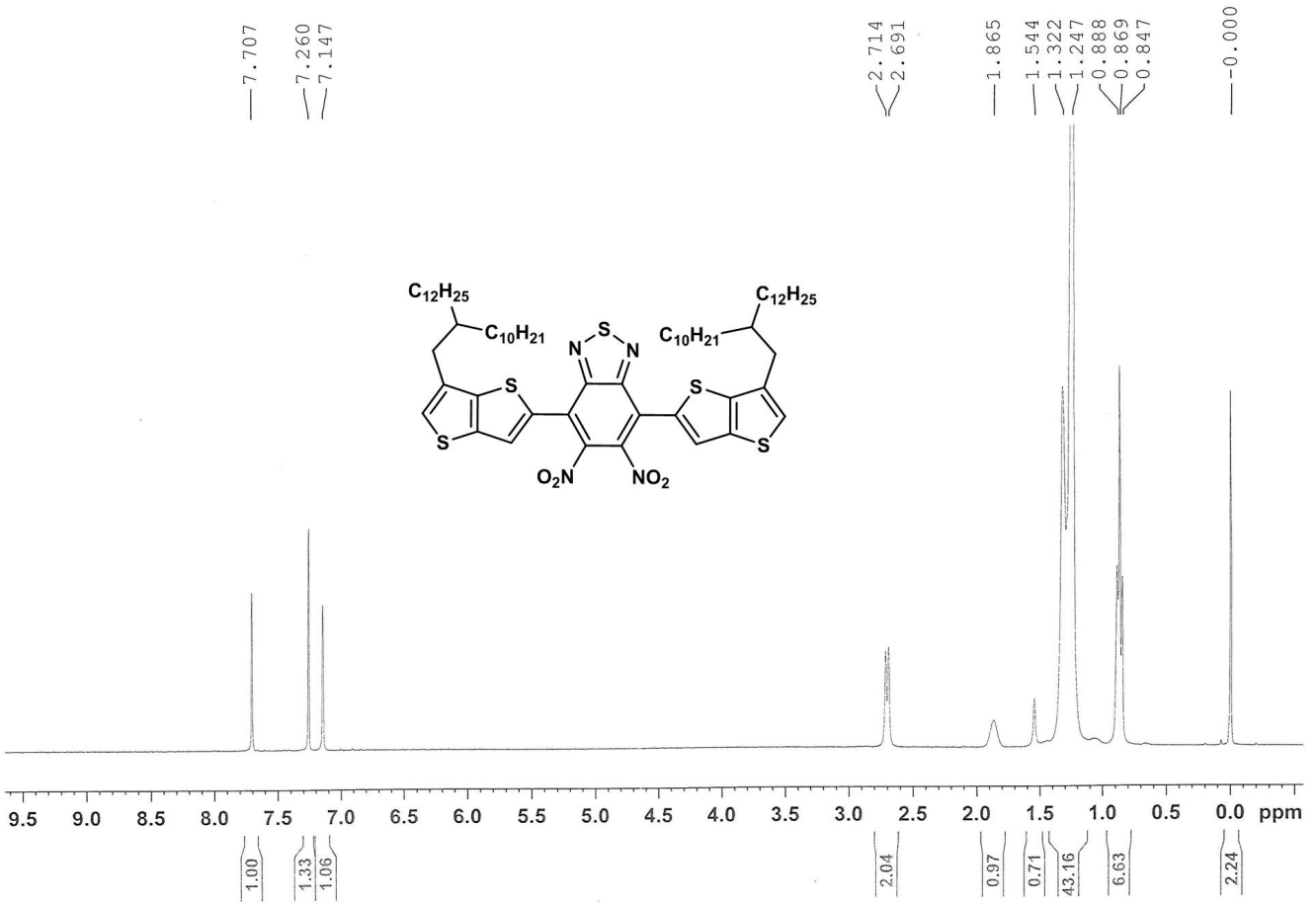

Supplementary Figure 48. ${ }^{1} \mathrm{H}$ NMR spectrum of 3-DT. 


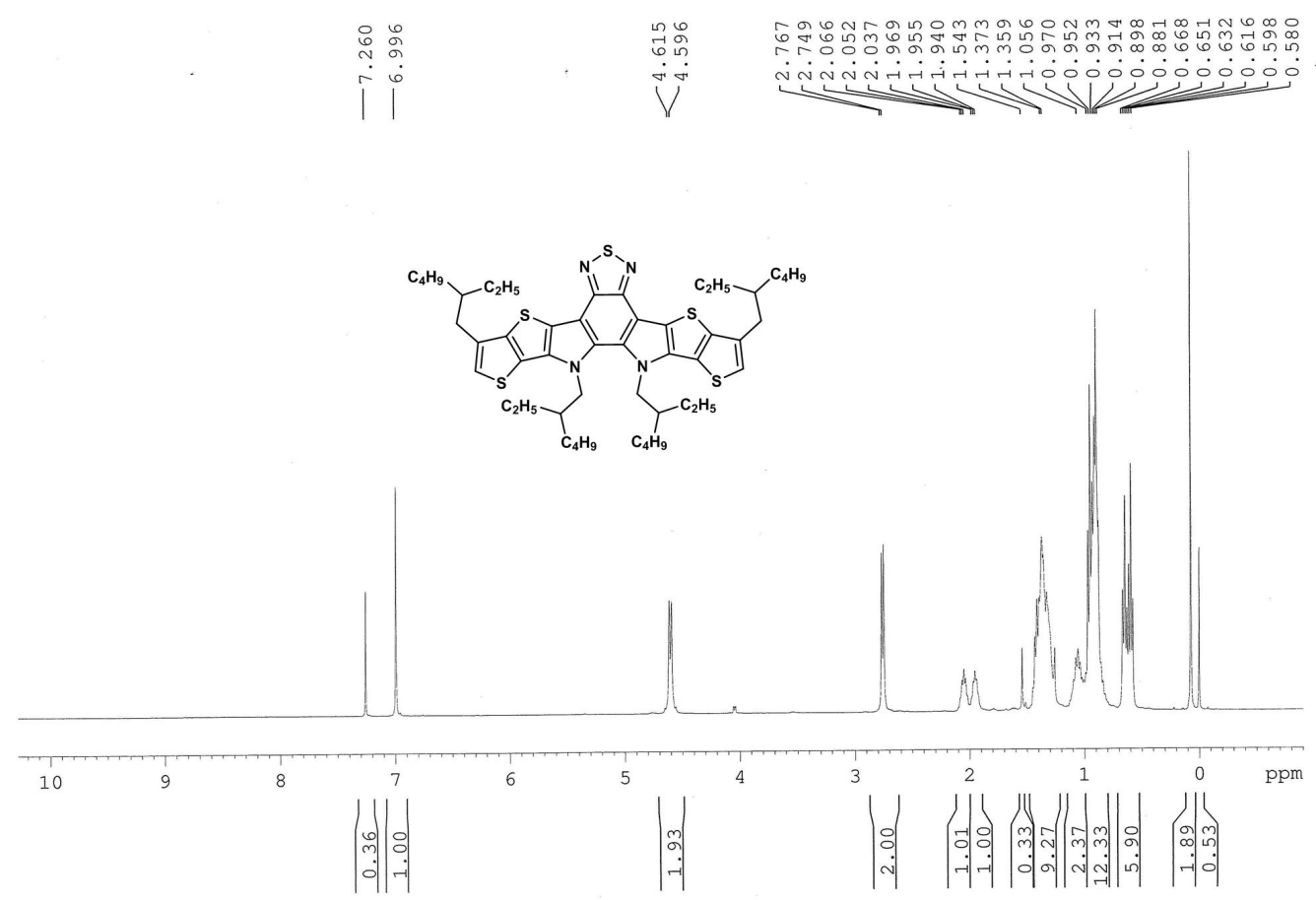

Supplementary Figure 49. ${ }^{1}$ H NMR spectrum of 4-EH. 


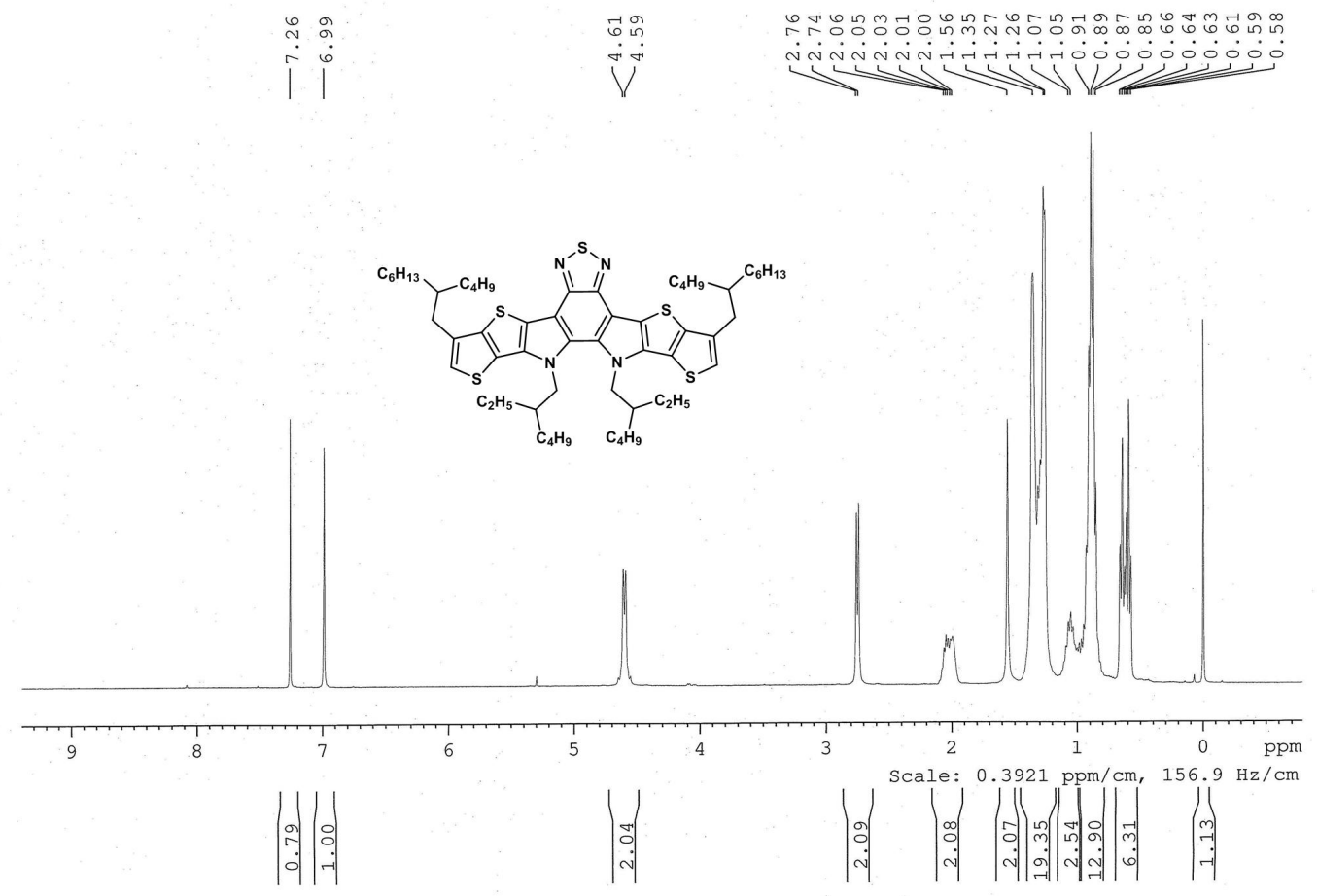

Supplementary Figure 50. ${ }^{1} \mathrm{H}$ NMR spectrum of 4-BO. 


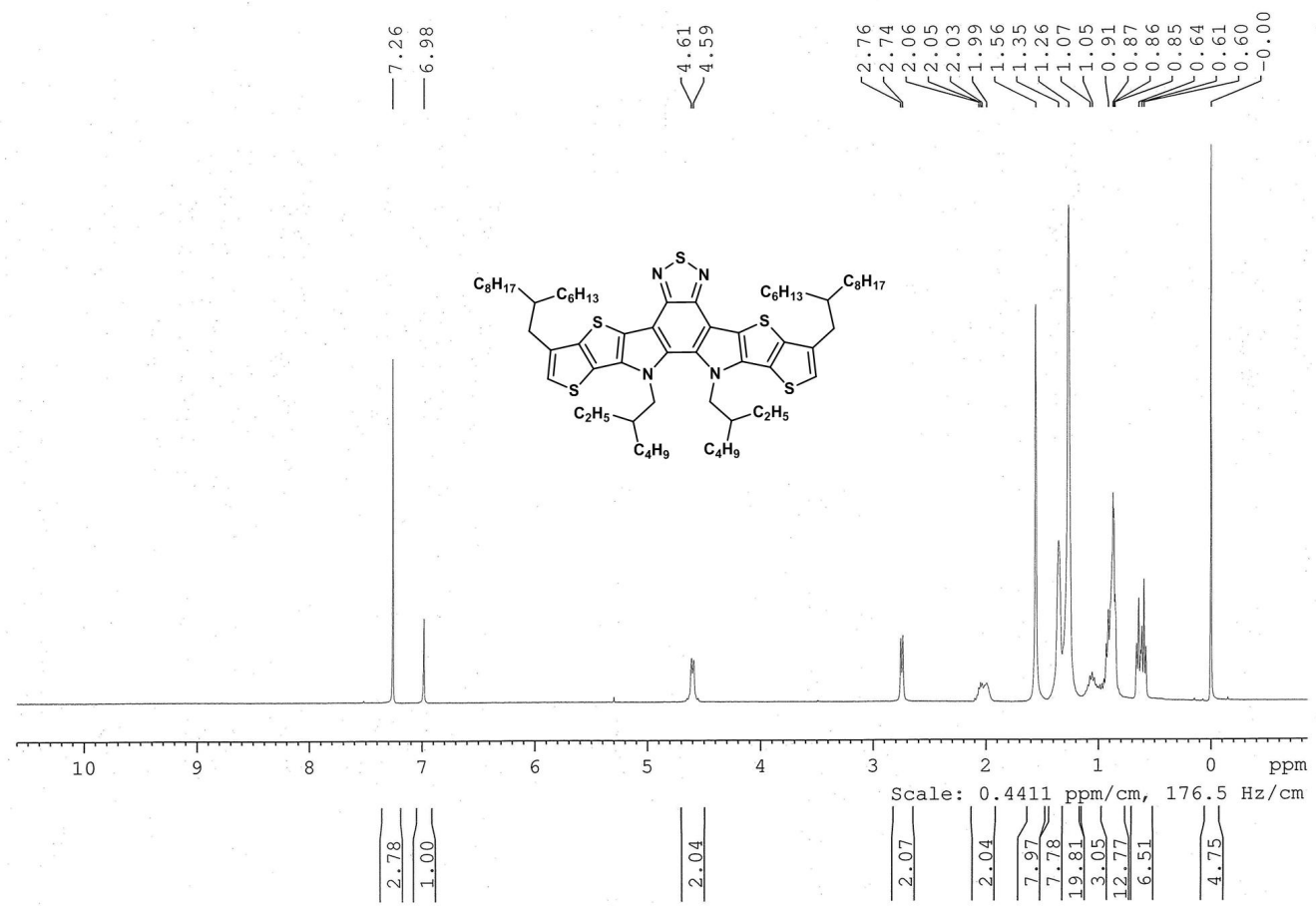

Supplementary Figure 51. ${ }^{1} \mathrm{H}$ NMR spectrum of 4-HD. 


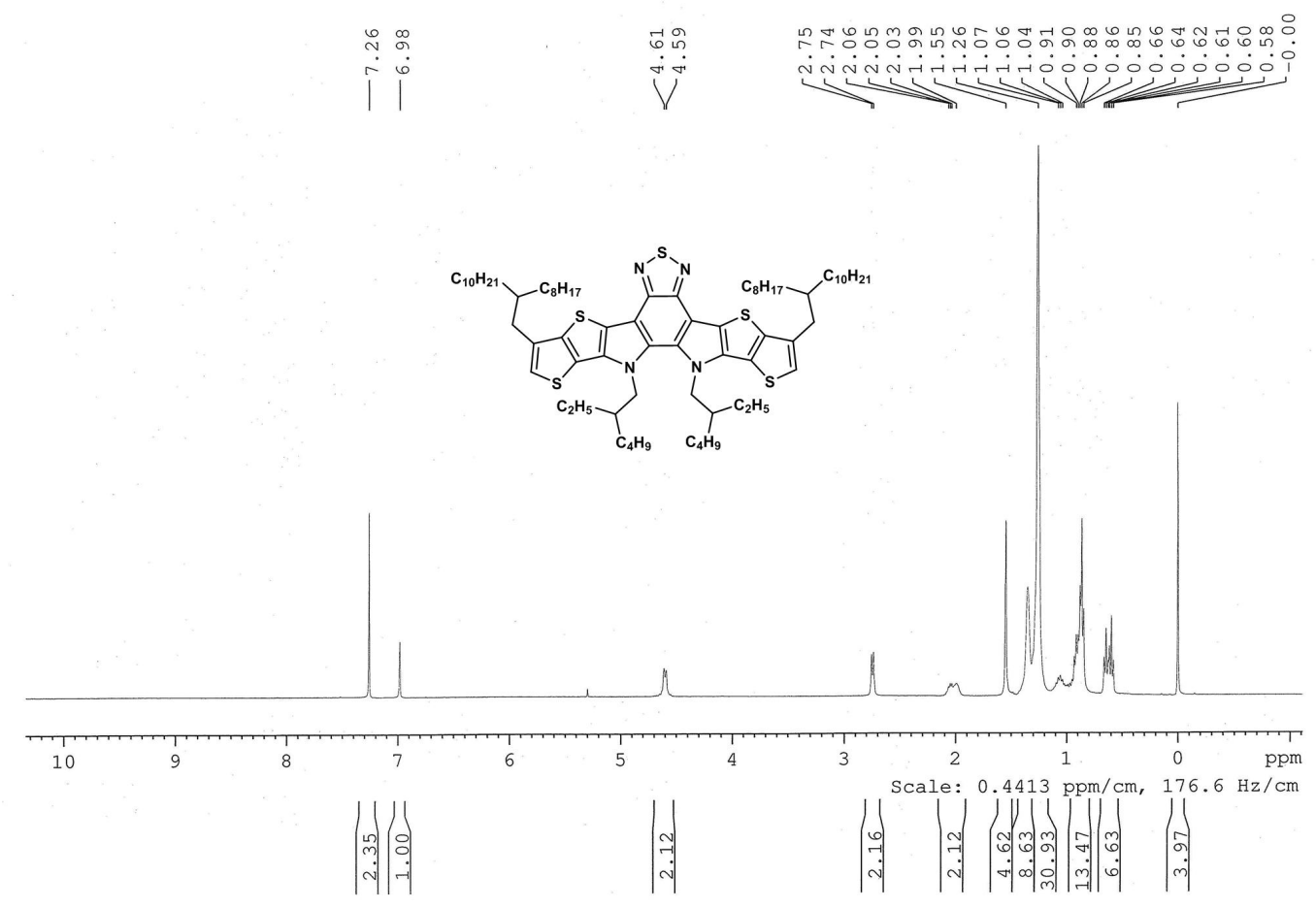

Supplementary Figure 52. ${ }^{1} \mathrm{H}$ NMR spectrum of 4-OD. 


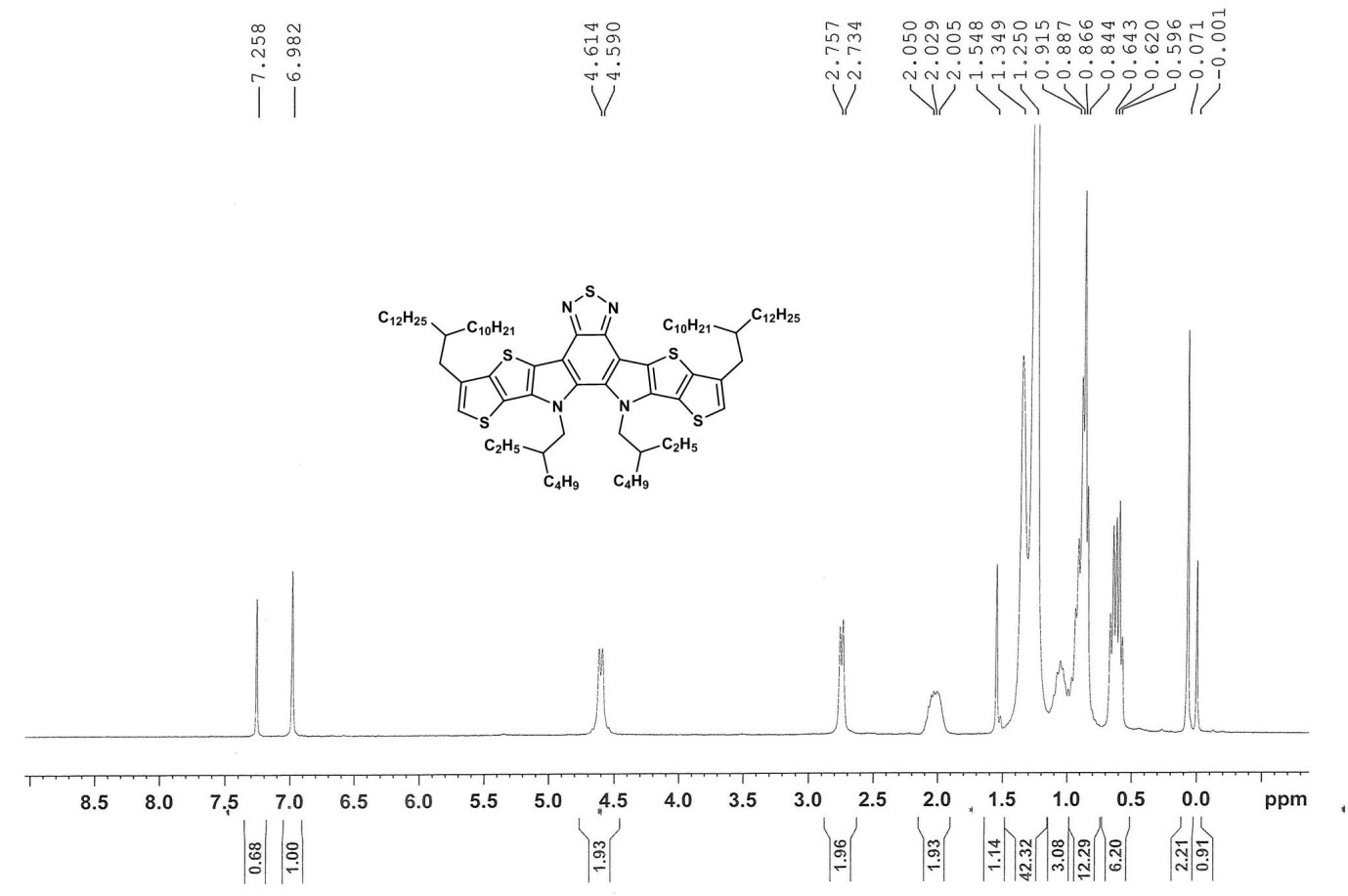

Supplementary Figure 53. ${ }^{1} \mathrm{H}$ NMR spectrum of 4-DT. 


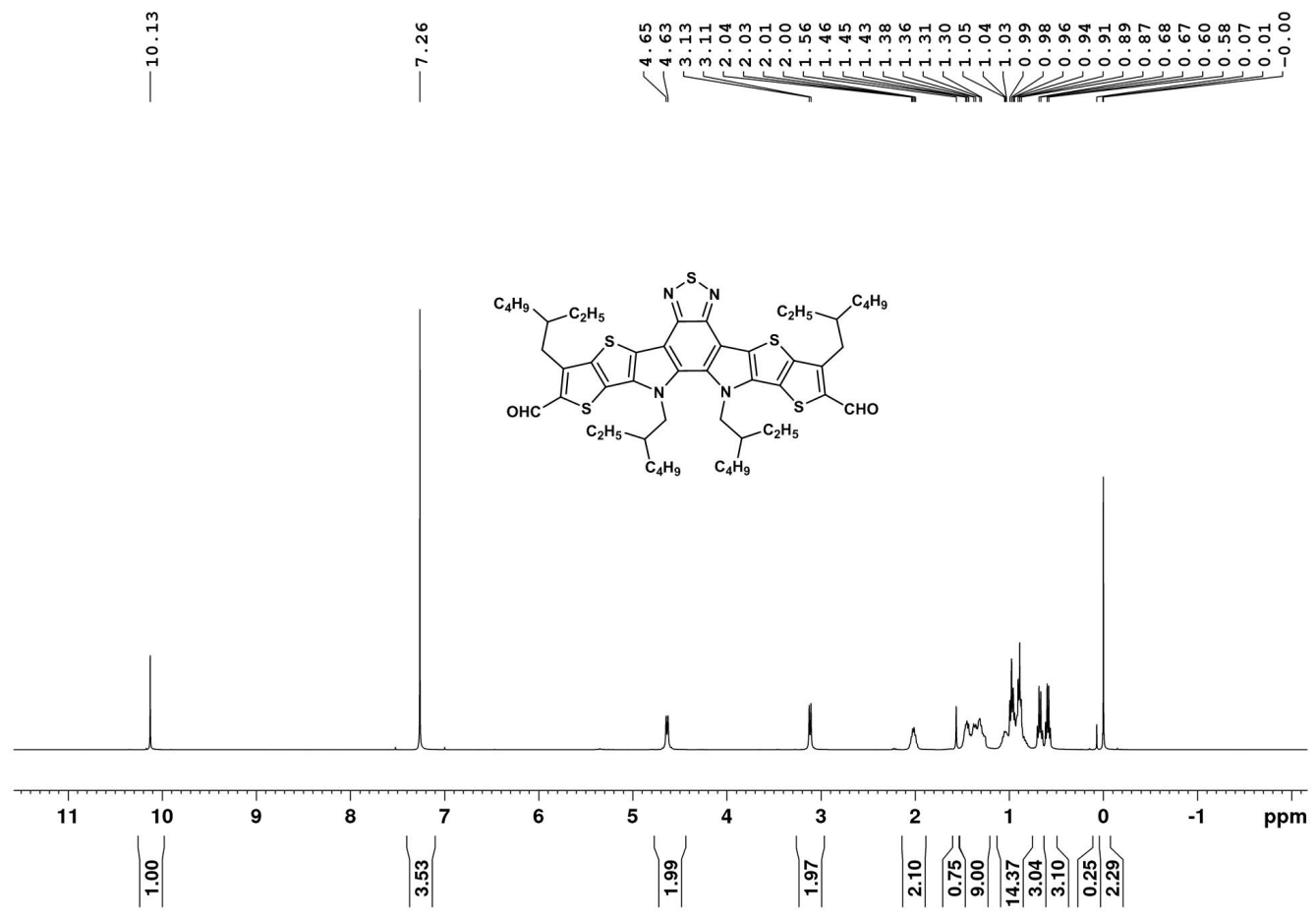

Supplementary Figure 54. ${ }^{1} \mathrm{H}$ NMR spectrum of 5-EH. 


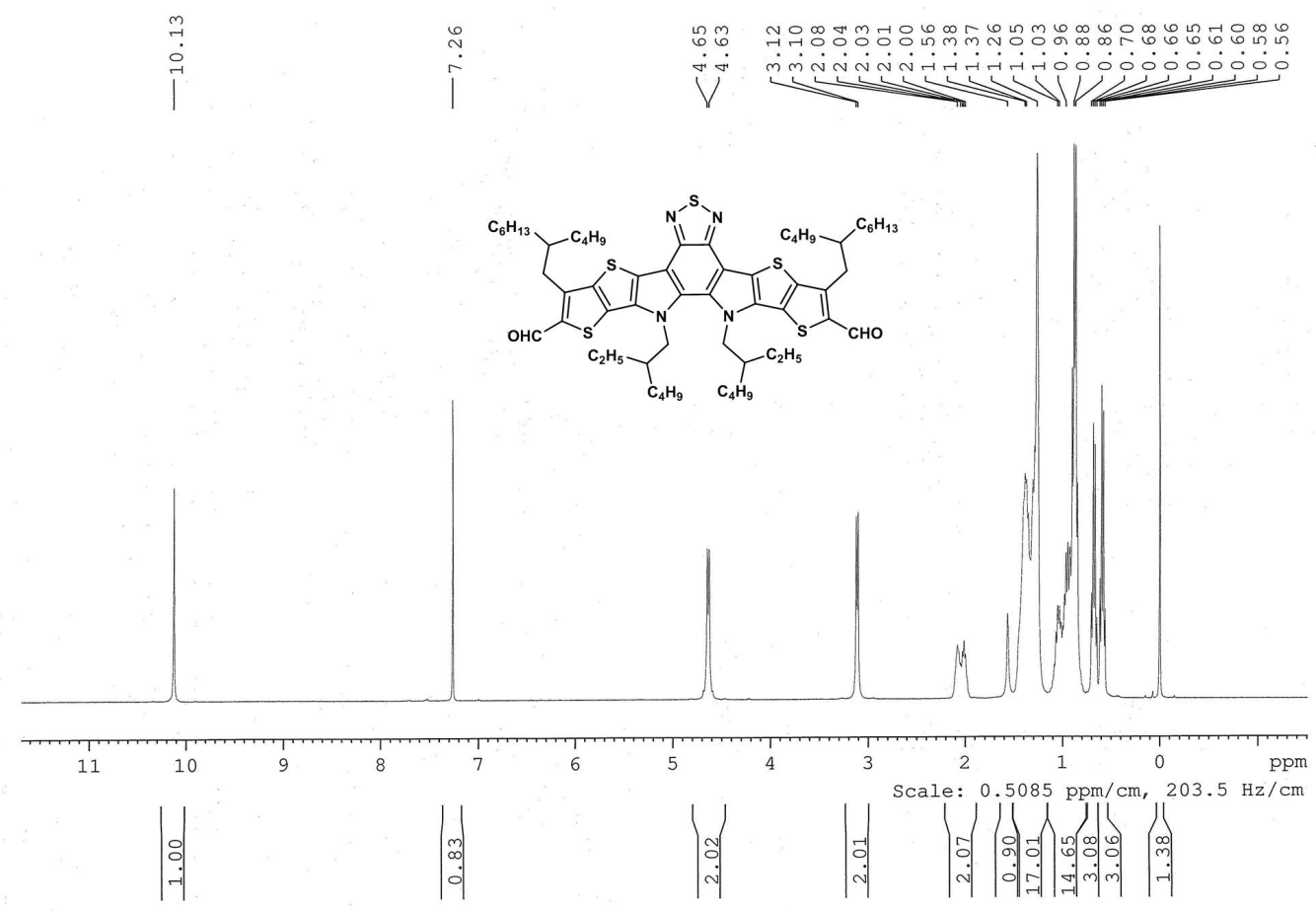

Supplementary Figure 55. ${ }^{1} \mathrm{H}$ NMR spectrum of 5-BO. 


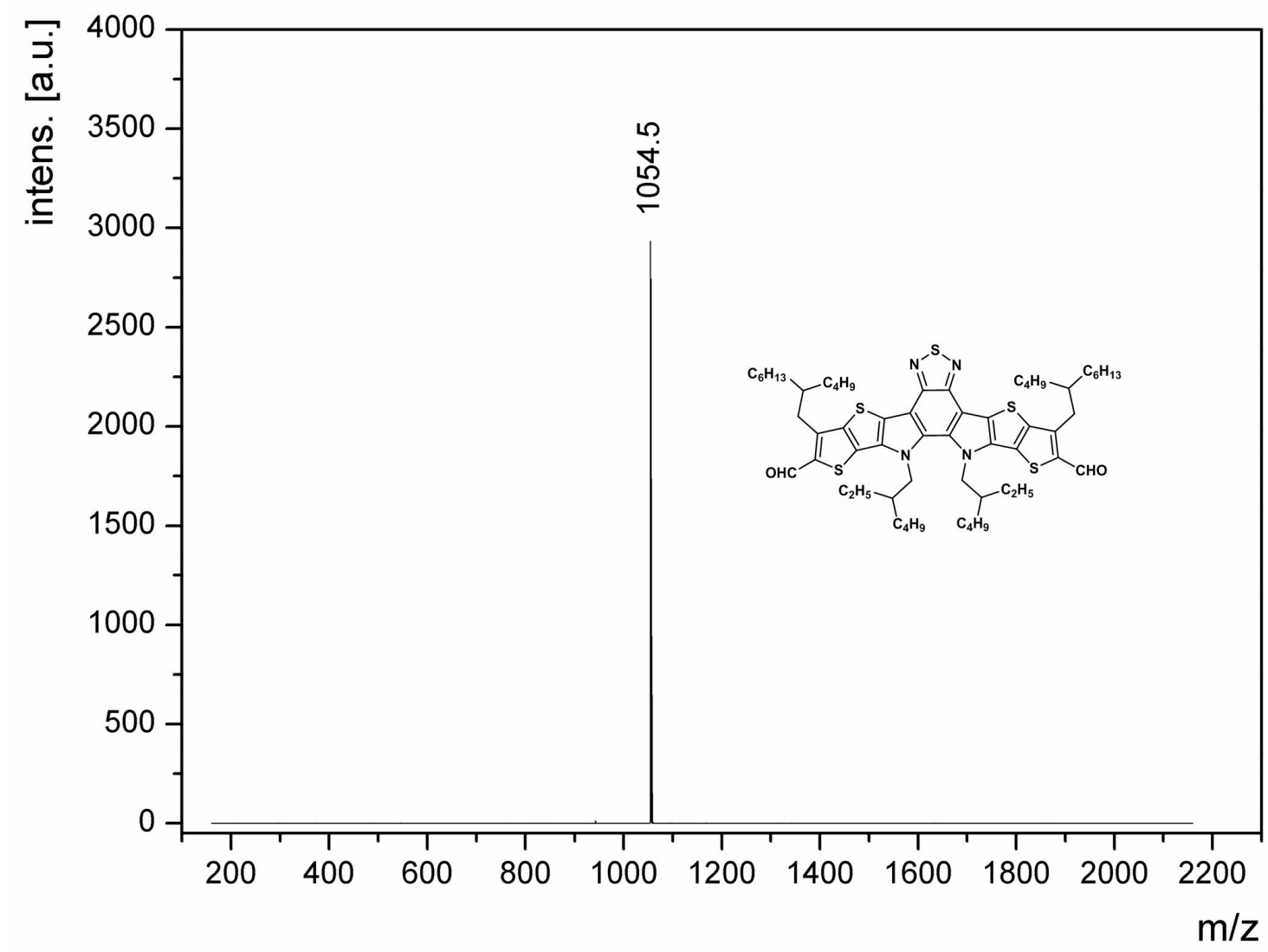

Supplementary Figure 56. MS (MALDI-TOF) spectrum of 5-BO. 


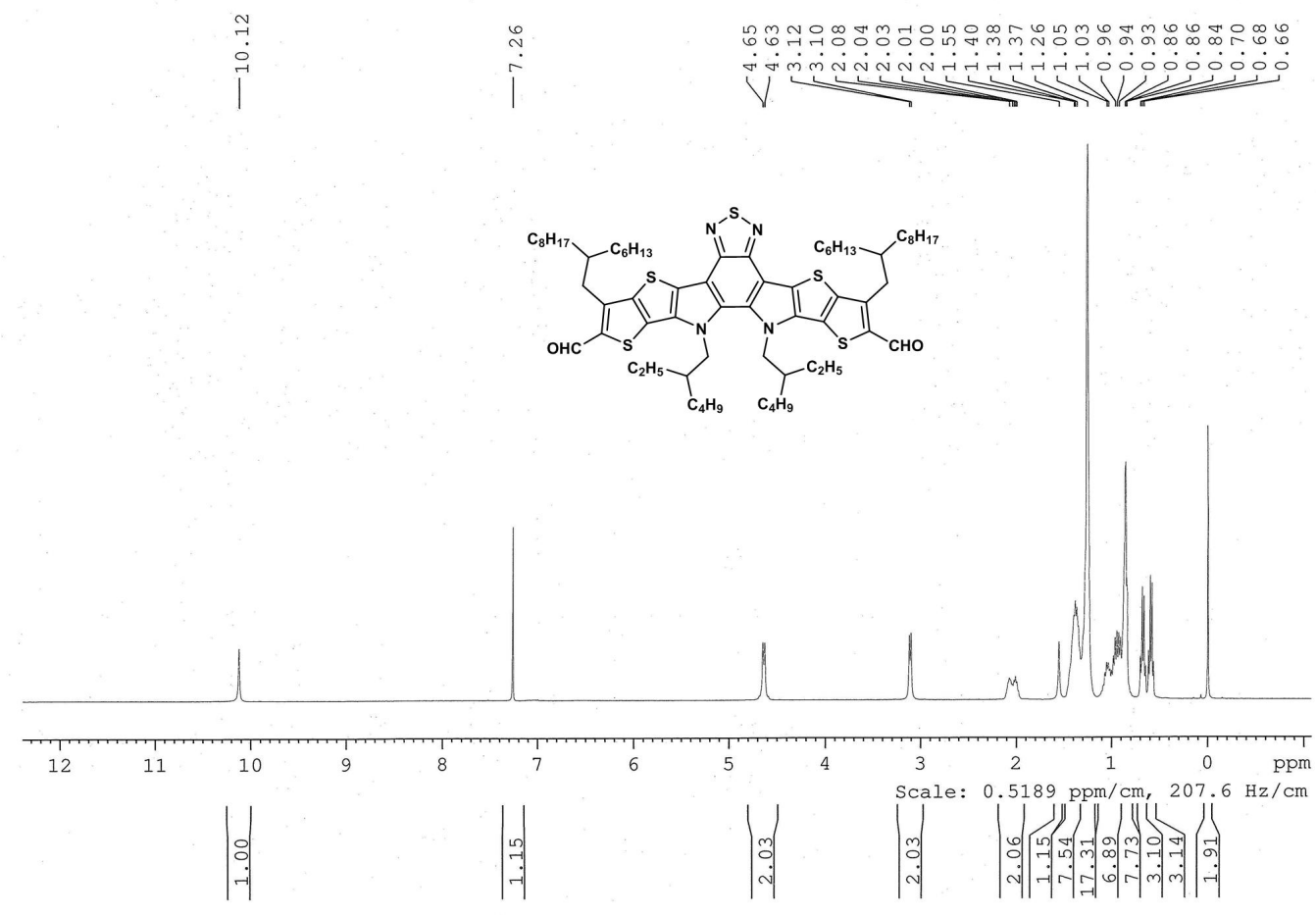

Supplementary Figure 57. ${ }^{1} \mathrm{H}$ NMR spectrum of 5-HD. 


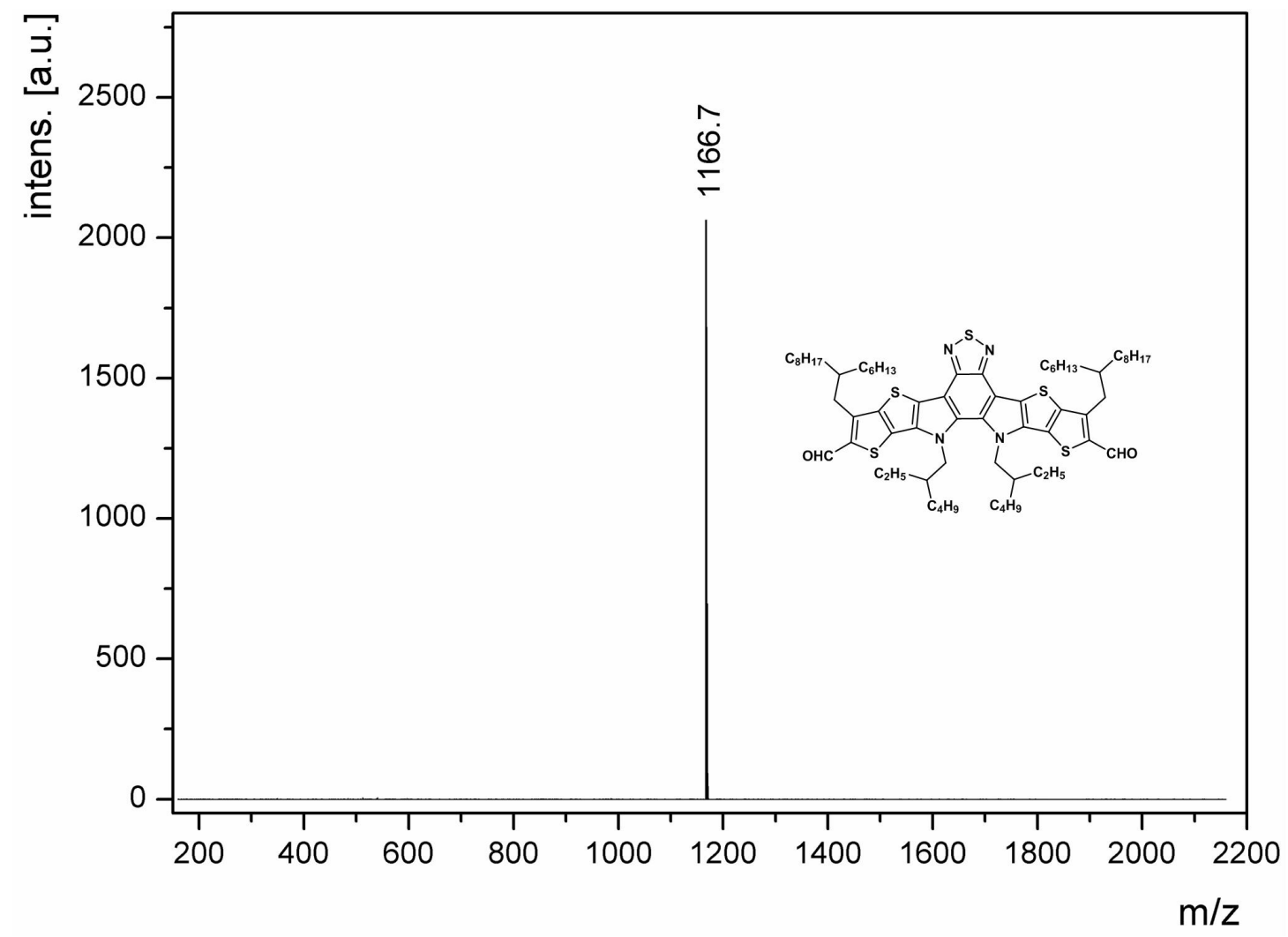

Supplementary Figure 58. MS (MALDI-TOF) spectrum of 5-HD. 


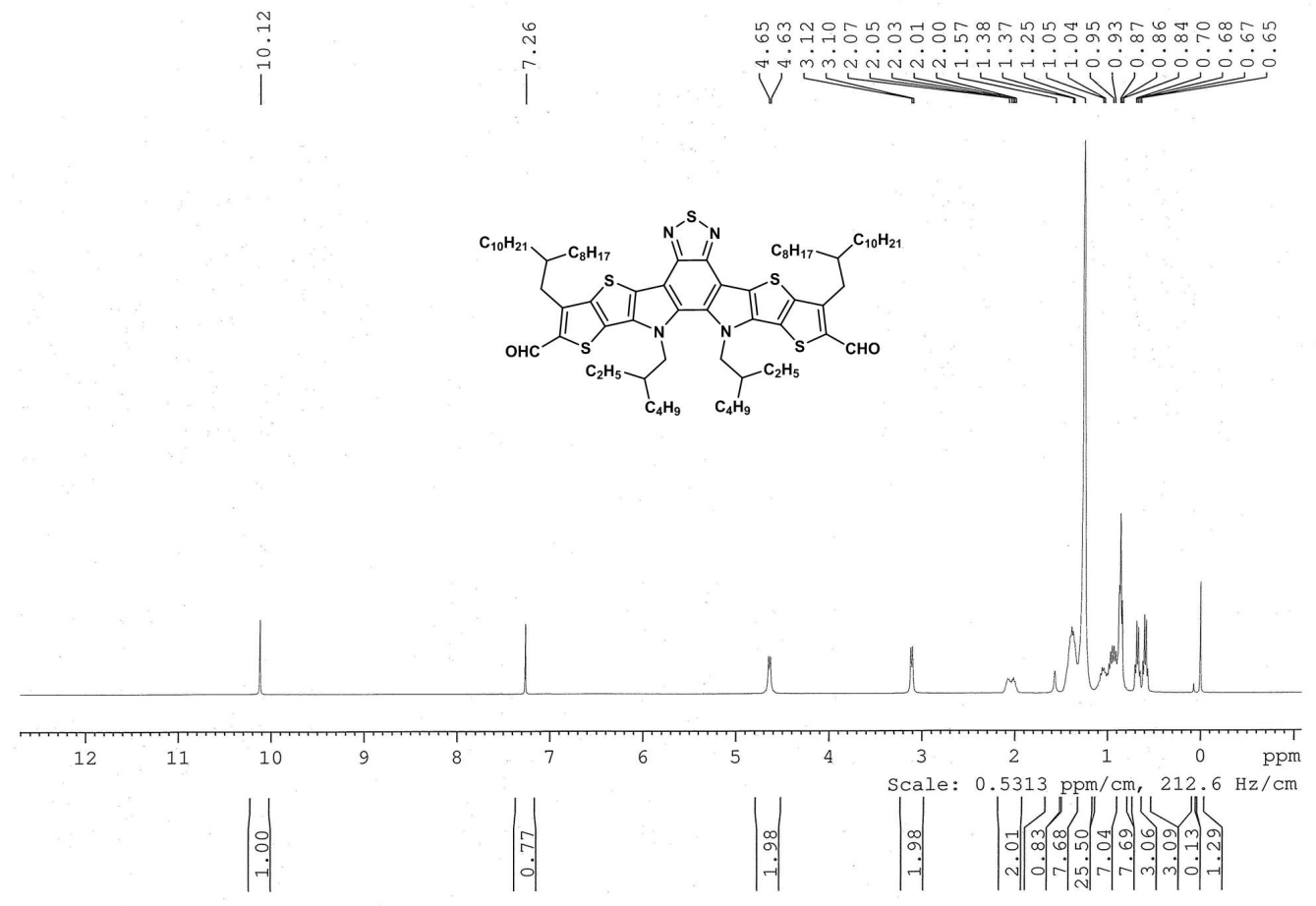

Supplementary Figure 59. ${ }^{1} \mathrm{H}$ NMR spectrum of 5-OD. 


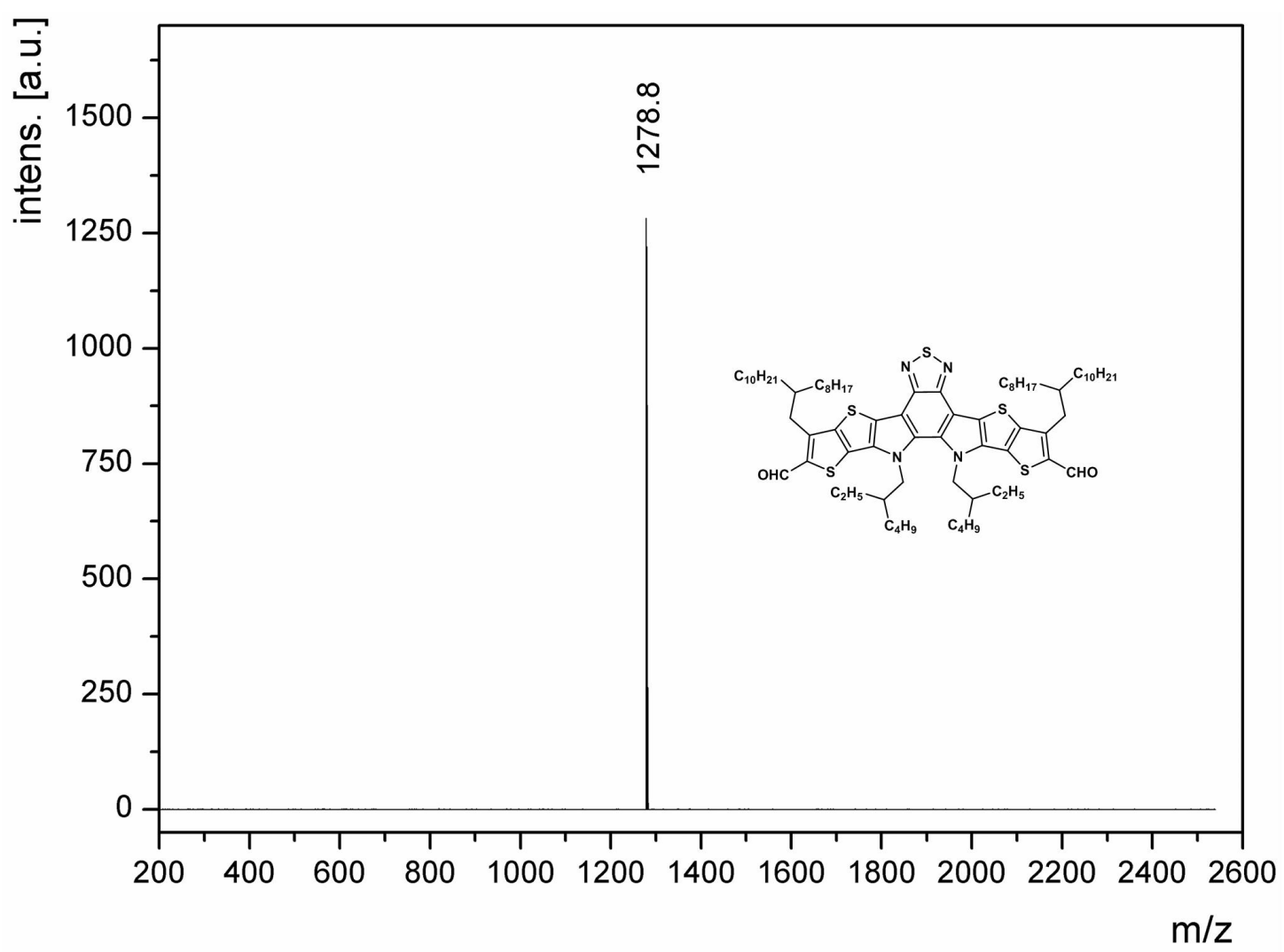

Supplementary Figure 60. MS (MALDI-TOF) spectrum of 5-OD. 


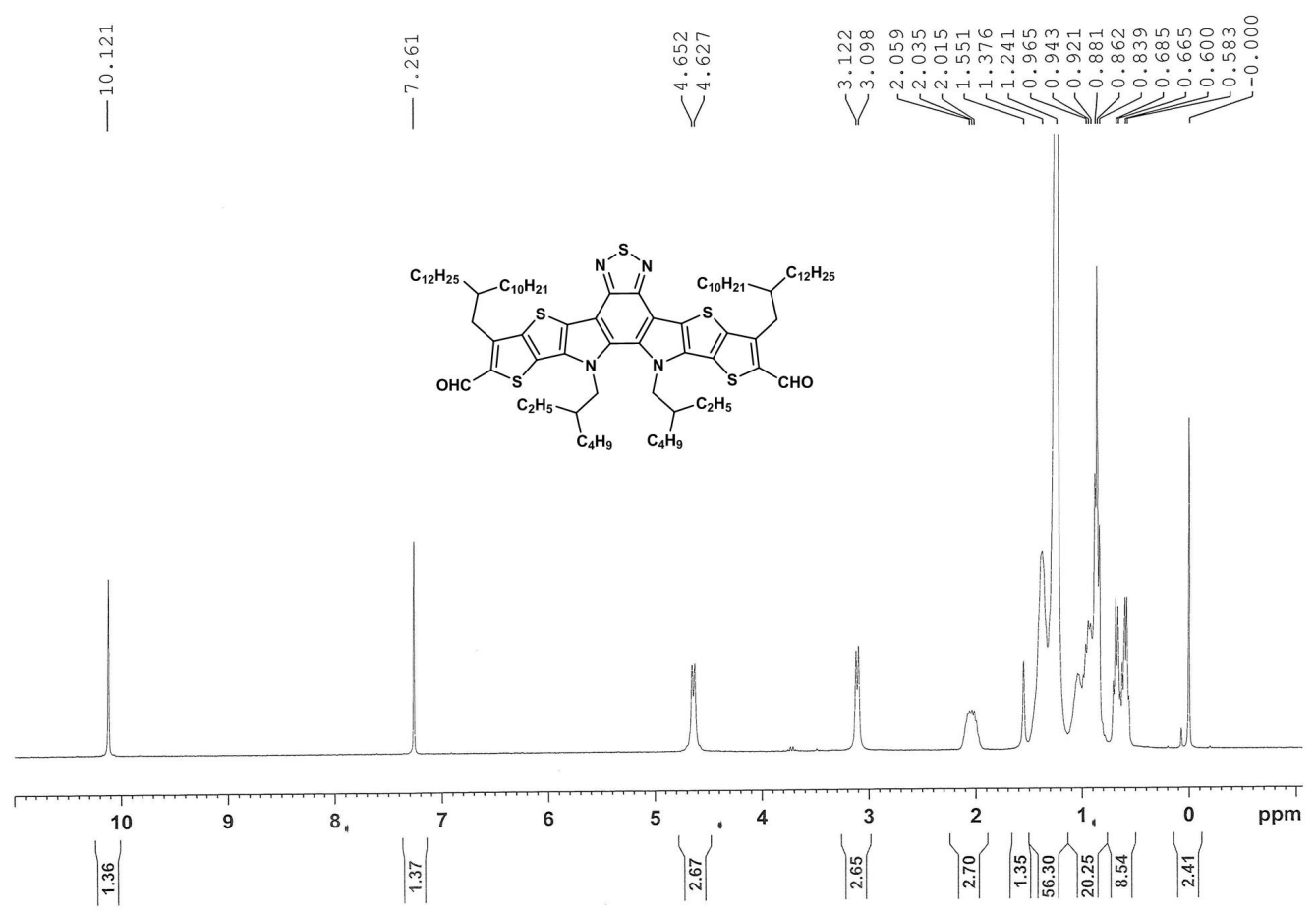

Supplementary Figure 61. ${ }^{1} \mathrm{H}$ NMR spectrum of 5-DT. 


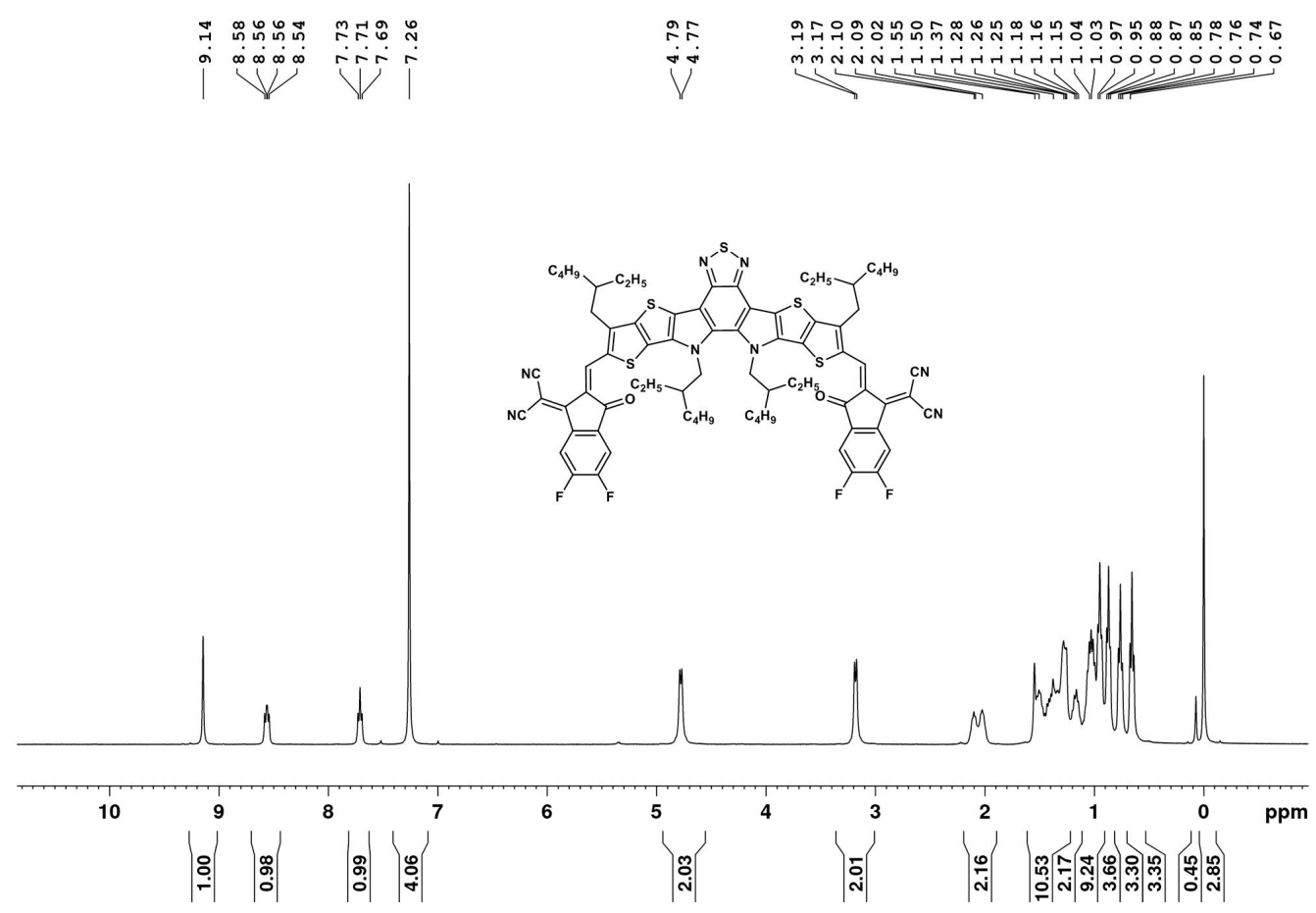

Supplementary Figure 62. ${ }^{1} \mathrm{H}$ NMR spectrum of L8-EH. 


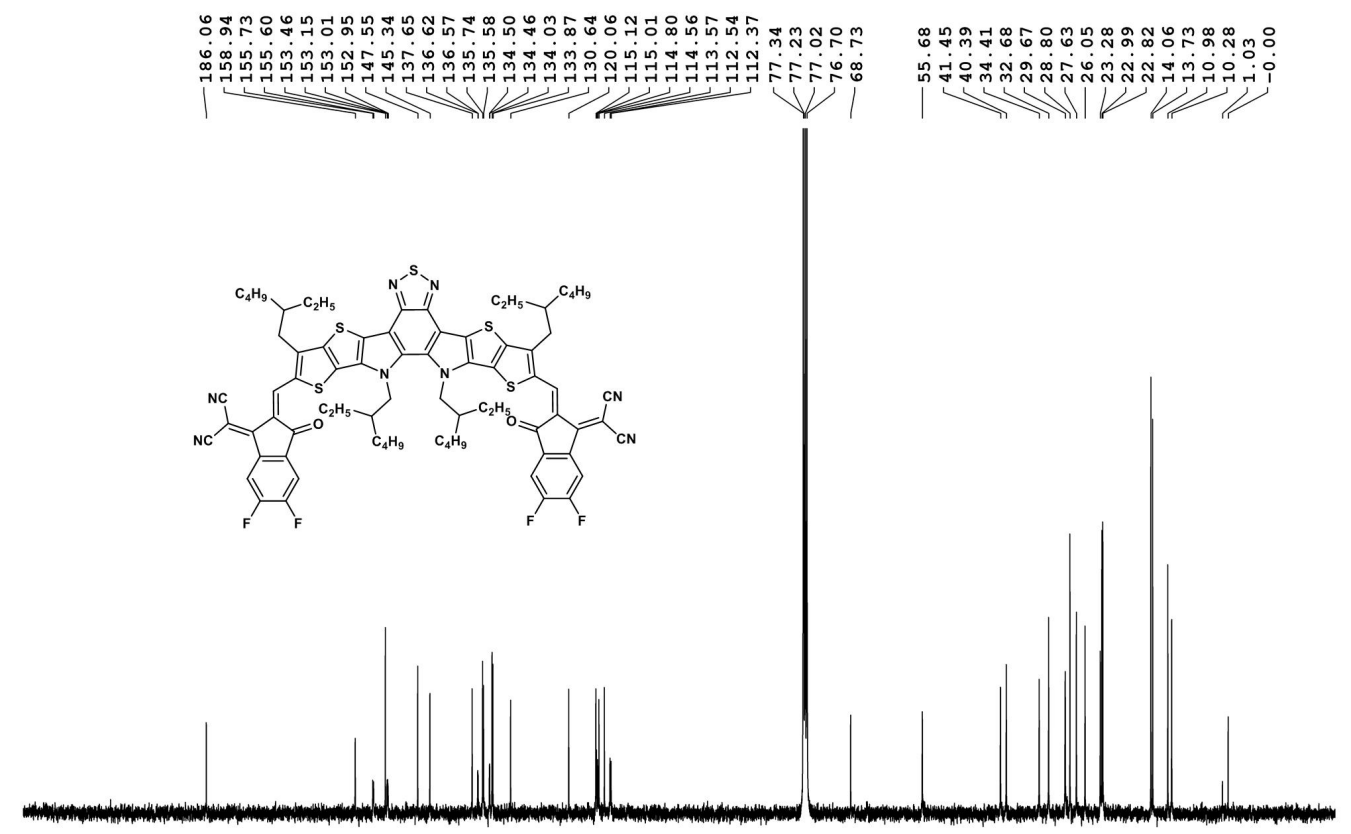

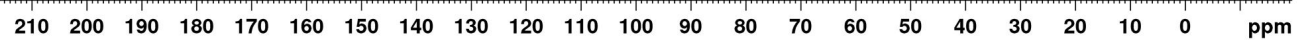

Supplementary Figure 63. ${ }^{13} \mathrm{C}$ NMR spectrum of L8-EH. 


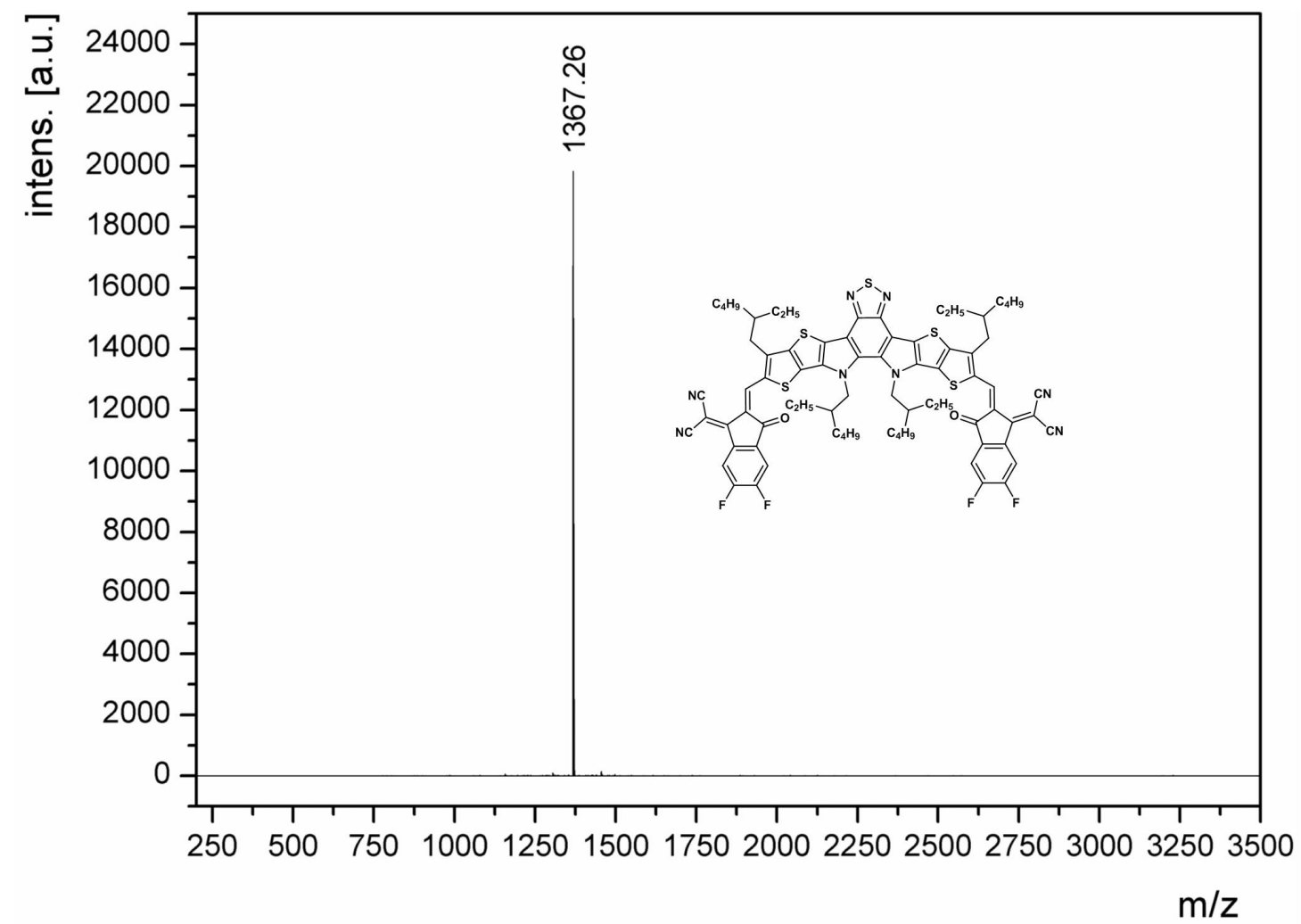

Supplementary Figure 64. MS (MALDI-TOF) spectrum of L8-EH. 


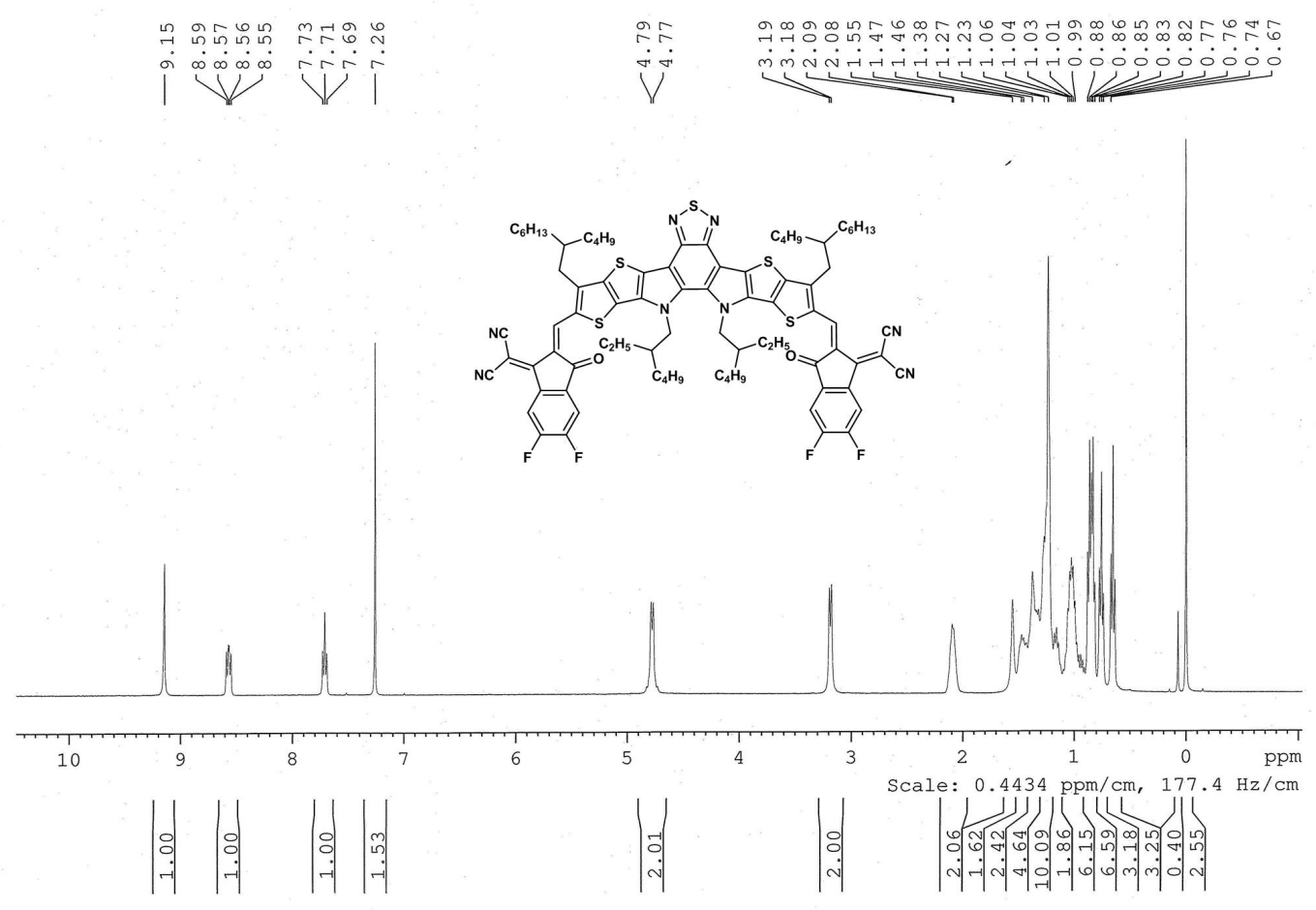

Supplementary Figure 65. ${ }^{1} \mathrm{H}$ NMR spectrum of L8-BO. 


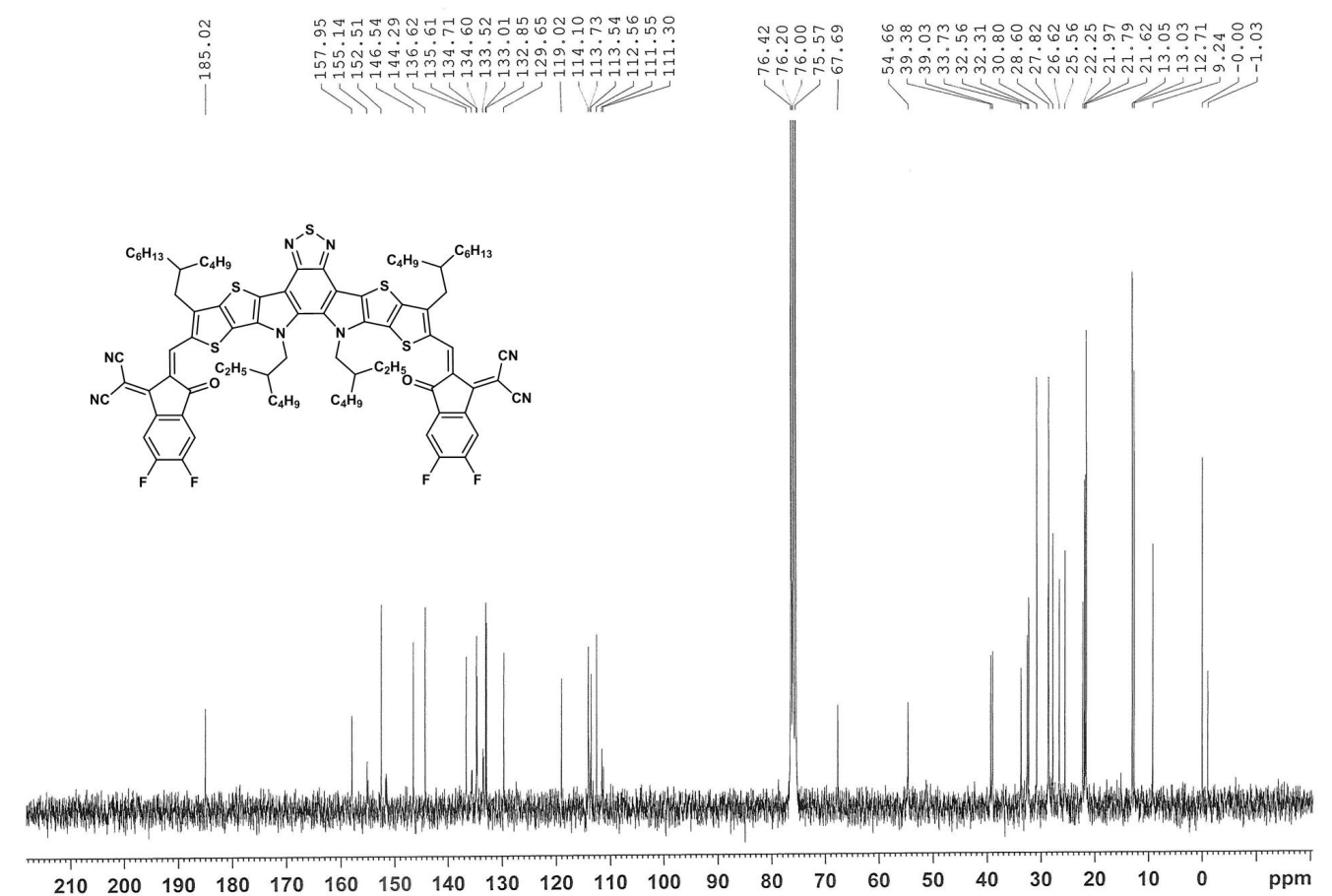

Supplementary Figure 66. ${ }^{13} \mathrm{C}$ NMR spectrum of L8-BO. 


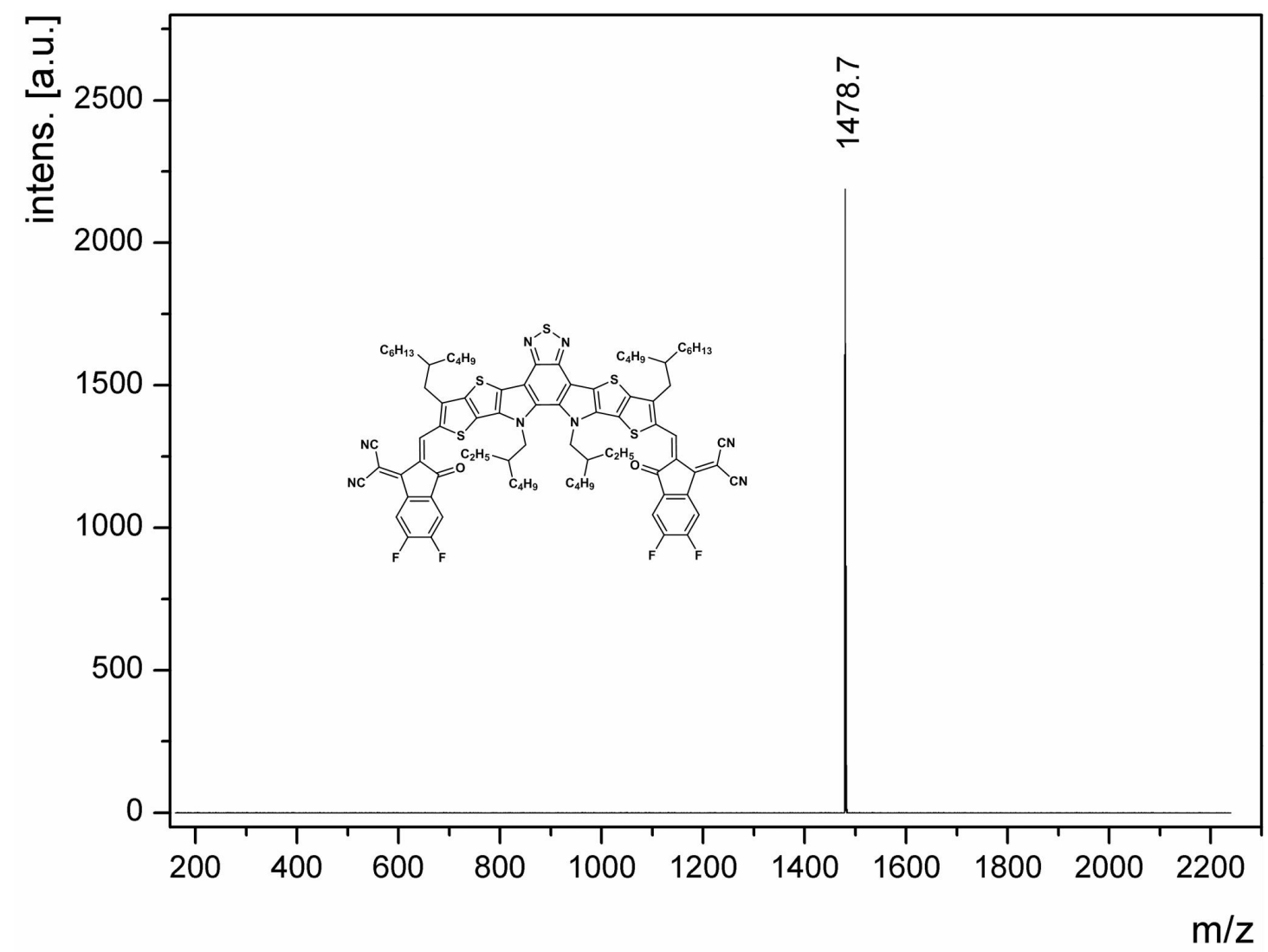

Supplementary Figure 67. MS (MALDI-TOF) spectrum of L8-BO. 


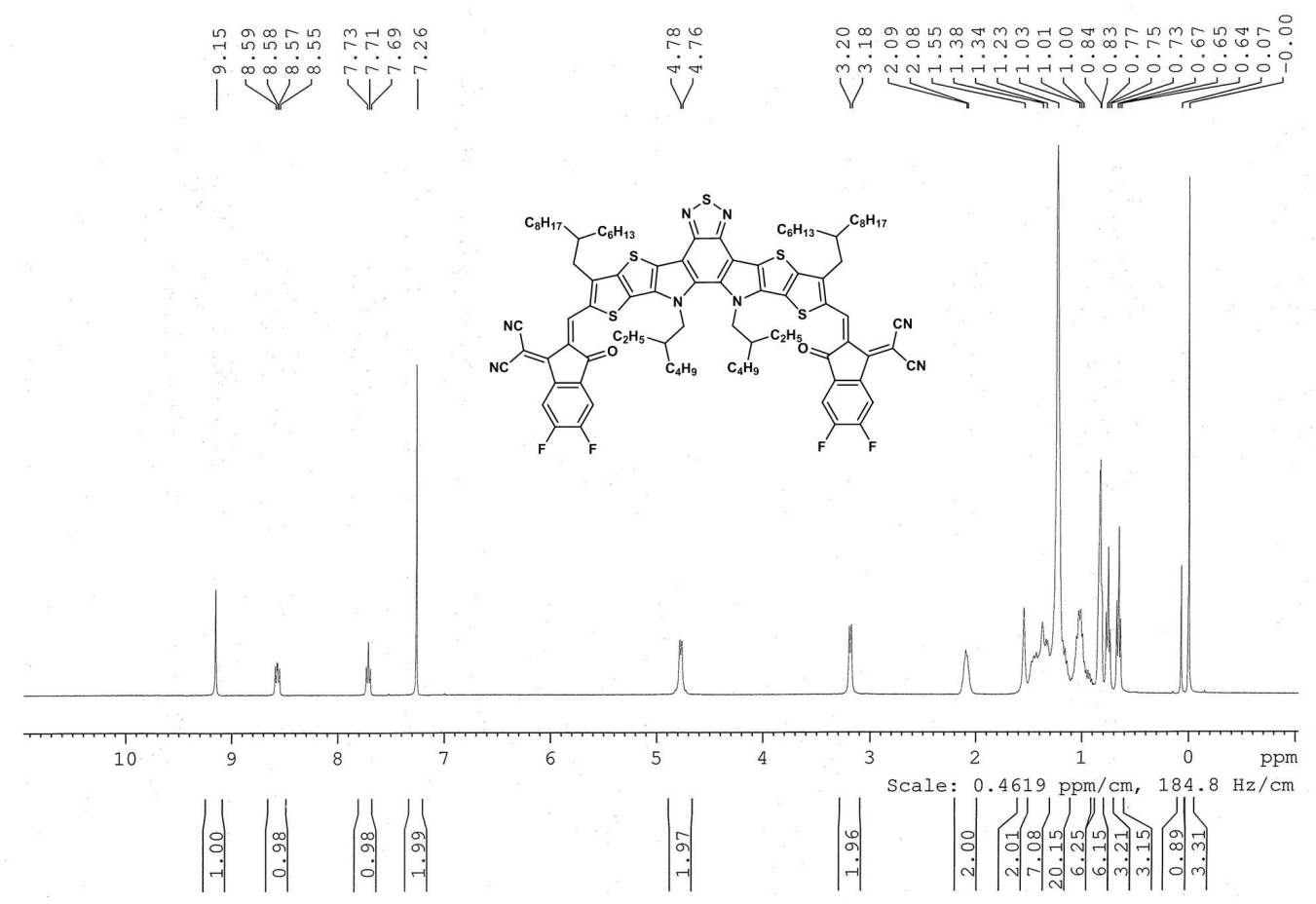

Supplementary Figure 68. ${ }^{1} \mathrm{H}$ NMR spectrum of L8-HD. 


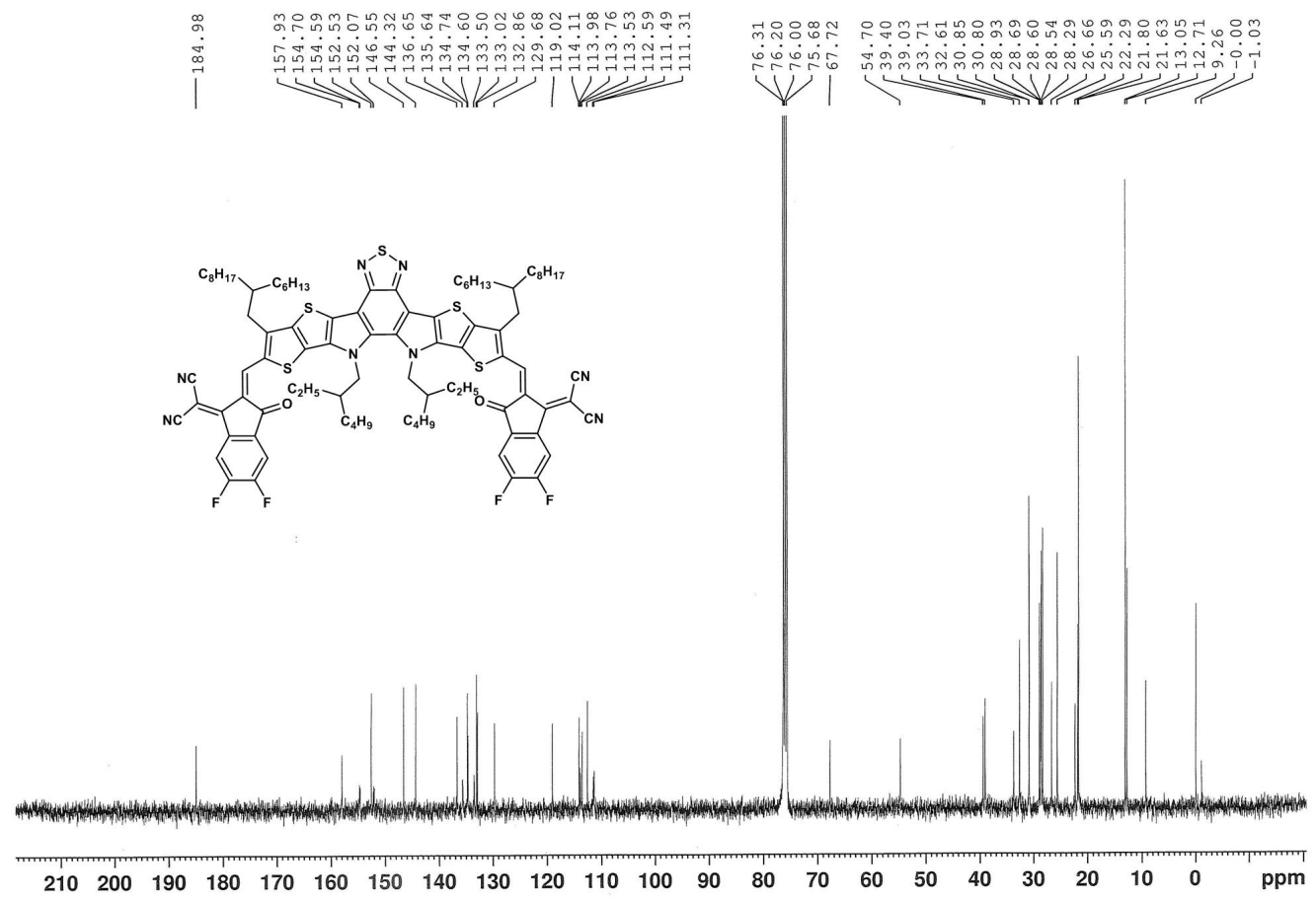

Supplementary Figure 69. ${ }^{13} \mathrm{C}$ NMR spectrum of L8-HD. 


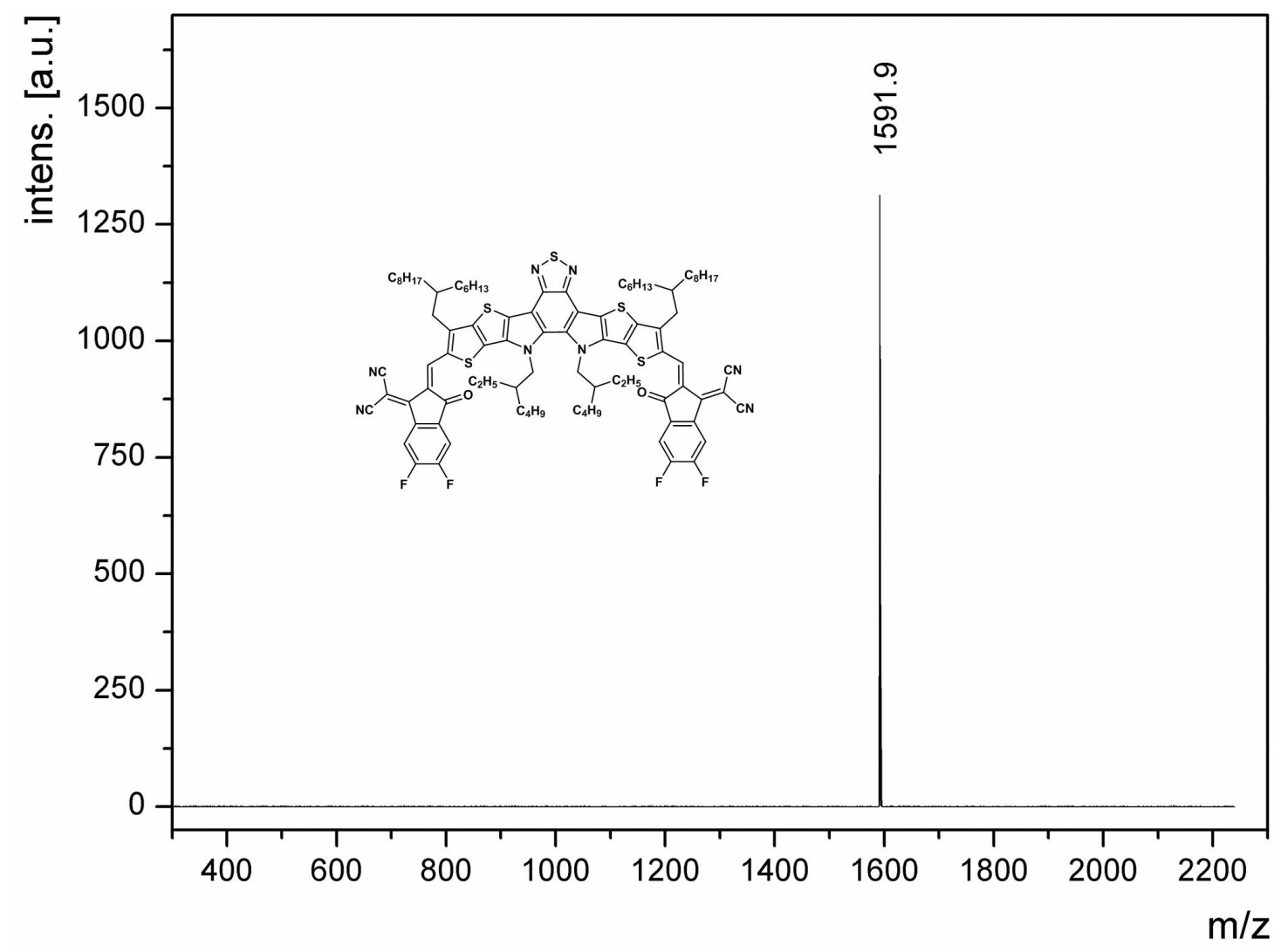

Supplementary Figure 70. MS (MALDI-TOF) spectrum of L8-HD. 


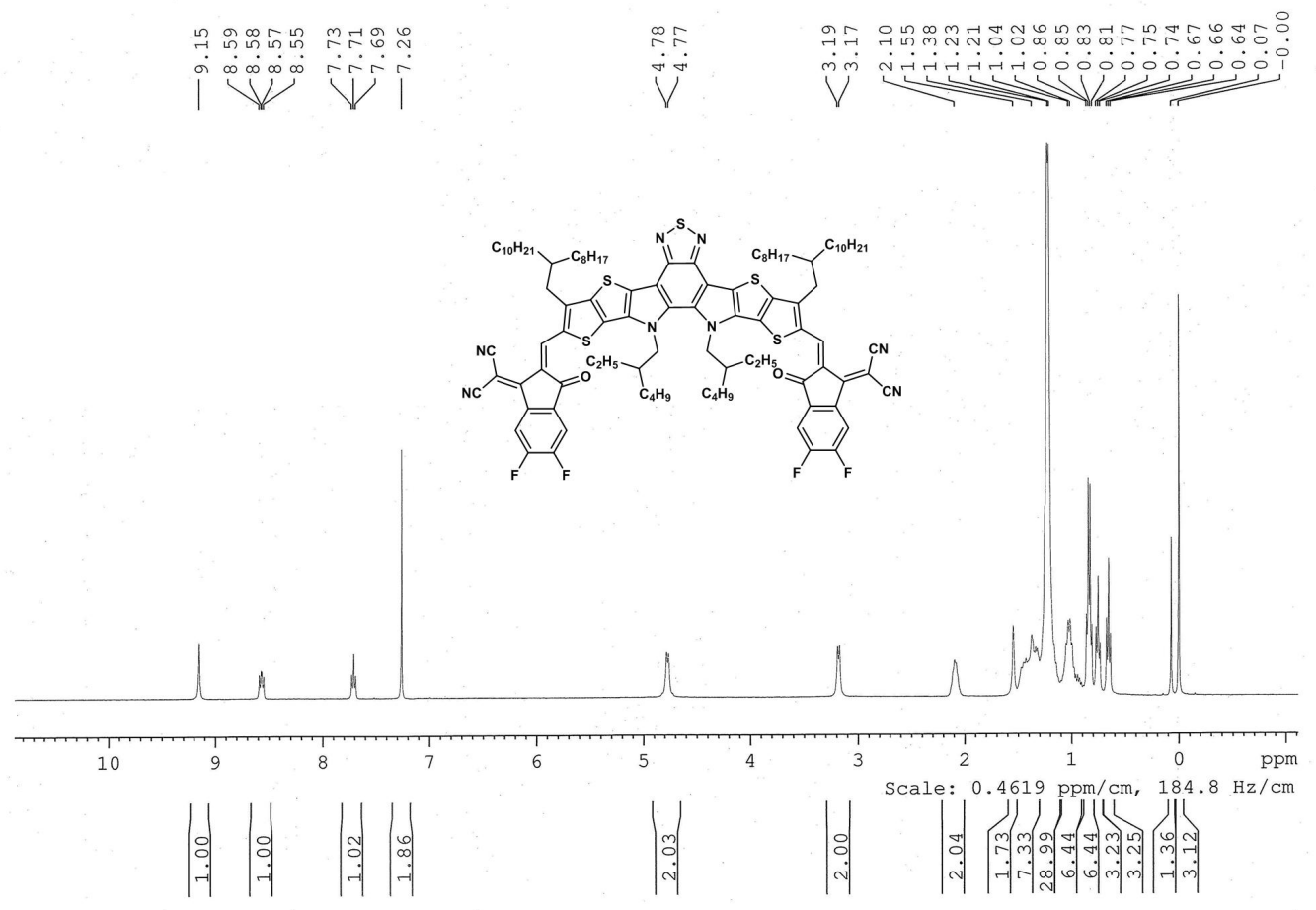

Supplementary Figure 71. ${ }^{1} \mathrm{H}$ NMR spectrum of L8-OD. 


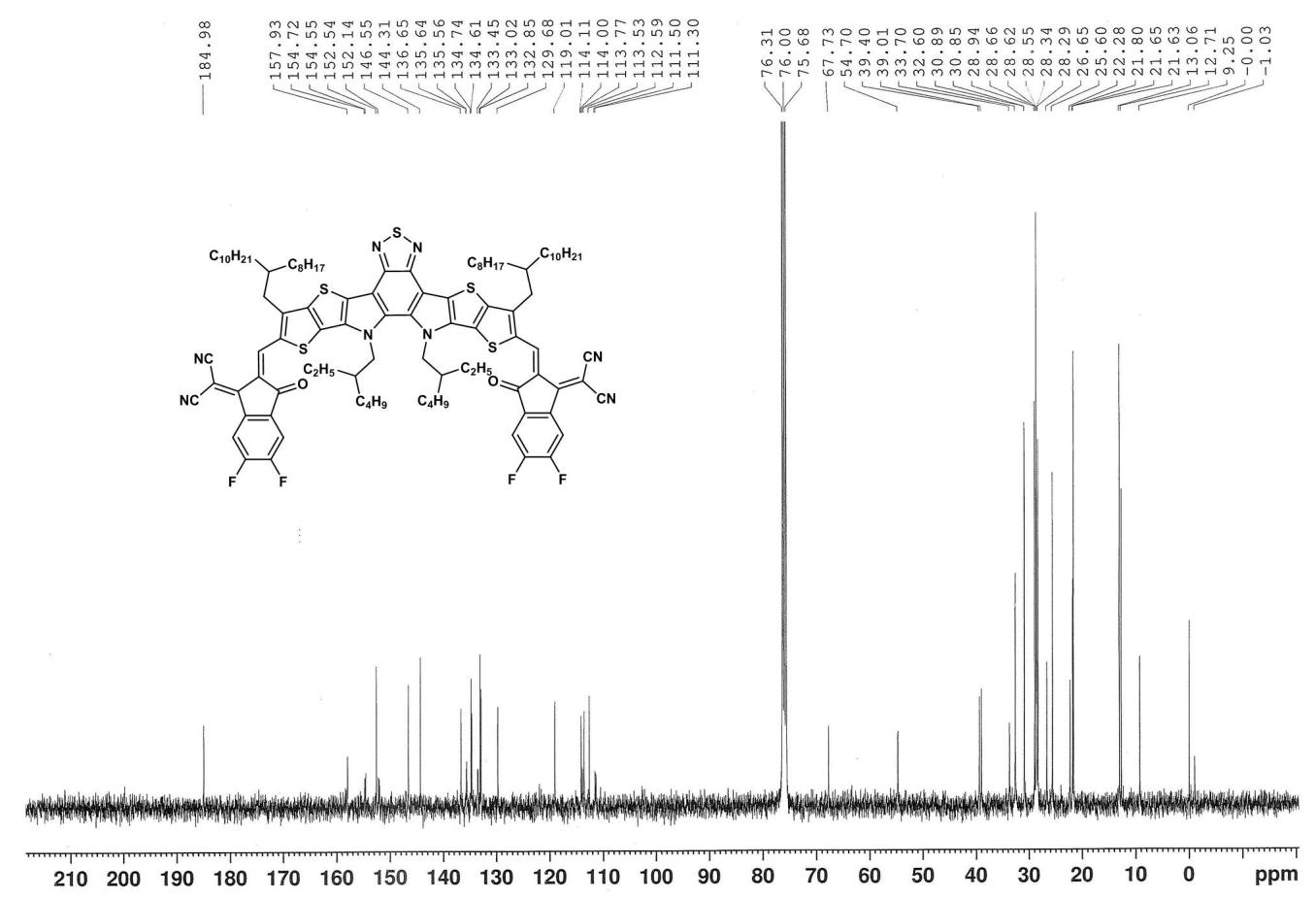

Supplementary Figure $72 .{ }^{13} \mathrm{C}$ NMR spectrum of L8-OD. 


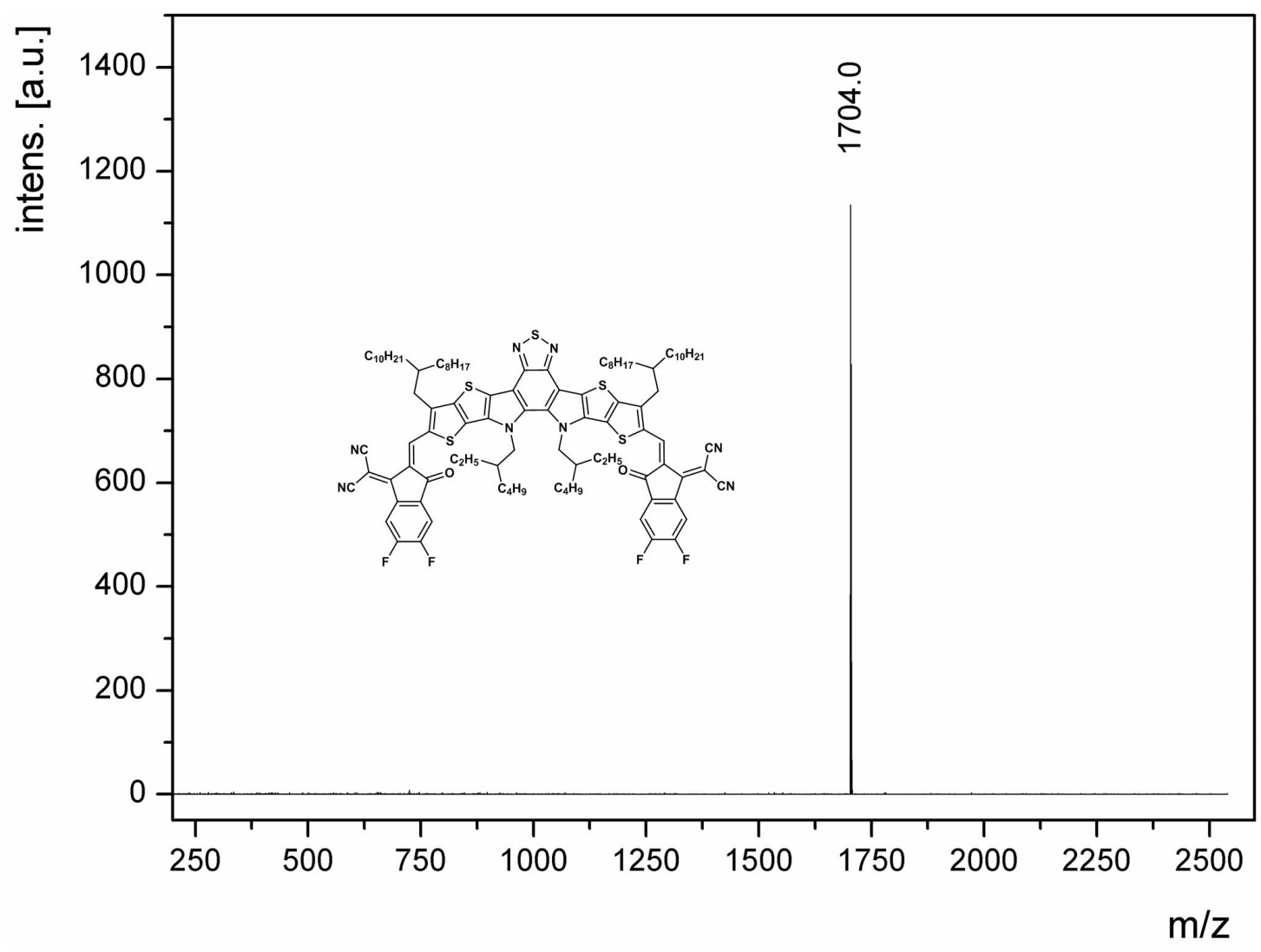

Supplementary Figure 73. MS (MALDI-TOF) spectrum of L8-OD. 


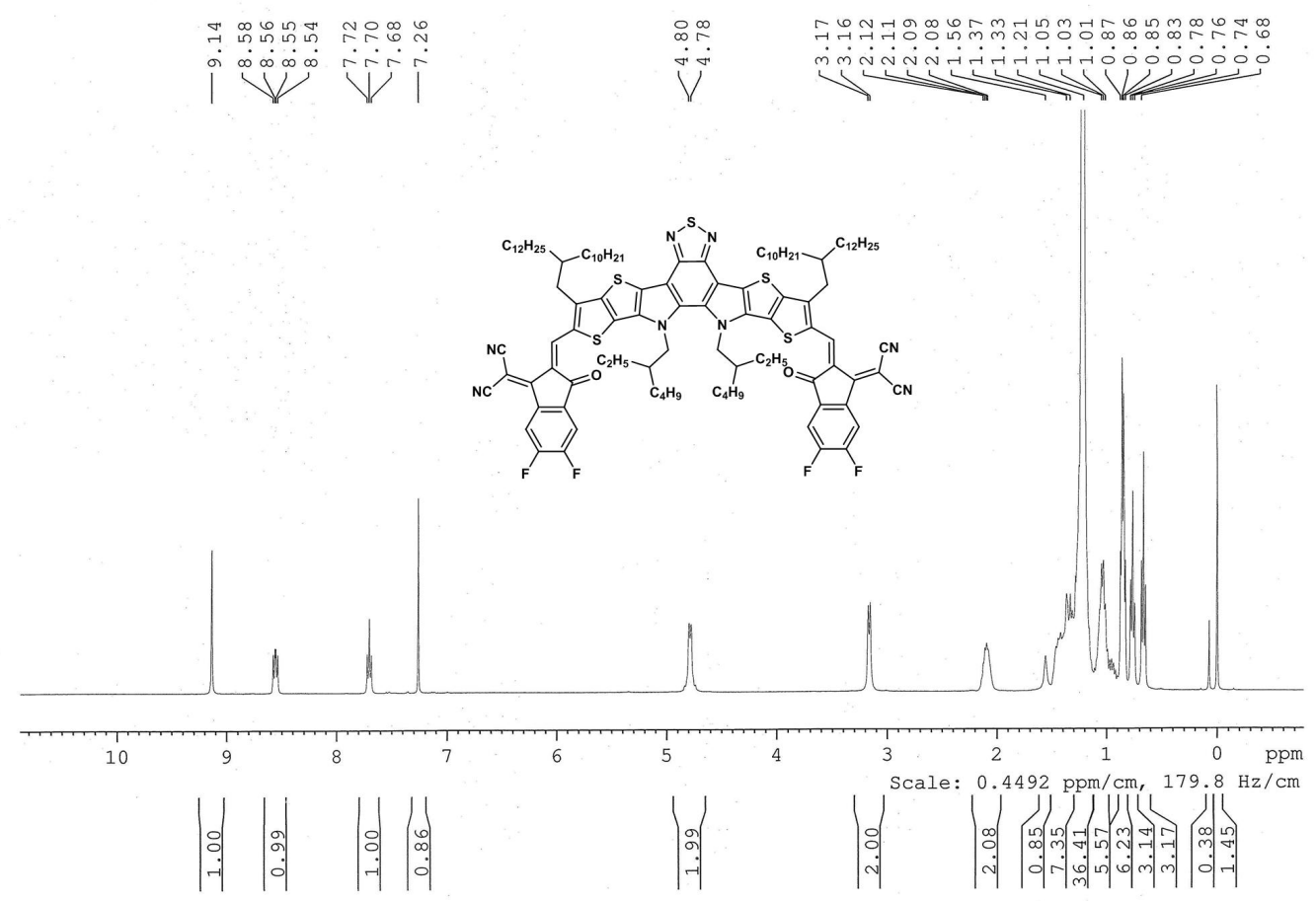

Supplementary Figure 74. ${ }^{1} \mathrm{H}$ NMR spectrum of L8-DT. 


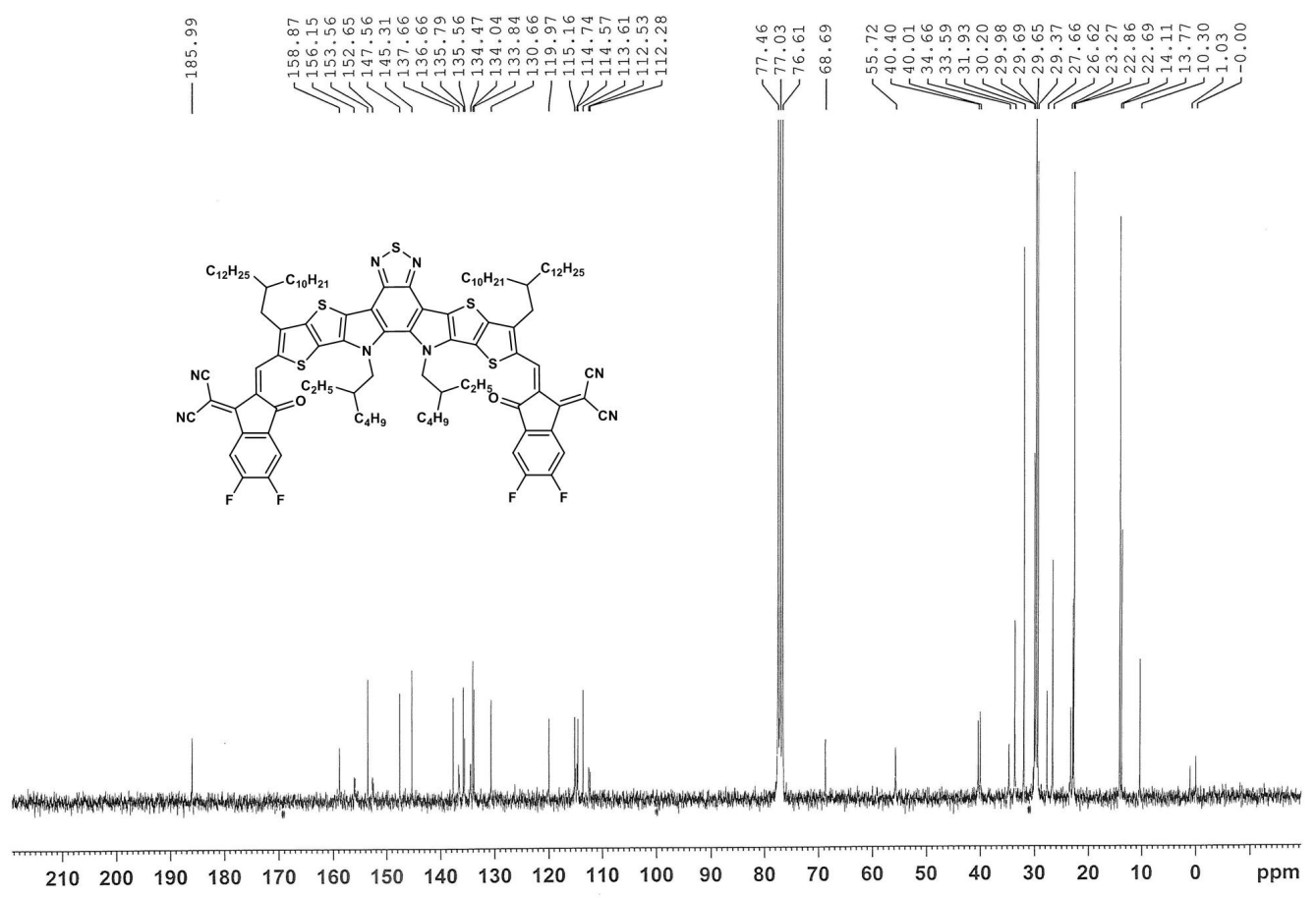

Supplementary Figure 75. ${ }^{13} \mathrm{C}$ NMR spectrum of L8-DT. 


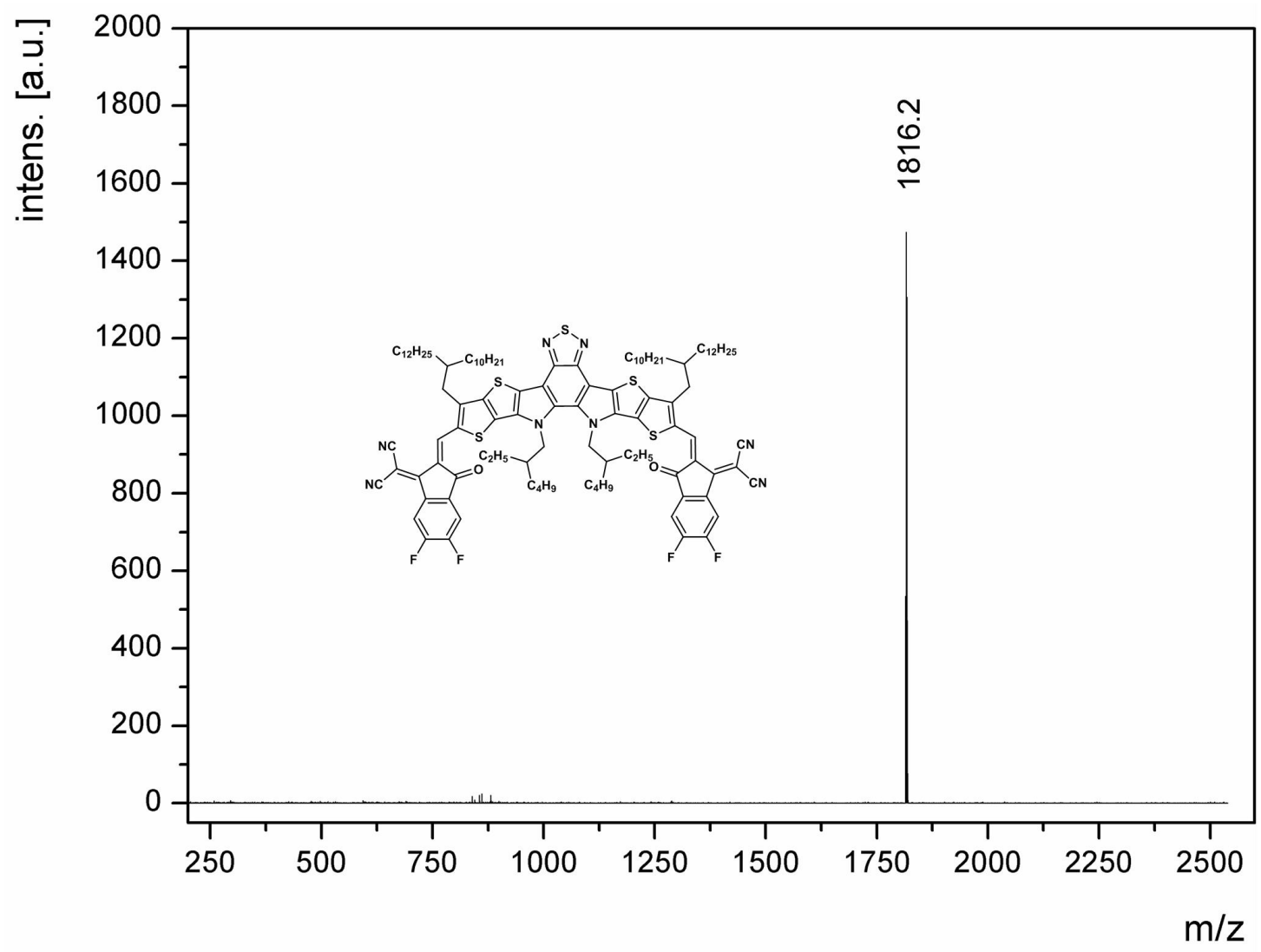

Supplementary Figure 76. MS (MALDI-TOF) spectrum of L8-DT. 


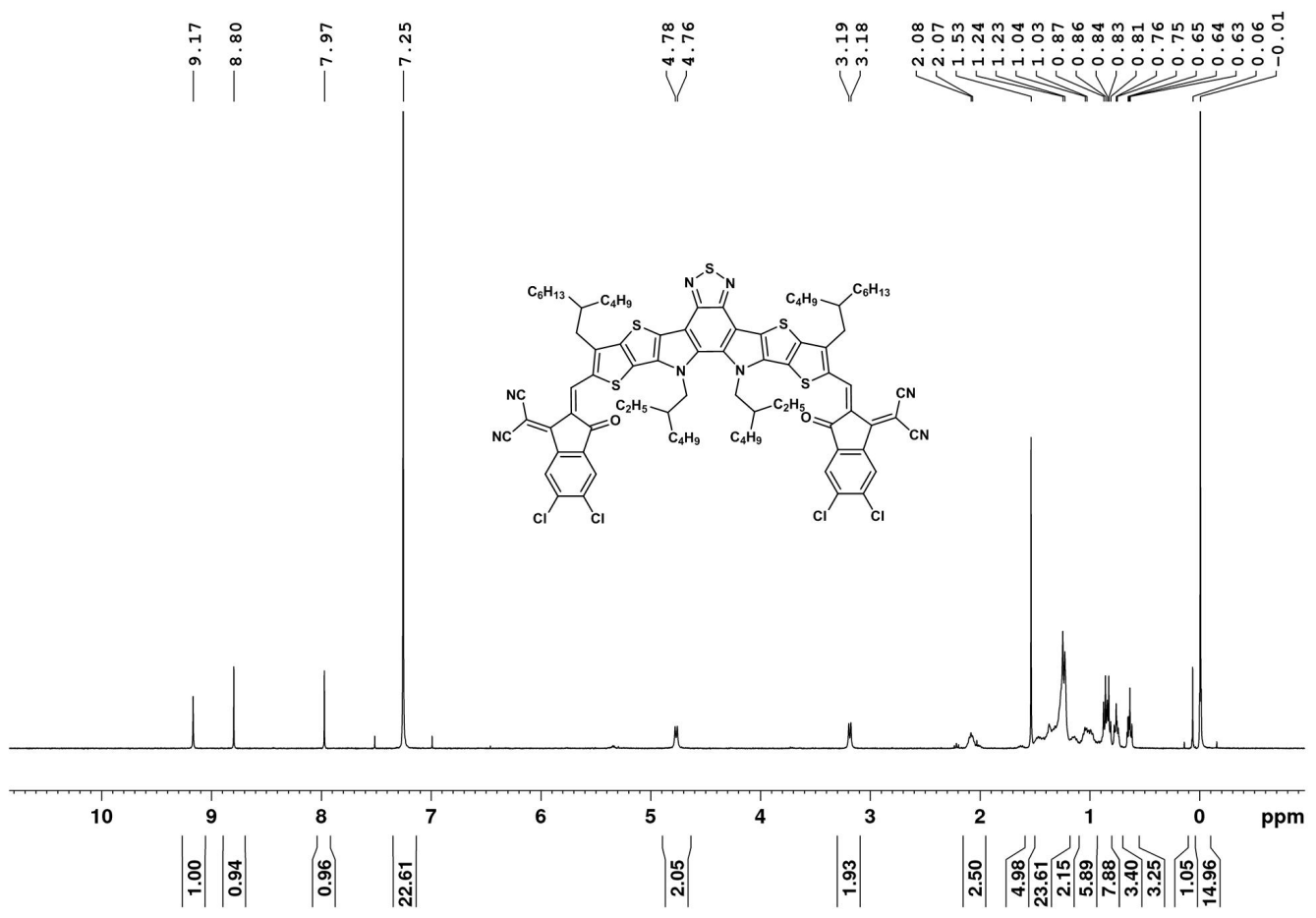

Supplementary Figure 77. ${ }^{1} \mathrm{H}$ NMR spectrum of LC333. 


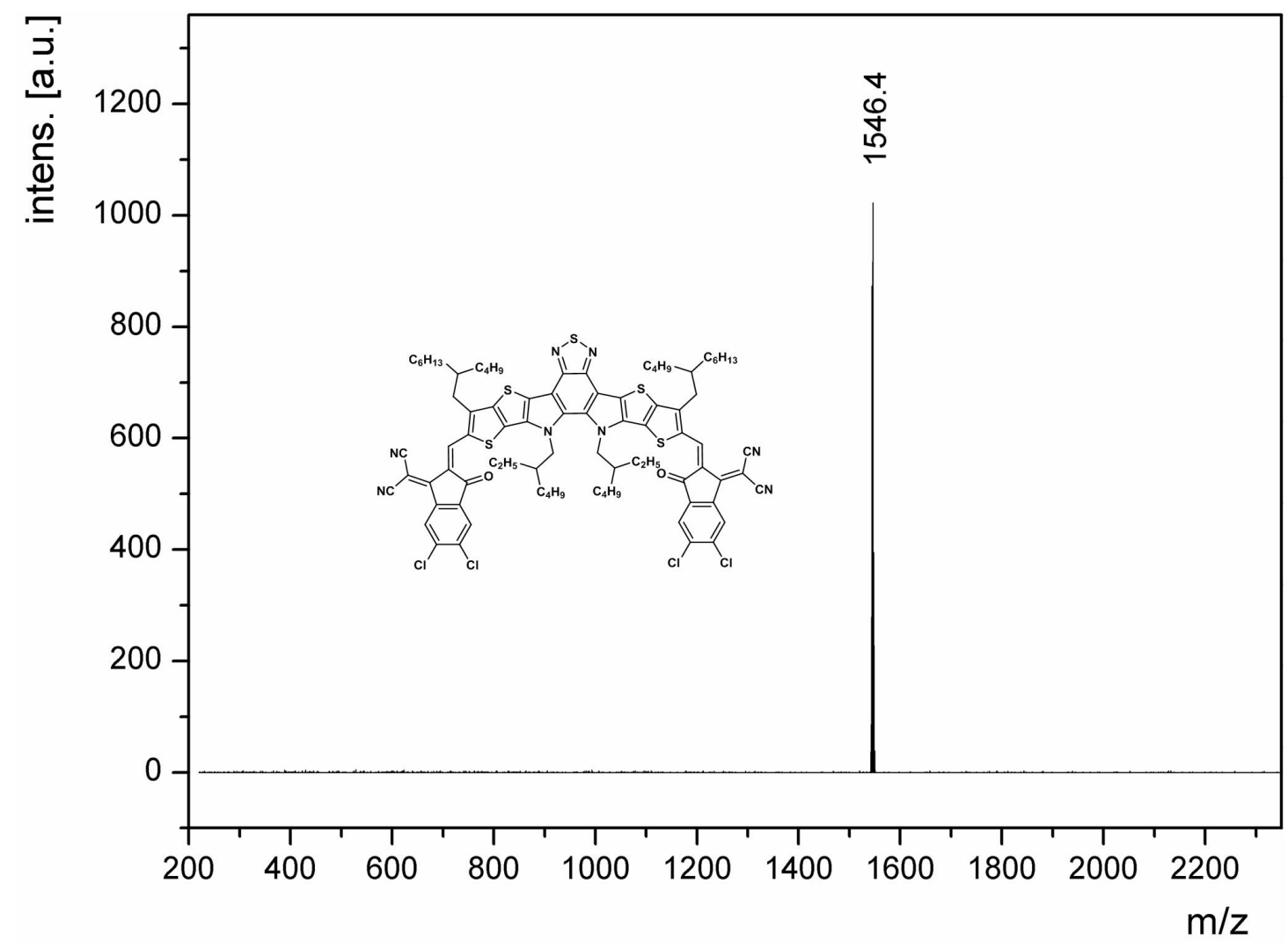

Supplementary Figure 78. MS (MALDI-TOF) spectrum of LC333. 


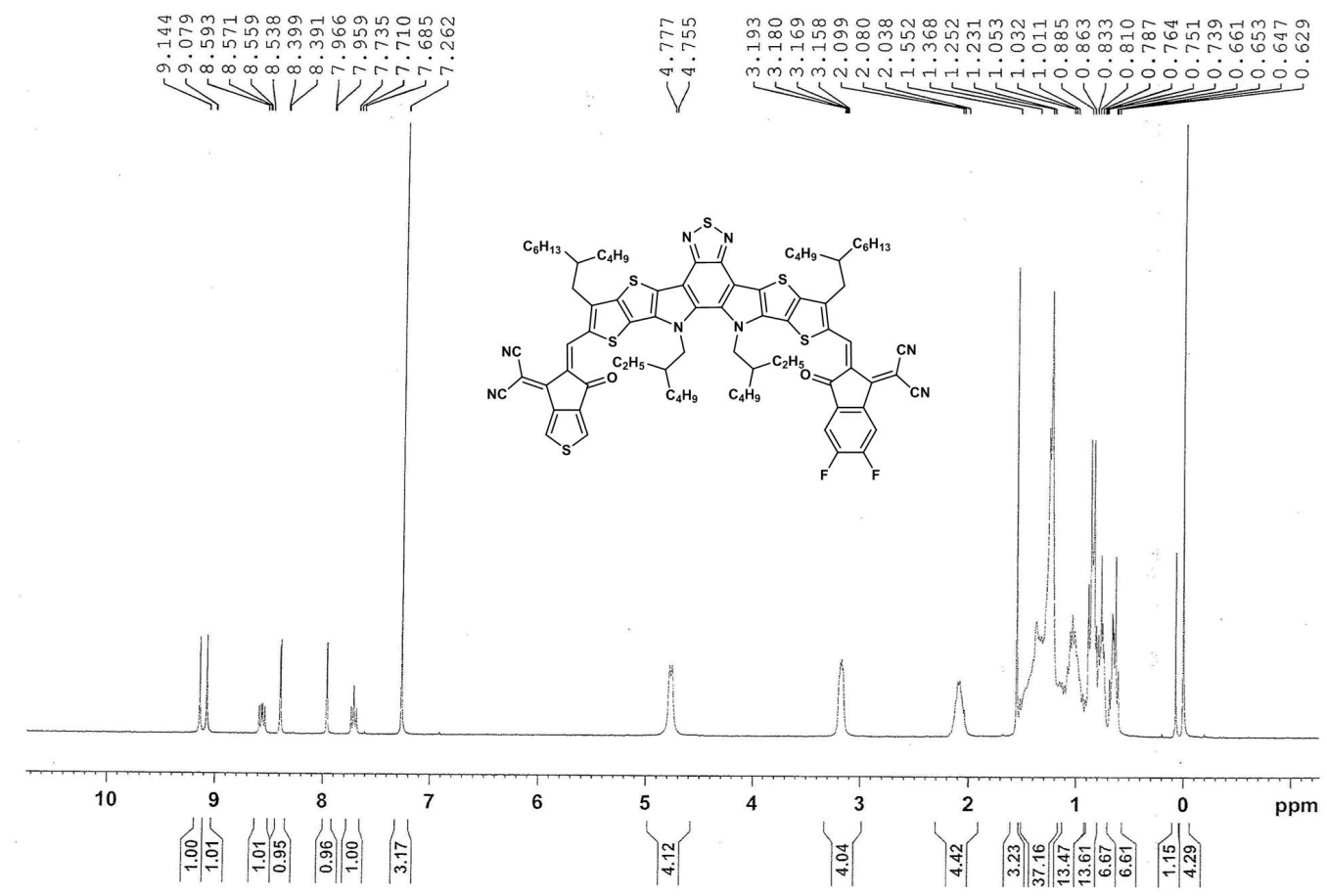

Supplementary Figure 79. ${ }^{1} \mathrm{H}$ NMR spectrum of LC301. 


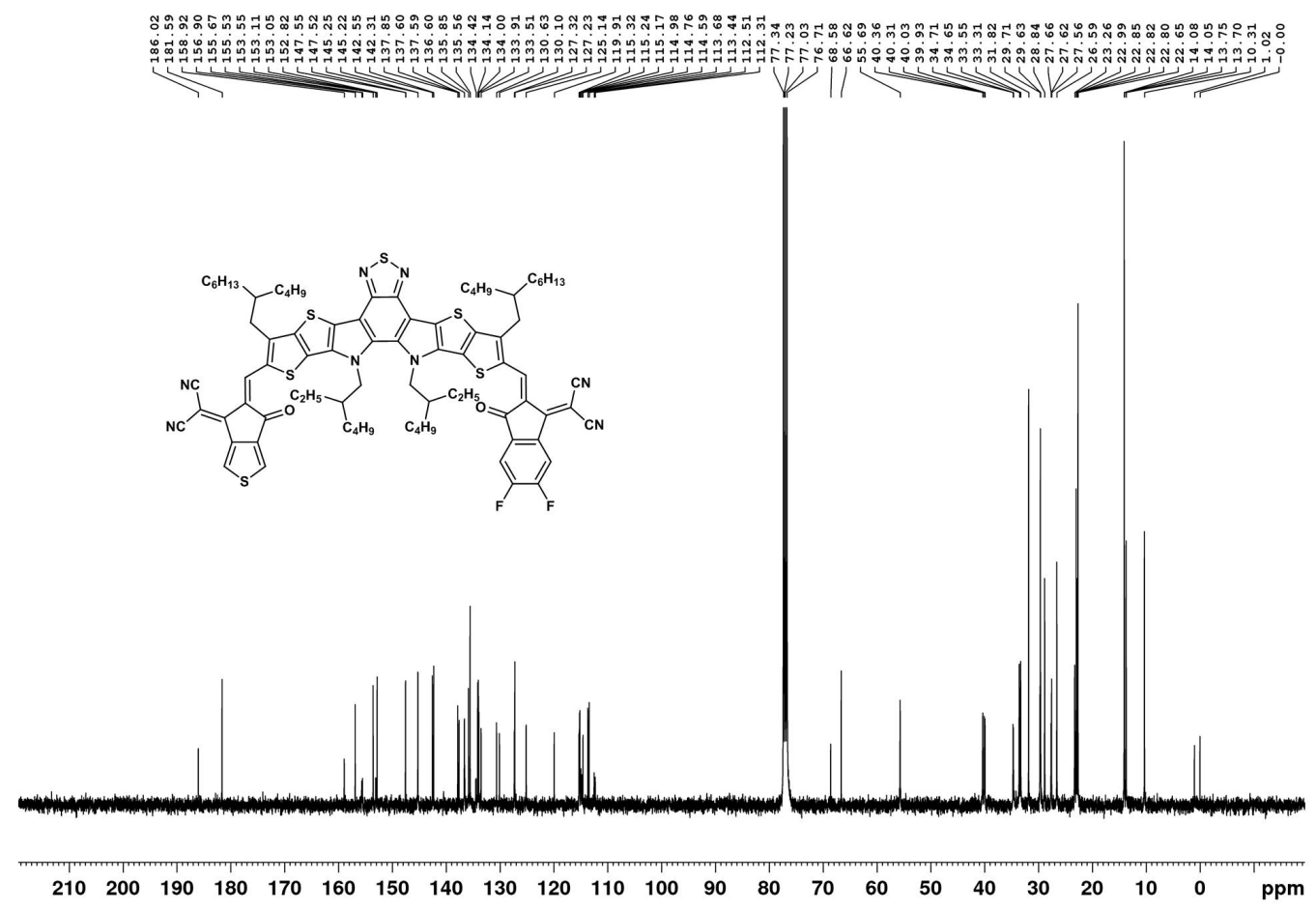

Supplementary Figure 80. ${ }^{13} \mathrm{C}$ NMR spectrum of LC301. 


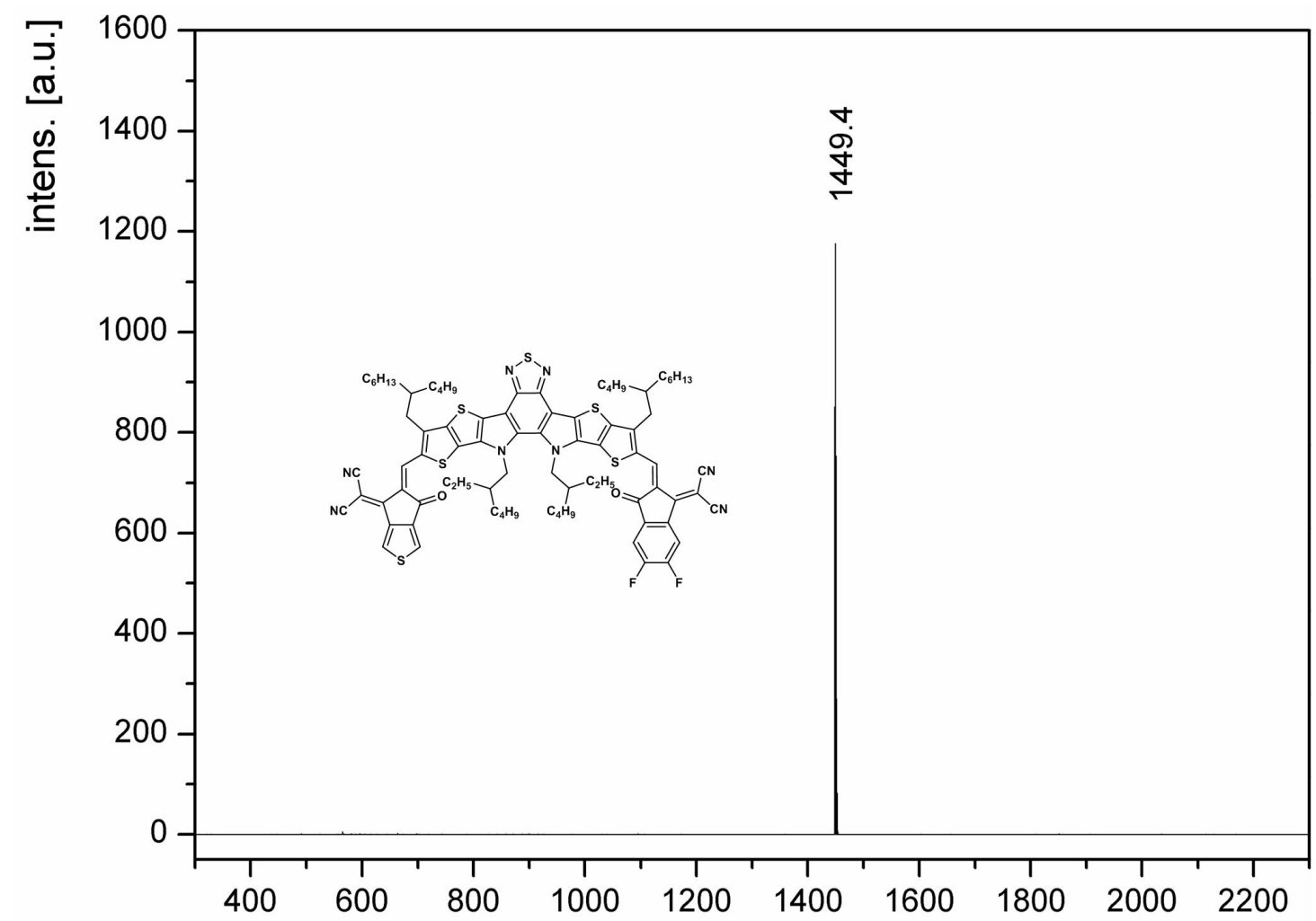

Supplementary Figure 81. MS (MALDI-TOF) spectrum of LC301. 


\section{Supplementary Tables}

Supplementary Table 1. The physicochemical properties and electron mobilities of Y6 and L8-R.

\begin{tabular}{|c|c|c|c|c|c|c|}
\hline NFA & $\begin{array}{c}\lambda_{\max }{ }^{\text {sol }} \\
(\mathrm{nm})\end{array}$ & $\begin{array}{c}\lambda_{\max }{ }^{\text {film }} \\
(\mathrm{nm})\end{array}$ & $\begin{array}{c}\lambda_{\text {onset }}{ }^{\text {film }} \\
(\mathrm{nm})\end{array}$ & $\begin{array}{c}E_{\mathrm{g}}{ }^{\mathrm{a}} \\
(\mathrm{eV})\end{array}$ & $\begin{array}{c}E_{\mathrm{ox}} / E_{\mathrm{red}} \\
(\mathrm{V})\end{array}$ & $\begin{array}{c}\mathrm{HOMO} / \mathrm{LUMO}^{\mathrm{b}} \\
(\mathrm{eV})\end{array}$ \\
\hline Y6 & 731 & 835 & 917 & 1.35 & $1.36 /-0.31$ & $-5.74 /-4.07$ \\
\hline L8-BO & 731 & 807 & 886 & 1.40 & $1.31 /-0.48$ & $-5.68 /-3.90$ \\
\hline L8-HD & 731 & 807 & 865 & 1.43 & $1.33 /-0.48$ & $-5.71 /-3.90$ \\
\hline L8-OD & 731 & 807 & 875 & 1.42 & $1.33 /-0.47$ & $-5.71 /-3.91$ \\
\hline
\end{tabular}

${ }^{\mathrm{a}}$ Estimated from the empirical formula: $E_{\mathrm{g}}=1240 / \lambda_{\text {onset }}$.

${ }^{\mathrm{b}}$ Calculated from the equation: $\mathrm{HOMO} / \mathrm{LUMO}=-\left(E_{\mathrm{ox}} / E_{\mathrm{red}}+4.38\right) \mathrm{eV}$. 
Supplementary Table 2. The calculated excitation energies $E(\mathrm{eV})$, and absorption maxima $\lambda_{\max , a b}(\mathrm{~nm})$ for the monomer and dimer of NFAs calculated at the TD-B3LYP/6-31G(d,p) level.

\begin{tabular}{|c|c|c|}
\hline NFA & $E(\mathrm{eV})$ & $\lambda(\mathrm{nm})$ \\
\hline L8-BO & 1.8372 & 674.87 \\
\hline L8-HD & 1.8318 & 676.83 \\
\hline L8-OD & 1.8411 & 673.42 \\
\hline Y6 & 1.8316 & 676.91 \\
\hline L8-BO2 & 1.6621 & 745.95 \\
\hline L8-HD2 & 1.6678 & 743.39 \\
\hline L8-OD2 & 1.659 & 747.35 \\
\hline Y62 & 1.6004 & 774.7 \\
\hline
\end{tabular}


Supplementary Table 3. Photovoltaic parameters of PM6:L8-BO OSCs under different device optimization conditions.

\begin{tabular}{|c|c|c|c|c|c|c|c|}
\hline $\begin{array}{c}\mathrm{D} / \mathrm{A} \\
(\mathrm{w} / \mathrm{w})\end{array}$ & $\begin{array}{c}\text { Temperature } \\
\left({ }^{\circ} \mathrm{C}\right)\end{array}$ & $\begin{array}{l}\mathrm{DIO} \\
(\%)\end{array}$ & $\begin{array}{l}V_{\mathrm{oc}} \\
(\mathrm{V})\end{array}$ & $\begin{array}{c}J_{\mathrm{sc}} \\
\left(\mathrm{mA} / \mathrm{cm}^{2}\right)\end{array}$ & $\begin{array}{c}J_{\mathrm{sc}},{ }^{\mathrm{cal}} \\
\left(\mathrm{mA} / \mathrm{cm}^{2}\right)\end{array}$ & $\begin{array}{l}\mathrm{FF} \\
(\%)\end{array}$ & $\begin{array}{l}\mathrm{PCE}^{\mathrm{a}} \\
(\%)\end{array}$ \\
\hline $1: 1.2$ & 25 & 0 & $\begin{array}{c}0.90 \\
(0.90 \pm 0.01)\end{array}$ & $\begin{array}{c}24.18 \\
(24.03 \pm 0.26)\end{array}$ & 23.75 & $\begin{array}{c}74.9 \\
(74.12 \pm 0.68)\end{array}$ & $\begin{array}{c}16.34 \\
(16.08 \pm 0.21)\end{array}$ \\
\hline $1: 1.2$ & 100 & 0 & $\begin{array}{c}0.89 \\
(0.89 \pm 0.01)\end{array}$ & $\begin{array}{c}24.74 \\
(24.56 \pm 0.18)\end{array}$ & 24.33 & $\begin{array}{c}76.5 \\
(75.78 \pm 0.82)\end{array}$ & $\begin{array}{c}16.88 \\
(16.64 \pm 0.17)\end{array}$ \\
\hline $1: 1$ & 100 & 0 & $\begin{array}{c}0.90 \\
(0.90 \pm 0.01)\end{array}$ & $\begin{array}{c}24.67 \\
(24.52 \pm 0.29)\end{array}$ & 24.24 & $\begin{array}{c}75.1 \\
(74.54 \pm 0.79)\end{array}$ & $\begin{array}{c}16.58 \\
(16.29 \pm 0.33)\end{array}$ \\
\hline $1: 1.4$ & 100 & 0 & $\begin{array}{c}0.89 \\
(0.89 \pm 0.01)\end{array}$ & $\begin{array}{c}24.82 \\
(24.67 \pm 0.43)\end{array}$ & 24.36 & $\begin{array}{c}75.4 \\
(74.65 \pm 0.90)\end{array}$ & $\begin{array}{c}16.67 \\
(16.47 \pm 0.36)\end{array}$ \\
\hline $1: 1.2$ & 100 & 0.25 & $\begin{array}{c}0.87 \\
(0.87 \pm 0.01) \\
\end{array}$ & $\begin{array}{c}25.72 \\
(25.66 \pm 0.27)\end{array}$ & 25.26 & $\begin{array}{c}81.5 \\
(80.46 \pm 0.91)\end{array}$ & $\begin{array}{c}18.32 \\
(17.97 \pm 0.18)\end{array}$ \\
\hline $1: 1.2$ & 100 & 0.35 & $\begin{array}{c}0.87 \\
(0.87 \pm 0.01)\end{array}$ & $\begin{array}{c}25.07 \\
(24.85 \pm 0.28)\end{array}$ & 24.63 & $\begin{array}{c}79.7 \\
(78.93 \pm 1.05)\end{array}$ & $\begin{array}{c}17.34 \\
(17.12 \pm 0.18)\end{array}$ \\
\hline
\end{tabular}

The error bars correspond to the standard deviation of multiple independent solar cells.

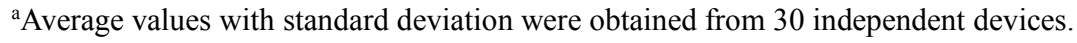


Supplementary Table 4. Photovoltaic parameters of PM6:L8-HD OSCs under different device optimization conditions.

\begin{tabular}{|c|c|c|c|c|c|c|c|}
\hline $\begin{array}{c}\mathrm{D} / \mathrm{A} \\
(\mathrm{w} / \mathrm{w})\end{array}$ & $\begin{array}{c}\text { Temperature } \\
\left({ }^{\circ} \mathrm{C}\right)\end{array}$ & $\begin{array}{l}\mathrm{DIO} \\
(\%)\end{array}$ & $\begin{array}{l}V_{\mathrm{oc}} \\
(\mathrm{V})\end{array}$ & $\begin{array}{c}J_{\mathrm{sc}} \\
\left(\mathrm{mA} / \mathrm{cm}^{2}\right)\end{array}$ & $\begin{array}{c}J_{\mathrm{sc}},{ }^{\mathrm{cal}} \\
\left(\mathrm{mA} / \mathrm{cm}^{2}\right)\end{array}$ & $\begin{array}{l}\mathrm{FF} \\
(\%)\end{array}$ & $\begin{array}{l}P E^{a} \\
(\%)\end{array}$ \\
\hline $1: 1.2$ & 25 & 0 & $\begin{array}{c}0.92 \\
(0.92 \pm 0.01)\end{array}$ & $\begin{array}{c}23.52 \\
(23.36 \pm 0.15)\end{array}$ & 23.10 & $\begin{array}{c}72.3 \\
(71.69 \pm 0.65)\end{array}$ & $\begin{array}{c}15.63 \\
(15.46 \pm 0.32)\end{array}$ \\
\hline $1: 1.2$ & 100 & 0 & $\begin{array}{c}0.90 \\
(0.90 \pm 0.01)\end{array}$ & $\begin{array}{c}24.80 \\
(24.66 \pm 0.22)\end{array}$ & 24.39 & $\begin{array}{c}74.8 \\
(74.44 \pm 0.52)\end{array}$ & $\begin{array}{c}16.62 \\
(16.35 \pm 0.25)\end{array}$ \\
\hline $1: 1$ & 100 & 0 & $\begin{array}{c}0.90 \\
(0.90 \pm 0.01)\end{array}$ & $\begin{array}{c}24.56 \\
(24.17 \pm 0.35)\end{array}$ & 24.13 & $\begin{array}{c}73.2 \\
(72.80 \pm 0.36)\end{array}$ & $\begin{array}{c}16.13 \\
(15.86 \pm 0.28)\end{array}$ \\
\hline $1: 1.4$ & 100 & 0 & $\begin{array}{c}0.89 \\
(0.89 \pm 0.01)\end{array}$ & $\begin{array}{c}24.98 \\
(24.73 \pm 0.29)\end{array}$ & 24.54 & $\begin{array}{c}71.9 \\
(71.28 \pm 0.78)\end{array}$ & $\begin{array}{c}15.97 \\
(15.77 \pm 0.23)\end{array}$ \\
\hline $1: 1.2$ & 100 & 0.25 & $\begin{array}{c}0.88 \\
(0.87 \pm 0.01) \\
\end{array}$ & $\begin{array}{c}25.08 \\
(24.95 \pm 0.26)\end{array}$ & 24.66 & $\begin{array}{c}78.8 \\
(77.90 \pm 1.00)\end{array}$ & $\begin{array}{c}17.39 \\
(17.12 \pm 0.20)\end{array}$ \\
\hline $1: 1.2$ & 100 & 0.35 & $\begin{array}{c}0.88 \\
(0.88 \pm 0.01)\end{array}$ & $\begin{array}{c}24.97 \\
(24.82 \pm 0.18)\end{array}$ & 24.53 & $\begin{array}{c}76.8 \\
(76.15 \pm 0.68)\end{array}$ & $\begin{array}{c}16.89 \\
(16.68 \pm 0.26)\end{array}$ \\
\hline
\end{tabular}

The error bars correspond to the standard deviation of multiple independent solar cells.

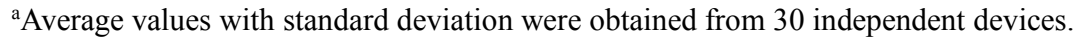


Supplementary Table 5. Photovoltaic parameters of PM6:L8-OD OSCs under different device optimization conditions.

\begin{tabular}{|c|c|c|c|c|c|c|c|}
\hline $\begin{array}{l}\mathrm{D} / \mathrm{A} \\
(\mathrm{w} / \mathrm{w})\end{array}$ & $\begin{array}{c}\text { Temperature } \\
\left({ }^{\circ} \mathrm{C}\right)\end{array}$ & $\begin{array}{l}\mathrm{DIO} \\
(\%)\end{array}$ & $\begin{array}{l}\mathrm{V}_{\mathrm{oc}} \\
(\mathrm{V})\end{array}$ & $\begin{array}{c}\mathrm{J}_{\mathrm{sc}} \\
\left(\mathrm{mA} / \mathrm{cm}^{2}\right)\end{array}$ & $\begin{array}{c}\mathrm{J}_{\mathrm{sc}},{ }^{\mathrm{cal}} \\
\left(\mathrm{mA} / \mathrm{cm}^{2}\right)\end{array}$ & $\begin{array}{l}\mathrm{FF} \\
(\%)\end{array}$ & $\begin{array}{l}\mathrm{PCE}^{\mathrm{a}} \\
(\%)\end{array}$ \\
\hline $1: 1.2$ & 25 & 0 & $\begin{array}{c}0.93 \\
(0.93 \pm 0.01)\end{array}$ & $\begin{array}{c}22.26 \\
(22.42 \pm 0.23)\end{array}$ & 22.21 & $\begin{array}{c}71.2 \\
(70.55 \pm 0.87)\end{array}$ & $\begin{array}{c}14.96 \\
(14.78 \pm 0.29)\end{array}$ \\
\hline $1: 1.2$ & 100 & 0 & $\begin{array}{c}0.89 \\
(0.89 \pm 0.01)\end{array}$ & $\begin{array}{c}24.71 \\
(24.55 \pm 0.19)\end{array}$ & 24.17 & $\begin{array}{c}69.7 \\
(68.96 \pm 0.95)\end{array}$ & $\begin{array}{c}15.26 \\
(14.99 \pm 0.35)\end{array}$ \\
\hline $1: 1$ & 100 & 0 & $\begin{array}{c}0.89 \\
(0.89 \pm 0.01)\end{array}$ & $\begin{array}{c}24.56 \\
(24.42 \pm 0.15)\end{array}$ & 24.13 & $\begin{array}{c}69.6 \\
(68.71 \pm 0.88)\end{array}$ & $\begin{array}{c}15.21 \\
(14.87 \pm 0.26)\end{array}$ \\
\hline $1: 1.4$ & 100 & 0 & $\begin{array}{c}0.88 \\
(0.88 \pm 0.01) \\
\end{array}$ & $\begin{array}{c}24.67 \\
(24.50 \pm 0.36) \\
\end{array}$ & 24.23 & $\begin{array}{c}69.2 \\
(68.48 \pm 0.92) \\
\end{array}$ & $\begin{array}{c}15.07 \\
(14.84 \pm 0.18) \\
\end{array}$ \\
\hline $1: 1.2$ & 100 & 0.25 & $\begin{array}{c}0.89 \\
(0.89 \pm 0.01)\end{array}$ & $\begin{array}{c}24.57 \\
(24.50 \pm 0.25)\end{array}$ & 24.15 & $\begin{array}{c}74.6 \\
(73.98 \pm 1.01)\end{array}$ & $\begin{array}{c}16.26 \\
(16.06 \pm 0.21)\end{array}$ \\
\hline $1: 1.2$ & 100 & 0.35 & $\begin{array}{c}0.88 \\
(0.88 \pm 0.01)\end{array}$ & $\begin{array}{c}24.45 \\
(24.33 \pm 0.18)\end{array}$ & 24.02 & $\begin{array}{c}72.4 \\
(71.65 \pm 1.12)\end{array}$ & $\begin{array}{c}15.64 \\
(15.36 \pm 0.15)\end{array}$ \\
\hline
\end{tabular}

The error bars correspond to the standard deviation of multiple independent solar cells.

${ }^{a}$ Average values with standard deviation were obtained from 30 independent devices. 
Supplementary Table 6. Recent progress of OSCs with PCEs of over 16\%.

\begin{tabular}{|c|c|c|c|c|c|c|c|}
\hline Active layer & Type & $\begin{array}{l}V_{\mathrm{oc}} \\
(\mathrm{V})\end{array}$ & $\begin{array}{c}J_{\mathrm{sc}} \\
\left.(\mathrm{mA} \mathrm{cm})^{-2}\right)\end{array}$ & $\begin{array}{l}\mathrm{FF} \\
(\%)\end{array}$ & $\begin{array}{l}\text { PCE } \\
(\%)\end{array}$ & $\begin{array}{c}\text { Certified PCE } \\
(\%)\end{array}$ & Ref. \\
\hline PBDT-T-SF:Y6:ITCT & normal & 0.885 & 24.75 & 73.67 & 16.14 & 15.0 & 6 \\
\hline PM6:BTP-4F-12 & normal & 0.855 & 25.3 & 76 & 16.4 & 16.1 & 7 \\
\hline PM6:BTP-4Cl & inverted & 0.867 & 25.4 & 75.0 & 16.5 & 15.83 & 8 \\
\hline PM6:Y6:PC ${ }_{61} \mathrm{BM}$ & inverted & 0.845 & 25.4 & 77.0 & 16.5 & 16.2 & 9 \\
\hline PM6:Y6:IDIC & normal & 0.868 & 25.39 & 74.92 & 16.51 & 15.4 & 10 \\
\hline PM6:AQx-2 & normal & 0.86 & 25.38 & 76.25 & 16.64 & 16.4 & 11 \\
\hline PM6:Y6:PC ${ }_{71} \mathrm{BM}$ & normal & 0.850 & 25.70 & 76.35 & 16.67 & 16.0 & 12 \\
\hline PM6:Y6:3TP3T-4F & inverted & 0.85 & 26.10 & 75.4 & 16.70 & 16.2 & 13 \\
\hline D16:Y6 & normal & 0.85 & 26.61 & 73.8 & 16.72 & 16.0 & 14 \\
\hline PM6:N3:PC ${ }_{71} B M$ & normal & 0.850 & 25.71 & 76.6 & 16.74 & 16.42 & 15 \\
\hline PM6:BTP-4Cl-12 & normal & 0.858 & 25.6 & 77.6 & 17.0 & 16.7 & 16 \\
\hline PM6:Y6:MF1 & normal & 0.853 & 25.68 & 78.61 & 17.22 & 16.8 & 17 \\
\hline PM6:Y6 & normal & 0.84 & 26.1 & 79 & 17.3 & 17.1 & 18 \\
\hline PM6:BTP-eC9 & normal & 0.839 & 26.2 & 81.1 & 17.8 & 17.3 & 19 \\
\hline PM6:L8-BO & normal & 0.87 & 25.72 & 81.5 & 18.32 & 17.9 & Our work \\
\hline
\end{tabular}


Supplementary Table 7. Charge transport properties of Y6, L8-BO, L8-HD and L8-OD neat films and the blend films.

\begin{tabular}{|c|c|c|c|}
\hline Active layer & $\begin{array}{c}\text { Hole mobility } \\
\left(10^{-4} \mathrm{~cm}^{2} \mathrm{~V}^{-1} \mathrm{~s}^{-1}\right)\end{array}$ & $\begin{array}{c}\text { Electron mobility } \\
\left(10^{-4} \mathrm{~cm}^{2} \mathrm{~V}^{-1} \mathrm{~s}^{-1}\right)\end{array}$ & $\mu_{\mathrm{h}} / \mu_{\mathrm{e}}$ \\
\hline Y6 & - & $4.49 \pm 0.47$ & - \\
\hline L8-BO & - & $6.79 \pm 0.10$ & - \\
\hline L8-HD & - & $5.54 \pm 0.87$ & - \\
\hline L8-OD & - & $4.87 \pm 0.67$ & 2.04 \\
\hline PM6:Y6 & $1.82 \pm 0.09$ & $3.71 \pm 0.18$ & 1.62 \\
\hline PM6: L8-BO & $3.58 \pm 0.20$ & $5.79 \pm 0.05$ & 2.64 \\
\hline PM6: L8-HD & $1.75 \pm 0.22$ & $4.62 \pm 0.19$ & 1.43 \\
\hline PM6: L8-OD & $1.61 \pm 0.09$ & $2.31 \pm 0.02$ & - \\
\hline
\end{tabular}

The error bars correspond to the standard deviation of multiple independent devices.

${ }^{a}$ The average mobilities were calculated from 8 independent devices. 
Supplementary Table 8. Crystal data and structure refinement for L8-BO, L8-HD and L8-OD.

\begin{tabular}{|c|c|c|c|c|}
\hline Identification code & Y6 & L8-BO & L8-HD & L8-OD \\
\hline Empirical formula & $\mathrm{C}_{82} \mathrm{H}_{86} \mathrm{~F}_{4} \mathrm{~N}_{8} \mathrm{O}_{2} \mathrm{~S}_{5}$ & $\mathrm{C}_{84} \mathrm{H}_{90} \mathrm{~F}_{4} \mathrm{~N}_{8} \mathrm{O}_{2} \mathrm{~S}_{5}$ & $\mathrm{C}_{92} \mathrm{H}_{106} \mathrm{~F}_{4} \mathrm{~N}_{8} \mathrm{O}_{2} \mathrm{~S}_{5}$ & $\mathrm{C}_{100} \mathrm{H}_{122} \mathrm{~F}_{4} \mathrm{~N}_{8} \mathrm{O}_{2} \mathrm{~S}_{5}$ \\
\hline CCDC number & 1959113 & 2005533 & 2005534 & 2005535 \\
\hline Formula weight & 1451.8 & 1479.93 & 1592.14 & 1704.35 \\
\hline Temperature/K & $100(2)$ & $150.00(10)$ & $150.00(10)$ & $149.99(10)$ \\
\hline Crystal system & monoclinic & monoclinic & monoclinic & monoclinic \\
\hline Space group & $\mathrm{C} 2 / \mathrm{c}$ & $\mathrm{C} 2 / \mathrm{c}$ & $\mathrm{C} 2 / \mathrm{c}$ & $\mathrm{C} 2 / \mathrm{c}$ \\
\hline $\mathrm{a} / \AA$ & 23.701(9) & $27.704(3)$ & $24.6803(12)$ & $24.799(3)$ \\
\hline $\mathrm{b} / \AA$ & $57.450(4)$ & $20.855(2)$ & $22.1858(12)$ & $24.044(4)$ \\
\hline $\mathrm{c} / \AA \AA$ & $14.396(9)$ & $28.363(3)$ & $32.616(2)$ & $33.623(3)$ \\
\hline$\alpha /^{\circ}$ & 90 & 90 & 90 & 90 \\
\hline$\beta /{ }^{\circ}$ & $118.541(4)$ & $105.949(10)$ & $106.818(6)$ & $110.385(11)$ \\
\hline$\gamma /{ }^{\circ}$ & 90 & 90 & 90 & 90 \\
\hline Volume $/ \AA^{3}$ & $17222(2)$ & $15756(3)$ & 17095.2(17) & 18792(4) \\
\hline Z & 8 & 8 & 8 & 8 \\
\hline$\rho_{\text {calc }} \mathrm{g} / \mathrm{cm}^{3}$ & 1.120 & 1.248 & 1.237 & 1.205 \\
\hline$\mu / \mathrm{mm}^{-1}$ & 0.19 & 1.85 & 1.74 & 1.614 \\
\hline $\mathrm{F}(000)$ & 6128 & 6256 & 6768 & 7280 \\
\hline Crystal size $/ \mathrm{mm}^{3}$ & $0.4 \times 0.2 \times 0.07$ & $0.12 \times 0.05 \times 0.04$ & $0.16 \times 0.1 \times 0.08$ & $0.08 \times 0.07 \times 0.05$ \\
\hline Radiation & $\operatorname{MoK} \alpha(\lambda=0.710)$ & $\mathrm{CuK} \alpha(\lambda=1.541)$ & $\mathrm{CuK} \alpha(\lambda=1.541)$ & $\mathrm{CuK} \alpha(\lambda=1.541)$ \\
\hline $\begin{array}{c}2 \Theta \text { range for data } \\
\text { collection }^{\circ}\end{array}$ & 1.418 to 25.027 & 5.382 to 92.726 & 5.464 to 91.68 & 5.288 to 134.132 \\
\hline Index ranges & $\begin{array}{c}-28 \leq \mathrm{h} \leq 28 \\
-68 \leq \mathrm{k} \leq 68 \\
-17 \leq 1 \leq 17\end{array}$ & $\begin{array}{c}-25 \leq \mathrm{h} \leq 25 \\
-19 \leq \mathrm{k} \leq 18 \\
-26 \leq 1 \leq 26\end{array}$ & $\begin{array}{c}-22 \leq \mathrm{h} \leq 22 \\
-20 \leq \mathrm{k} \leq 18 \\
-30 \leq 1 \leq 30\end{array}$ & $\begin{array}{c}-29 \leq \mathrm{h} \leq 28 \\
-24 \leq \mathrm{k} \leq 28 \\
-40 \leq 1 \leq 36\end{array}$ \\
\hline Reflections collected & 29810 & 54211 & 28761 & 49454 \\
\hline $\begin{array}{l}\text { Independent } \\
\text { reflections }\end{array}$ & 15085 & 6451 & 6678 & 16182 \\
\hline Goodness-of-fit on $\mathrm{F}^{2}$ & 1.088 & 1.115 & 1.198 & 1.06 \\
\hline $\begin{array}{l}\text { Final } R \text { indexes } \\
\qquad[\mathrm{I}>=2 \sigma(\mathrm{I})]\end{array}$ & $\begin{array}{c}\mathrm{R}_{1}=0.177 \\
\mathrm{wR}_{2}=0.4202\end{array}$ & $\begin{array}{c}\mathrm{R}_{1}=0.1476, \\
\mathrm{wR}_{2}=0.3349\end{array}$ & $\begin{array}{c}\mathrm{R}_{1}=0.1205 \\
\mathrm{wR}_{2}=0.2959\end{array}$ & $\begin{array}{c}\mathrm{R}_{1}=0.1368 \\
\mathrm{wR}_{2}=0.3313\end{array}$ \\
\hline $\begin{array}{l}\text { Final } \mathrm{R} \text { indexes [all } \\
\text { data] }\end{array}$ & $\begin{array}{c}\mathrm{R}_{1}=0.4205 \\
\mathrm{wR}_{2}=0.5272\end{array}$ & $\begin{array}{c}\mathrm{R}_{1}=0.2998 \\
\mathrm{wR}_{2}=0.4350\end{array}$ & $\begin{array}{c}\mathrm{R}_{1}=0.1805, \\
\mathrm{wR}_{2}=0.3535\end{array}$ & $\begin{array}{c}\mathrm{R}_{1}=0.2476 \\
\mathrm{wR}_{2}=0.4182\end{array}$ \\
\hline
\end{tabular}

The X-ray diffraction signals of single crystals were collected on Rigaku XtaLAB P2000 FR-X diffractometer using $\mathrm{CuK} \alpha$ radiation $\left(\lambda=1.54184 \AA\right.$ ) at $150 \mathrm{~K}$. Structure was solved by intrinsic phasing method (SHELXT ${ }^{20}$ ) and refined by least squares method $\left(\mathrm{SHELXL}^{21}\right)$ integrated in Olex $2^{22}$. 
Supplementary Table 9. Packing coefficients of average distance for L8-BO, L8-HD, L8-OD and Y6.

\begin{tabular}{|c|c|c|}
\hline & $\begin{array}{c}\text { Packing Coefficient }{ }^{\mathrm{a}} \\
(\%)\end{array}$ & $\begin{array}{c}\text { Average } \pi-\pi \text { Distance }^{\mathrm{b}} \\
(\AA)\end{array}$ \\
\hline L8-BO & 64.1 & 3.19 \\
\hline L8-HD & 64.2 & 3.30 \\
\hline L8-OD & 63.7 & 3.40 \\
\hline Y6 & 54.5 & 3.20 \\
\hline
\end{tabular}

aPacking index was calculated using PLATON software ${ }^{23}$.

${ }^{\mathrm{b}}$ The average $\pi-\pi$ distances are calculated by the distances between 10 molecular layers for L8-BO, L8-HD and L8-OD and 8 layers for Y6. 
Supplementary Table 10. Summary of device parameters of the optimized conventional OSCs based on Y6, L8-EH, L8-DT, LC333, LC301 and BTP-4Cl acceptors.

\begin{tabular}{|c|c|c|c|c|}
\hline Active layer & $V_{\mathrm{oc}}(\mathrm{V})$ & $J_{\mathrm{sc}}\left(\mathrm{mA} \mathrm{cm}^{-2}\right)$ & $\mathrm{FF}(\%)$ & PCE $^{\mathrm{a}}(\%)$ \\
\hline PM6:Y6 & $0.84(0.84 \pm 0.01)$ & $25.91(25.57 \pm 0.37)$ & $76.0(75.7 \pm 0.9)$ & $16.61(16.27 \pm 0.17)$ \\
\hline PM6:L8-EH & $0.86(0.86 \pm 0.01)$ & $25.93(25.78 \pm 0.33)$ & $78.6(77.58 \pm 1.02)$ & $17.55(17.25 \pm 0.23)$ \\
\hline PM6:L8-DT & $0.89(0.89 \pm 0.01)$ & $24.41(24.19 \pm 0.22)$ & $78.6(77.92 \pm 0.88)$ & $17.07(16.85 \pm 0.16)$ \\
\hline PM6:LC333 & $0.88(0.88 \pm 0.01)$ & $24.67(24.50 \pm 0.51)$ & $78.3(77.9 \pm 0.05)$ & $17.1(16.9 \pm 0.21)$ \\
\hline PM6:LC301 & $0.91(0.91 \pm 0.01)$ & $24.21(24.08 \pm 0.22)$ & $78.1(77.6 \pm 0.5)$ & $17.2(17.02 \pm 0.19)$ \\
\hline PM6:BTP-4Cl & 0.87 & 25.40 & 75.0 & $16.5^{\mathrm{b}}$ \\
\hline
\end{tabular}

The error bars correspond to the standard deviation of multiple independent solar cells.

${ }^{a}$ The average parameters were calculated from 30 and 10 independent cells for Y6 and the other NFAs based devices, respectively.

${ }^{\text {b}}$ The efficiency was reported in Nat. Commun. 10, 2515 (2019). 
Supplementary Table 11. Detailed GIWAXS data of neat and blend films.

\begin{tabular}{|c|c|c|c|c|c|c|c|c|}
\hline \multirow[b]{2}{*}{ Materials } & \multicolumn{4}{|c|}{ (100) peak } & \multicolumn{4}{|c|}{ (010) peak } \\
\hline & $\begin{array}{c}q^{a} \\
\left(\AA^{-1}\right)\end{array}$ & $\begin{array}{c}d \text {-spacing }^{\mathrm{b}} \\
(\AA)\end{array}$ & $\begin{array}{c}\text { FWHM }^{\mathrm{c}} \\
\left(\AA^{-1}\right)\end{array}$ & $\begin{array}{l}\mathrm{CCL}^{\mathrm{d}} \\
(\AA)\end{array}$ & $\begin{array}{c}q^{a} \\
\left(\AA^{-1}\right)\end{array}$ & $\begin{array}{c}d \text {-spacing }^{\mathrm{b}} \\
(\AA)\end{array}$ & $\begin{array}{c}\text { FWHM }^{\mathrm{c}} \\
\left(\AA^{-1}\right)\end{array}$ & $\begin{array}{c}\mathrm{CCL}^{\mathrm{d}} \\
(\AA)\end{array}$ \\
\hline PM6 & 0.308 & 20.390 & 0.103 & 54.873 & 1.726 & 3.638 & 0.199 & 28.402 \\
\hline Y6 & 0.289 & 21.730 & 0.106 & 53.320 & 1.781 & 3.526 & 0.213 & 26.535 \\
\hline L8-BO & 0.504 & 12.460 & 0.143 & 39.524 & 1.752 & 3.584 & 0.406 & 13.921 \\
\hline L8-HD & 0.448 & 14.018 & 0.183 & 30.885 & 1.721 & 3.649 & 0.457 & 12.367 \\
\hline L8-OD & 0.403 & 15.583 & 0.198 & 28.545 & 1.713 & 3.666 & 0.476 & 11.873 \\
\hline PM6:Y6 & 0.309 & 20.324 & 0.0661 & 85.506 & 1.773 & 3.542 & 0.229 & 24.681 \\
\hline PM6:L8-BO & 0.324 & 19.383 & 0.0752 & 75.159 & 1.765 & 3.558 & 0.308 & 18.350 \\
\hline PM6:L8-HD & 0.322 & 19.503 & 0.0656 & 86.158 & 1.756 & 3.576 & 0.312 & 18.115 \\
\hline PM6:L8-OD & 0.319 & 19.687 & 0.0656 & 86.158 & 1.751 & 3.587 & 0.325 & 17.390 \\
\hline
\end{tabular}

${ }^{a}$ Obtained from the original data.

${ }^{\mathrm{b}}$ Calculated from the equation: $\mathrm{d}$ spacing $=2 \pi / \mathrm{q}$.

${ }^{\mathrm{c}}$ Obtained from the fitting patterns of line-cut profiles.

${ }^{\mathrm{d} C a l c u l a t e d}$ from the Scherrer equation: $\mathrm{CCL}=2 \pi \mathrm{K} / \mathrm{FWHM}$, where FWHM is the full-width at half-maximum of the peak and $\mathrm{K}$ is a shape factor (here we use 0.9). 
Supplementary Table 12. Y6 and L8-BO neat film GIWAXS out-of-plane line-cuts multi-peak fitting results with $\pi-\pi$ region.

\begin{tabular}{|c|c|c|c|c|c|}
\hline Film & Location $\left(\AA^{-1}\right)$ & d space $(\AA)$ & Area (a.u.) & FWHM $\left(\AA^{-1}\right)$ & $\operatorname{CCL}(\AA)$ \\
\hline Y6 & 1.410 & 4.454 & 28.943 & 0.646 & 9.721 \\
\cline { 2 - 6 } & 1.779 & 3.530 & 50.421 & 0.254 & 24.724 \\
\hline L8-BO & 1.751 & 3.586 & 95.513 & 0.480 & 13.083 \\
\hline
\end{tabular}




\section{Supplementary Methods}

The synthetic routes toward non-fullerene acceptor L8-R series with branched alkyl chains are shown in Supplementary Figure 1. Compound 1-R was synthesized by initially treating the commercially available 3-bromothieno[3,2-b]thiophene with $\mathrm{n}-\mathrm{BuLi}$, followed by the addition of aldehyde R'-CHO. Compound 2-R was prepared by the dehydroxylation of compound 1-R using $\mathrm{LiAlH}_{4}$ and $\mathrm{AlCl}_{3}$. Treatment of compound 2-R with $\mathrm{n}$-BuLi followed by quenching with $\mathrm{SnBu}_{3} \mathrm{Cl}$ gave tributylstannane-substituted derivative, which was subjected to Stille cross-coupling reaction with 4,7-dibromo-5,6-dinitrobenzo[c][1,2,5]thiadiazole to yield compound 3-R. The compound 3-R was then converted to compound 4-R via the double intramolecular Cadogan reductive cyclization of compound 3-R with $\mathrm{P}(\mathrm{OEt})_{3}$, followed by the reaction with 1-bromo-2-ethylhexane under alkaline condition. The Vilsmeier-Haack reaction of compound 4-R with $\mathrm{POCl}_{3}$ and $\mathrm{DMF}$ generated compound 5-R, which was further converted to the desired compound L8-R via the Knoevenagel condensation reaction of compound 5-R with 2-(5,6-difluoro-3-oxo-2,3-dihydro-1H-inden-1-ylidene)malononitrile. To verify the effectiveness of branched alkyl design strategy, we have further synthesize L8-EH and L8-DT via further decreasing or increasing $\beta$-position branched alkyl chain length. Besides, through the end-group modulation and design of asymmetric structure, we have also synthesized chlorinated LC333 and asymmetric LC301 on the basis of our branched alkyl chain strategy. The synthetic routes of L8-EH and L8-DT are similar to that of L8-R provided in Supplementary Figure 1. The synthetic routes toward LC333 and LC301 are shown in Supplementary Figure 2. The LC333 was synthesized via the Knoevenagel condensation reaction of compound 5-BO with 2-(5,6-dichloro-3-oxo-2,3-dihydro-1H-inden-1-ylidene)malononitrile, while the LC301 was synthesized via the one-pot Knoevenagel condensation reaction of compound 5-BO with 2-(6-oxo-5,6-dihydro-4H-cyclopenta[c]thiophen-4-ylidene)malononitrile and 
2-(5,6-difluoro-3-oxo-2,3-dihydro-1H-inden-1-ylidene)malononitrile. The NMR spectra of the synthesized compounds are reported in Suppl. Figs. 34-81.

\section{Synthesis of compound 1-R}

To a stirring solution of compound $\mathrm{R}^{\prime}-\mathrm{CH}_{2} \mathrm{OH}(23.36 \mathrm{mmol})$ in $\mathrm{CHCl}_{3}(100 \mathrm{~mL})$ was added pyridinium chlorochromate (PCC) $(7.55 \mathrm{~g}, 35 \mathrm{mmol})$ at room temperature. After stirring at room temperature for another 4 hours, the resulting mixture was filtered and the filtrate was concentrated under reduced pressure. The residue was purified by column chromatography on silica gel using petroleum ether: dichloromethane $(1: 1.5, \mathrm{v}: \mathrm{v})$ as the eluent to get compound R'-CHO as a colorless liquid, which was used directly to the next reaction. Under nitrogen protection, n-BuLi (7 mL, $17.5 \mathrm{mmol}, 2.5 \mathrm{M}$ in hexane) was added dropwise to the stirring solution of 3-bromothieno[3,2-b]thiophene (3.84 g, $17.5 \mathrm{mmol})$ in $\mathrm{Et}_{2} \mathrm{O}(100 \mathrm{~mL})$ at $-78^{\circ} \mathrm{C}$. After keeping stirring at $-78{ }^{\circ} \mathrm{C}$ for another 1.5 hours, the freshly prepared R'-CHO (21 mmol) was added quickly. The resultant mixture was allowed to warm to room temperature and stirred overnight. The resulting mixture was poured into water and extracted with dichloromethane. The combined organic phase was concentrated under reduced pressure to give crude product, which was further purified by column chromatography on silica gel using petroleum ether: ethyl acetate $(20: 1, \mathrm{v}: \mathrm{v})$ as an eluent to give compound 1-R.

Compound 1-EH: Here, R'-CH2 $\mathrm{CH}_{\text {was }}$ 2-ethylhexan-1-ol (3.04 g, 23.36 mmol). The final product compound 1-EH was obtained as a colorless liquid $(4.10 \mathrm{~g}, 87.3 \%){ }_{-}{ }^{1} \mathrm{H}$ NMR (300 MHz, $\left.\mathrm{CDCl}_{3}, \delta\right):$ 7.39-7.37 (d, 1H), 7.24 (s, 1H), 7.18 (s, 1H), 4.89-4.85 (m, 1H), 1.91-1.89 (m, 1H), 1.30-1.25 (m, 8H), 0.93-0.83 (m, 6H).

Compound 1-BO: $\mathrm{R}^{\prime}-\mathrm{CH}_{2} \mathrm{OH}$ was 2-butyloctan-1-ol (4.35 g, $\left.23.36 \mathrm{mmol}\right)$. The final product compound 1-BO was obtained as a light grey liquid (5.21 g, 91.6\%). ${ }^{1} \mathrm{H}$ NMR (300 MHz, $\left.\mathrm{CDCl}_{3}, \delta\right): 7.38-7.37$ (d, 1H), 7.24 (s, 1H), 7.18 (s, 1H), 4.89-4.87 (d, 1H), 1.91-1.90 (m, 1H), 1.29-1.21 (m, 16H), 0.88-0.83 (t, 6H).

Compound 1-HD: $\mathrm{R}^{\prime}-\mathrm{CH}_{2} \mathrm{OH}$ was 2-hexyldecan-1-ol (5.66 g, 23.36 mmol). The final 
product compound 1-HD was obtained as a colorless liquid (6.6 g, 86.2\%). ${ }^{1} \mathrm{H}$ NMR (300 MHz, $\left.\mathrm{CDCl}_{3}, \delta\right):$ 7.38-7.37 (d, 1H), 7.24 (s, 1H), 7.18 (s, 1H), 4.88-4.87 (d, 1H), $1.91-1.90(\mathrm{~m}, 1 \mathrm{H}), 1.23-1.21(\mathrm{~m}, 24 \mathrm{H}), 0.87-0.83(\mathrm{t}, 6 \mathrm{H})$.

Compound 1-OD: $\mathrm{R}^{\prime}-\mathrm{CH}_{2} \mathrm{OH}$ was 2-octyldodecan-1-ol (6.97 g, $\left.23.36 \mathrm{mmol}\right)$. The final product compound 1-OD was obtained as a colorless liquid (5.96 g, 89.3\%). ${ }^{1} \mathrm{H}$ NMR (300 MHz, $\left.\mathrm{CDCl}_{3}, \delta\right):$ 7.38-7.37 (d, 1H), 7.24 (s, 1H), 7.18 (s, 1H), 4.88-4.87 (d, $1 \mathrm{H}), 1.91-1.90(\mathrm{~m}, 1 \mathrm{H}), 1.23-1.21(\mathrm{~m}, 32 \mathrm{H}), 0.89-0.85(\mathrm{t}, 6 \mathrm{H})$.

Compound 1-DT: Here, R'-CH2OH was 2-decyltetradecan-1-ol (8.28 g, 23.36 mmol). The final product compound 1-DT was obtained as a colorless liquid (7.73 g, 89.5\%). ${ }^{1} \mathrm{H}$ NMR (300 MHz, $\left.\mathrm{CDCl}_{3}, \delta\right): 7.39-7.37$ (d, 1H), $7.24(\mathrm{~s}, 1 \mathrm{H}), 7.18(\mathrm{~s}, 1 \mathrm{H})$, 4.89-4.87 (d, 1H), 1.91-1.90 (m, 1H), 1.24-1.21 (m, 40H), 0.90-0.86 (t, 6H).

\section{Synthesis of compound 2-R}

Under nitrogen stream, $\mathrm{AlCl}_{3}(2 \mathrm{~g}, 15 \mathrm{mmol})$ and $\mathrm{LiAlH}_{4}(1.14 \mathrm{~g}, 30 \mathrm{mmol})$ were added slowly to $\mathrm{Et}_{2} \mathrm{O}(100 \mathrm{~mL})$ at $0{ }^{\circ} \mathrm{C}$. After the addition, the mixture was gradually warmed to room temperature and stirred for another 3 hours. Subsequently, the mixture was cooled to $0{ }^{\circ} \mathrm{C}$, and compound 1-R (10 mmol) dissolved in $\mathrm{Et}_{2} \mathrm{O}(15 \mathrm{~mL})$ was added dropwise. After stirring overnight at room temperature, the mixture was cautiously poured into ice and then concentrated $\mathrm{HCl}(10 \mathrm{~mL})$ was added. The resulting mixture was extracted with dichloromethane, dried over $\mathrm{MgSO}_{4}$, filtrated and concentrated under reduced pressure to give crude product, which was further purified by column chromatography on silica gel using petroleum ether as an eluent to afford compound 2-R.

Compound 2-EH: The starting material compound 1-R should be compound 1-EH (2.68 $\mathrm{g}, 10 \mathrm{mmol})$. The final product compound 2-EH was obtained as a colorless liquid (2.03 g, 80.6\%). ${ }^{1} \mathrm{H}$ NMR (300 $\mathrm{MHz} \mathrm{CDCl}_{3}, \delta$ ): 7.28-7.27 (d, 1H), 7.18-7.17 $(\mathrm{d}, 1 \mathrm{H}), 6.90(\mathrm{~s}, 1 \mathrm{H}), 2.59-2.58(\mathrm{~d}, 2 \mathrm{H}), 1.75-1.72(\mathrm{t}, 1 \mathrm{H}), 1.24-1.21(\mathrm{~m}, 8 \mathrm{H})$, 0.84-0.81 (t, 6H).

Compound 2-BO: The starting material compound 1-R should be compound 1-BO 
(3.25 g, $10 \mathrm{mmol})$. The final product compound 2-BO was obtained as a colorless liquid (2.15 g, 85.2\%). ${ }^{1} \mathrm{H}$ NMR (300 $\mathrm{MHz}, \mathrm{CDCl}_{3}, \delta$ ): 7.35-7.34 (d, 1H), 7.24-7.23 (d, 1H), $6.96(\mathrm{~s}, 1 \mathrm{H}), 2.66-2.64(\mathrm{~d}, 2 \mathrm{H}), 1.85(\mathrm{~m}, 1 \mathrm{H}), 1.29-1.25(\mathrm{~m}, 16 \mathrm{H}), 0.88-0.85$ $(\mathrm{t}, 6 \mathrm{H})$.

Compound 2-HD: The starting material compound 1-R should be compound 1-HD (3.81 g, $10 \mathrm{mmol})$. The final product compound 2-HD was obtained as a colorless liquid (2.62 g, 85\%). ${ }^{1} \mathrm{H}$ NMR (300 MHz, $\mathrm{CDCl}_{3}, \delta$ ): 7.35-7.34 (d, 1H), 7.24-7.23 (d, 1H), $6.96(\mathrm{~s}, 1 \mathrm{H}), 2.66-2.64(\mathrm{~d}, 2 \mathrm{H}), 1.84(\mathrm{~m}, 1 \mathrm{H}), 1.29-1.24(\mathrm{~m}, 24 \mathrm{H}), 0.89-0.85(\mathrm{t}$, $6 \mathrm{H})$.

Compound 2-OD: The final product compound 2-OD was obtained as a colorless liquid (3.56 g, 84.5\%). ${ }^{1} \mathrm{H}$ NMR (300 $\mathrm{MHz}, \mathrm{CDCl}_{3}, \delta$ ): 7.35-7.34 (d, 1H), 7.24-7.23 (d, 1H), 6.96 (s, 1H), 2.66-2.64 (d, 2H), $1.84(\mathrm{~m}, 1 \mathrm{H}), 1.29-1.24(\mathrm{~m}, 32 \mathrm{H}), 0.89-0.86$ $(\mathrm{t}, 6 \mathrm{H})$.

Compound 2-DT: The starting material compound 1-R should be compound 1-DT (4.93 $\mathrm{g}, 10 \mathrm{mmol})$. The final product compound 2-DT was obtained as a colorless liquid (4.1 g, 86\%). ${ }^{1} \mathrm{H}$ NMR (300 MHz, $\mathrm{CDCl}_{3}, \delta$ ): 7.36-7.34 (d, 1H), 7.25-7.23 (d, $1 \mathrm{H}), 6.96(\mathrm{~s}, 1 \mathrm{H}), 2.66-2.63(\mathrm{~d}, 2 \mathrm{H}), 1.84(\mathrm{~m}, 1 \mathrm{H}), 1.25(\mathrm{~m}, 40 \mathrm{H}), 0.90-0.86(\mathrm{t}, 6 \mathrm{H})$.

\section{Synthesis of compound 3-R}

Under nitrogen protection, $\mathrm{n}-\mathrm{BuLi}(3.48 \mathrm{~mL}, 8.71 \mathrm{mmol}, 2.5 \mathrm{M}$ in hexane) was added dropwise to the stirring solution of compound $2-\mathrm{R}(8.71 \mathrm{mmol})$ in THF $(80 \mathrm{~mL})$ at $-78{ }^{\circ} \mathrm{C}$. After stirring at $-78{ }^{\circ} \mathrm{C}$ for 1.5 hours, Tri-n-butyltin chloride $(4.37 \mathrm{~g}, 13.44$ mmol) was added. The solution was then allowed to warm to room temperature and stirred overnight. The mixture was concentrated under reduced pressure to get crude tributylstannane-substituted derivative, which was used directly to the next reaction. To solution of 4,7-dibromo-5,6-dinitrobenzo[c][1,2,5]thiadiazole $(1.29 \mathrm{~g}, 3.35 \mathrm{mmol})$ and $\mathrm{Pd}\left(\mathrm{PPh}_{3}\right)_{2} \mathrm{Cl}_{2} \quad(118 \mathrm{mg}, 0.17 \mathrm{mmol})$ in toluene $(60 \mathrm{~mL})$ was added tributylstannane-substituted derivative $(8.71 \mathrm{mmol})$ under nitrogen protection. The reaction mixture was heated to reflux and stirred overnight. After cooling to room 
temperature, the mixture was added water and extracted with dichloromethane. The organic phase was concentrated under reduced pressure to provide crude product, which was further purified with column chromatography on silica gel using a mixture solvent of petroleum ether and dichloromethane as an eluent to give compound 3-R.

Compound 3-EH: The starting material compound 2-R should be compound 2-EH $(2.20 \mathrm{~g}, 8.71 \mathrm{mmol})$. The eluent is petroleum ether: dichloromethane $=2.5: 1(\mathrm{v}: \mathrm{v})$. The final product compound 3-EH was obtained as a red solid $(2.00 \mathrm{~g}, 82.3 \%) .{ }^{1} \mathrm{H}$ NMR (300 MHz, $\left.\mathrm{CDCl}_{3}, \delta\right):{ }^{1} \mathrm{H}$ NMR (300 MHz, $\left.\mathrm{CDCl}_{3}, \delta\right): 7.71$ (s, 2H), 7.16 (s, 2H), 2.72-2.71 (d, 4H), 1.84-1.82 (m, 2H), $1.33(\mathrm{~m}, 16 \mathrm{H}), 0.95-0.88(\mathrm{~m}, 12 \mathrm{H})$.

Compound 3-BO: The starting material compound 2-R should be compound 2-BO $(2.69 \mathrm{~g}, 8.71 \mathrm{mmol})$. The eluent is petroleum ether: dichloromethane $=3: 1(\mathrm{v}: \mathrm{v})$. The final product compound 3-BO was obtained as a red solid $(2.35 \mathrm{~g}, 83.3 \%)$. ${ }^{1} \mathrm{H}$ NMR (300 MHz, $\left.\mathrm{CDCl}_{3}, \delta\right): 7.71(\mathrm{~s}, 2 \mathrm{H}), 7.15(\mathrm{~s}, 2 \mathrm{H}), 2.72-2.70(\mathrm{~d}, 4 \mathrm{H}), 1.87(\mathrm{~m}, 2 \mathrm{H})$, 1.32-1.27 (m, 32H), 0.89-0.85 (t, 12H).

Compound 3-HD: The starting material compound 2-R should be compound 2-HD $(3.18 \mathrm{~g}, 8.71 \mathrm{mmol})$. The eluent is petroleum ether: dichloromethane $=4: 1(\mathrm{v}: \mathrm{v})$. The final product compound 3-HD was obtained as a red solid (2.58 g, 80.7\%). ${ }^{1} \mathrm{H}$ NMR $\left(300 \mathrm{MHz}, \mathrm{CDCl}_{3}, \delta\right): 7.71(\mathrm{~s}, 2 \mathrm{H}), 7.15(\mathrm{~s}, 2 \mathrm{H}), 2.72-2.69(\mathrm{~d}, 4 \mathrm{H}), 1.87(\mathrm{~m}, 2 \mathrm{H})$, $1.33-1.26(\mathrm{~m}, 48 \mathrm{H}), 0.87-0.85(\mathrm{t}, 12 \mathrm{H})$.

Compound 3-OD: The starting material compound 2-R should be compound 2-OD $(3.67 \mathrm{~g}, 8.71 \mathrm{mmol})$. The eluent is petroleum ether: dichloromethane $=5: 1(\mathrm{v}: \mathrm{v})$. The final product compound 3-OD was obtained as a red solid (2.96 g, 82.9\%). ${ }^{1} \mathrm{H}$ NMR $\left(300 \mathrm{MHz}, \mathrm{CDCl}_{3}, \delta\right): 7.71(\mathrm{~s}, 2 \mathrm{H}), 7.15(\mathrm{~s}, 2 \mathrm{H}), 2.72-2.69(\mathrm{~d}, 4 \mathrm{H}), 1.87(\mathrm{~m}, 2 \mathrm{H})$, $1.33-1.25(\mathrm{~m}, 64 \mathrm{H}), 0.89-0.85(\mathrm{t}, 12 \mathrm{H})$.

Compound 3-DT: The starting material compound 2-R should be compound 2-DT $(4.15 \mathrm{~g}, 8.71 \mathrm{mmol})$. The eluent is petroleum ether: dichloromethane $=5: 1(\mathrm{v}: \mathrm{v})$. The final product compound 3-DT was obtained as a red solid (3.22 g, 81.5\%). ${ }^{1} \mathrm{H}$ NMR (300 MHz, $\left.\mathrm{CDCl}_{3}, \delta\right): 7.71(\mathrm{~s}, 2 \mathrm{H}), 7.15(\mathrm{~s}, 2 \mathrm{H}), 2.71-2.69(\mathrm{~d}, 4 \mathrm{H}), 1.87(\mathrm{~m}, 2 \mathrm{H})$, 
$1.32-1.25(\mathrm{~m}, 80 \mathrm{H}), 0.89-0.85(\mathrm{t}, 12 \mathrm{H})$.

\section{Synthesis of compound 4-R}

Under nitrogen atmosphere, $\mathrm{P}(\mathrm{OEt})_{3}(5 \mathrm{~mL})$ was added to the solution of compound $3-\mathrm{R}(1 \mathrm{mmol})$ in o-DCB $(15 \mathrm{~mL})$. The reaction mixture was heated to reflux at $180^{\circ} \mathrm{C}$ and stirred overnight. After cooling to room temperature, the solvent was removed under reduced pressure and the residue was added to $100 \mathrm{~mL}$ two-necked round bottom flask which containing 1-bromo-2-ethylhexane (3.09 g, $16 \mathrm{mmol}), \mathrm{K}_{2} \mathrm{CO}_{3}$ (2.21 g, $16 \mathrm{mmol}), \mathrm{KI}(2.66 \mathrm{~g}, 16 \mathrm{mmol})$ and DMF $(30 \mathrm{~mL})$. The reaction mixture was heated at $80{ }^{\circ} \mathrm{C}$ and stirred overnight. After cooling to room temperature, the mixture was added water and extracted with dichloromethane for three times. The combined organic phase was further washed with water, dried over $\mathrm{MgSO}_{4}$, filtrated and concentrated under reduced pressure. The residue was purified with column chromatography on silica gel using a mixture solvent of petroleum ether and dichloromethane as an eluent to give compound 4-R.

Compound 4-EH: The starting material compound 3-R should be compound 3-EH $(0.73 \mathrm{~g}, 1 \mathrm{mmol})$. The eluent is petroleum ether: dichloromethane $=9: 1(\mathrm{v}: \mathrm{v})$. The final product compound 4-EH was obtained as an orange solid (0.38 g, 42.7\%). ${ }^{1} \mathrm{H}$ NMR (300 MHz, $\left.\mathrm{CDCl}_{3}, \delta\right): 7.00$ (s, 2H), 4.62-4.60 (d, 4H), 2.77-2.75 (d, 4H), 2.07-2.04 (m, 2H), 1.97-1.94 (m, 2H), 1.37-1.36 (m, 16H), $1.06(\mathrm{~m}, 4 \mathrm{H})$ 0.97-0.88 (m, 24H), $0.67-0.58(\mathrm{~m}, 12 \mathrm{H})$.

Compound 4-BO: The starting material compound 3-R should be compound 3-BO $(0.84 \mathrm{~g}, 1 \mathrm{mmol})$. The eluent is petroleum ether: dichloromethane $=9: 1(\mathrm{v}: \mathrm{v})$. The final product compound 4-BO was obtained as an orange yellow solid $(0.5 \mathrm{~g}, 50 \%)$. ${ }^{1} \mathrm{H}$ NMR (300 MHz, $\mathrm{CDCl}_{3}, \delta$ ): 6.99 (s, 2H), 4.61-4.59 (d, 4H), 2.76-2.74 (d, 4H), 2.06-2.00 (m, 4H), 1.35-1.26 (m, 36H), 0.91-0.87 (m, 24H), 0.66-0.58 (m, 12H).

Compound 4-HD: The starting material compound 3-R should be compound 3-HD $(0.95 \mathrm{~g}, 1 \mathrm{mmol})$. The eluent is petroleum ether: dichloromethane $=9: 1(\mathrm{v}: \mathrm{v})$. The final product compound 4-HD was obtained as a fluorescent yellow solid (0.48 g, 
43.2\%). ${ }^{1} \mathrm{H}$ NMR (300 MHz, $\mathrm{CDCl}_{3}, \delta$ ): 6.98 (s, 2H), 4.61-4.59 (d, 4H), 2.76-2.74 (d, $4 \mathrm{H}), 2.06-1.99(\mathrm{~m}, 4 \mathrm{H}), 1.35-1.26(\mathrm{~m}, 52 \mathrm{H}), 0.87-0.85(\mathrm{~m}, 24 \mathrm{H}), 0.64-0.60(\mathrm{~m}, 12 \mathrm{H})$.

Compound 4-OD: The starting material compound 3-R should be compound 3-OD $(1.06 \mathrm{~g}, 1 \mathrm{mmol})$. The eluent is petroleum ether: dichloromethane $=15: 1(\mathrm{v}: \mathrm{v})$. The final product compound 4-OD was obtained as an orange solid $(0.47 \mathrm{~g}, 38.2 \%) .{ }^{1} \mathrm{H}$ NMR (300 MHz, $\left.\mathrm{CDCl}_{3}, \delta\right): 6.98$ (s, 2H), 4.61-4.59 (d, 4H), 2.75-2.74 (d, 4H), 2.06-1.99 (m, 4H), 1.35-1.26 (m, 68H), 0.88-0.85 (m, 24H), 0.66-0.58 (m, 12H).

Compound 4-DT: The starting material compound 3-R should be compound 3-DT $(1.18 \mathrm{~g}, 1 \mathrm{mmol})$. The eluent is petroleum ether: dichloromethane $=15: 1(\mathrm{v}: \mathrm{v})$. The final product compound 4-DT was obtained as an orange solid $(0.65 \mathrm{~g}, 48.4 \%) .{ }^{1} \mathrm{H}$ NMR (300 MHz, $\left.\mathrm{CDCl}_{3}, \delta\right): 6.98$ (s, 2H), 4.61-4.59 (d, 4H), 2.76-2.73 (d, 4H), 2.05-2.01 (m, 4H), 1.35-1.25 (m, 84H), 0.89-0.84 (m, 24H), 0.64-0.60 (m, 12H).

\section{Synthesis of compound 5-R}

Under nitrogen protection, $\mathrm{POCl}_{3}(2 \mathrm{~mL})$ was added dropwise to a solution of anhydrous $N, N$-Dimethylformamide (DMF) $(20 \mathrm{~mL})$ at $0{ }^{\circ} \mathrm{C}$ and stirred at room temperature for another $30 \mathrm{~min}$. Then, compound 4-R $(0.4 \mathrm{mmol})$ dissolved in 1,2-dichloroethane $(20 \mathrm{~mL})$ was added to the mixture and stirred at $80^{\circ} \mathrm{C}$ overnight. The mixture was cooled to room temperature and extracted with dichloromethane. The combined organic extracts were washed with water for three times, dried with anhydrous $\mathrm{MgSO}_{4}$, filtered, and the solvent was removed under reduced pressure. The obtained crude product was further purified by column chromatography on silica gel with a mixture solvent of petroleum ether and dichloromethane as an eluent to afford compound 5-R.

Compound 5-EH: The starting material compound 4-R should be compound 4-EH $(0.35 \mathrm{~g}, 0.4 \mathrm{mmol})$. The eluent is petroleum ether: dichloromethane (1:1.5, v:v). The final product compound 5-EH was obtained as a bright yellow solid (0.32 g, 83.5\%). ${ }^{1} \mathrm{H}$ NMR (300 MHz, $\left.\mathrm{CDCl}_{3}, \delta\right): 10.13$ (s, 2H), 4.63 (d, 4H), 3.13-3.11 (d, 4H), 2.04-2.01 (m, 4H), 1.45-1.31 (m, 16H), 1.05-0.89 (m, 28H), 0.68-0.67 (m, 6H), 
$0.60-0.58(\mathrm{~m}, 6 \mathrm{H})$.

Compound 5-BO: The starting material compound 4-R should be compound 4-BO $(0.40 \mathrm{~g}, 0.4 \mathrm{mmol})$. The eluent is petroleum ether: dichloromethane $(1: 2, \mathrm{v}: \mathrm{v})$. The final product compound 5-BO was obtained as a bright yellow solid ( $0.36 \mathrm{~g}, 85.2 \%)$. ${ }^{1} \mathrm{H}$ NMR (300 MHz, $\mathrm{CDCl}_{3}, \delta$ ): 10.13 (s, 2H), 4.65-4.63 (d, 4H), 3.12-3.10 (d, 4H), 2.08-2.00 (m, 4H), 1.38-1.26 (m, 36H), 0.88-0.86 (m, 24H), 0.70-0.65 (m, 6H), 0.61-0.56 (m, 6H). MS (MALDI-TOF) $m / z$ : $[\mathrm{M}+\mathrm{H}]^{+}$calcd for $\mathrm{C}_{60} \mathrm{H}_{86} \mathrm{~N}_{4} \mathrm{O}_{2} \mathrm{~S}_{5}$, 1054.54, found: 1054.5 .

Compound 5-HD: The starting material compound 4-R should be compound 4-HD $(0.44 \mathrm{~g}, 0.4 \mathrm{mmol})$. The eluent is petroleum ether: dichloromethane $=1: 1.5(\mathrm{v}: \mathrm{v})$. The final product compound 5-HD was obtained as a bright yellow solid $(0.38 \mathrm{~g}, 81.4 \%)$. ${ }^{1} \mathrm{H}$ NMR (300 MHz, $\left.\mathrm{CDCl}_{3}, \delta\right): 10.12$ (s, 2H), 4.65-4.63 (d, 4H), 3.12-3.10 (d, 4H), 2.08-2.00 (m, 4H), 1.38-1.26 (m, 52H), 0.96-0.93 (m, 12H), 0.86-0.84 (m, 12H), 0.70 $(\mathrm{t}, 6 \mathrm{H}), 0.68-0.66(\mathrm{t}, 6 \mathrm{H})$. MS (MALDI-TOF) $m / z:[\mathrm{M}+\mathrm{H}]^{+}$calcd for $\mathrm{C}_{68} \mathrm{H}_{102} \mathrm{~N}_{4} \mathrm{O}_{2} \mathrm{~S}_{5}$, 1166.66, found: 1166.7 .

Compound 5-OD: The starting material compound 4-R should be compound 4-OD $(0.49 \mathrm{~g}, 0.4 \mathrm{mmol})$. The eluent is petroleum ether: dichloromethane $=1: 1.5(\mathrm{v}: \mathrm{v})$. The final product compound 5-OD was obtained as a bright yellow solid $(0.43 \mathrm{~g}, 84 \%) .{ }^{1} \mathrm{H}$ NMR (300 MHz, $\left.\mathrm{CDCl}_{3}, \delta\right): 10.12$ (s, 2H), 4.65-4.63 (d, 4H), 3.12-3.10 (d, 4H), 2.07-2.00 (m, 4H), 1.38-1.25 (m, 68H), 0.95-0.93 (m, 12H), 0.87-0.84 (m, 12H), 0.7-0.68 (t, 6H), 0.67-0.65 (t, 6H). MS (MALDI-TOF) $m / z:[\mathrm{M}+\mathrm{H}]^{+}$calcd for $\mathrm{C}_{76} \mathrm{H}_{118} \mathrm{~N}_{4} \mathrm{O}_{2} \mathrm{~S}_{5}, 1278.79$, found: 1278.8 .

Compound 5-DT: The starting material compound 4-R should be compound 4-DT $(0.53 \mathrm{~g}, 0.4 \mathrm{mmol})$. The eluent is petroleum ether: dichloromethane $(1: 1, \mathrm{v}: \mathrm{v})$. The final product compound 5-DT was obtained as a bright yellow solid (0.46 g, 82.6\%). ${ }^{1} \mathrm{H}$ NMR (300 MHz, $\left.\mathrm{CDCl}_{3}, \delta\right): 10.12$ (s, 2H), 4.65-4.63 (d, 4H), 3.12-3.10 (d, 4H), 2.06-2.02 (m, 4H), 1.38-1.24 (m, 84H), 0.94-0.84 (m, 24H), 0.69-0.67 (t, 6H), $0.60-0.58(\mathrm{t}, 6 \mathrm{H})$. 


\section{Synthesis of compound L8-R}

Under nitrogen protection, compound 5-R $(0.1 \quad \mathrm{mmol})$, 2-(5,6-difluoro-3-oxo-2,3-dihydro-1H-inden-1-ylidene)malononitrile (106 mg, 0.5 mmol) and chloroform $(30 \mathrm{~mL})$ was added to $50 \mathrm{~mL}$ two-necked round bottom flask. After the reaction mixture was stirred at room temperature for 10 mins, pyridine $(0.5$ $\mathrm{mL}$ ) was then added. The reaction mixture was allowed to stir at $55^{\circ} \mathrm{C}$ for 12 hours. After removal of solvent of reaction mixture, methanol was added and the precipitate was collected by filtration to get crude product, which was further purified by column chromatography on silica gel with petroleum ether: dichloromethane (1:1) as an eluent to afford compound L8-R.

Compound L8-EH: The starting material compound 5-R should be compound 5-EH (94 mg, $0.1 \mathrm{mmol}$ ). The final product compound L8-EH was obtained as a dark solid (100 mg, 72.9 \%). ${ }^{1} \mathrm{H}$ NMR (300 MHz, $\mathrm{CDCl}_{3}, \delta$ ): 9.15 (s, 2H), 8.58-8.54 (m, 2H), 7.73-7.69 (t, 2H), 4.79-4.77 (d, 4H), 3.19-3.17 (d, 4H), 2.10-2.04 (m, 4H), 1.43-1.20 (m, 16H), 1.18-1.15 (m, 4H), 1.08-1.01 (m, 10H), 0.99-0.93 (m, 8H), 0.89-0.85 (m, $6 \mathrm{H}), 0.78-0.76(\mathrm{t}, 6 \mathrm{H}), 0.67-0.64(\mathrm{t}, 6 \mathrm{H}) .{ }^{13} \mathrm{C} \mathrm{NMR}\left(100 \mathrm{MHz}, \mathrm{CDCl}_{3}, \delta\right):$ 186.06, $158.95,153.46,147.55,145.35,137.65,135.75,135.58,134.03,133.87,130.65$, $120.06,115.13,115.02,114.80,114.57,113.58,112.55,112.37,68.74,55.68,41.46$, $40.40,34.42,32.69,29.71,29.67,28.80,27.64,26.06,23.28,23.00,22.82$, 14.06,13.74, 10.98, 10.28, 1.03. MS (MALDI-TOF) $m / z:[\mathrm{M}+\mathrm{H}]^{+}$calcd for $\mathrm{C}_{76} \mathrm{H}_{74} \mathrm{~F}_{4} \mathrm{~N}_{8} \mathrm{O}_{2} \mathrm{~S}_{5}, 1366.45$, found: 1367.26.

Compound L8-BO: The starting material compound 5-R should be compound 5-BO (106 mg, $0.1 \mathrm{mmol}$ ). The final product compound L8-BO was obtained as a dark solid (121 mg, 81.6\%). ${ }^{1} \mathrm{H}$ NMR (300 MHz, $\mathrm{CDCl}_{3}, \delta$ ): 9.15 (s, 2H), 8.59-8.55 (m, 2H), 7.73-7.69 (t, 2H), 4.79-4.77 (d, 4H), 3.19-3.18 (d, 4H), 2.09-2.08 (m, 4H), 1.47-1.23 (m, 36H), 1.06-1.01 (m, 12H), 0.88-0.82 (m, 12H), 0.77-0.76 (t, 6H), $0.67(\mathrm{t}, 6 \mathrm{H}) .{ }^{13} \mathrm{C}$ NMR (100 MHz, $\left.\mathrm{CDCl}_{3}, \delta\right):$ 185.02, 157.95, 155.14, 152.51, 146.54, 144.29, 136.62, $135.61,134.71,134.60,133.52,133.01,132.85,129.65,119.02,114.10,113.73$, $113.54,112.56,111.55,111.30,67.69,54.66,39.38,39.03,33.73,32.56,32.31,30.80$, 
$28.60,27.82,26.62,25.56,22.25,21.97,21.62,13.05,13.03,12.71,9.24 . \mathrm{MS}$ (MALDI-TOF) $m / z$ : $[\mathrm{M}+\mathrm{H}]^{+}$calcd for $\mathrm{C}_{84} \mathrm{H}_{90} \mathrm{~F}_{4} \mathrm{~N}_{8} \mathrm{O}_{2} \mathrm{~S}_{5}, 1478.57$, found: 1478.7 .

Compound L8-HD: The starting material compound 5-R should be compound 5-HD (117 mg, $0.1 \mathrm{mmol})$. The final product compound L8-HD was obtained as a dark solid (111 mg, 69.7 \%). ${ }^{1} \mathrm{H}$ NMR (300 MHz, $\mathrm{CDCl}_{3}, \delta$ ): 9.15 (s, 2H), 8.59-8.55 (m, 2H), 7.73-7.69 (t, 2H), 4.78-4.76 (d, 4H), 3.20-3.18 (d, 4H), 2.09-2.08 (m, 4H), 1.38-1.23 $(\mathrm{m}, 52 \mathrm{H}), 1.03-1.00(\mathrm{~m}, 12 \mathrm{H}), 0.84-0.83(\mathrm{~m}, 12 \mathrm{H}), 0.77-0.73(\mathrm{t}, 6 \mathrm{H}), 0.67-0.64(\mathrm{t}$, 6H). ${ }^{13} \mathrm{C}$ NMR (100 MHz, $\left.\mathrm{CDCl}_{3}, \delta\right): 184.98,157.93,154.70,154.59,152.53,152.07$, $146.55,144.32$, 136.65, 135.64, 134.74, 134.60, 133.50, 133.02, 132.86, 129.68, 119.02, 114.11, 113.98, 113.76, 113.53, 112.59, 111.49, 111.31, 67.72, 54.70, 39.40, $39.03,33.71,32.61,30.85,30.80,28.93,28.69,28.60,28.54,28.29,26.66,25.59$, 22.29, 21.80, 21.63, 13.05, 12.71, 9.26. MS (MALDI-TOF) $m / z:[\mathrm{M}+\mathrm{H}]^{+}$calcd for $\mathrm{C}_{92} \mathrm{H}_{106} \mathrm{~F}_{4} \mathrm{~N}_{8} \mathrm{O}_{2} \mathrm{~S}_{5}, 1590.70$, found: 1591.9.

Compound L8-OD: The starting material compound 5-R should be compound 5-OD (128 mg, $0.1 \mathrm{mmol}$ ). The final product compound L8-OD was obtained as a dark solid (137 mg, 80.5 \%). ${ }^{1} \mathrm{H}$ NMR (300 MHz, $\mathrm{CDCl}_{3}, \delta$ ): 9.15 (s, 2H), 8.59-8.55 (q, 2H), 7.73-7.69 (t, 2H), 4.78-4.77 (d, 4H), 3.19-3.17 (d, 4H), $2.10(\mathrm{~m}, 4 \mathrm{H}), 1.38-1.21(\mathrm{~m}$, $68 \mathrm{H}), 1.04-1.02(\mathrm{~m}, 12 \mathrm{H}), 0.86-0.81(\mathrm{~m}, 12 \mathrm{H}), 0.77-0.74(\mathrm{t}, 6 \mathrm{H}), 0.67-0.64(\mathrm{t}, 6 \mathrm{H})$. ${ }^{13} \mathrm{C}$ NMR (100 MHz, $\left.\mathrm{CDCl}_{3}, \delta\right): 184.98,157.93,154.72,154.55,152.54,152.14$, $146.55,144.31,136.65,135.64,135.56,134.74,134.61,133.45,133.02,132.85$, $129.68,119.01,114.11,114.00,113.77,113.53,112.59,111.50,111.30,67.73,54.70$, $39.40,39.01,33.70,32.60,30.89,30.85,28.94,28.66,28.62,28.55,28.34,28.29$, $26.65,25.60,22.28,21.80,21.65,21.63,13.06,12.71,9.25$. MS (MALDI-TOF) $\mathrm{m} / \mathrm{z}$ : $[\mathrm{M}+\mathrm{H}]^{+}$calcd for $\mathrm{C}_{100} \mathrm{H}_{122} \mathrm{~F}_{4} \mathrm{~N}_{8} \mathrm{O}_{2} \mathrm{~S}_{5}, 1702.82$, found: 1704.0.

Compound L8-DT: The starting material compound 5-R should be compound 5-DT (139 mg, $0.1 \mathrm{mmol}$ ). The final product compound L8-DT was obtained as a dark solid (135 mg, $74.6 \%$ \%). ${ }^{1} \mathrm{H}$ NMR (300 MHz, $\left.\mathrm{CDCl}_{3}, \delta\right): 9.14$ (s, 2H), 8.58-8.54 (q, 2H), 7.72-7.68 (t, 2H), 4.80-4.78 (d, 4H), 3.17-3.16 (d, 4H), 2.12-2.08 (m, 4H), 1.37-1.21 $(\mathrm{m}, 84 \mathrm{H}), 1.05-1.01(\mathrm{~m}, 12 \mathrm{H}), 0.87-0.83(\mathrm{~m}, 12 \mathrm{H}), 0.78-0.76(\mathrm{t}, 6 \mathrm{H}), 0.74-0.68(\mathrm{t}$, 
6H). $\left.{ }^{13} \mathrm{C} \mathrm{NMR} \mathrm{(100} \mathrm{MHz,} \mathrm{CDCl}_{3}, \delta\right): 185.99,158.87,156.15,153.56,152.65,147.56$, $145.31,137.66,136.66,135.79,135.56,134.47,134.04,133.84,130.66,119.97$, 115.16, 114.74, 114.57, 113.61, 112.53, 112.28, 68.69, 55.72, 40.40, 40.01, 34.66, $33.59,31.93,30.20,29.98,29.69,29.65,29.37,27.66,26.62,23.27,22.86,22.69$, 14.11, 13.77, 10.30. MS (MALDI-TOF) $m / z:[\mathrm{M}+\mathrm{H}]^{+}$calcd for $\mathrm{C}_{108} \mathrm{H}_{138} \mathrm{~F}_{4} \mathrm{~N}_{8} \mathrm{O}_{2} \mathrm{~S}_{5}$, 1814.95, found: 1816.2 .

\section{Synthesis of compound LC333}

To a $100 \mathrm{~mL}$ two-necked round-bottomed flask was charged with compound 5-BO $(120$ $\mathrm{mg}$ 0.114 mmol), 2-(5,6-dichloro-3-oxo-2,3-dihydro-1H-inden-1-ylidene)malononitrile (90 mg, 0.341 mmol) and $\mathrm{CHCl}_{3}(30 \mathrm{~mL})$. After the reaction mixture was stirred at room temperature for 10 mins under protection of nitrogen, pyridine $(0.5 \mathrm{~mL})$ was added and the reaction was stirred at $55{ }^{\circ} \mathrm{C}$ for 6 hours. After removal of the solvent under vacuum, the residue was purified by column chromatography on silica gel with petroleum ether: dichloromethane (1:1.5, v:v) as an eluent to yield an isolated LC333 as a black solid (112 mg, 63.6\%). Due to the limited solubility of LC333 in chloroform when conducting ${ }^{13} \mathrm{C} \mathrm{NMR}$ test, it is hard to obtain clear ${ }^{13} \mathrm{C} \mathrm{NMR}$ spectrum of LC333, therefore we don't provide it here. ${ }^{1} \mathrm{H} \mathrm{NMR}\left(300 \mathrm{MHz}, \mathrm{CDCl}_{3}\right.$,

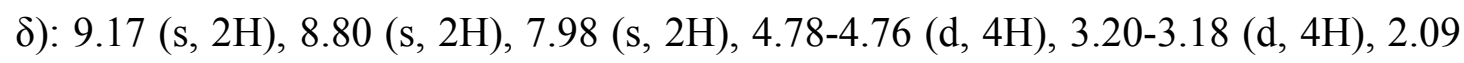
$(\mathrm{m}, 4 \mathrm{H}), 1.47-1.23(\mathrm{~m}, 36 \mathrm{H}), 1.05-1.03(\mathrm{~m}, 12 \mathrm{H}), 0.88(\mathrm{~m}, 12 \mathrm{H}), 0.78-0.75(\mathrm{~m}, 6 \mathrm{H})$, 0.66-0.62 (m,6H). MS (MALDI-TOF) $m / z:[\mathrm{M}+\mathrm{H}]^{+}$calcd for $\mathrm{C}_{84} \mathrm{H}_{90} \mathrm{Cl}_{4} \mathrm{~N}_{8} \mathrm{O}_{2} \mathrm{~S}_{5}$, 1544.45, found: 1546.4 .

\section{Synthesis of compound LC301}

To a $100 \mathrm{~mL}$ two-necked round-bottomed flask was charged sequentially with compound 5-BO (120 mg, $0.114 \quad \mathrm{mmol}, 1 \mathrm{equiv})$, 2-(5,6-difluoro-3-oxo-2,3-dihydro-1H-inden-1-ylidene)malononitrile (26 mg, 0.125 mmol, 1.1 equiv),

2-(6-oxo-5,6-dihydro-4H-cyclopenta[c] thiophen-4-ylidene)malononitrile $\quad(25 \mathrm{mg}$, $0.125 \mathrm{mmol}, 1.1$ equiv) and $\mathrm{CHCl}_{3}(30 \mathrm{~mL})$. After the reaction mixture was stirred at 
room temperature for 10 mins under protection of nitrogen, pyridine $(0.5 \mathrm{~mL})$ was added and the reaction was stirred at $55{ }^{\circ} \mathrm{C}$ for 4 hours. After removal of the solvent under vacuum, the residue was purified by column chromatography on silica gel with petroleum ether: dichloromethane (1:1.5, v:v) as an eluent to yield an isolated LC301 as a black solid (63 mg, 38.2\%). ${ }^{1} \mathrm{H}$ NMR $\left(300 \mathrm{MHz}, \mathrm{CDCl}_{3}, \delta\right): 9.14$ (s, 1H), 9.08 (s, $1 \mathrm{H}), 8.59-8.54(\mathrm{q}, 1 \mathrm{H}), 8.40-8.39(\mathrm{~d}, 1 \mathrm{H}), 7.97-7.96(\mathrm{~d}, 1 \mathrm{H}), 7.74-7.69(\mathrm{t}, 1 \mathrm{H})$, 4.78-4.76 (d, 4H), 3.19-3.16 (d, 4H), 2.10-2.04 (m, 4H), 1.37-1.23 (m, 36H), $1.05-1.02(\mathrm{~m}, 12 \mathrm{H}), 0.89-0.81(\mathrm{~m}, 12 \mathrm{H}), 0.79-0.74(\mathrm{~m}, 6 \mathrm{H}), 0.66-0.63(\mathrm{~m}, 6 \mathrm{H}) .{ }^{13} \mathrm{C}$ NMR (100 MHz, $\left.\mathrm{CDCl}_{3}, \delta\right)$ : 186.02, 181.59, 158.92, 156.90, 155.67, 155.53, 153.55, $153.11,153.05,152.82,147.55,147.52,145.25,145.22,142.55,142.31,137.85$, $137.60,137.59,136.60,135.85,135.56,134.42$, 134.14, 134.00, 133.91, 133.51, $130.63,130.10,127.32,127.23,125.14,119.91,115.32,115.24,115.17,114.98$, 114.76, 114.59, 113.68, 113.44, 112.51, 112.31, 68.58, 66.62, 55.69, 40.36, 40.31, $40.03,39.93,34.71,34.65,33.55,33.31,31.82,29.71,29.63,28.84,27.66,27.62$, $27.56,26.59,23.26,22.99,22.85,22.82,22.80,22.65,14.08,14.05,13.75,13.70$, 10.31, 1.02. MS (MALDI-TOF) $m / z$ : $[\mathrm{M}+\mathrm{H}]^{+}$calcd for $\mathrm{C}_{82} \mathrm{H}_{90} \mathrm{~F}_{2} \mathrm{~N}_{8} \mathrm{O}_{2} \mathrm{~S}_{6}, 1448.55$; Found, 1449.4. 


\section{Supplementary References}

1. Lu, T. \& Chen, F. Multiwfn: A Multifunctional Wavefunction Analyzer, J. Comput. Chem. 33, 580-592 (2012).

2. Ridley, J. E. \& Zerner, M. C. An Intermediate Neglect of Differential Overlap Technique for Spectroscopy: Pyrrole and the Azines. Theoret. Chim. Acta 32, 111-134 (1973).

3. Frisch, M. J. et al. Gaussian16, Gaussian, Inc., Wallingford, CT, 2016.

4. Becke, A. D. Density-functional thermochemistry. III. The role of exact exchange. J. Chem.Phys.98, 5648 (1993).

5. Lee, C., Yang, W. \& Parr, R.G. Development of the Colle-Salvetti correlation-energy formula into a functional of the electron density, Phys. Rev. B 37, 785-789(1988).

6. Chang, Y. et al. The synergy of host-guest nonfullerene acceptors enables $16 \%$-efficiency polymer solar cells with increased open-circuit voltage and fill-factor. Mater. Horiz. 6, 2094-2102 (2019).

7. Hong, L. et al. Eco-Compatible Solvent-Processed Organic Photovoltaic Cells with Over 16\% Efficiency. Adv. Mater. 31, 1903441 (2019).

8. Cui, Y. et al. Over $16 \%$ efficiency organic photovoltaic cells enabled by a chlorinated acceptor with increased open-circuit voltages. Nat. Commun. 10, 2515 (2019).

9. Yu, R. et al. Improved Charge Transport and Reduced Nonradiative Energy Loss Enable Over 16\% Efficiency in Ternary Polymer Solar Cells. Adv. Mater. 31, 1902302 (2019).

10. Li, K. et al. Ternary Blended Fullerene-Free Polymer Solar Cells with $16.5 \%$ Efficiency Enabled with a Higher-LUMO-Level Acceptor to Improve Film Morphology. Adv. Energy Mater. 9, 1901728 (2019).

11. Zhou, Z. et al. Subtle Molecular Tailoring Induces Significant Morphology Optimization Enabling over 16\% Efficiency Organic Solar Cells with Efficient Charge Generation. Adv. Mater. 32, 1906324 (2020).

12. Yan, T. et al. $16.67 \%$ Rigid and $14.06 \%$ Flexible Organic Solar Cells Enabled by Ternary Heterojunction Strategy. Adv. Mater. 31, 1902210 (2019).

13. Song, J. et al. Ternary Organic Solar Cells with Efficiency $>16.5 \%$ Based on Two Compatible Nonfullerene Acceptors. Adv. Mater. 31, 1905645 (2019).

14. Xiong, J. et al. Thiolactone copolymer donor gifts organic solar cells a $16.72 \%$ efficiency. Sci. Bull. 64, 1573-1576 (2019).

15. Jiang, K. et al. Alkyl Chain Tuning of Small Molecule Acceptors for Efficient Organic Solar Cells. Joule 3, 3020-3033 (2019).

16. Cui, Y. et al. $17 \%$ efficiency organic photovoltaic cell with superior processability. Natl. Sci. Rev. 7, 1239-1246 (2019).

17. An, Q. et al. Alloy-like ternary polymer solar cells with over $17.2 \%$ efficiency. Sci. Bull. 65 , 538-545 (2020).

18. Liu, L. et al. Graphdiyne Derivative as Multifunctional Solid Additive in Binary Organic Solar Cells with 17.3\% Efficiency and High Reproductivity. Adv. Mater. 32, 1907604 (2020).

19. Cui, Y. et al. Single-Junction Organic Photovoltaic Cells with Approaching 18\% Efficiency. $A d v$. Mater. 32, 1908205 (2020).

20. Dolomanov, O. V.; Bourhis, L. J.; Gildea, R. J.; Howard, J. A. K. \& Puschmann, H. OLEX2: a Complete Structure Solution, Refinement and Analysis Program. J. Appl. Cryst. 42, 339-341 (2009).

21. Sheldrick. G. M. SHELXT: Integrating Space Group Determination and Structure Solution. Acta 
Crystallogr. A 70, C1437 (2014).

22. Sheldrick, G. M. Crystal Structure Refinement with SHELXL. Acta Crystallogr. C 71, 3-8 (2015).

23. Spek, A. L. Single-crystal structure validation with the program PLATON. J. Appl. Cryst. 36, 7-13 (2003). 